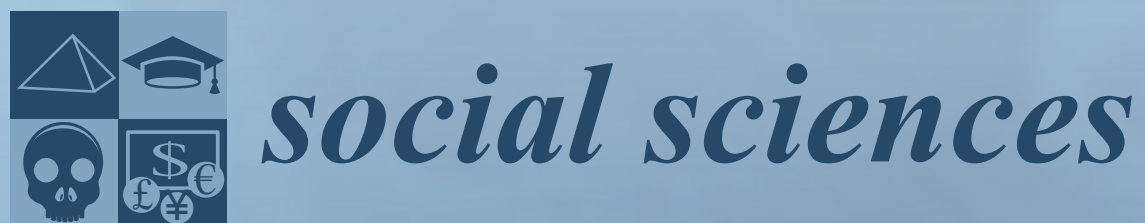

\title{
We Are Best Friends Animals in Society
}

Edited by Leslie Irvine Printed Edition of the Special Issue Published in Social Sciences 
We Are Best Friends 



\section{We Are Best Friends}

\section{Animals in Society}

Special Issue Editor

Leslie Irvine

MDPI • Basel • Beijing • Wuhan • Barcelona • Belgrade

\section{MDPI}


Special Issue Editor

Leslie Irvine

University of Colorado

USA

\section{Editorial Office}

MDPI

St. Alban-Anlage 66

4052 Basel, Switzerland

This is a reprint of articles from the Special Issue published online in the open access journal Social Sciences (ISSN 2076-0760) from 2018 to 2019 (available at: https://www.mdpi.com/journal/ socsci/special_issues/Animals_Society).

For citation purposes, cite each article independently as indicated on the article page online and as indicated below:

LastName, A.A.; LastName, B.B.; LastName, C.C. Article Title. Journal Name Year, Article Number, Page Range.

ISBN 978-3-03921-536-2 (Pbk)

ISBN 978-3-03921-537-9 (PDF)

Cover image courtesy of istockphoto.com.

(c) 2019 by the authors. Articles in this book are Open Access and distributed under the Creative Commons Attribution (CC BY) license, which allows users to download, copy and build upon published articles, as long as the author and publisher are properly credited, which ensures maximum dissemination and a wider impact of our publications.

The book as a whole is distributed by MDPI under the terms and conditions of the Creative Commons license CC BY-NC-ND. 


\section{Contents}

About the Special Issue Editor $\ldots \ldots \ldots \ldots \ldots \ldots \ldots$ vii

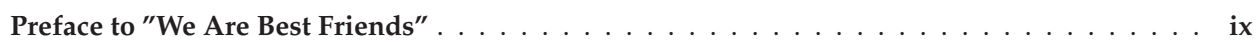

Cary A. Brown, Yuluan Wang and Eloise C. J. Carr

Undercover Dogs: Pet Dogs in the Sleep Environment of Patients with Chronic Pain

Reprinted from: Social Sciences 2018, 7, 157, doi:10.3390/socsci7090157 _ . . . . . . . . . . . 1

Cameron T. Whitley

Exploring the Place of Animals and Human-Animal Relationships in Hydraulic Fracturing Discourse

Reprinted from: Social Sciences 2019, 8, 61, doi:10.3390/socsci8020061 . . . . . . . . . . . 12

Mary Trachsel

Befriending Your Food: Pigs and People Coming of Age in the Anthropocene

Reprinted from: Social Sciences 2019, 8, 106, doi:10.3390/socsci8040106 . . . . . . . . . . . . 31

Nicole R. Pallotta

Chattel or Child: The Liminal Status of Companion Animals in Society and Law

Reprinted from: Social Sciences 2019, 8, 158, doi:10.3390/socsci8050158 _ . . . . . . . . . . . 49

Devon Thacker Thomas and Jenny R. Vermilya

Framing 'Friend': Media Framing of 'Man's Best Friend' and the Pattern of Police Shootings of Dogs

Reprinted from: Social Sciences 2019, 8, 107, doi:10.3390/socsci8040107 _ . . . . . . . . . . 93

Helen Peterson and Kristina Engwall

“Why Would You Want a Baby When You Could Have a Dog?" Voluntarily Childless Women's "Peternal" Feelings, Longing and Ambivalence

Reprinted from: Social Sciences 2019, 8, 126, doi:10.3390/socsci8040126 . . . . . . . . . . . . 117

Catherine Lee

Keeping Lily Safe: An Autoethnographic Exploration of Human-Animal Attachment during Adversity

Reprinted from: Social Sciences 2019, 8, 217, doi:10.3390/socsci8070217 . . . . . . . . . . . 132 



\section{About the Special Issue Editor}

Leslie Irvine, Professor of Sociology. Leslie Irvine is Professor of Sociology at the University of Colorado Boulder. Her research focuses on the roles of animals in society. Her books include My Dog Always Eats First: Homeless People and their Animals, Filling the Ark: Animal Welfare in Disasters, and If You Tame Me: Understanding our Connection with Animals, which received the Distinguished Scholarship Award from the Animals \& Society Section of the American Sociological Association. Her articles have appeared in Society \& Animals, Anthrozoös, Gender \& Society, Social Problems, The Sociological Quarterly, Qualitative Sociology, and Symbolic Interaction. 



\section{Preface to "We Are Best Friends"}

The story of friendship between animals and humans is an ancient one. Although we cannot determine whether ancient humans regarded dogs and cats as friends, signs of companionship between people and animals date back thousands of years. Some of the most compelling evidence comes from the intentional burial of animals. As anthropologist Darcy Morey has written, "Nothing signifies the social importance that people have attached to dogs more conspicuously than their deliberate interment upon death" (2006: 159). Although mere burial suggests little more than a hygienic way to dispose of corpses, the discovery of numerous animal graves in locations all around the world suggests other motives. As Morey points out, "regardless of how [dogs] died, they were buried with the kind of care that signifies friendship, symbolic of a projected afterlife in the 'spirit world', more regularly than other animals" (2006:166). Early humans often arranged the bodies of dogs in sleeping postures after death. Dog remains have been found curled up, with the head placed on the paws. Special offerings, such as the clamshells arranged around the head of a dog found in Rhode Island, suggest the individual and deliberate preparation of graves. This, in turn, suggests the status of dogs "as real friends of people while they were alive" (Morey 2006: 164).

The earliest known site of a canine burial, at Bonn-Oberkasskel, Germany, is especially intriguing because it contains the bones of a dog along with those of two human beings, implying companionship. The canine bones have been identified as a dog, morphologically distinct from a wolf, and the three were buried together around 14,000 BPE. At the time, this finding put the date of the domestication of dogs far earlier than previously thought. However, a more recent discovery suggests that human-canine friendships may be yet older. Chauvet Cave, in southern France, is well known for its stunning paintings of animals dating from almost 32,000 years ago. About a decade ago, in a chamber of the cave, the footprints of a boy were discovered, imprinted in the mud. The boy was estimated to have been eight- or ten-years-old at the time. The paw prints of a large canid appear alongside his footprints. Dog historian Mark Derr (2011) aptly characterizes this animal as a "dogwolf," a dog-like or highly socialized wolf who kept company with humans. Study of the foot and paw prints suggests that the boy and the dogwolf walked through the cave together, as companions. The carbon from the torch the boy carried enabled archaeologists to determine that the prints are 26,000 years old. This discovery pushes back the historical record of the human-canine relationship by 12,000 years.

Scholars long believed that the ancient Egyptians were the first to keep cats as pets, starting around 3600 years ago. Genetic and archaeological discoveries have since revised this thinking. In 2004, a French archaeological team working on the island of Cyprus found a 9500-year-old grave of an adult human of unknown sex. In the grave were various items, including a few stone tools, a lump of iron oxide, some seashells and, in its own tiny grave 40 centimeters away, an eight-month-old cat (Vigne et al. 2004). As cats are not native to most Mediterranean islands, people must have brought them over by boat, probably from the Levantine coast. Together, the transport of cats to Cyprus and the burial of the human with a cat indicate that people had special relationships with cats nearly 10,000 years ago.

In the contemporary context, the possibility of friendship between humans and non-human animals was, until recently, dismissed as anthropomorphism or sentimental projection. However, after decades of research on the emotional and cognitive capacities of animals, we now recognize human-animal friendships as true reciprocal relationships. Friendships with animals have many of 
the same characteristics as friendships between humans. Both parties enjoy the shared presence that friendship entails along with the pleasures that come with knowing another being (see Sanders 1999, 2003; Irvine 2004). Both friends develop ways of communicating apart from, or in addition to, spoken language.

Having an animal as a best friend often takes the form of relationship known as the "pet", but it can also take other forms. People who work with animals often characterize their non-human partners as friends. Those who have raised animals considered to be "livestock" have described forming friendships with certain animals (Wilkie 2010; Ellis 2014). People who work with search-and-rescue dogs, herding dogs, or police dogs develop and depend on the closeness of friendship (Sanders 2000, 2006). The same holds for equestrians, as horses and riders must understand each other's bodies and movements intimately (Brandt 2004). In some situations, animals provide the sole source of affection and interaction in people's lives. Homeless people who live on the streets with animal companions experience togetherness 24/7 (Irvine 2013).

The chapters in this volume explore the various forms these friendships take. Together, the authors shed light on what these friendships mean and expand upon the interdisciplinary knowledge of the roles of animals in society. Cary Brown, Yuluan Wang, and Eloise Carr examine how sleeping with a pet dog-a common aspect of human-canine friendship-affects sleep among people experiencing chronic pain. Sleep is important for everyone, and the relationship between pain and sleep is not fully understood. People who have pet dogs often enjoy the dog's company at night, finding the presence of a furry companion comforting and reassuring. Yet, having a dog in one's bed, or even in the bedroom, can also disrupt sleep. People who seek help for sleep disorders are often advised not to allow their dogs in the bedroom, despite a lack of evidence that banishing the dog improves sleep. Based on interviews with people experiencing chronic pain, Brown and co-authors shed intriguing light on the question of how dogs affect their owners' sleep.

Cameron Whitley examines how animals are portrayed in the literature on the impact of hydraulic fracturing - a method of natural gas and oil extraction. Known colloquially as "fracking", the method involves drilling into the earth and injecting a high-pressure mixture of water, sand, and chemicals so that rock formations fracture, making it easier to extract previously unreachable oil and gas. Fracking is highly controversial, and a growing body of research literature has examined its consequences. Whitley's analysis shows that one theme within the literature focuses on the impacts of hydraulic fracturing on species or ecosystems. Literature taking another theme addresses animals in passing or even implicitly while focusing broadly on the environment. Yet another theme discusses the role of animals as sentinels of potential harm to human health. Whitley finds a paucity of research that acknowledges the human-animal relationship in energy development. Overall, animals are valued for what they reveal about the risks posed to humans.

The closest and most frequent contact children have with animals is usually through pets. Consequently, relationships with pets have provided most of the scholarly knowledge on children's friendships with animals. Little research has examined the relationships children have with "livestock", i.e., animals brought into existence to die (see Ellis and Irvine 2010). Mary Trachsel's chapter addresses this gap by exploring human-pig friendships in three coming-of-age novels aimed at young adult readers. Trachsel notes that although some animals, such as sheep and cows, are valued for wool or milk, "pigs stand out among livestock animals as creatures domesticated exclusively for slaughter". Consequently, most stories about pigs end tragically, leaving readers to cope with the complex emotional experience that Arluke (1994) calls the "caring-killing paradox." 
The novels Trachsel analyses chart a different course. They challenge anthropocentric assumptions about the fate of pigs, instead offering deep moral insights about friendship.

Nicole Pallotta examines the contradictions between the legal standing of animals in the United States and the cultural constructions of pets. Legally, animals are considered property, making them disposable commodities with little intrinsic value. By contrast, societal norms imbue pets with emotional value and give them the status of family members. Increasingly, the property status of animals conflicts with their cultural status as part of the family. Pallotta draws upon examples from the realms of domestic violence, animal abuse, wrongful death, custody battles, and provisions for pets in wills to illustrate how the importance of animals in people's lives is increasingly recognized by law.

Devon Thacker Thomas and Jenny Vermilya also investigate law and pets. Analyzing print news articles on police shootings of companion dogs in the United States, they show how the media sustains existing species hierarchies and creates hierarchies within species. Although social norms now deem human-canine friendship acceptable, not all dogs are seen as equally worthy of the role of "friend". Depending on how the media frames the human-canine relationship, stories can shape public opinion about whether a shooting was justified. Thomas and Thacker found that "print news media commands very real power to shape how humans decide which dog-human friendships are more or less socially acceptable."

The chapter by Helen Peterson and Kristina Engwall investigates the common assumption that pets serve as substitute children. This assumption, known as the "deficiency argument" (Irvine 2004), suggests that people who have pets lack the interactional skills that would allow them to have "appropriate" relationships with other humans. Couples and individuals without children are often viewed through this lens. The image of the "crazy cat lady" epitomizes the deficiency argument, as does the stereotype of the animal rights activist, portrayed as sympathetic toward animals but allegedly unmoved by human suffering. By interviewing intentionally child-free women, Peterson and Engwall discovered diverse constructions of the meaning of relationships with pets. Along with adding to the research on human-animal bonds, their work also contributes to the literature on the experiences of women who intentionally remain child-free.

Catherine Lee's autoethnography offers a deeply intimate portrait of her relationship with her cat, Lily. Her research is situated in the context of an escalating dispute with a neighbor who threatened to make Lee's life "a living misery". Identifying as a childless lesbian in a same-sex relationship, Lee emphasizes how Lily allowed her partner and her to enjoy the pleasures of caretaking without the patriarchal constraints of heteronormative motherhood. The experience with the intrusive, homophobic neighbor made Lee fear for Lily's safety. Lee's autoethnography draws on diary entries and notes from therapy to show how, as she puts it, "human-animal attachments are comparable with human-human attachments, and where attachments to companion animals are as strong as those toward humans, fear of harm, loss of safe haven and eventually grief over the death of an animal can be devastating and akin to losing a human family member".

Acknowledgements

Leslie Irvine thanks the authors, reviewers, and the editors of Social Sciences who made this volume possible.

Leslie Irvine

Special Issue Editor 


\section{References}

Arluke, Arnold. 1994. "Managing emotions in an animal shelter." Pp. 145-165 in Animals and human society: Changing perspectives, edited by A. Manning and J. Serpell. London: Routledge.

Brandt, Keri. 2004. "A language of their own: An interactionist approach to human-horse communication." Society \& Animals 12: 299-316.

Derr, Mark. 2011. "From the cave to the kennel." Wall Street Journal, October 29: https://www.wsj.com/articles/SB10001424052970203554104577001843790269560 (accessed 8/6/19). Ellis, Colter. 2014. "Boundary labor and the production of emotionless commodities: The case of beef production." The Sociological Quarterly 55: 92-118.

Irvine, Leslie. 2004. If You Tame Me: Understanding our connection with animals. Philadelphia: Temple University Press.

Irvine, Leslie. 2013. My dog always eats first: Homeless people and their animals. Boulder, CO: Lynne Rienner Publishers.

Irvine, Leslie, and Colter Ellis. 2010. "Reproducing dominion: Emotional apprenticeship in the 4-H youth livestock program." Society $\mathcal{E}$ Animals 18: 21-39.

Morey, Darcy F. 2006. "Burying key evidence: the social bond between dogs and people." Journal of Archaeological Science 33: 158-175.

Sanders, Clinton R. 1999. Understanding Dogs: Living and Working with Canine Companions. Philadelphia: Temple University Press.

Sanders, Clinton R. 2000. "The impact of guide dogs on the identity of people with visual impairments." Anthrozoös 13: 131-139.

Sanders, Clinton R. 2003. "Actions speak louder than words: Close relationships between humans and nonhuman animals." Symbolic Interaction 26: 405-426.

Sanders, Clinton R. 2006. "The dog you deserve: Ambivalence in the k-9 officer/patrol dog relationship." Journal of Contemporary Ethnography 35: 148-172.

Vigne, J-D., Jean Guilaine, Karyne Debue, Laurent Haye, and Patrice Gérard. 2004. "Early taming of the cat in Cyprus." Science 304: 259-259.

Wilkie, Rhoda. 2010. Livestock/deadstock: Working with farm animals from birth to slaughter. Temple University Press. 


\title{
Undercover Dogs: Pet Dogs in the Sleep Environment of Patients with Chronic Pain
}

\author{
Cary A. Brown ${ }^{1, *(\mathbb{D})}$, Yuluan Wang ${ }^{2}$ and Eloise C. J. Carr ${ }^{3}(\mathbb{C}$ \\ 1 Department of Occupational Therapy, Faculty of Rehabilitation Medicine, University of Alberta, \\ 2-64 Corbett Hall, Edmonton, AB T6G2G4, Canada \\ 2 Faculty of Rehabilitation Medicine, University of Alberta, 3-48 Corbett Hall, \\ Edmonton, AB T6G2G4, Canada; yuluan@ualberta.ca \\ 3 Faculty of Nursing, University of Calgary, 2500 University Drive NW, Calgary, AB T2N1N4, Canada; \\ ecarr@ucalgary.ca \\ * Correspondence: cary.brown@ualberta.ca; Tel.: +1-780-492-9545
}

Received: 3 August 2018; Accepted: 10 September 2018; Published: 13 September 2018

\begin{abstract}
Background: Chronic pain is a significant and prevalent condition in many industrialized nations. Pain and sleep's reciprocal nature suggests that interventions to improve sleep may decrease pain symptoms. Little attention has been paid to the influence that owning a pet dog has on the pain/sleep relationship. Typical advice to remove pets from the bedroom negates the possible positive benefit of human-animal co-sleeping. Aim: To investigate pain patients' perceived impact of pet dog ownership on sleep. (2) Methods: We carried out a content analysis of interview data focused on the impact of pet dog ownership on sleep. The qualitative dataset comes from a subgroup of participants in a larger study examining the pain patient/canine relationship. This subgroup of participants from the larger study was asked, "Does your dog have a positive or negative impact on your sleep?" The data were thematically coded using an iterative approach. (3) Findings: Codes included: companionship; physical presence/'cuddles'; routine/schedule; distraction from anxiety/worry at night; reassuring/protective presence; active intervention to keep participant safe; daytime activity to promote sleeping at night; and reciprocal concern for the sleep of the pet dog. (4) Conclusions: Pet dogs may play important roles in helping people with chronic pain achieve sleep onset and maintenance. Removing the dog to improved sleep could be counter-productive and lead to additional sleep-related issues.
\end{abstract}

Keywords: human-animal interaction; dog; sleep; chronic pain; content analysis

\section{Introduction}

Both chronic pain and sleep disorders are prevalent and growing problems with significant costs to the individual, family, employers and society at large (Antaky et al. 2017; Ferrie et al. 2011; Phillips 2009). Chronic pain has an estimated prevalence rate of between $10-20 \%$ in many industrialized nations and has been identified as a significant public health concern (Goldberg and McGee 2011). Costs of chronic pain include not only medical treatment but also lost productivity and other socio-economic impacts such as family and citizenship roles. A 2012 study in the United States determined that, conservatively estimated, the yearly costs of chronic pain were greater than those related to heart disease ( $\$ 309$ billion), cancer ( $\$ 243$ billion) and diabetes ( $\$ 188$ billion) (Gaskin and Richard 2012). Similarly, the prevalence rates of sleep deficiency are high, with reports of upwards of $30 \%$ of adults in industrialized countries routinely achieving less than the recommended hours per night (Hafner et al. 2017). This pattern is also seen in developing nations and is anticipated to increase as industrialization and other socio-political factors evolve (Stranges et al. 2012). 
That sleep deficiency is a significant issue for persons living with pain has been well-established (Andrews et al. 2014; Finan et al. 2013) and conservative estimates are that between 50-90\% of patients in treatment for chronic pain also experience sleep problems (Tang 2008). The relationship is multifactorial. For example, pain interferes with relaxation and rest, the consequences of living with pain can increase stress and worry; and stress and worry can trigger neurochemical and hormonal reactions that preclude sleep (Han et al. 2012). The hypothalamic-pituitary-adrenal (HPA) axis is strongly related to both pain and sleep (Generaal et al. 2014) and a growing body of evidence reflects that pain and sleep have both a reciprocal nature and multiple shared neurophysiological mechanisms (Aili et al. 2015; American Sleep Association n.d.; Lerman et al. 2017; Smith and Haythornthwaite 2004). This bidirectional relationship suggests that interventions to improve sleep will contribute to a decrease in negative symptoms for persons with pain (Lerman et al. 2017; Smith and Haythornthwaite 2004).

Because of their complex, bio-psycho-social etiologies, both pain and chronic sleep deficiency are resistant to intervention. Typically, pain patients will receive medication and, if available, non-pharmacological psych-education and behavioral therapies to assist with sleep (Stiefel and Stagno 2004). However, ongoing use of sleep medication can contribute to a range of negative side-effects and insomnia management guidelines recommend short term use only (Riemann et al. 2017). While cognitive-behavioral therapies (CBT) are regarded as first-line interventions (Riemann et al. 2017) this form of treatment is not always acceptable to patients nor readily available (Koffel et al. 2018). Beyond CBT, few studies exist specific to development and testing of pragmatic and accessible non-pharmacological sleep strategies for persons with pain and research is much needed.

This paper addresses one such under-explored area; the possible influence of owning a pet dog on the pain/sleep relationship. The typical advice for anyone experiencing sleep problems is to remove the pet from the bedroom, underline the singular assumption that pets interfere with sleep (American Sleep Association n.d.; Bloom et al. 2009). Research on the relationship between service dogs and sleep is meager and a search of the literature revealed no systematic reviews, only a literature review published in a sleep magazine (Rose et al. 2015). Research regarding pet animals and specifically dogs, is even more sparse (Patel et al. 2017).

In this paper, we are interested in pet dogs ("an animal that you keep in your home to give you company and pleasure") (Collins Online English Dictionary n.d.) as opposed to service dogs ("any dog that is individually trained to do work or perform tasks for the benefit of an individual with a disability, including a physical, sensory, psychiatric, intellectual, or other mental disability") (Americans with Disability Act National Network 2014). As a preliminary step in addressing the existing evidence-gap regarding pet dogs (who are not trained service dogs), we carried out a content analysis of comments specifically focused on the impact of dog ownership on sleep. The qualitative dataset came from a subgroup of participants in a larger study examining the human/canine relationship for those persons living with chronic pain (Carr et al.).

Many people co-sleep with a human partner, a pet, or both. Co-sleeping is defined as sharing a bed or bedroom during any portion of the night, where individuals are in close enough proximity to exchange at least two sensory stimuli such as touch, smell, movement, sight and sound (Goldberg and Keller 2007). These sensory stimuli would be similar regardless if the co-sleeping occurred with a human or a pet and our background literature search included both. However, we found little research specific to persons with pain co-sleeping with either other people, pets, or both. We did find one study of co-sleep between children and parents with pain whose authors concluded that co-sleeping may be advantageous in certain contexts. These researchers questioned the benefit of generic recommendations to avoid co-sleeping (Goldberg and Keller 2007). One review (Smith et al. 2017) identified that co-sleeping research had focused predominantly on human/human co-sleep and, to all intents, has neglected the highly prevalent practice of human/pet co-sleeping. Studying human/pet co-sleeping and the general influence of pet ownership on sleep overall is important on many levels. The practice of co-sleeping alters the sleep environment by introducing 
additional sound, movement, odor and sources of body heat/temperature change (Krahn et al. 2015). Co-sleeping increases an individual's vulnerability to disturbances (such as snoring or toilet visits of a partner), which may lead to sleep deficiency and subsequent impairment in daily function (Smith et al. 2017). Research has demonstrated relationships between sleep and environmental aspects of the sleep environment but, to-date, little attention has been paid to other aspects of co-sleeping that influence the quality of sleep. Internationally, approximately half of pet owners share their bed or bedroom with their pets (Smith et al. 2017). Industry reports suggest that the practice of having a dog for a pet is common and growing (Walden 2015). For example, 32\% of Canadian households have one or more dogs (Consumer Corner 2014) and as many as $90 \%$ of pet owners identify their pets as a family member and include them in as many aspects of their lives as possible (Ferrie et al. 2011; Walden 2015). For many, including people with sleep problems and people with pain, this includes sharing a sleep environment (Duthuluru et al. 2014; Krahn et al. 2015). A study of 300 patients with sleep disorders found that $52.3 \%$ participants had one or more pets, primarily cats and dogs. Of these participants, 58\% slept with their pets in the bedroom (Shepard 2002). While there is a strong body of evidence reporting that dogs are beneficial for general health (alleviating daily stresses, reducing anxiety, loneliness and depression, enhancing feelings of autonomy, competence and self-esteem, facilitating social interactions between people and increased physical activity) (Cutt et al. 2007; Duvall Antonacopoulos and Pychyl 2017), there is limited literature exploring how the presence of pets in the bedroom affects an individual's sleep (Duthuluru et al. 2014; Wells 2009). An Australian online survey of sleep wellness compared pet owners who slept with their pets and those who did not (Smith et al. 2014). Of the 2036 participants, 1018 (50\%) allowed pets to sleep with them in bed. There was no significant difference reported in sleep quantity between those who did and did not sleep with their pet. However, although the effect size was small, there was a difference of $4.07 \mathrm{~min}$ delay for pet co-sleepers to fall asleep and these participants were also more likely to report feeling tired upon waking. There was no difference in reports of daytime fatigue. Additionally, participants who co-slept with pets were no more likely to report waking up from sleep disturbances than those who did not co-sleep with pets. Of note, participants with health conditions were more likely to sleep with a pet in their beds than those who did not (59\% and $41 \%$ respectively) (Smith et al. 2014). One of the few studies to use an objective sleep assessment tool (actigraphy) to collect data on human/pet co-sleeping variables included 40 healthy adults with dogs over six months of age. Participants wore an Actiwatch 2, while their dogs wore a FitBark dog activity monitor for seven nights. Findings revealed that participants with a single dog in the bedroom but not on the bed, maintained good sleep efficiency (ratio of time in bed to time asleep) but sleep efficiency decreased significantly $(83.1 \%$ and $80.1 \%$ respectively; $p=0.003$ ) when dogs slept on the bed. This suggests that the problem for sleep efficiency is not so much human/pet co-sleeping, but rather a dog's position on or off the bed (Patel et al. 2017).

\subsection{Sleep-Negative Influences of the Human/Pet Relationship}

Some disturbances in sleep while co-sleeping with a pet are linked to mismatches in human/pet core body temperatures and the different sleep-wake cycle between humans and dogs (Campbell and Tobler 1984; Smith et al. 2017; Thompson and Smith 2014). Sleep disturbances may also occur given dogs' responsiveness to auditory stimuli regardless of whether in a sleep state or an active state (Adams and Johnson 1994). In the Shepard (2002) study, 53\% of the participants who slept with a pet in the bedroom considered their sleep to be disturbed most nights. The most common cause of disturbance dog owners in the Shepard (2002) study identified was that the pet snored (21\%). Other risks to restorative sleep presented by human/pet co-sleeping (such as immunologic responses leading to allergies or asthma, transmission of zoonotic agents, bites and scratches causing tissue damage and pain, and the behavioral and toileting issues of young dogs) are considered to be relatively low if dogs are routinely bathed, provided with required veterinarian care, and properly trained (Campbell and Tobler 1984). A survey by Wells (2009) of 168 patients with chronic fatigue syndrome, 
aged 45 and over, found that of the $58.3 \%$ who had a pet, $41.8 \%$ reported disadvantages (including increased fatigue due to pet-care demands, expense, disruptions to sleep during the night, behavior problems, bereavement following pet loss and increased worry and stress when ailments occurs). Finally, as noted previously, sleeping with a pet on the bed may also delay sleep onset by several minutes (Smith et al. 2014).

\subsection{Sleep-Positive Influences of the Human/Pet Relationship}

Pets are commonly seen as members of the family and telling individuals to stop sleeping with a pet can be the same as telling individuals to stop sleeping with their partner or children (Patel et al. 2017; Rose et al. 2015). Belk (1996) reported that pets are seen to make life interesting and are a source of entertainment. Thus, pet owners often tolerate mischief from their pets and are willing to change their lives and schedules to accommodate their pets.

In a 2015 study, involving 150 patients with significant sleep disorders, $49 \%$ of participants reported having pets and of these, $56 \%$ allowed pets in the bedroom. While $20 \%$ described their pets as disruptive to sleep, twice as many $(41 \%)$ perceived their pets as unobtrusive or beneficial for sleep (Krahn et al. 2015). Participants who described their pets as beneficial, especially those who did not co-sleep with a human, reported that their pets provided them with security, companionship, and relaxation that aided their sleep. Similarly, in the Wells (2009) study cited previously, all of the participants who owned a pet made positive comments and attributed pet ownership with a wide range of advantages for health and physical and psychological well-being including; companionship, emotional bond, decreased loneliness, better mood, reduced depression, increased sense of calm and a sense of purpose, and distraction from worry about health concerns. The role pets played in motivation to get out of bed (keeping to a regular schedule) and encouragement to take exercise, both considered to be important contributors to restorative sleep, were also frequently mentioned. The link to psychological well-being has been identified in additional studies (Beetz et al. 2012; Cassels et al. 2017; Irvine and Cilia 2017) and some researchers suggest that pets can play a transitional role at bedtime, triggering a sense of routine, order and security, thus easing the path to sleep (Wells 2009).

There is also an aligned but distinct, growing body of research regarding trained service dogs. While our primary concern relates to pet dogs, some brief mention of studies of service dogs specific to sleep is warranted. A 2015 literature review (Rose et al. 2015) identified several small pilot and case studies specific to service dogs and sleep. One study cited in the review used dogs to intervene by awakening participants during a sleep apnea event and thus helping reset heart rate and facilitate reoxygenation (Smith et al. 2017). A second study trained service dogs, owned by persons with post-traumatic stress disorder, to wake their owners to preclude the onset of nightmares (Marston and Kopicki 2015). A third study involved training dogs to wake post-traumatic stress (PTSD) patients before the onset of nightmares and to provide comfort after a nightmare (Rose et al. 2015). The literature also contains reports of service dogs being trained to provide up to a five minute warning of an impending narcolepsy attack so patients can take precaution to minimize risk of injury during a fall (Dominguez-Ortega et al. 2013), and to place themselves in front of patients to avoid danger, call 911 from a specially designed phone, retrieve medication, and to cue patients to take medication (Roy 2014). These studies highlight that, in certain conditions, some disturbances during the night may be beneficial. The literature seems promising and suggests that the practice of co-sleeping with a dog may be a valuable non-pharmacological treatment option for some individuals with sleep disorders (Rose et al. 2015). However, service dogs are not readily available nor affordable for most people and research into the influence of sleep consequent to human/pet co-sleeping should not be neglected.

In summary, the question of animals in the sleep environment is complex. Undeniably, there are disadvantages for some people who co-sleep with their pet dog (Thompson and Smith 2014). However, research is growing identifying that having a pet in the bedroom or on the bed can have advantages such as feelings of security, contentment and relaxation, and especially for those who do not co-sleep with another human. Many pets are a source of unconditional support, comfort, security 
and stability (Crowe et al. 2017; Giaquinto and Valentini 2009; Smith et al. 2014) and, for some people, the advantages of human/pet co-sleeping likely outweigh the disadvantages (Smith et al. 2017).

While we know that in the general population co-sleeping with a pet appears to be common practice, there is little research available focused on persons living with chronic pain. Being told by a healthcare provider to discontinue co-sleeping with a pet dog, on the basis of the current evidence shortfall, can potentially be stressful and unnecessary. It may also increase a pain patient's feelings of isolation and being a burden to other family members who may have to take on more nighttime dog care responsibilities. Addressing the current evidence gap will assist healthcare practitioners and pain patients who wish to practice human/pet co-sleeping, develop strategies for optimal sleep outcomes (Krahn et al. 2015). The specific aim of this study is to explore chronic pain patients' experiences and beliefs about the impact of their pet $\operatorname{dog}(\mathrm{s})$ on their sleep.

\section{Materials and Methods}

\subsection{Design}

The participants in this paper were part of a larger study (Carr, et al. in press), which used a sequential exploratory mixed methods design (Creswell 2003; Creswell et al. 2011) where the qualitative phase is followed by a quantitative phase. The qualitative study, reported elsewhere, explored the experiences of people with chronic pain related to pet dog ownership (Carr et al.). The sleep question was only added to the larger study towards the end and resulted in a subgroup of participants (seven in total) who were specifically asked during the larger study interview, "Does your dog have a positive or negative impact on your sleep?" The larger qualitative study recruited participants (including the subgroup reported here) from a major chronic pain management program in Western Canada. The study had ethical approval from the University of Calgary Conjoint Health Ethics Research Board (CHREB\#16-2040).

\subsection{Participants}

The larger qualitative study used a purposeful sampling strategy to recruit participants best able to provide rich qualitative data (Creswell 2003). To capture a range of experiences, participants were recruited between the ages of 18-90, who had lived with chronic pain for $\geq$ six months measuring $\geq$ four on a Visual Analogue Scale (VAS, 0-10mm), at the time of invitation to the study. This criteria for having lived with pain for six or greater months aligns with the operational definition of chronic pain. Participants must also have owned a dog at the time of the study, been able to provide informed consent and converse in English. During later stages of the iterative data analysis, the relevance of a sleep-specific question was identified and added. Consequently, we have a smaller number of participants who responded to the sleep specific question then in the larger study. However, qualitative research methodologists suggest that 6-20 key informants are adequate for achieving data saturation (Creswell 2003), and we believe that the seven participants, who were asked the sleep specific question that is the focus of this paper, provided significant, rich and relevant data.

\subsection{Recruitment and Data Collection}

The larger study recruited participants through flyers and posters displayed in high traffic areas of a major chronic pain management program in Western Canada. No incentives were offered. Interested patients who owned a dog contacted the research team and, if they met the inclusion criteria, they were sent a consent form by mail or email and a convenient time scheduled for the interview. The main data collection method was a digitally recorded semi-structured telephone interview. For all study participants, the interviewer (EC) asked participants to reflect on their personal experiences of living with chronic pain and how having a dog affected how they experienced and managed chronic pain. In addition to those questions, the subgroup reported in this paper (seven in total), were also asked specifically, "Does your dog have a positive or negative impact on your sleep?" 


\subsection{Analysis}

Verbatim transcripts were scanned electronically for any mention of the keywords "sleep, rest, naps, insomnia." Given the emerging research linking daytime activity to restorative nighttime sleep (Moules 2002), we also searched for data specific to participation in daytime walks with the dog. Relevant text was extracted, and, following repeated readings, comments were coded and then organized into categories (Bowling 2002). A sample of the transcripts (15\%) were read, coded and categorized by a third party, not involved with the study, to audit for coding consistency. No discrepancies emerged.

\section{Results}

Six women and one man, all with chronic pain, responded specifically to the impact of their pet $\operatorname{dog}(\mathrm{s})$ on their sleep. Participants ranged in age from 45 to 70, had lived with pain for between 8-30+ years and six participants were not working or were retired. Five participants lived with a partner. Five participants had one dog and two participants had two dogs. The dogs aged in range from under 1 year to $10+$ years (Table 1). The age and breed of dog was not specifically recorded unless mentioned by the participant. A number of participants' comments reflected that they allowed their pet dog to sleep in the bed with them but, as we did not ask this question specifically, it is not possible to determine if this was common practice or if the pet sleep in the bedroom but not on the bed.

Table 1. Participant demographics.

\begin{tabular}{ccccccc}
\hline $\begin{array}{c}\text { Participant } \\
\text { (Gender) }\end{array}$ & Age & Employment & $\begin{array}{c}\text { Living } \\
\text { Arrangements }\end{array}$ & $\begin{array}{c}\text { Duration of } \\
\text { Pain }\end{array}$ & $\begin{array}{c}\text { Number of } \\
\text { Pet Dogs }\end{array}$ & $\begin{array}{c}\text { Age of Dog } \\
\text { (years) }\end{array}$ \\
\hline $1(\mathrm{~F})$ & 67 & Not working & Partner & 22 & 1 & 8 \\
$2(\mathrm{~F})$ & 45 & Not working & Partner & 12 & 1 & 2 \\
$3(\mathrm{~F})$ & 45 & Part-time & Partner & $20+$ & 1 & $7+$ \\
$4(\mathrm{~F})$ & 55 & Not working & Alone & 8 & 1 & 2 \\
$5(\mathrm{~F})$ & 68 & Not working & Partner & $30+$ & 2 & $\mathrm{u} / \mathrm{k}$ \\
$6(\mathrm{~F})$ & 55 & Not working & Alone & 8 & 1 & $10+$ \\
$7(\mathrm{M})$ & 70 & Not working & Partner & $30+$ & 2 & $<1, \mathrm{u} / \mathrm{k}$ \\
\hline \multicolumn{7}{c}{ Key: u/k = unknown } \\
\hline \multicolumn{7}{c}{}
\end{tabular}

\subsection{Codes}

The emergent codes reflected three categories: positive, negative and reciprocal beliefs held by participants in relation to the impact on their sleep of having a pet dog.

\subsubsection{Category 1: Positive Impact}

Over $80 \%$ of the comments reflected the belief that owning a dog had a beneficial effect on sleep (Table 2). The five codes in the category of Positive Impact and illustrative comments from participants $[\mathrm{P}]$, are listed below.

\section{Physical Presence/'Cuddles'}

Participants identified that the actual physical presence of their dog was reassuring, prevented loneliness and reduced stress so that sleep onset was easier; " ... I've got my buddy and I've got my companion hanging out with me and I don't get that loneliness"[P2] and " ... when I am not well he is there for comfort ... you know I always have got somebody to cuddle and make me feel loved when I am lonely and in pain and when I am trying to sleep ... " [P3].

2. Routine and a Schedule

The role having a dog played in setting a routine that was linked to sleep was mentioned several times; “ ... it helps in some way for the cuing... the thing they do for my sleep is the pattern of sleep 
to go to bed ..." "[P4] and "... it's time to go to bed. She [the dog] knows what the phrase means. It is obvious as she'll get up and walk up the stairs. She'll walk $2-3$ steps and look at me like 'are you coming? [P7].

\section{Distraction from Anxiety/Reassuring Presence at Night}

Three participants explained that their dog played a role in reducing psychological anxiety, stress and fear prior to bedtime; "... I get anxiety attacks/ anxiety moments, and, you know, he can't help stopping my mind from racing ... it's that comfort and knowing that he is there and even if I am awake all night I have company ... " [P3]. Similarly, Participant 5 stated " ... she [the dog] is just like a really solid friend ... she is there and she listens. She listens when no one else is around."

\section{Active Intervention to Keep Participant Safe}

Several participants talked specifically about perceptions that their pet dog took active intervention when the participant was experiencing challenges to restorative sleep. For example, Participant 2 reported that her dog seemed to monitor her pain medication pump and alerted the participant and her partner if there were problems, " ... she came and woke my husband up seconds before an alarm went off on the pump, like seconds." Similarly, Participant 6 said, " ... she can tell when I am still asleep having a night terror ... she will nuzzle up. I don't know what I would be doing without her, I wouldn't be sleeping."

\section{Daytime Activity to Promote Being Tired at Night}

Most participants mentioned that their dogs increased their activity during the day that contributed to better sleep; “... my days revolve around lots of walking with the dog ... [P2]. Participant 1 spoke of how her daytime activity increased dramatically as she cared for her dog with very complex health needs. She stated “ ... I think he was a real gift ... because of him and looking after him, you know, feeding and medication and then we started therapy ... over the next four months I got feeling better and got out of the house and had to do stuff for him and walk him ...."

\subsubsection{Category 2: Negative Impact}

Only two participants mentioned having their sleep disrupted by their pet dog, and, for the most part, these comments did not reflect that participants believed this to be a particularly troubling aspect. Rather, it was most common for participants to bracket these comments about their sleep being disturbed by jokes or statements intended to balance the negative aspect. For example, Participant 3 stated, " ... if they [the dog] decide they are not going to be sleeping that night they are gonna bug you and wake you up and, you know, be a bit naughty. I get that too. But it's not every time with him and generally he is pretty good about letting you rest, it was definably a comfort when I was on my own because I was lonely and he helped me sleep."

\subsubsection{Category 3: Reciprocal Impact}

Interestingly, a third thematic category emerged reflecting several participants' reciprocal concern for the sleep of their pet dog. As opposed to expressing concern for their own sleep being disrupted they talked about their strategies to help their dogs who had pain or illness to get a better sleep. For example, Participant 5 talked about her dog having a lot of joint pain: " ... she [the dog] has days when she experiences lots of pain, I make myself get down on the floor at her level .... I will sit with her and talk with her and very softly, very calmly, I make a point of massaging her ever so gently ... I find this brings down her heart rate, she's not in pain, the pain is starting to go down. I can physically see the changes in her and eventually she nods off to sleep." One participant pointed out that human/pet sleep disturbances were also reciprocal, stating " . . if anything I disturb their sleep ... he helps me get the little bit of sleep I get" [P4]. 
Table 2. Categories of codes from statements specific to dogs and sleep.

\begin{tabular}{cc}
\hline Category & Code \\
\hline 1. Positive & Physical presence/"cuddles" \\
& Routine and a schedule \\
& $\begin{array}{c}\text { Distraction from anxiety/reassuring presence at night } \\
\text { Active intervention to keep participant safe } \\
\text { Daytime activity }\end{array}$ \\
\hline 2. Negative & Disturbs sleep with toileting or play demands \\
\hline 3. Reciprocal relationship & Owner concerned over pet dog's sleep \\
\hline
\end{tabular}

\section{Discussion and Conclusions}

We know that sleep, like pain, is best understood through the application of a biopsychosocial lens (Ferrie et al. 2011). Additionally, there is growing evidence that sleep and pain have a bidirectional relationship such that it is reasonable to assume that improved perceptions of sleep may positively influence how a patient experiences pain (Finan et al. 2013). If this, as the evidence seems to suggest, is the case, it is essential that we apply a much more comprehensive examination to the factors affecting both the perceived and measured outcome of sleep for persons living with chronic pain. To-date, most advice about how to improve sleep takes a fairly simplistic approach to managing sleep problems in the presence of a pet; remove the pet (American Sleep Association n.d.). However, removing distractions is only one of a multitudes of sleep hygiene principles. Sleep hygiene also stresses the importance of daytime activity, daylight exposure, stress reduction, and daily routines (National Sleep Foundation n.d.). Participants offered numerous examples of how their pet dogs facilitated adherence to these principles. Based on these findings we believe that more detailed research is warranted into the role pet dogs play in helping with sleep onset and maintenance through both physical (increased daytime activity, monitoring of breathing and other sleep-related technology) and psychological (maintenance of habits, routines, roles and responsibilities, stress/anxiety reduction, sense of safety and companionship) components of sleep hygiene. Additionally, the findings related to the concern some participants expressed about disturbing their pet dog's sleep were particularly intriguing and require further, more nuanced, study. It may be that some elements of social contract theory are at play and participants' comments reflect a sense of obligation towards the pet dog who is providing emotional resources to the owner. We do not have sufficient data from this study to speculate further but will look to social contract theorists such as Palmer (1997), to guide further research in this understudied area,

Chronic pain is a complex, biopsychosocial condition (Brown 2009) and privileging biological interventions alone is inadequate. We need to better understand if removing pet dogs as a solution to improved sleep could be counter-productive and lead to more, not less, sleep-related issues, including the potential for increased reliance on sleep medication and the increased need for other costlier, demanding, and less accessible, interventions such as cognitive behavioral therapy and pain-related surgery.

There were limitations to the study; with the small sample the analysis may not have reached thematic saturation, and it is possible that collecting phone interview data about sleep at the same time as other aspects of pet ownership and pain introduced some fatigue in participants and some responses may have been less detailed then optimal. Also, the participants self-selected and were therefore likely to be more positive about the aspects of dog ownership in their lives. Additionally, we did not collect quantitative sleep indicators which would have built a better picture of the extent of sleep deficiency in these participants. However, a number of sleep-positive codes emerged and even the two participants who identified negative aspects of co-sleeping with their dog unfailingly bracketed those comments with humor and other examples of where the dog was a sleep-positive influence.

Sleep is an essential human requirement, which, for many people with chronic pain, is a significant challenge. The evidence-base supporting the bi-directional nature of sleep and chronic pain is clear 
and requires closer attention. This small study shines a light on this important and yet neglected area of research. It reveals that for these participants their dog appears to enhance their sleep in many ways. Further research is warranted to explore more fully the ways in which pet dogs influence sleep for people with chronic pain.

Author Contributions: Conceptualization, C.A.B., Y.W. and E.C.J.C.; Methodology, E.C.J.C.; Formal Analysis, C.A.B. and Y.W.; Investigation, E.C.J.C.; Writing-Original Draft Preparation, C.A.B. and Y.W.; Funding Acquisition, E.C.J.C.

Funding: This research received partial funding from a Team Development Grant, Faculty of Nursing, University of Calgary.

Conflicts of Interest: The authors declare no conflict of interest. The funders had no role in the design of the study; in the collection, analyses, or interpretation of data; in the writing of the manuscript and in the decision to publish the results.

\section{References}

Adams, Graham, and Kenneth Johnson. 1994. Behavioural responses to barking and other auditory stimuli during nighttime sleeping and waking in the domestic dog (Canis familiaris). Applied Animal Behaviour Science 39: 151-62. [CrossRef]

Aili, Katrina, Teresia Nyman, Magnus Svartengren, and Lena Hillert. 2015. Sleep as a predictive factor for the onset and resolution of multi-site pain: A 5-year prospective study. European Journal of Pain 19: 341-49. [CrossRef] [PubMed]

American Sleep Association. n.d. Sleep Hygiene Tips—Research \& Treatments. Available online: https://www. sleepassociation.org/about-sleep/sleep-hygiene-tips/ (accessed on 1 May 2018).

Americans with Disability Act National Network. 2014. Service animal. Available online: https://adata.org/ factsheet/service-animals (accessed on 1 May 2018).

Andrews, Nicole E., Jenny Strong, Pamela J. Meredith, and Rachel G. D’Arrigo. 2014. Association between physical activity and sleep in adults with chronic pain: A momentary, within-person perspective. Physical Therapy 94: 499-510. [CrossRef] [PubMed]

Antaky, Elie, Lyne Lalonde, Mireille E. Schnitzer, Élizabeth Martin, Djamal Berbiche, Sylvie Perreault, David Lussier, and Manon Choinière. 2017. Identifying heavy health care users among primary care patients with chronic non-cancer pain. Canadian Journal of Pain 1: 22-36. [CrossRef]

Beetz, Andrea, Henri Julius, Dennis Turner, and Kurt Kotrschal. 2012. Effects of social support by a dog on stress modulation in male children with insecure attachment. Frontiers in Psychology 3: 1-9. [CrossRef] [PubMed]

Belk, Russell W. 1996. Metaphoric relationships with pets. Society and Animals 4: 121-145. [CrossRef]

Bloom, Harrison G., Imran Ahmed, Cathy A. Alessi, Sonia Ancoli-Israel, Daniel J. Buysse, Meir H. Kryger, Barbara A. Phillips, Michael J. Thorpy, Michael V. Vitiello, and Phyllis C. Zee. 2009. Evidence-based recommendations for the assessment and management of sleep disorders in older persons. Journal of the American Geriatrics Society 57: 761-89. [CrossRef] [PubMed]

Bowling, Ann. 2002. Research Methods in Health: Investigating health and health services. In UK Higher Education OUP Humanities \& Social Sciences Health, 2nd ed. London: Open University Press.

Brown, Cary A. 2009. Mazes, conflict and paradox: Tools for understanding chronic pain. Pain Practice 9: 235-43. [CrossRef] [PubMed]

Campbell, Scott S., and Irene Tobler. 1984. Animal sleep: a review of sleep duration across phylogeny. Neuroscience E Biobehavioral Reviews 8: 269-300.

Carr, Eloise, Jean Wallace, Peter Hellyer, Lori Kogan, and Chie Onyewuchi. Forthcoming. Exploring the meaning and experience of chronic pain with people who own a dog: A qualitative study. Anthrozoos. in press.

Cassels, Matthew T., Naomi White, Nancy Gee, and Claire Hughes. 2017. One of the family? Measuring young adolescents' relationships with pets and siblings. Journal of Applied Development Psychology 49: 12-20. [CrossRef]

Collins Online English Dictionary. n.d. Definition of the Word "Pet". Available online: https://www. collinsdictionary.com/dictionary/english/pet (accessed on 1 May 2018).

Consumer Corner. 2014. Canadian Pet Market Outlook. Available online: http://www1.agric.gov.ab.ca/ \$department/deptdocs.nsf/all/sis14914 (accessed on 1 May 2018). 
Creswell, John W. 2003. Research Design: Qualitative, Quantitative and Mixed Methods Approaches, 2nd ed. London: Sage.

Creswell, John W., Ann C. Klassen, Vicki L. Plano-Clark, and Katherine Clegg-Smith. 2011. Best Practices for Mixed Methods Research in the Health Sciences. National Institutes of Health: Office of Behavioral and Social Sciences Research (OBSSR). Available online: https:/ /www2.jabsom.hawaii.edu/native/docs/tsudocs / Best_Practices_for_Mixed_Methods_Research_Aug2011.pdf (accessed on 1 May 2018).

Crowe, Terry K., Victoria Sanchez, Alyse Howard, Brenna Western, and Stephanie Barger. 2017. Veterans transitioning from isolation to integration: A look at veteran/service dog partnerships. Disability $\mathcal{E}$ Rehabilitation 13: 1-9. [CrossRef]

Cutt, Hayley, Billie Giles-Corti, Matthew Knuiman, and Valerie Burke. 2007. Dog ownership, health and physical activity: A critical review of the literature. Health $\mathcal{E}$ Place 13: 261-72. [CrossRef]

Dominguez-Ortega, Luis, Elena Díaz-Gállego, Francisco Pozo, Cabrera S. García-Armenter, Manuel Serrano Comino, and E. Dominguez-Sanchez. 2013. Narcolepsy and odor: preliminary report. Semergen 39: 41-46. [CrossRef] [PubMed]

Duthuluru, Sowjanya, Damien Stevens, and Suzanne Stevens. 2014. Sleep quality due to co-sleeping with pets. Poster session. Paper presented at the 28th annual meeting of the Associated Professional Sleep Societies, Minneapolis, MN, USA, May 31-June 4.

Duvall Antonacopoulos, Nikolina M., and Timothy A. Pychyl. 2017. Acquiring a Dog and Walking It: A Preliminary Examination of the Possible Physical Activity and Health Benefits. Human Animal Interaction Bulletin 5: 36-60.

Ferrie, E. Jane, Meena Kumari, Paula Salo, Archana Singh-Manoux, and Mika Kivimäki. 2011. Sleep epidemiologyA rapidly growing field. International Journal of Epidemiology 40: 1431-37. [CrossRef] [PubMed]

Finan, Patrick H., Burel R. Goodin, and Michael T. Smith. 2013. The association of sleep and pain: An update and a path forward. The Journal of Pain 14: 1539-52. [CrossRef] [PubMed]

Gaskin, Darrel J., and Patrick Richard. 2012. The economic costs of pain in the United States. Journal of Pain 13: 715-24. [CrossRef] [PubMed]

Generaal, Ellen, Nicole Vogelzangs, Gary J. Macfarlane, Rinie Geenen, Johannes H. Smit, Brenda WJH Penninx, and Joost Dekker. 2014. Reduced hypothalamic-pituitary-adrenal axis activity in chronic multi-site musculoskeletal pain: partly masked by depressive and anxiety disorders. BMC Musculoskeletal Disorders 15: 227. [CrossRef] [PubMed]

Giaquinto, Salvatore, and Fabio Valentini. 2009. Is there a scientific basis for pet therapy? Disability \& Rehabilitation 31: 595-89. [CrossRef]

Goldberg, Wendy A., and Meret A. Keller. 2007. Co-sleeping during infancy and early childhood: key findings and future directions. Infant and Child Development 16: 457-69. [CrossRef]

Goldberg, Daniel S., and Summer J. McGee. 2011. Pain as a global public health priority. BMC Public Health 11: 770. [CrossRef]

Hafner, Marco, Martin Stepanek, Jirka Taylor, Wendy M. Troxel, and Christian van Stolk. 2017. Why Sleep Matters-The Economic Costs of Insufficient Sleep: A Cross-Country Comparative Analysis. Rand Health Quarterly 6: 11. Available online: https://www.ncbi.nlm.nih.gov/pmc/articles/PMC5627640/ (accessed on 1 May 2018). [PubMed]

Han, Kuem Sun, Lin Kim, and Insop Shim. 2012. Stress and Sleep Disorder. Experimental Neurobiology 21: 141-50. [CrossRef] [PubMed]

Irvine, Leslie, and Laurent Cilia. 2017. More-than-human families: Pets, people, and practices in multispecies households. Sociology Compass 11: e12468. [CrossRef]

Koffel, Erin, Adam D. Bramoweth, and Christi S. Ulmer. 2018. Increasing access to and utilization of cognitive behavioral therapy for insomnia (CBT-I): a narrative review. Journal of General Internal Medicine 33: 1-8. [CrossRef] [PubMed]

Krahn, Lois E., M. Diane Tovar, and Bernie Miller. 2015. Are pets in the bedroom a problem? Mayo Clinic Proceedings 90: 1663-65. [CrossRef] [PubMed]

Lerman, Sheera F., Patrick H. Finan, Michael T. Smith, and Jennifer A. Haythornthwaite. 2017. Psychological interventions that target sleep reduce pain catastrophizing in knee osteoarthritis. Pain 158: 2189-2195. [CrossRef] [PubMed] 
Marston, Holloway, and Alicia Kopicki. 2015. The Impact of Service Dogs on Posttraumatic Stress Disorder in the Veteran Population. Available online: http://www.apadivisions.org/division-19/publications/newsletters / military/2015/04/service-dogs.aspx (accessed on 1 May 2018).

Moules, Nancy J. 2002. Hermeneutic inquiry: Paying heed to history and Hermes. International Journal of Qualitative Methods 1: 1-21. [CrossRef]

National Sleep Foundation. n.d. Sleep Hygiene. Available online: https: / sleepfoundation.org/sleep-topics / sleep-hygiene (accessed on 1 May 2018).

Palmer, Clare. 1997. The Idea of the Domesticated Animal Contract. Environmental Values 6: 411-25. [CrossRef]

Patel, Salma I., Bernie W. Miller, Heidi E. Kosiorek, James M. Parish, Philip J. Lyng, and Louis E. Krahn. 2017. The effect of dogs on human sleep in the home sleep environment. Mayo Clinic Proceedings 92: 1368-72. [CrossRef] [PubMed]

Phillips, Ceri J. 2009. The cost and burden of chronic pain. Reviews in Pain 3: 2-5. [CrossRef] [PubMed]

Riemann, Dieter, Chiara Baglioni, Claudio Bassetti, Bjørn Bjorvatn, Leja Dolenc Groselj, Jason G. Ellis, Colin A. Espie, Diego Garcia-Borreguero, Michaela Gjerstad, Marta Gonçalves, and et al. 2017. European guideline for the diagnosis and treatment of insomnia. Journal of Sleep Research 26: 675-700. [CrossRef] [PubMed]

Rose, Mary W., Colleen Lance, and Carlos H. Schenck. 2015. Dogs and Their Promising Roles in Sleep Disorders Therapy. June 22. Available online: http://www.sleepreviewmag.com/2015/06/dogs-promising-rolessleep-disorders-therapy/ (accessed on 1 May 2018).

Roy, Sree. 2014. Service Dogs Support Narcolepsy Patients, Literally and Figuratively. October 31. Available online: http:/ / www.sleepreviewmag.com/article/service-dogs-narcolepsy-patients (accessed on 1 May 2018).

Shepard, John W. 2002. Pets and sleep. Poster session. Paper presented at the 16th annual meeting of the Associated Professional Sleep Societies. Sleep 25, Seattle, WA, USA, June 8-13.

Smith, Michael T., and Jennifer A. Haythornthwaite. 2004. How do sleep disturbance and chronic pain inter-relate? Insights from the longitudinal and cognitive-behavioral clinical trials literature. Sleep Medicine Reviews 8: 119-32. [CrossRef]

Smith, Bradley, Kirrilly Thompson, Larissa Clarkson, and Drew Dawson. 2014. The prevalence and implications of human-animal co-sleeping in an Australian sample. Anthrozoos 27: 543-51. [CrossRef]

Smith, Bradley P., Peta C. Hazelton, Kirrilly R. Thompson, Joshua L. Trigg, Hayley C. Etherton, and Sarah L. Blunden. 2017. A multispecies approach to co-sleeping: integrating human-animal co-sleeping practices into our understanding of human sleep. Human Nature 28: 255-73. [CrossRef] [PubMed]

Stiefel, Frederic, and Daniele Stagno. 2004. Management of insomnia in patients with chronic pain conditions. CNS drugs 18: 285-96. [CrossRef] [PubMed]

Stranges, Saverio, William Tigbe, Francesc Xavier Gómez-Olivé, Margaret Thorogood, and Ngianga-Bakwin Kandala. 2012. Sleep Problems: An Emerging Global Epidemic? Findings from the INDEPTH WHO-SAGE Study Among More Than 40,000 Older Adults From 8 Countries Across Africa and Asia. Sleep 35: 1173-81. [CrossRef] [PubMed]

Tang, Nicole K. Y. 2008. Insomnia co-occurring with chronic pain: Clinical features, interaction, assessments and possible interventions. Reviews in Pain 2: 2-7. [CrossRef] [PubMed]

Thompson, Kirrilly R., and Bradley P. Smith. 2014. Should we let sleeping dogs lie ... with us? Synthesizing the literature and setting the agenda for research on human-animal co-sleeping practices. Humanimalia 6: 114-27.

Walden, Liz. 2015. A Guide to Worldwide Pet Ownership. May 13. Available online: https:/ /www.petsecure.com. au/pet-care/a-guide-to-worldwide-pet-ownership/ (accessed on 1 May 2018).

Wells, Deborah L. 2009. Associations between pet ownership and self-reported health status in people suffering from chronic fatigue syndrome. The Journal of Alternative and Complementary Medicine 15: 407-13. [CrossRef] [PubMed]

(C) 2018 by the authors. Licensee MDPI, Basel, Switzerland. This article is an open access article distributed under the terms and conditions of the Creative Commons Attribution (CC BY) license (http:/ / creativecommons.org/licenses/by/4.0/). 


\title{
Article \\ Exploring the Place of Animals and Human-Animal Relationships in Hydraulic Fracturing Discourse
}

\author{
Cameron T. Whitley \\ Faculty of Arts and Sciences, Rutgers University, Camden, NJ 08102, USA; cameron.whitley@rutgers.edu \\ Received: 23 January 2019; Accepted: 11 February 2019; Published: 18 February 2019
}

\begin{abstract}
Throughout human history, energy security has been a prominent concern. Historically, animals were used as energy providers and as companions and sentinels in mining operations. While animals are seldom used for these purposes in developed communities today, this legacy of use is likely to have far-reaching consequences for how animals and human-animal relationships are acknowledged in energy development. The US is currently experiencing an energy boom in the form of high volume horizontal drilling and hydraulic fracturing (HVHHF); because animals are the most at risk from this boom, this study uses a thorough content analysis of peer-reviewed HVHHF articles mentioning animals from 2012-2018 to assess how animals and human-animal relationships are discussed. Three dominant article theme classifications emerge: animal-focused articles, animal-observant articles, and animal sentinel articles. Across themes, articles seldom acknowledge the inherent value or the social and psychological importance of animals in human lives; instead, the focus is almost exclusively on the use of animals as sentinels for potential human health risks. Further, what is nearly absent from this body of literature is any social science research. Given that relationships with animals are an integral part of human existence, this study applies environmental justice principles, serving as a call to action for social science scholars to address the impacts of HVHHF on animals and human-animal relationships.
\end{abstract}

Keywords: hydraulic fracturing; animal studies; environmental sociology; environmental justice; companion animals; energy development

\section{Introduction}

On a small plot of land in Pennsylvania, Stacey Haney and Beth Voyles raised animals and children. In 2008, they combined their land in order to rent it to a Texas-based oil company that would use high volume horizontal drilling and hydraulic fracturing (HVHHF) to harvest natural gas. Both women thought it was a beneficial plan, providing them with additional income for their respective farms. However, in less than a year after drilling began, Haney's animals, Hunter (dog), Boots (goat), and Boots' offspring had all died. Similarly, Voyles lost her prized dog, Cummins, and at least 15 of Cummins' offspring. Both families also experienced health repercussions (see, e.g., (Griswold 2011)). Their land sits above the Marcellus Shale Deposit, which is an American natural-gas field often used for HVHHF. HVHHF is a type of energy development that involves forcing high volumes of water, sand, and hundreds of hazardous chemicals into horizontally drilled wells to stimulate fractures and free up oil and gas stores that can then be recovered.

Over the last two decades, there has been increased debate and documentation of the impacts that HVHHF is having, and will have, on communities and individuals. Social scientists have been at the forefront of this discussion, detailing such things as the public perceptions of the social-environmental issues caused by HVHHF (Ladd 2013, 2018; Morrone et al. 2015; Vasi et al. 2015), local opposition and community division over HVHHF, differences in public and elite perceptions (Crowe et al. 2015), influence of familiarity with HVHHF on opinion (Willits et al. 2016), and HVHHF's negative impacts 
(Hauter 2016). What this literature tells us is that there is great division among the general public about the necessity of HVHHF and the impacts that it will have on individuals and communities. More importantly, the nuances in energy development discussions and perceptions are often location or community specific (see, e.g., Hula et al. 2017). Although, as the text above details, animals are an integral part of the HVHHF story, little attention has been paid to addressing the intersection of humans, animals, and HVHHF.

Outside of energy debates, social scientists are increasingly recognizing the value of including animals and human-animal relationships in social research, often discussing animals as a critically important but missing or overlooked variable (Carter and Charles 2018; Cudworth 2015; Peggs 2012; Tovey 2003). By bringing animals back into the conversation, social scientists have identified important connections that have led to significant social and policy changes. For instance, Fitzgerald and colleagues (Barrett et al. 2018; Fitzgerald 2007) argue that women in abusive relationships are often reluctant to leave their abusive partners because of fear that their companion animals may sustain increased violence or that domestic violence shelters will not accept them with a companion animal. This finding has led to an increase in domestic violence shelters accepting companion animals. In another area of research, Irvine (2009) documents the horrors of animal violence, neglect and abuse by authorities that kept local residents from leaving their homes during hurricane Katrina. This extended conversation led to the 2006 federal Pets Evacuation and Transportation Standards (PETS) Act, which directs state and local emergency plans to take pets and service animals into account in emergency planning. While these are only two examples of many, they demonstrate how understanding animals and human-animal relationships is becoming critical to understanding larger social issues. The current article is designed to continue this conversation, by looking at how animals (wild, agriculture and companion) and human-animal relationships are discussed and addressed in HVHHF research.

In 2012, Michelle Bamberger and Robert Oswald, a veterinarian and a pharmacologist, published a paper with the intention of starting a conversation about the impacts of HVHHF on animal populations and the associated connections to human health. Their article relies on 24 reported cases of animal harm. Opening a new avenue for discussion and making clear connections between animal and human well-being, the paper received widespread attention (see, e.g., Phillips 2012). Although their paper does not offer generalizable statements about the broad impacts of HVHHF on animals or the associated costs to human health, it does raise numerous questions about the use of animals as, what Whitley (2017) terms, unintentional sentinels in the expansion of HVHHF. This issue should be part of a larger discussion about the use of animals in energy development, a topic that has implications for both animal and human health, as well as for human-animal relationships more broadly.

Animals have a long and varied history in energy development that has often been overlooked (see, e.g., Whitley 2017, 2018). From antiquity until recent times, animals were used as energy providers. This dynamic only changed with technological innovation, at which point animals became intentional sentinels in mining operations and laboratory experiments, being used to assess the risks that mining toxins posed to humans. Though using animals as intentional sentinels fell out of favor in the 1960s, HVHHF's rapid expansion has reintroduced their use as harbingers of human risk. Researchers are monitoring (as unintentional sentinels) and once again conducting laboratory experiments on animals (as intentional sentinels) to assess the impacts of HVHHF toxin exposure, often with the objective of learning more about potential risks to human health.

Understanding the impact HVHHF has on animals and human-animal relationships is important for four key reasons. First, animals are inherently valuable; they contribute to ecosystem success and HVHHF will likely have individual and symbiotic impacts on their wellbeing. Second, although impacts on animals may signal potential risks to humans, they are also likely to impact human-animal relationships. For instance, in the example above, Haney and Voyles both experienced psychological trauma over the loss of their animals. Such trauma could be magnified in sensitive populations such as in senior populations living with pets (see, e.g., Himsworth and Rock 2013). In addition, this type 
of trauma could have implications for animal ownership and rescue in high HVHHF regions. Third, the impact HVHHF has on animals may affect public perceptions of risk and behavior, as is the case with natural disasters, where harm to animals influences individuals' risk perceptions and behaviors (see, e.g., Irvine 2009). Additionally, HVHHF can impact veterinary services. Bamberger and Oswald (2012) argue that non-disclosure policies make treating animals exposed to HVHHF fluids a challenge. Along these lines, veterinarians in high HVHHF areas are likely coming into contact with greater numbers of exposure cases, changing how veterinary medicine is practiced.

Research on HVHHF is highly interdisciplinary and implications for animals are often embedded in ways that make it unclear whether these topics are being investigated. This study seeks to overcome this challenge by conducting a thorough content analysis of all peer-reviewed literature, published from 2012-2018, on HVHHF that mentions animals to provide a report on the state of the field that (1) determines how animals and human-animal relationships are featured in scientific literature on the impacts of HVHHF; (2) identifies themes among the suite of studies and; (3) assesses what additional research is needed as a call to action.

\section{Background and Theory}

\section{Environmental Justice and the Place of Animals}

The recognition of animals in energy development and the associated link to human lives is best situated within an environmental justice (EJ) framework. Historically, EJ has addressed the inequitable distribution of environmental services and burdens to vulnerable populations. Social scientists have long drawn on work from deviance studies, political economy and environmental justice to explain toxic exposure, consistently concluding that the poor and people of color have been victims of egregious ecological injustice (see, e.g., Mohai and Saha 2006, 2007). This literature is connected to a larger body of work that assesses how social and political inequalities are reinforced through access and distribution of the natural environment (see, e.g., Bullard 2005; Pellow 2017). Much of the literature is focused on the production, manipulation and unlawful disposal of toxic waste (see, e.g., Massari and Monzini 2004; Pearce and Tombs 2009; Ruggiero 1996). It should be noted that this body of literature within social science originated with a human emphasis. Specifically, Bullard and colleagues (Bullard 1994; Bullard and Wright 1993) were attempting to counter the environmental movement approach, which focused on impacts on the natural environment, by drawing attention to the impacts on vulnerable populations. At this time, the recognition of the interconnectedness between humans and animals was not fully realized, and remains an issue. EJ scholar David Pellow has been particularly interested in reincorporating animals into EJ conversations, especially around toxic exposure (Mohai et al. 2009; Pellow 2014, 2017). However, there remains a space for a deeper discussion not just about the impacts on wildlife populations, but about the shared impacts across species and the impact on human-animal relationships broadly.

Though there has been a concerted effort to apply concepts of EJ to human populations, nonhuman animals remain nearly absent from this discourse (Kopnina 2014). Kopnina (2014) argues that scholars are influenced by the "dominant neoliberal ideology of anthropocentrism" (p. 2) (see also, e.g., Callicott 1999; Catton and Dunlap 1978; Crist 2012; Kopnina 2012a, 2012b). The traditional tendency of social science to be anthropocentric has limited inquiry into animal-environment issues to discussions of the implications of these issues to humans, without regard for the inherent value of animal species (Beirne 2009; Nibert 2002). Kopnina (2014) clarifies this argument, suggesting that the "view of animals as culturally, socially or economically significant objects sees non-humans as facilitators of technological advancements (e.g., medical experiments or genetic manipulations), as an attribute of cultural practice (hunting or whaling) as the objects of economic interest (e.g., animal trade) symbolic ritual (e.g., animal sacrifice), or collateral damage (e.g., road kill or forest clearings)" (p. 4). In energy development, animals have not only been the facilitators of technological advancements, but they have 
also served as sentinels, living indicators of risks posed to humans (Whitley 2017). In this way, the use and investigation of animals in energy development has been and remains anthropocentric.

An issue becomes an EJ concern when it is socially constructed as a problem (Taylor 2000). White (2013) argues that the nature of mining inherently creates EJ concerns because vulnerable populations always suffer. Several researchers have documented the potential risks HVHHF poses to human health through water contamination, fracking fluid spills, air pollution, etc. (Korfmacher et al. 2013; Kovats et al. 2014; Wattenberg et al. 2015). In doing so, these researchers have constructed a narrative about HVHHF as an EJ issue, with a focus on human health implications. What remains absent from this work, and the larger body of EJ literature, is any recognition of animals or human-animal relationships.

Schlosberg (2013) argues that, "one of the remaining border challenges of environmental justice theory is to make important connections with the environment itself ... Yes, most of the discussion is about environmental bads and injustices to human beings, but the origins of environmental injustices are as much in the treatment of the non-human realm as in relations among human beings" (pp. 43-44). Although all mining practices have environmental impacts, the expansion of development, potential for chemical pollution, and hydrological alteration make HVHHF particularly concerning. Animals are likely to be the first affected in HVHHF development. Direct impacts on animals could have lasting effects on biodiversity and ecological services (Kiviat 2013). In particular, vulnerable animal populations such as those who have restricted ranges, are sensitive to environmental changes, or if endangered, may experience amplified effects. The potential risks are so concerning that HVHHF has been identified as a global conservation issue (Lloyd et al. 2005). Importantly, wildlife are not the only victims; the health and wellbeing of livestock and companion animals is also at risk (see, e.g., Bamberger and Oswald 2012, 2015), bringing up questions about the rights of animals to have equitable access to environmental services such as clean water and air. This study seeks to demonstrate that HVHHF is not just an EJ issue for humans, but that animals and human-animal relationships should be considered as well. The study that follows uses a content analysis approach to evaluate the extent to which animals are considered in HVHHF discussions within peer reviewed journal articles. In doing so, it provides tangible evidence in support of Schlosberg (2013) assertion that we need more discussions of animals as victims in environmental justice narratives.

\section{Data}

All peer-reviewed articles published between 2012 and 2018 that are about HVHHF and mention animals were examined. To ensure that the analysis is inclusive, data collection was conducted using three steps. The process began with Bamberger and Oswald's 2012 paper, described in the introduction, as it is considered the seminal article exploring the potential impacts HVHHF has on animals. All citations within the articles citing Bamberger and Oswald (2012) were analyzed. Next, all peer-reviewed articles citing Bamberger and Oswald (2012) were reviewed. Finally, the resulting list was cross-referenced with a search in the Web of Science database looking for peer-reviewed articles featuring hydraulic fracturing (using key terms: hydraulic fracturing, fracking, unconventional energy development, and natural gas development) and animals (using key terms: animals, ecosystems, fisheries, wildlife, livestock, agriculture, invertebrates, biodiversity, fauna, and mammals). A total of 118 articles were identified.

\section{Method}

A content analysis approach was applied, which is a widely used technique to identify and describe patterns in textual data. All text was coded in Nvivo 11.4. Nvivo is a qualitative data analysis software tool that allows for the coding, sorting, querying and sharing of unstructured data. Line data were coded into nodes and then consolidated into categorical themes. First, all articles were reviewed to give the researcher a feel for these data. Second, abstracts were coded for the presence of animal terms. For instance, if animals were featured in the abstract it was assumed that the animals were 
a central focus of the article. If animals were not featured in the abstract, it was assumed that they had little importance in the article or were simply a line reference. Additional nodes were identified to code the central themes of each abstract, regardless of animal inclusion. Abstracts were chosen as the first level of analysis, because they provide summaries of articles and are likely the first thing people assess before reading an entire article. Third, a line-by-line review of all articles was done to assess when and how animals were discussed. Finally, a second coder was asked to independently code all text. Inconsistencies between the two coders were discussed until consensus was reached. Limited inconsistencies were found, as nodes relied on the presence of specific words related to animals or other subcategories of environmental and social impacts. Three major themes emerged. These themes and the associated subthemes are discussed below.

\section{Results and Discussion}

The analysis aims to clarify how animals and human-animal relationships are included or excluded in scientific discussion on HVHHF. Of the 118 articles analyzed, only 44 (37\%) mention animals in the abstract. Across all articles, three dominant themes emerged. First, 25 (21\%) articles directly mention animals or ecosystems in the abstract and focus on the impacts HVHHF has on a specific animal, group, or species. These 25 articles are referred to as "animal-focused" articles. Second, $23(20 \%)$ articles review the impacts of HVHHF and mention animals or ecosystems in the abstract but do not exclusively focus on animals, including non-animal impacts as well. These are referred to as "animal-observant" articles. Finally, the majority of articles (70 articles, 59\%) did not mention animals in the abstract but cited the Bamberger and Oswald (2012) article to support a claim about the impacts of HVHHF on humans. These articles are referred to as "animal-sentinel" articles. Within each theme, subthemes emerged.

\subsection{Animal-Focused Articles}

The articles within this group either provide a general overview of the impacts of HVHHF on ecosystems or focus on specific impacts on a species. General overviews of ecosystem impacts consistently conclude that freshwater organisms, species sensitive to land fragmentation, and animals with restricted ranges are the most at risk (Gillen and Kiviat 2012; Kiviat 2013). In these articles, animals are the focal point and the research examines how HVHHF affects them. For instance, research suggests that the redfin darter, a fish that is endangered in some US states, is vulnerable to silt input in streams (Stearman et al. 2015); native brook trout conservation and restoration are at risk (Weltman-Fahs and Taylor 2013), as are Zebra fish and their habitats (Folkerts et al. 2017; He et al. 2018); migrating fracturing fluids may cause adverse effects in rainbow trout (He et al. 2016; Folkerts et al. 2017); fish exposed to waters contaminated with fracking fluids show signs of general stress and higher incidences of gill lesions compared to unexposed fish (Papoulias and Velasco 2013); and a positive correlation exists between the presence of HVHHF wells and mercury concentrations in crayfish, and other predatory macro invertebrates and brook trout (Grant et al. 2015; Blewett et al. 2017a; Blewett et al. 2017b). In addition, non-aquatic animals may also be affected by water contamination. For instance, metal accumulation in riparian songbirds is higher in heavy HVHHF areas compared to those residing in areas without HVHHF (Latta et al. 2015) and the leopard frog may be particularly vulnerable (Funk and Stabenau 2017).

A handful of articles that focus on specific species demonstrate that land fragmentation contributes to animals avoiding roadways, which isolates them to smaller areas of land, a trend documented in grassland bird species (Thompson et al. 2015), salamanders (Brand et al. 2014), mule deer (Lendrum et al. 2012), and river otters (Godwin et al. 2015). Although land fragmentation is not likely to have a big impact on livestock and companion animals, range restrictions might; despite this possibility, studies of the impacts of HVHHF on livestock and companion animals are scarce. For instance, in the only identified study on livestock, Finkel et al. (2013b) assess how HVHHF affects cow and milk production over a five-year period, finding that production decreased as 
HVHHF development increased. Similarly, beyond the original Bamberger and Oswald (2012) article, only three studies report on the impacts on companion animals and human-animal relationships. First, Slizovskiy et al. (2015) use a community health survey with questions about companion and livestock health to assess how the distance to the nearest HVHHF well relates to reported human and animal health. They find that the reported health of dogs is significantly lower for people living within $1 \mathrm{~km}$ of a gas well compared to those living farther away. Second, a follow-up article by Bamberger and Oswald (2015) demonstrates that the negative health impacts decrease for families (including animals) moving away from HVHHF areas, while health impacts remain the same or increase for those continuing to reside in high volume drilling areas. Finally, in conducting interviews among Pennsylvania residents with a focus on women, McHenry (2017) finds that people are particularly concerned with how hydraulic fracturing impacts their family pets.

Assessing the articles in this thematic category leads to three broad conclusions. First, although these articles focus almost exclusively on animals and tend to argue for the inherent value of animals, they largely justify studying impacts on animals by connecting them to human systems. For example, this group of studies generally mentions human health or the preservation of ecosystem services in the conclusion as a justification for focusing exclusively or almost exclusively on animals. Second, there is limited social science research in this body of literature. Only one study, McHenry (2017), is from a social science perspective. Specifically, there is no broad assessment of how hydraulic fracturing is impacting animals or human-animal relationships; there are only assessments of the impacts on animals that may signal potential risks to humans. Finally, and perhaps most surprisingly, the lengthy history of testing mining toxins on animals to assess and mitigate human health risks is alive and well in research with a few studies reporting on the use of laboratory mice to assess toxin exposure extremes (Kassotis et al. 2015; Kassotis et al. 2016a). This is interesting because it goes beyond the assumption that animals are simply serving as unintentional sentinels in HVHHF development. Instead, this evidence suggests that animals are also serving as intentional sentinels.

\subsection{Animal-Observant Articles}

The articles in this group $(\mathrm{N}=23)$ mention animals in the context of other HVHHF risks and do not focus on a specific animal or species. In most cases, these articles focus on environmental damage or contamination. Terms such as "animals" and "ecosystems" are widely used. Unlike the previous category, the focus of these articles is on the broad effects, which happen to include impacts on animals. So, for instance, in thinking about water contamination, the author might mention all of the potential impacts, where in the previous category the analysis or discussion would be on the impacts HVHHF has on a particular species or group of animals. There are no social science articles in this group.

The majority of articles in this thematic category emphasize freshwater ecosystems as their animal focal point. This is not surprising, as these articles cite many of the "Animal-Focused Articles" listed above as supporting evidence. For instance, studies show that chemicals used in hydraulic fracturing pose a risk to ecosystems (Entrekin et al. 2018; He et al. 2017; Loh and Loh 2016; Vandecasteele et al. 2015; Yao et al. 2015). Specifically, Kassotis et al. (2016b) find that injection well disposal sites reveal elevated levels of toxins that could disrupt reproduction and development in aquatic animals (see, e.g., Elliott et al. 2017). Additionally, HVHHF leads to increases in $\mathrm{pH}$ in area streams (Lutz and Grant 2016), and water contamination can enter the food chain impacting cattle, poultry, and aquatic life (Kun et al. 2014; Pothukuchi et al. 2018). Notice that in all of these cases, animals are mentioned, but they are mentioned in the context of environmental contamination where the focal point is on contamination and not on animals.

Instead of centering on a particular environmental impact, some articles provide general overviews of environmental risks (Brittingham et al. 2014; Burton et al. 2014; Lave and Lutz 2014; Souther et al. 2014) or information about regulatory processes (Ralston and Kalmbach 2018). For instance, in an analysis of land use and shale development, Moran et al. (2015) assert that, "shale gas development will likely have substantial negative impact effects on forested habitats and 
the organisms that depend upon them" (p. 1276) and Abrahams et al. (2015) note, "well pads, access roads, and gathering lines fragment forestland resulting in irreversible alterations to the forest ecosystem" (p. 153). Similarly, in a paper looking at how Saskatchewan is responding to hydraulic fracturing, the authors note that people are concerned about impacts on animals and ecosystems (Olive and Valentine 2018).

Finally, a key component of articles within this theme is the effort to position research as important for supporting human systems. For example, multiple scholars argue that failing to understand threats to ecosystems and provide proper regulatory mechanisms are likely to contribute to ecosystem loss, which has implications for human health (Allred et al. 2015; Bamberger and Oswald 2014; Down et al. 2013; Finkel et al. 2013a; Finkel et al. 2013b; Jones et al. 2015; Kassotis et al. 2016a; Kassotis et al. 2016b; Robbins 2013; Ticleanu et al. 2014). Three important takeaways emerge from this group. First, articles mention animals as being impacted by HVHHF, but do not focus on a specific group or species. Second, unlike the articles in the animal-focused group, these articles center on making a connection between animal (and environmental) impacts and human health, paying less attention to the inherent value of nature or animals. Finally, there are no social science articles.

\subsection{Animal Sentinel Articles}

Animal sentinel articles do not mention animals or ecosystems in the abstract $(\mathrm{n}=70)$. Overall, this group uses the Bamberger and Oswald (2012) article to support discussions on one of five key HVHHF subthemes: public health concerns ( $n=24$ or $35 \%$ of animal sentinel articles), environmental impacts ( $n=19$ or $27 \%$ of animal sentinel articles), community impacts and public perceptions $(n=16$ or $23 \%$ of animal sentinel articles), policy ( $n=7$ or $10 \%$ of animal sentinel articles), and general reviews of broad impacts ( $n=4$ or $6 \%$ of animal sentinel articles).

First, the largest group of articles in this theme emphasizes public health concerns $(\mathrm{n}=$ 24). These articles discuss the impacts of HVHHF on either broad public health categories (see, e.g., Adekola et al. 2016; Boyle et al. 2016; Ferrar et al. 2013; Finkel and Hays 2013; Goldstein and Kriesky 2012; Korfmacher et al. 2013; Mitka 2012; Penning et al. 2014; Perry 2013; Rabinowitz et al. 2015; Rafferty and Limonik 2013; Redmond 2014; Saberi 2013; Saberi et al. 2014; Saunders et al. 2016; Shonkoff et al. 2014; Steinzor et al. 2013; Tuller 2015; Werner et al. 2015; Willems et al. 2016) or specifically to infant or reproductive and developmental health (Kassotis et al. 2015; Ma et al. 2016; Payne et al. 2014; Webb et al. 2014). If mentioned, animals are only used to situate the potential and realized impacts on human health or to assert that more research is needed (see, e.g., Ma et al. 2016). For instance, in a review of HVHHF health impacts, Shonkoff et al. (2014) cite Bamberger and Oswald (2012) after discussing fracking fluid containment by noting "These containment ponds are often, but not always, lined to protect against leakage; however, case studies have documented reported ruptures to these liners that may have led to water and soil contamination and contributed to fish and livestock deaths (Bamberger and Oswald 2012, p. 793)". This is the only reference to animals in the article and is simply used to support the thesis that additional epidemiological studies are needed to evaluate risks to human health.

Second, a group of studies within this theme speak to environmental impacts $(n=19)$. Two articles review broad environmental impacts (Arent et al. 2015; Reible et al. 2016), while the remaining 17 focus on air quality or water use and contamination. For instance, HVHHF is known to have broad impacts on air quality (Bai et al. 2016; Brown et al. 2014; Brown et al. 2015; Bunch et al. 2014; Colborn et al. 2012; Field et al. 2014; Moore et al. 2014). Similar to the health impacts subtheme, this group minimally mentions animals in the text or uses Bamberger and Oswald (2012) as a general nod to potential impacts on human health. For instance, Bunch et al. (2014) do not mention animals at all, but cite the article to show that few "studies have focused on atmospheric emissions and, in particular, on the potential impacts of such emissions on human health" (p. 833). A second group of environmental impact articles speak to issues of water quality. For instance, these articles discuss the chemical composition of water and wastewater disposal wells near HVHHF sites (Kassotis et al. 2013; 
Rich and Crosby 2013; Zhai et al. 2016), wastewater spills and water contamination (Koh et al. 2016; Konkel 2016; Penningroth et al. 2013; Sang et al. 2014), and broad debates about water use and contamination (Ernstoff and Ellis 2013). Overall, animals are excluded or only mentioned in superficial ways.

Third, there are 16 community impacts and public perception articles. This subtheme is the only one to include social science articles. In these articles, HVHHF is evaluated in terms of public perceptions (Choma et al. 2016; Dokshin 2016; Israel et al. 2015; Morrone et al. 2015; Powers et al. 2015), community disorder and boomtown issues (Jerolmack and Berman 2016; Ruddell and Ortiz 2014), changes in traffic (Graham et al. 2015), economic impacts (Barth 2013; Muresan and Ivan 2015), broad or case-specific social impacts (Garvie et al. 2014; Perry 2012), and environmental justice and human rights (see, e.g., Clough and Bell 2016; Fry et al. 2015; Johnston et al. 2016; Short et al. 2015). Once again, these articles give little attention to the impacts of HVHHF on animals. Specifically, animals and human-animal relationships are not mentioned in survey analyses or in discussions about community impacts broadly. What is most interesting about this collection is that even among the environmental justice focused articles, animals are non-existent. For instance, in discussing the connection between human rights and HVHHF, Short et al. (2015) cite the Bamberger and Oswald (2012) article to suggest that "Land can also be impacted through water, air or soil pollution as we have seen above, along with damage to livestock, vegetation and wildlife" (p. 15), but give no designated attention to animals or human-animal relationships in their analysis. Once again, this group mentions animals or ecosystems to support the discussion of potential risks to humans.

Fourth, some articles focus on policy initiatives and debates $(n=7)$. Within this group, articles focus on policies and practices in monitoring and management (Centner and Eberhart 2015; Wylie and Albright 2014), local distance ordinances and management (Centner and Kostandini 2015; Fry 2013), political debates and public policy (Bamberger and Oswald 2013; Beebeejaun 2013), and national acts and orders (Geltman et al. 2016). As with the others, articles in this subtheme either do not specifically mention animals or only mention them to support a claim about human or environmental wellbeing. The single exception to this is Bamberger and Oswald's 2015 follow up article to their original 2012 publication, in which they deliberately discuss the impact of HVHHF on livestock, mentioning that livestock remaining in HVHHF areas recovered from reproductive distress initially seen on the onset of production, but developed long-term respiratory issues.

Finally, a small group of articles provide general overviews of the impacts of HVHHF, addressing both environmental and social concerns $(n=4)$ (see, e.g., Esterhuyse et al. 2016; Hays et al. 2015; Stephenson 2016; Wang et al. 2014). Once again, this group cites Bamberger and Oswald (2012) without mentioning animals. For instance, Stephenson (2016) notes, "concerns over additives used in hydraulic fracturing fluid mainly center on them reaching the environment from spills at the surface or in transport, from illegal dumping of wastewater, or from damage to the liners of wastewater impoundment dams" (p. 8), which is followed with the Bamberger and Oswald citation. The article does not specifically mention animals. By evaluating articles in the animal sentinel theme, two conclusions emerge. First, the majority of articles that cite the Bamberger and Oswald (2012) article only use the citation to situate research on the impacts of HVHHF on humans, paying little or no attention to the direct impacts that HVHHF has on animals and human-animal relationships. Second, it is clear that social science, including environmental justice scholars, have neglected this area of research.

\section{Conclusions}

As HVHHF continues to expand, numerous environmental and social impacts are being acknowledged; however, the place of animals in this discourse remains limited, especially among social scientists (see, e.g., Whitley 2017, 2018). Assessing the impacts of HVHHF on animals and human-animal relationships is particularly important because animals have inherent value, they contribute to ecosystem viability, and there will likely be shared impacts between humans and animals. Studies that mention animals or cite animal-related research in the context of HVHHF 
can be divided into three thematic categories: animal-focused, animal-observant, and animal sentinel articles. Animal-focused articles assess the risks of HVHHF on animal life, often on a particular species. Animal-observant articles mention impacts of HVHHF on animals, but in the context of other issues or themes. Articles in this group do not focus on animals, but impacts on animals are acknowledged. Finally, the majority of articles cite animal-focused articles to make a claim about the impacts HVHHF has on something or some community other than animals. Social science work is nearly absent from all categories. Specifically, there is no focused discussion of human-animal relationships in the face of HVHHF or of how the impacts of HVHHF on animals influence social and community dynamics. The clear gap in literature mimics the assertions that social science has neglected the natural environment and, in this case, animals as an important topic of analysis for social life. What this analysis shows is that there are many ways that social scientists can engage with broadly understanding the intersection between humans, animals and energy development, and HVHHF in particular.

While some studies acknowledge the inherent value of animals (studies in the animal-focused theme), most cite risks to animals as a means of understanding the potential risks to human health. This is perhaps unsurprising, given humans' lengthy history of using animals as intentional and unintentional sentinels in energy development and the EJ focus on human lives. For instance, scholars have often argued that the tracking and monitoring of sentinel species is an important technique to assess human health risks (McCarthy et al. 1990; Rabinowitz et al. 2009). A benefit of observing animals in HVHHF areas is that this approach does not isolate and expose animals to toxic chemicals in a laboratory (Rabinowitz et al. 2010). However, animals are only tracked and monitored when exposure to humans has occurred or is expected to occur. As a consequence, such work may negate the inherent value of animals, since tracking and monitoring is unlikely to occur when there is no concern over human health risks. Tacking may also involve the capture and tracking of animals, which could put stress on a particular animal or population. In many ways, animals observed in this form have become the new "canaries in the coal mines" as unintentional sentinels.

Importantly, animals continue to be used in laboratory settings to test energy development chemicals. So, not only are animals being tracked as unintentional sentinels in their natural environments to signal human health risks, but are also being experimented on in laboratory environments to explore the toxicity of HVHHF fluids. There is growing research that suggests that experimentation on animals is often flawed, misleading, and wasteful (see, e.g., Arluke 2010; Arluke and Michael 2007; Eisenman 2016). Because of this, many scholars and industries have called for alternatives to animal-based experimentation (see, e.g., Khilnani and Khilnani 2016; Kumar et al. 2017). Although, field observation can make isolating the effects of HVHHF difficult, motivating experiments on animals, several of the studies mentioned above have used field experimentation to document impacts effectively with minimal risk to animals. Many of the field experiments have a dual human and animal focus. This means that the researchers are interested in monitoring human risk as well as supporting biodiversity. Although there has been some work to assert that animals are sentinels in HVHHF expansion, the use of animals in laboratory experiments to document the potential effects of HVHHF toxins has not been addressed. It is unlikely that many, even within Animal Rights circles, are aware of the laboratory testing conducted on animals to gain insight into the harmful effects of HVHHF chemicals. Such information may be particularly important in aligning animal rights activists and fracktivists movements (a range of people from those who strongly oppose hydraulic fracturing to those who support extensive policy and practice reform before expansion is allowed to continue). Scholars should consider looking into the use of animals in laboratory environments to get a better understanding of how widespread this practice is across energy platforms and how this practice has increased or decreased over time.

Ultimately, this content analysis of literature highlights numerous gaps in assessing the impact HVHHF has on animals and human-animal relationships. Not only are more geographically- and species-diverse studies needed to assess vulnerability and reliance by all scientists, but social scientists 
in particular need to assess the effects HVHHF has on human-animal relationships. In particular, environmental justice scholars need to include animals and human-animal relationships in their analyses of the impacts of HVHHF. Several reports suggest that people and animals may suffer shared health problems because of HVHHF. Scholars should investigate what this shared suffering means for companion animal ownership, loss, veterinary care, self-identity, and family life as well as exploring the social and psychological implications. In addition, scholars should investigate questions such as how rescue organizations are responding to HVHHF, especially in high development areas, and how people in HVHHF areas are working to keep their animals and themselves safe. Beyond this, research suggests that boomtowns may fuel social disorder, which can lead to increases in violence. Scholars should explore how animals fit into this equation and whether there is increased violence against animals in these communities.

Across thematic categories, human health remains a dominant subtheme. Most studies, regardless of their central focus, conclude by discussing the potential or realized risks of HVHHF to human health, but not to human-animal relationships. Despite this, the reality is that the impacts of HVHHF on animals will likely go beyond shared health concerns. As with the example in the beginning, seeing companion or agriculture animals in distress can increase human stress, something that has been documented in other studies, particularly in studies assessing the impacts of companion animal death on human wellbeing. Scholars should take inventory of how individuals in heavy HVHHF areas are negotiating these relationships and if the impacts on animals are having negative impacts on human mental health.

Finally, human relationships with animals may alter how people respond to HVHHF risks (see, e.g., Whitley 2017). There is some work that has also highlighted this claim, but has not evaluated this question extensively (see, e.g., McHenry 2017; Olive and Valentine 2018). More should be done to assess how our relationships with animals inform our understanding of, and response to, HVHHF risks. Identity and value structures are known to play a role in how people think about various environmental issues (see, e.g., Dietz and Whitley 2018b) and may also be important in how people think about the intersection of energy development, humans and animals. More attention should also be placed on looking at how racially diverse communities consider these issues in order to challenge the assumption that communities of color do not care about environmental issues or animals (see, e.g., Dietz and Whitley 2018a). Further, research shows that framing HVHHF in terms of impacts on animals may be powerful in generating greater concern (see, e.g., Whitley 2017). There is a wealth of studies that document the importance of how environmental issues are framed and how animal framing, such as the iconic polar bear for climate change, can drive public perception (Whitley and Kalof 2014; Kalof et al. 2017). Ultimately, this analysis suggests that there is much work to be done to centralize animals and human-animal relationships as essential in assessing the impacts of HVHHF and that this work should be done by social scientists from an environmental justice perspective, supporting Schlosberg (2013) assertion that we need more discussions of animals as victims in environmental justice narratives.

There are limitations to this study. The focus on peer-reviewed published articles could be considered a limitation. There are several non-peer-reviewed sources that address the impacts of HVHHF on animals (DeDonder et al. 2015; Hill 2013; National Parks Conservation Association 2013). Further, there may be additional social and natural science HVHHF articles that discuss animals, but that were not considered as contributing to the dominant discussion because they did not cite the Bamberger and Oswald (2012) article and could not be found when searching for animal key terms. Finally, because of the historical exclusion of the natural environment and animals from social science literature, there may be social science scholars working in this area that have yet to publish their work. If this is the case, broad searches of all materials including conference papers, dissertations, etc., should reveal additional sources that would not have been considered for this analysis but could be evaluated in the future.

Funding: This research received no external funding. 
Conflicts of Interest: The author declares no conflict of interest.

\section{References}

Abrahams, Leslie S., W. Michael Griffin, and H. Scott Matthews. 2015. Assessment of Policies to Reduce Core Forest Fragmentation from Marcellus Shale Development in Pennsylvania. Ecological Indicators 52: 153-60. [CrossRef]

Adekola, Josephine, Moira Fischbacher-Smith, Denis Fischbacher-Smith, and Olalekan Adekola. 2016. Health Risks from Environmental Degradation in the Niger Delta, Nigeria. Environment and Planning C: Government and Policy 35: 334-54. [CrossRef]

Allred, Brady W., W. Kolby Smith, Dirac Twidwell, Julia H. Haggerty, Steven W. Running, David E. Naugle, and Samuel D. Fuhlendorf. 2015. Ecosystem Services Lost to Oil and Gas in North America. Science 348: 401-2. [CrossRef]

Arent, Douglas, Jeffrey Logan, Jordan Macknick, William Boyd, Kenneth Medlock, Francis O'Sullivan, Jae Edmonds, Leon Clarke, Hillard Huntington, Garvin Heath, and et al. 2015. A Review of Water and Greenhouse Gas Impacts of Unconventional Natural Gas Development in the United States. MRS Energy $\mathcal{E}$ Sustainability 2: E4.

Arluke, Arnold. 2010. Regarding Animals. London: Pearson Education.

Arluke, Arnold, and Mike Michael. 2007. The Sacrifice: How Scientific Experiments Transform Animals and People. West Lafayette: Purdue University Press.

Bai, Linyi, Avijit Jana, Huijun Phoebe Tham, Kim Truc Nguyen, Parijat Borah, and Yanli Zhao. 2016. Remarkable Vapochromic Behavior of Pure Organic Octahedron Embedded in Porous Frameworks. Small 12: 3302-8. [CrossRef]

Bamberger, Michelle, and Robert E. Oswald. 2012. Impacts of Gas Drilling on Human and Animal Health. New Solutions: A Journal of Environmental and Occupational Health Policy 22: 51-77. [CrossRef]

Bamberger, Michelle, and Robert E. Oswald. 2013. Science and Politics of Shale Gas Extraction. New Solutions: A Journal of Environmental and Occupational Health Policy 23: 1-12. [CrossRef]

Bamberger, Michelle, and Robert E. Oswald. 2014. Unconventional Oil and Gas Extraction and Animal Health. Environmental Science: Processes \& Impacts 16: 1860-65.

Bamberger, Michelle, and Robert E. Oswald. 2015. Long-Term Impacts of Unconventional Drilling Operations on Human and Animal Health. Journal of Environmental Science and Health, Part A 50: 447-59. [CrossRef]

Barrett, Betty Jo, Amy Fitzgerald, Amy Peirone, Rochelle Stevenson, and Chi Ho Cheung. 2018. Help-Seeking among Abused Women with Pets: Evidence from a Canadian Sample. Violence and Victims 33: 604-26. [CrossRef]

Barth, Jannette M. 2013. The Economic Impact of Shale Gas Development on State and Local Economies: Benefits, Costs, and Uncertainties. New Solutions: A Journal of Environmental and Occupational Health Policy 23: 85-101. [CrossRef] [PubMed]

Beebeejaun, Yasminah. 2013. The Politics of Fracking: A Public Policy Dilemma? Political Insight 4: 18-21. [CrossRef]

Beirne, Piers. 2009. Confronting Animal Abuse: Law, Criminology, and Human-Animal Relationships. Washington: Rowman \& Littlefield Publishers.

Blewett, Tamzin A., Alyssa M. Weinrauch, Perrine L. M. Delompré, and Greg G. Goss. 2017a. The Effect of Hydraulic Flowback and Produced Water on Gill Morphology, Oxidative Stress and Antioxidant Response in Rainbow Trout (Oncorhynchus mykiss). Scientific Reports 7: 46582. Available online: https:/ /www.nature. com/articles/srep46582 (accessed on 22 January 2018). [CrossRef]

Blewett, Tamzin A., Perrine L. M. Delompré, Yuhe He, Erik J. Folkerts, Shannon L. Flynn, Daniel S. Alessi, and Greg G. Goss. 2017b. Sublethal and Reproductive Effects of Acute and Chronic Exposure to Flowback and Produced Water from Hydraulic Fracturing on the Water Flea Daphnia Magna. Environmental Science E Technology 51: 3032-39.

Boyle, Meleah D., Devon C. Payne-Sturges, Thurka Sangaramoorthy, Sacoby Wilson, Keeve E. Nachman, Kelsey Babik, Christian C. Jenkins, Joshua Trowell, Donald K. Milton, and Amir Sapkota. 2016. Hazard Ranking Methodology for Assessing Health Impacts of Unconventional Natural Gas Development and Production: The Maryland Case Study. PLoS ONE 11: e0145368. [CrossRef] 
Brand, Adrianne B., Amber N. M. Wiewel, and Evan H. Campbell Grant. 2014. Potential Reduction in Terrestrial Salamander Ranges Associated with Marcellus Shale Development. Biological Conservation 180: 233-40. [CrossRef]

Brittingham, Margaret C., Kelly O. Maloney, Aïda M. Farag, David D. Harper, and Zachary H. Bowen. 2014. Ecological Risks of Shale Oil and Gas Development to Wildlife, Aquatic Resources and Their Habitats. Environmental Science \& Technology 48: 11034-47.

Brown, David, Beth Weinberger, Celia Lewis, and Heather Bonaparte. 2014. Understanding Exposure from Natural Gas Drilling Puts Current Air Standards to the Test. Reviews on Environmental Health 29: 277-92. [CrossRef]

Brown, David R., Celia Lewis, and Beth I. Weinberger. 2015. Human Exposure to Unconventional Natural Gas Development: A Public Health Demonstration of Periodic High Exposure to Chemical Mixtures in Ambient Air. Journal of Environmental Science and Health, Part A 50: 460-72. [CrossRef]

Bullard, Robert D. 1994. Environmental Justice for All: It's the Right Thing to Do. Journal of Environmental Law and Litigation 9: 281-308.

Bullard, Robert D. 2005. Quest for Environmental Justice. San Francisco: Sierra Club Books.

Bullard, Robert D., and Beverly H. Wright. 1993. Environmental Justice for All: Community Perspectives on Health and Research. Toxicology and Industrial Health 9: 821-41. [CrossRef]

Bunch, A. G., Camarie S. Perry, L. Abraham, Daniele. S. Wikoff, J. Andrew Tachovsky, J. Gregory Hixon, Jonathon. D. Urban, Mark A. Harris, and Laurie C. Haws. 2014. Evaluation of Impact of Shale Gas Operations in the Barnett Shale Region on Volatile Organic Compounds in Air and Potential Human Health Risks. Science of the Total Environment 468: 832-42. [CrossRef]

Burton, G. Allen, Niladri Basu, Brian R. Ellis, Katherine E. Kapo, Sally Entrekin, and Knute Nadelhoffer. 2014. Hydraulic 'Fracking': Are Surface Water Impacts an Ecological Concern? Environmental Toxicology and Chemistry 33: 1679-89. [CrossRef]

Callicott, J. Baird. 1999. Beyond the Land Ethic: More Essays in Environmental Philosophy. Albany: SUNY Press.

Carter, Bob, and Nickie Charles. 2018. The Animal Challenge to Sociology. European Journal of Social Theory 21: 79-97. [CrossRef]

Catton, William R., and Riley E. Dunlap. 1978. Environmental Sociology: A New Paradigm. The American Sociologist 13: 41-49.

Centner, Terence J., and Nicholas S. Eberhart. 2015. The Use of Best Management Practices to Respond to Externalities from Developing Shale Gas Resources. Journal of Environmental Planning and Management. 59: 746-68. [CrossRef]

Centner, Terence J., and Genti Kostandini. 2015. Local Governments Want Authority to Address Problems: The Case of Horizontal Drilling and Hydraulic Fracturing in the United States. Land Use Policy 49: 227-35. [CrossRef]

Choma, Becky L., Yaniv Hanoch, and Shannon Currie. 2016. Attitudes toward Hydraulic Fracturing: The Opposing Forces of Political Conservatism and Basic Knowledge about Fracking. Global Environmental Change 38: 108-17. [CrossRef]

Clough, Emily, and Derek Bell. 2016. Just Fracking: A Distributive Environmental Justice Analysis of Unconventional Gas Development in Pennsylvania, USA. Environmental Research Letters 11: 025001. [CrossRef]

Colborn, Theo, Kim Schultz, Lucille Herrick, and Carol Kwiatkowski. 2012. An Exploratory Study of Air Quality near Natural Gas Operations. Human and Ecological Risk Assessment: An International Journal 20: 86-105. [CrossRef]

Crist, Eileen. 2012. Abundant Earth and Population. In Life on the Brink: Environmentalists Confront Overpopulation. Edited by Eileen Crist and Philip Cafaro. Athens: University of Georgia, pp. 141-53.

Crowe, Jessica, Tony Silva, Ryan G. Ceresola, Amanda Buday, and Charles Leonard. 2015. Differences in Public Perceptions and Leaders' Perceptions on Hydraulic Fracturing and Shale Development. Sociological Perspectives 58: 441-63. [CrossRef]

Cudworth, Erika. 2015. Killing Animals: Sociology, Species Relations and Institutionalized Violence. The Sociological Review 63: 1-18. [CrossRef] 
DeDonder, Keith D., Ronette Gehring, Ronald E. Baynes, Lisa A. Tell, Thomas W. Vickroy, and Jim E. Riviere. 2015. Oil and Petroleum Product Exposures to Livestock. Food Animal Residue Avoidance Databank. Available online: http:/ / www.farad.org/publications/perspectives/livestock\&fracking.pdf (accessed on 1 March 2017).

Dietz, Thomas, and Cameron T. Whitley. 2018a. Inequality, Decisions, and Altruism. Sociology of Development 4: 282-303. [CrossRef]

Dietz, Thomas, and Cameron T. Whitley. 2018b. Environmentalism, Norms, and Identity. Proceedings of the National Academy of Sciences USA 115: 12334-36. [CrossRef] [PubMed]

Dokshin, Fedor A. 2016. Whose Backyard and What's at Issue? Spatial and Ideological Dynamics of Local Opposition to Fracking in New York State, 2010 to 2013. American Sociological Review 81: 921-48. [CrossRef]

Down, Adrian, Martin Armes, and Robert B. Jackson. 2013. Shale Gas Extraction in North Carolina: Research Recommendations and Public Health Implications. Environmental Health Perspectives 121: A292. [CrossRef] [PubMed]

Eisenman, Stephen F. 2016. Criticizing Animal Experimentation, at My Peril. Altex 33: 3-12. [CrossRef]

Elliott, Elise G., Adrienne S. Ettinger, Brian P. Leaderer, Michael B. Bracken, and Nicole C. Deziel. 2017. A Systematic Evaluation of Chemicals in Hydraulic-fracturing Fluids and Wastewater for Reproductive and Developmental Toxicity. Journal of Exposure Science and Environmental Epidemiology 27: 1-10. [CrossRef]

Entrekin, Sally, Anne Trainor, James Saiers, Lauren Patterson, Kelly Maloney, Joseph Fargione, Joseph Kiesecker, Sharon Baruch-Mordo, Katherine Konschnik, Hannah Wiseman, and et al. 2018. Water stress from high-volume hydraulic fracturing potentially threatens aquatic biodiversity and ecosystem services in Arkansas, United States. Environmental Technology 52: 2349-58. [CrossRef]

Ernstoff, Alexi Sara, and Brian R. Ellis. 2013. Clearing the Waters of the Fracking Debate. Michigan Journal of Sustainability 1: 109-29. [CrossRef]

Esterhuyse, Surina, Marinda Avenant, Nola Redelinghuys, Andrzej Kijko, Jan Glazewski, Lisa Plit, Marthie Kemp, Ansie Smit, A. Tascha Vos, and Richard Williamson. 2016. A Review of Biophysical and Socio-Economic Effects of Unconventional Oil and Gas extraction-Implications for South Africa. Journal of Environmental Management 184: 419-30. [CrossRef] [PubMed]

Ferrar, Kyle J., Jill Kriesky, Charles L. Christen, Lynne P. Marshall, Samantha L. Malone, Ravi K. Sharma, Drew R. Michanowicz, and Bernard D. Goldstein. 2013. Assessment and Longitudinal Analysis of Health Impacts and Stressors Perceived to Result from Unconventional Shale Gas Development in the Marcellus Shale Region. International Journal of Occupational and Environmental Health 19: 104-12. [CrossRef] [PubMed]

Field, R. A., J. Soltis, and S. Murphy. 2014. Air Quality Concerns of Unconventional Oil and Natural Gas Production. Environmental Science: Processes \& Impacts 16: 954-69.

Finkel, Madelon L., and Jake Hays. 2013. The Implications of Unconventional Drilling for Natural Gas: A Global Public Health Concern. Public Health 127: 889-93. [CrossRef] [PubMed]

Finkel, Madelon L., Jake Hays, and Adam Law. 2013a. The Shale Gas Boom and the Need for Rational Policy. American Journal of Public Health 103: 1161-63. [CrossRef] [PubMed]

Finkel, Medelon L., Jane Selegean, Jake Hays, and Nitin Kondamudi. 2013b. Marcellus Shale Drilling's Impact on the Dairy Industry in Pennsylvania: A Descriptive Report. New Solutions: A Journal of Environmental and Occupational Health Policy 23: 189-201. [CrossRef] [PubMed]

Fitzgerald, Amy J. 2007. 'They Gave Me a Reason to Live': The Protective Effects of Companion Animals on the Suicidality of Abused Women. Humanity \& Society 31: 355-78.

Folkerts, Erik J., Tamzin A. Blewett, Yuhe He, and Greg G. Goss. 2017. Cardio-respirometry Disruption in Zebrafish (Danio rerio) Embryos Exposed to Hydraulic Fracturing Flowback and Produced Water. Environmental Pollution 231: 1477-87. [CrossRef]

Fry, Matthew. 2013. Urban Gas Drilling and Distance Ordinances in the Texas Barnett Shale. Energy Policy 62: 79-89. [CrossRef]

Fry, Matthew, Adam Briggle, and Jordan Kincaid. 2015. Fracking and Environmental (in) Justice in a Texas City. Ecological Economics 117: 97-107. [CrossRef]

Funk, Alexander N., and Erich K. Stabenau. 2017. Examination of the Physiological Effects of Ethylene Glycol Exposure on Muscle and Liver Tissue of the Leopard Frog, Rana pipiens. The FASEB Journal 31: 874-78.

Garvie, Kathryn H., Lana Lowe, and Karena Shaw. 2014. Shale Gas Development in Fort Nelson First Nation Territory: Potential Regional Impacts of the LNG Boom. BC Studies 184: 45. 
Geltman, Elizabeth Glass, Gunwant Gill, and Miriam Jovanovic. 2016. Impact of Executive Order 13211 on Environmental Regulation: An Empirical Study. Energy Policy 89: 302-10. [CrossRef]

Gillen, Jennifer L., and Erik Kiviat. 2012. Environmental Reviews and Case Studies: Hydraulic Fracturing Threats to Species with Restricted Geographic Ranges in the Eastern United States. Environmental Practice 14: 320-31. [CrossRef]

Godwin, Braden L., Shannon E. Albeke, Harold L. Bergman, Annika Walters, and Merav Ben-David. 2015. Density of River Otters (Lontra canadensis) in Relation to Energy Development in the Green River Basin, Wyoming. Science of The Total Environment 532: 780-90. [CrossRef] [PubMed]

Goldstein, Bernard D., and Jill Kriesky. 2012. The Public Health Implications of Unconventional Natural Gas Drilling. Proceedings of the Water Environment Federation 2012: 2050-60. [CrossRef]

Graham, Jove, Jennifer Irving, Xiaoqin Tang, Stephen Sellers, Joshua Crisp, Daniel Horwitz, Lucija Muehlenbachs, Alan Krupnick, and David Carey. 2015. Increased Traffic Accident Rates Associated with Shale Gas Drilling in Pennsylvania. Accident Analysis \& Prevention 74: 203-9.

Grant, Christopher J., Alexander B. Weimer, Nicole K. Marks, Elliott S. Perow, Jacob M. Oster, Kristen M. Brubaker, Ryan V. Trexler, Caroline M. Solomon, and Regina Lamendella. 2015. Marcellus and Mercury: Assessing Potential Impacts of Unconventional Natural Gas Extraction on Aquatic Ecosystems in Northwestern Pennsylvania. Journal of Environmental Science and Health, Part A 50: 482-500. [CrossRef]

Griswold, Eliza. 2011. Situation Normal All Fracked Up. New York Times, November 20.

Hauter, Wenonah. 2016. Frackopoly: The Battle for the Future of Energy and the Environment. New York: The New Press.

Hays, Jake, Madelon L. Finkel, Michael Depledge, Adam Law, and Seth B. C. Shonkoff. 2015. Considerations for the Development of Shale Gas in the United Kingdom. Science of The Total Environment 512: 36-42. [CrossRef]

He, Yuhe, Erik J. Folkerts, Yifeng Zhang, Jonathan W. Martin, Daniel S. Alessi, and Greg G. Goss. 2016. Effects on Biotransformation, Oxidative Stress and Endocrine Disruption in Rainbow Trout (Oncorhynchus mykiss) Exposed to Hydraulic Fracturing Flowback and Produced Water. Environmental Science E Technology 51: 940-47.

He, Yuhe, Shannon L. Flynn, Erik J. Folkerts, Yifeng Zhang, Dongliang Ruan, and Daniel S. Alessi. 2017. Chemical and Toxicological Characterizations of Hydraulic Fracturing Flowback and Produced Water. Water Research 114: 78-87. [CrossRef] [PubMed]

He, Yuhe, Chenxing Sun, Yifeng Zhang, Erik J. Folkerts, Jonathan W. Martin, and Greg G. Goss. 2018. Developmental Toxicity of the Organic Fraction from Hydraulic Fracturing Flowback and Produced Waters to Early Life Stages of Zebrafish (Danio rerio). Environmental Science \& Technology 52: 3820-30.

Hill, Elaine L. 2013. Shale Gas Development and Infant Health: Evidence from Pennsylvania. Charles H. Dyson School of Applied Economics and Management, Cornell University, Working Paper. 86-105. Available online: http://www.farad.org/publications/perspectives/livestock\&fracking.pdf (accessed on 1 March 2017).

Himsworth, Chelsea G., and Melanie Rock. 2013. Pet Ownership, Other Domestic Relationships, and Satisfaction with Life among Seniors: Results from a Canadian National Survey. Anthrozoös 26: 295-305. [CrossRef]

Hula, Richard C., Melanie Bowers, Cameron T. Whitley, and William Isaac. 2017. Science, Politics and Policy: How Michiganders think about the Risks Facing the Great Lakes. Human Ecology 45: 833-44. [CrossRef]

Irvine, Leslie. 2009. Filling the Ark: Animal Welfare in Disasters. Philadelphia: Temple University Press.

Israel, Andrei L., Gabrielle Wong-Parodi, Thomas Webler, and Paul C. Stern. 2015. Eliciting Public Concerns about an Emerging Energy Technology: The Case of Unconventional Shale Gas Development in the United States. Energy Research \& Social Science 8: 139-50.

Jerolmack, Colin, and Nina Berman. 2016. Fracking Communities. Public Culture 28: 193-214. [CrossRef]

Johnston, Jill E., Emily Werder, and Daniel Sebastian. 2016. Wastewater Disposal Wells, Fracking, and Environmental Injustice in Southern Texas. Journal Information 106: 550-56. [CrossRef] [PubMed]

Jones, Nathan F., Liba Pejchar, and Joseph M. Kiesecker. 2015. The Energy Footprint: How Oil, Natural Gas, and Wind Energy Affect Land for Biodiversity and the Flow of Ecosystem Services. BioScience 65: 290-301. [CrossRef]

Kalof, Linda, Cameron T. Whitley, Stephen Vrla, and Jessica Bell Rizzo. 2017. Anthropogenic Food Sources in the Co-Existence of Humans with Liminal Animals in Northern Environments. In Shared Lives of Humans and Animals: Animal Agency in the Global North. Edited by Tuomas Rasanen and Taina Syrjamma. New York: Routledge, pp. 147-62. 
Kassotis, Christopher D., Donald E. Tillitt, J. Wade Davis, Annette M. Hormann, and Susan C. Nagel. 2013. Estrogen and Androgen Receptor Activities of Hydraulic Fracturing Chemicals and Surface and Ground Water in a Drilling-Dense Region. Endocrinology 155: 897-907. [CrossRef] [PubMed]

Kassotis, Christopher D., Kara C. Klemp, Danh C. Vu, Chung-Ho Lin, Chun-Xia Meng, Cynthia L. Besch-Williford, Lisa Pinatti, R. Thomas Zoeller, Erma Z. Drobnis, Victoria D. Balise, and et al. 2015. Endocrine-Disrupting Activity of Hydraulic Fracturing Chemicals and Adverse Health Outcomes after Prenatal Exposure in Male Mice. Endocrinology 156: 4458-73. [CrossRef]

Kassotis, Christopher D., John J. Bromfield, Kara C. Klemp, Chun-Xia Meng, Andrew Wolfe, R. Thomas Zoeller, Victoria D. Balise, Chiamaka J. Isiguzo, Donald E. Tillitt, and Susan C. Nagel. 2016a. Adverse Reproductive and Developmental Health Outcomes Following Prenatal Exposure to a Hydraulic Fracturing Chemical Mixture in Female C57Bl/6 Mice. Endocrinology 157: 3469-81. [CrossRef] [PubMed]

Kassotis, Christopher D., Luke R. Iwanowicz, Denise M. Akob, Isabelle M. Cozzarelli, Adam C. Mumford, William H. Orem, and Susan C. Nagel. 2016b. Endocrine Disrupting Activities of Surface Water Associated with a West Virginia Oil and Gas Industry Wastewater Disposal Site. Science of The Total Environment 557: 901-10. [CrossRef] [PubMed]

Khilnani, Gurudas, and Ajeet Kumar Khilnani. 2016. Restructuring Postgraduate Curriculum in Pharmacology: Time to Incorporate Alternatives to Animal Experimentation. Indian Journal of Pharmacology 48: 336. [CrossRef] [PubMed]

Kiviat, Erik. 2013. Risks to Biodiversity from Hydraulic Fracturing for Natural Gas in the Marcellus and Utica Shales. Annals of the New York Academy of Sciences 1286: 1-14. [CrossRef] [PubMed]

Koh, Amanda, Anna Wong, Alexis Quinteros, Christine Desplat, and Richard Gross. 2016. Influence of Sophorolipid Structure on Interfacial Properties of Aqueous-Arabian Light Crude and Related Constituent Emulsions. Journal of the American Oil Chemists' Society 94: 1-13. [CrossRef]

Konkel, Lindsey. 2016. Salting the Earth: The Environmental Impact of Oil and Gas Wastewater Spills. Environmental Health Perspectives 124: A230. [CrossRef] [PubMed]

Kopnina, Helen. 2012a. Re-Examining Culture/Conservation Conflict: The View of Anthropology of Conservation through the Lens of Environmental Ethics. Journal of Integrative Environmental Sciences 9: 9-25. [CrossRef]

Kopnina, Helen. 2012b. Toward Conservational Anthropology: Addressing Anthropocentric Bias in Anthropology. Dialectical Anthropology 36: 127-46. [CrossRef]

Kopnina, Helen. 2014. Environmental Justice and Biospheric Egalitarianism: Reflecting on a Normative-Philosophical View of Human-Nature Relationship. Earth Perspectives 1: 8. [CrossRef]

Korfmacher, Katrina Smith, Walter A. Jones, Samantha L. Malone, and Leon F. Vinci. 2013. Public Health and High Volume Hydraulic Fracturing. New Solutions: A Journal of Environmental and Occupational Health Policy 23: 13-31. [CrossRef]

Kovats, Sari, Michael Depledge, Andy Haines, Lora E. Fleming, Paul Wilkinson, Seth B. Shonkoff, and Noah Scovronick. 2014. The Health Implications of Fracking. The Lancet 383: 757. [CrossRef]

Kumar, Vipin, Avantika Chandra, and Zeba Usmani. 2017. Impact of Coal Mining on Soil Properties and Their Efficient Eco-Restoration. International Journal of Energy Technology and Policy 13: 158-65. [CrossRef]

Kun, Luis, B. Linkous, C. Gibson, and N. Roldos. 2014. The Arsenic Threat: Interdependencies of Water, Agriculture, Food Supply, Public Health and Energy Critical Infrastructure. Health and Technology 4: 145-57. [CrossRef]

Ladd, Anthony E. 2013. Stakeholder Perceptions of Socioenvironmental Impacts from Unconventional Natural Gas Development and Hydraulic Fracturing in the Haynesville Shale. Journal of Rural Social Sciences 28: 56.

Ladd, Anthony E. 2018. Fractured Communities: Risk, Impacts, and Protest Against Hydraulic Fracking in US Shale Regions. New Brunswick: Rutgers University Press.

Latta, Steven C., Leesia C. Marshall, Mack W. Frantz, and Judith D. Toms. 2015. Evidence from Two Shale Regions That a Riparian Songbird Accumulates Metals Associated with Hydraulic Fracturing. Ecosphere 6: 1-10. [CrossRef]

Lave, Rebecca, and Brian Lutz. 2014. Hydraulic Fracturing: A Critical Physical Geography Review. Geography Compass 8: 739-54. [CrossRef]

Lendrum, Patrick E., Charles R. Anderson Jr., Ryan A. Long, John G. Kie, and R. Terry Bowyer. 2012. Habitat Selection by Mule Deer during Migration: Effects of Landscape Structure and Natural-Gas Development. Ecosphere 3: 82. [CrossRef] 
Lloyd, Penn, Thomas E. Martin, Roland L. Redmond, Ute Langner, and Melissa M. Hart. 2005. Linking Demographic Effects of Habitat Fragmentation across Landscapes to Continental Source-sink Dynamics. Ecological Applications 15: 1504-14. [CrossRef]

Loh, Hsue-Peng, and Nancy Loh. 2016. Hydraulic Fracturing and Shale Gas: Environmental and Health Impacts. In Advances in Water Resources Management. Berlin: Springer, pp. 293-337.

Lutz, Allison K., and Christopher J. Grant. 2016. Impacts of Hydraulic Fracturing Development on Macroinvertebrate Biodiversity and Gill Morphology of Net-Spinning Caddisfly (Hydropsychidae, Diplectrona) in Northwestern Pennsylvania, USA. Journal of Freshwater Ecology 31: 211-17. [CrossRef]

Ma, Zhen-qianq, Katie C. Sneeringer, Longjian Liu, and Lewis H. Kuller. 2016. Time Series Evaluation of Birth Defects in Areas with and without Unconventional Natural Gas Development. Journal of Epidemiol Public Health Rev 1: 1-7. [CrossRef]

Massari, Monica, and Paola Monzini. 2004. Dirty Businesses in Italy: A Case-Study of Illegal Trafficking in Hazardous Waste. Global Crime 6: 285-304. [CrossRef]

McCarthy, John F., Braulio D. Jimenez, Lee R. Shugart, Frederick V. Sloop, and Aimo Oikari. 1990. Biological Markers in Animal Sentinels: Laboratory Studies Improve Interpretation of Field Data. In In Situ Evaluation of Biological Hazards of Environmental Pollutants. Berlin: Springer, pp. 163-75.

McHenry, Kristen Abatsis. 2017. Fracking Women: A Feminist Critical Analysis of Hydraulic Fracturing in Pennsylvania. IJFAB: International Journal of Feminist Approaches to Bioethics 10: 79-104. [CrossRef]

Mitka, Mike. 2012. Rigorous Evidence Slim for Determining Health Risks from Natural Gas Fracking. Journal of the American Medical Association 307: 2135-36. [CrossRef] [PubMed]

Mohai, Paul, and Robin Saha. 2006. Reassessing Racial and Socioeconomic Disparities in Environmental Justice Research. Demography 43: 383-99. [CrossRef] [PubMed]

Mohai, Paul, and Robin Saha. 2007. Racial Inequality in the Distribution of Hazardous Waste: A National-level Reassessment. Social Problems 54: 343-70. [CrossRef]

Mohai, Paul, David Pellow, and J. Timmons Roberts. 2009. Environmental Justice. Annual Review of Environment and Resources 34: 405-30. [CrossRef]

Moore, Christopher W., Barbara Zielinska, Gabrielle Pétron, and Robert B. Jackson. 2014. Air Impacts of Increased Natural Gas Acquisition, Processing, and Use: A Critical Review. Environmental Science E Technology 48: 8349-59.

Moran, Matthew D., A. Brandon Cox, Rachel L. Wells, Chloe C. Benichou, and Maureen R. McClung. 2015. Habitat Loss and Modification due to Gas Development in the Fayetteville Shale. Environmental Management 55: 1276-84. [CrossRef] [PubMed]

Morrone, Michele, Amy E. Chadwick, and Natalie Kruse. 2015. A Community Divided: Hydraulic Fracturing in Rural Appalachia. Journal of Appalachian Studies 21: 207-28. [CrossRef]

Muresan, Jianu Daniel, and Mihail Vincentiu Ivan. 2015. Controversies Regarding Costs, Uncertainties and Benefits Specific to Shale Gas Development. Sustainability 7: 2473-89. [CrossRef]

National Parks Conservation Association. 2013. National Parks and Hydraulic Fracturing: Balancing Energy Needs, Nature, and America's National Heritage. Washington: NPCA Center for Park Research, Available online: https: / / www.npca.org/resources/2663-national-parks-and-hydraulic-fracturing (accessed on 13 February 2019).

Nibert, David. 2002. Animal Rights/Human Rights: Entanglements of Oppression and Liberation. Washington: Rowman \& Littlefield Publishers.

Olive, Andrea, and Katie Valentine. 2018. Is Anyone Out There? Exploring Saskatchewan's Civil Society Involvement in Hydraulic Fracturing. Energy Research \& Social Science 39: 192-97.

Papoulias, Diana M., and Anthony L. Velasco. 2013. Histopathological Analysis of Fish from Acorn Fork Creek, Kentucky, Exposed to Hydraulic Fracturing Fluid Releases. Southeastern Naturalist 12: 92-111.

Payne, Madeleine E., Heather F. Chapman, Janet Cumming, and Frederic D. L. Leusch. 2014. In Vitro Cytotoxicity Assessment of a Hydraulic Fracturing Fluid. Environmental Chemistry 12: 286-92. [CrossRef]

Pearce, Frank, and Steve Tombs. 2009. Toxic Capitalism: Corporate Crime and the Chemical Industry. London: Open University Press.

Peggs, Kay. 2012. Animals and Sociology. Berlin: Springer.

Pellow, David Naguib. 2014. Total Liberation: The Power and Promise of Animal Rights and the Radical Earth Movement. Minneapolis: University of Minnesota Press.

Pellow, David Naguib. 2017. What Is Critical Environmental Justice? Medford: Polity Press. 
Penning, Trevor M., Patrick N. Breysse, Kathleen Gray, Marilyn Howarth, and Beizhan Yan. 2014. Environmental Health Research Recommendations from the Inter-Environmental Health Sciences Core Center Working Group on Unconventional Natural Gas Drilling Operations. Environmental Health Perspectives 122: 1155. [CrossRef] [PubMed]

Penningroth, Stephen M., Matthew M. Yarrow, Abner X. Figueroa, Rebecca J. Bowen, and Soraya Delgado. 2013. Community-Based Risk Assessment of Water Contamination from High-Volume Horizontal Hydraulic Fracturing. New Solutions: A Journal of Environmental and Occupational Health Policy 23: 137-66. [CrossRef] [PubMed]

Perry, Simona L. 2012. Environmental Reviews and Case Studies: Addressing the Societal Costs of Unconventional Oil and Gas Exploration and Production: A Framework for Evaluating Short-Term, Future, and Cumulative Risks and Uncertainties of Hydrofracking. Environmental Practice 14: 352-65. [CrossRef]

Perry, Simona L. 2013. Using Ethnography to Monitor the Community Health Implications of Onshore Unconventional Oil and Gas Developments: Examples from Pennsylvania's Marcellus Shale. New Solutions: A Journal of Environmental and Occupational Health Policy 23: 33-53. [CrossRef]

Phillips, Susan. 2012. Dead Calves and Hairless Puppies. State Impact NPR, January 19. Available online: https://stateimpact.npr.org/pennsylvania/2012/01/19/dead-calves-and-hairless-puppies/ (accessed on 20 August 2015).

Pothukuchi, Kameshwari, Melissa Arrowsmith, and Natalie Lyon. 2018. Hydraulic Fracturing: A Review of Implications for Food Systems Planning. Journal of Planning Literature 33: 155-70. [CrossRef]

Powers, Martha, Poune Saberi, Richard Pepino, Emily Strupp, Eva Bugos, and Carolyn C. Cannuscio. 2015. Popular Epidemiology and 'fracking': Citizens' Concerns Regarding the Economic, Environmental, Health and Social Impacts of Unconventional Natural Gas Drilling Operations. Journal of Community Health 40: 534-41. [CrossRef]

Rabinowitz, Peter, Matthew Scotch, and Lisa Conti. 2009. Human and Animal Sentinels for Shared Health Risks. Veterinaria Italiana 45: 23.

Rabinowitz, Peter M., Matthew L. Scotch, and Lisa A. Conti. 2010. Animals as Sentinels: Using Comparative Medicine to Move beyond the Laboratory. ILAR Journal 51: 262-67. [CrossRef]

Rabinowitz, Peter M., Ilya B. Slizovskiy, Vanessa Lamers, Sally J. Trufan, Theodore R. Holford, James D. Dziura, Peter N. Peduzzi, Michael J. Kane, John S. Reif, Theresa R. Weiss, and et al. 2015. Proximity to Natural Gas Wells and Reported Health Status: Results of a Household Survey in Washington County, Pennsylvania. Environmental Health Perspectives 123: 21. [CrossRef] [PubMed]

Rafferty, Margaret A., and Elena Limonik. 2013. Is Shale Gas Drilling an Energy Solution or Public Health Crisis? Public Health Nursing 30: 454-62. [CrossRef] [PubMed]

Ralston, Jonah J., and Jason A. Kalmbach. 2018. Regulating Under Conditions of Uncertainty and Risk: Lessons learned from state regulation of hydraulic fracturing. Environmental Practice 20: 68-79. [CrossRef]

Redmond, Helen. 2014. Impact of Energy Generation on Health: Unconventional Gas. Proceedings of the Royal Society of Victoria 126: 38-39. [CrossRef]

Reible, Danny D., Soraya Honarparvar, Chau-Chyun Chen, Tissa H. Illangasekare, and Margaret MacDonell. 2016. Environmental Impacts of Hydraulic Fracturing. In Environmental Technology in the Oil Industry. Berlin: Springer, pp. 199-219.

Rich, Alisa L., and Ernest C. Crosby. 2013. Analysis of Reserve Pit Sludge from Unconventional Natural Gas Hydraulic Fracturing and Drilling Operations for the Presence of Technologically Enhanced Naturally Occurring Radioactive Material (TENORM). New Solutions: A Journal of Environmental and Occupational Health Policy 23: 117-35. [CrossRef] [PubMed]

Robbins, Kalyani. 2013. Awakening the Slumbering Giant: How Horizontal Drilling Technology Brought the Endangered Species Act to Bear on Hydraulic Fracturing. Case Western Reserve Law Review 63: 13-16.

Ruddell, Rick, and Natalie R. Ortiz. 2014. Boomtown Blues: Long-Term Community Perceptions of Crime and Disorder. American Journal of Criminal Justice 40: 129-46. [CrossRef]

Ruggiero, Vincenzo. 1996. Organized and Corporate Crime in Europe: Offers That Can't Be Refused. Hanover: Dartmouth.

Saberi, Pouné. 2013. Navigating Medical Issues in Shale Territory. New Solutions: A Journal of Environmental and Occupational Health Policy 23: 209-21. [CrossRef] 
Saberi, Pouné, Kathleen Joy Propert, Martha Powers, Edward Emmett, and Judith Green-McKenzie. 2014. Field Survey of Health Perception and Complaints of Pennsylvania Residents in the Marcellus Shale Region. International Journal of Environmental Research and Public Health 11: 6517-27. [CrossRef]

Sang, Wenjing, Cathelijne R. Stoof, Wei Zhang, Verónica L. Morales, Bin Gao, Robert W. Kay, Lin Liu, Yalei Zhang, and Tammo S. Steenhuis. 2014. Effect of Hydrofracking Fluid on Colloid Transport in the Unsaturated Zone. Environmental Science \& Technology 48: 8266-74.

Saunders, P. J., D. McCoy, R. Goldstein, A. T. Saunders, and A. Munroe. 2016. A Review of the Public Health Impacts of Unconventional Natural Gas Development. Environmental Geochemistry and Health 40: 1-57. [CrossRef] [PubMed]

Schlosberg, David. 2013. Theorising Environmental Justice: The Expanding Sphere of a Discourse. Environmental Politics 22: 37-55. [CrossRef]

Shonkoff, Seth B. C., Jake Hays, and Madelon L. Finkel. 2014. Environmental Public Health Dimensions of Shale and Tight Gas Development. Environmental Health Perspectives 122: 787-95. [CrossRef]

Short, Damien, Jessica Elliot, Kadin Norder, Edward Lloyd-Davies, and Joanna Morley. 2015. Extreme Energy, 'fracking' and Human Rights: A New Field for Human Rights Impact Assessments? The International Journal of Human Rights 19: 697-736. [CrossRef]

Slizovskiy, Ilya B., Lisa A. Conti, Sally J. Trufan, John S. Reif, Vanessa T. Lamers, Meredith H. Stowe, J. Dziura, and Peter M. Rabinowitz. 2015. Reported Health Conditions in Animals Residing near Natural Gas Wells in Southwestern Pennsylvania. Journal of Environmental Science and Health, Part A 50: 473-81. [CrossRef] [PubMed]

Souther, Sara, Morgan W. Tingley, Viorel D. Popescu, David TS Hayman, Maureen E. Ryan, Tabitha A. Graves, Brett Hartl, and Kimberly Terrell. 2014. Biotic Impacts of Energy Development from Shale: Research Priorities and Knowledge Gaps. Frontiers in Ecology and the Environment 12: 330-38. [CrossRef]

Stearman, Loren W., Ginny Adams, and Reid Adams. 2015. Ecology of the Redfin Darter and a Potential Emerging Threat to Its Habitat. Environmental Biology of Fishes 98: 623-35. [CrossRef]

Steinzor, Nadia, Wilma Subra, and Lisa Sumi. 2013. Investigating Links between Shale Gas Development and Health Impacts through a Community Survey Project in Pennsylvania. New Solutions: A Journal of Environmental and Occupational Health Policy 23: 55-83. [CrossRef]

Stephenson, Michael H. 2016. Shale Gas in North America and Europe. Energy Science \& Engineering 4: 4-13.

Taylor, Dorceta E. 2000. The Rise of the Environmental Justice Paradigm: Injustice Framing and the Social Construction of Environmental Discourses. American Behavioral Scientist 43: 508-80. [CrossRef]

Thompson, Sarah J., Douglas H. Johnson, Neal D. Niemuth, and Christine A. Ribic. 2015. Avoidance of Unconventional Oil Wells and Roads Exacerbates Habitat Loss for Grassland Birds in the North American Great Plains. Biological Conservation 192: 82-90. [CrossRef]

Ticleanu, M., Radu Nicolescu, and Adriana Ion. 2014. Exploitation of Shale Gas by Hydraulic Fracturing-A Method with Possible Middle and Long Term Catastrophic Consequenses. Paper presented at the 14th SGEM GeoConference on Ecology, Economics, Education and Legislation Albena, Bulgeria, June 19-25; pp. 299-306.

Tovey, Hilary. 2003. Theorising Nature and Society in Sociology: The Invisibility of Animals. Sociologia Ruralis 43: 196-215. [CrossRef]

Tuller, David. 2015. As Fracking Booms, Dearth of Health Risk Data Remains. Health Affairs 34: 903. [CrossRef] [PubMed]

Vandecasteele, Ine, Inés Marí Rivero, Serenella Sala, Claudia Baranzelli, Ricardo Barranco, Okke Batelaan, and Carlo Lavalle. 2015. Impact of Shale Gas Development on Water Resources: A Case Study in Northern Poland. Environmental Management 55: 1285-99. [CrossRef]

Vasi, Ion Bogdan, Edward T. Walker, John S. Johnson, and Hui Fen Tan. 2015. 'No Fracking Way!' Documentary Film, Discursive Opportunity, and Local Opposition against Hydraulic Fracturing in the United States, 2010 to 2013. American Sociological Review 80: 934-59. [CrossRef]

Wang, Qiang, Xi Chen, Awadhesh N. Jha, and Howard Rogers. 2014. Natural Gas from Shale Formation-The Evolution, Evidences and Challenges of Shale Gas Revolution in United States. Renewable and Sustainable Energy Reviews 30: 1-28. [CrossRef] 
Wattenberg, Elizabeth V., Jeffrey M. Bielicki, Ashley E. Suchomel, Jessica T. Sweet, Elizabeth M. Vold, and Gurumurthy Ramachandran. 2015. Assessment of the Acute and Chronic Health Hazards of Hydraulic Fracturing Fluids. Journal of Occupational and Environmental Hygiene 12: 611-24. [CrossRef]

Webb, Ellen, Sheila Bushkin-Bedient, Amanda Cheng, Christopher D. Kassotis, Victoria Balise, and Susan C. Nagel. 2014. Developmental and Reproductive Effects of Chemicals Associated with Unconventional Oil and Natural Gas Operations. Reviews on Environmental Health 29: 307-18. [CrossRef]

Weltman-Fahs, Maya, and Jason M. Taylor. 2013. Hydraulic Fracturing and Brook Trout Habitat in the Marcellus Shale Region: Potential Impacts and Research Needs. Fisheries 38: 4-15. [CrossRef]

Werner, Angela K., Sue Vink, Kerrianne Watt, and Paul Jagals. 2015. Environmental Health Impacts of Unconventional Natural Gas Development: A Review of the Current Strength of Evidence. Science of the Total Environment 505: 1127-41. [CrossRef] [PubMed]

White, Rob. 2013. Resource Extraction Leaves Something behind: Environmental Justice and Mining. International Journal for Crime, Justice and Social Democracy 2: 50-64. [CrossRef]

Whitley, Cameron T. 2017. Altruism, Risk, Energy Development and the Human-Animal Relationship. East Lansing: Michigan State University.

Whitley, Cameron T. 2018. Engines, Sentinels, and Objects: Assessing the Impacts of Unconventional Energy Development on Animals in the Marcellus Shale Region. In Fractured Communities: Risk, Impacts, and Protest Against Hydraulic Fracturing in US Shale Regions. Edited by Anthony E. Ladd. New Brunswick: Rutgers University Press, pp. 128-48.

Whitley, Cameron T., and Linda Kalof. 2014. Animal Imagery in the Discourse of Climate Change. International Journal of Sociology 44: 10-33. [CrossRef]

Willems, Mieke, Mohamed Aqiel Dalvie, Leslie London, and Hanna-Andrea Rother. 2016. Environmental Reviews and Case Studies: Health Risk Perception Related to Fracking in the Karoo, South Africa. Environmental Practice 18: 53-68. [CrossRef]

Willits, Fern K., Gene L. Theodori, and A. E. Luloff. 2016. Self-Reported Familiarity of Hydraulic Fracturing and Support for Natural Gas Drilling: Substantive and Methodological Considerations. Journal of Rural Social Sciences 31: 83-101.

Wylie, Sara, and Len Albright. 2014. WellWatch: Reflections on Designing Digital Media for Multi-Sited Para-Ethnography. Journal of Political Ecology 21: 321-48. [CrossRef]

Yao, Yixin, Tingting Chen, Steven S. Shen, Yingmei Niu, Thomas L. DesMarais, Reka Linn, Eric Saunders, Zhihua Fan, Paul Lioy, Thomas Kluz, and et al. 2015. Malignant Human Cell Transformation of Marcellus Shale Gas Drilling Flow Back Water. Toxicology and Applied Pharmacology 288: 121-30. [CrossRef]

Zhai, Jun, Zejin Huang, Md Hasibur Rahaman, Yue Li, Longyue Mei, Hongpu Ma, Xuebin Hu, Haiwen Xiao, Zhiyong Luo, and Kunping Wang. 2016. Comparison of Coagulation Pretreatment of Produced Water from Natural Gas Well by Polyaluminium Chloride and Polyferric Sulphate Coagulants. Environmental Technology 38: 1200-10. [CrossRef]

(C) 2019 by the author. Licensee MDPI, Basel, Switzerland. This article is an open access article distributed under the terms and conditions of the Creative Commons Attribution (CC BY) license (http:/ / creativecommons.org/licenses/by/4.0/). 


\title{
Article \\ Befriending Your Food: Pigs and People Coming of Age in the Anthropocene
}

\author{
Mary Trachsel \\ Rhetoric, University of Iowa, Iowa City, IA 52242, USA; mary-trachsel@uiowa.edu \\ Received: 15 February 2019; Accepted: 23 March 2019; Published: 31 March 2019
}

\begin{abstract}
Geologists and ecologists report that Earth is undergoing its sixth massive extinction event, an occasion that calls for radical revision of conservation ethics. The biologist Edward O. Wilson has proposed that conservation projects in the Anthropocene should be grounded in biophilia, an evolved, relational (or biocentric) mode of perception that activates aesthetic and affective responses to non-human life alongside cognitive understanding. Because biophilia includes non-rational modes of perception, the nurturing of biophilic conservation ethics cannot fall to ecology alone; imaginative literature, for example, can prompt readers to imagine and work to realize more environmentally friendly roles for humans and, further, can assist in cultivating a conservation ethic suited to current ecological conditions. In particular, coming-of-age novels about friendships between people and pigs offer an alternative to the industrial "pork story" that seeks to gain narrative control of relational norms between people and pigs, at the expense of biodiversity and ecological health. Three such novels published in 2017 depict human-pig friendships, a relational model created by pigs' shift in status from food to companion animals. In presenting this realignment, the stories facilitate development of a biophilic conservation ethic.
\end{abstract}

Keywords: biocentrism; biophilia; conservation ethics; friendship; human-animal relationships; narrative ethics; pig; relational ethics; young adult literature

\section{Biophilia Opens a Relational Approach to Conservation Ethics}

Well before the term "Anthropocene" entered public usage, scientists were already describing the end of the 20th century in geological terms, as an era witnessing Earth's sixth massive wave of extinction (See Leakey and Lewin 1995; Kolbert 2014). They report that an event like this has not registered in the geological record since the dinosaurs closed down the cretaceous period, 65 million years ago. The biologist Edward O. Wilson offers the name "Eremocene," the age of loneliness, as an alternative label that calls attention not to humans but to other forms of life that are rapidly becoming lost to the world. Such reports rarely penetrate human awareness very deeply, given that we experience our lifetimes in months, years, and decades rather than geological eras, and that the human species itself apparently is not facing imminent extinction. Still, ecologists tell us we should be worried about the fates of our fellow species, because our lives are tied up in theirs-because any one species' chances of survival are enhanced by the biodiversity of its environment, while its likelihood of extinction rises as fewer species share the work of shoring up the system against ecological collapse.

Like many other biologists and environmentalists ${ }^{1}$, Wilson has argued that we need to take a long view of ourselves as participants, along with all other species, in a global web of life in order to establish

1 Many environmental scientists and philosophers throughout the world share Wilson's premise that human action to preserve the non-human environment requires a departure from anthropocentric ethics and an engagement of multiple human perceptive modes. A listing of but a few of these thinkers and writers includes the Norwegian philosopher Arne Naess, who coined the term and developed the concept of "deep ecology," the US science writer, Rachel Carson, whose Silent Spring (1962) brought public awareness to the environmental impacts of human activity, the Australian philosopher Val Plumwood, 
a conservation ethic that is scientifically grounded and more fully engaged with non-human nature than science alone permits. Wilson envisions a coming together of biology and bioethics to produce "moral reasoning of a new and more powerful kind" (Biophilia, p. 138), a multi-modal, relational way of knowing that he calls "biophilia." Literally, the term translates as "love for life," but Wilson means it much more broadly. For him, biophilia describes an orientation to the natural world that engages not just the sensory and rational intelligence of the scientist, but also the aesthetic and affective powers of human mind that cause us sapiens to care about what we know of life beyond ourselves.

Biophilic perception, Wilson has hypothesized, arises from an innate sense of human "affiliation" with other forms of life (Wilson 2002; Wilson 1984, p. 1). This relational way of knowing finds its biological explanation in the Darwinian premise of the phylogenetic continuity of all life on Earth. As a biologist, Wilson assumes a human kinship with other living things that is traceable in our common genetic ancestry. To the extent that we regard our own species as the crown of creation and the mind or soul of the planet, we are disinclined to acknowledge nonhuman kin, but Wilson rejects this anthropocentric worldview. In its place, he proposes a conservation ethic in which interspecies kinship neither shames nor diminishes humanity, but instead, elevates nonhuman life to family status. Such a move, Wilson believes, is necessary to dissuade us from treating other species as though they are disposable. At the heart of Wilson's biophilic conservation ethic is a human willingness to share Earth's finite natural resources with other species, and in performing this willingness, he recommends a property-sharing contract that dedicates half the Earth's surface to the support of nonhuman life (Wilson 2016).

Wilson worried in 1984 that bioethics was lagging behind biological understanding of human continuity with the rest of life. As a discipline, bioethics has been primarily concerned with human-centered questions about the interface of human life and technology-about the allocation of organs for transplantation, for example, or about the manipulation of human genetics and reproduction, or about the technological capacity to extend or terminate human life. Alongside these anthropocentric concerns, Wilson noted, bioethicists at the end of the century had "only begun to consider the relationships between human beings and [other] organisms with the same rigor" (Biophilia, p. 119). Biophilia is his response to this imbalance, a biocentric morality that arises from feelings about, as well as knowledge of, our connectedness to other-than-human life.

Wilson has argued that science education shares with other academic branches a moral educational mission to promote care as well as knowledge of the natural world. Science, he maintains, should help humanity compose an ethical response to the ongoing loss of biodiversity around us, and this response should be informed by instincts and feelings excluded by the calculational reasoning and empirical focus of science. Many ecologically-minded science education programs throughout the world do seek to foster feelings of care that translate into action on behalf of nonhuman life. Jane Goodall's internationally recognized "Roots and Shoots" program is a prominent case in point, and in the U.S., science education with an emphasis on relational knowing has assumed the battle cry, "No Child Left Inside." A program directly influenced by Wilson's biophilia hypothesis is Richard Louv's (2005) Children and Nature Network, popularized through the best-selling Last Child in the Woods and The Nature Principle (Louv 2011). As in comparable science education programs, the methodology of Louv's "New Nature Movement," is immersion in the natural world to counteract "nature deficit disorder" and to re-establish the aesthetic and affective bonds with nature that have evolved within the human psyche.

whose Environmental Culture (2002) lays out the framework for "ecological rationality," and the US environmentalist Frances Moore Lappe, whose EcoMind (2011) similarly prescribes an internal transformation in order to bring humans into greater harmony with the rest of the natural world. 
A shortcoming of immersion programs like Goodall's and Louv's, however, is that their implementation is largely confined to children's education. ${ }^{2}$ Although Louv argues in The Nature Principle that adults as well as children suffer from nature deficit disorder, most advanced levels of science education continue to focus exclusively on scientific method, empirical knowledge, and the use of observational enhancement technology. Advanced science education continues to separate the biological science of ecology from the relational experience of nature, reinforcing a conceptual divide between natural science and naturalism. In such a system, the notion of human kinship with other organisms appears sentimental and non-scientific, discouraging the revolution in moral reasoning that Wilson and others have insisted we need.

Cultivating a sense of kinship with nonhuman life, then, especially as children age into adulthood, becomes a moral education responsibility that science alone is not equipped to uphold. A scientific view of more-than-human nature exercises and sharpens human observational powers, but it does little to cultivate, and is often hostile to, narrative engagement. By "narrative engagement" I mean a relational engagement that entails caring about characters to whom things happen.

Many nonfiction accounts of interspecies relationships perform the narrative function of cultivating care for and about the nonhuman world. Ethologists in the narrative footsteps of Konrad Lorenz, for instance, have introduced anecdotes about nonhuman individuals to the observational repertoire of science, as have field primatologists, whose narrative styles were pioneered by Kinzi Imanishi in Japan and by Jane Goodall, Dian Fossey, and Birute Galdikas in Europe and the U.S. The interspecies narrative focus of the present study, however, is imaginative literature-fictional stories about relationships between human and nonhuman characters. In particular, I focus on the fictional type known as the coming-of-age story—what the German language has famously named der Bildungsroman-the story of a young person's moral crossing from childhood into maturity. This kind of story holds considerable appeal for listeners and readers who are themselves undertaking or preparing to undertake such a crossing, and it has historically served as a powerful medium of moral education. The present study examines an intersection of the coming-of-age story with another narrative form of moral instruction, what the moral philosopher Margaret Urban Walker (2007) calls "narratives of relationship." Walker's primary concern is human-to-human relational morality, but this study applies her moral analysis to a particular type of interspecies narrative of relationship: Stories about friendships between people and pigs.

In scrutinizing this very particular genre-coming-of-age stories about human-pig friendships-as a text of moral education, I trace a development in a relational worldview that supports a biophilic conservation ethic. These stories perform this support by recategorizing a quintessential food animal as a companion animal. In Biophilia, Wilson observes the human tendency to "favor certain animals because they fill the superficial role of surrogate kin," noting that dogs are especially apt to be chosen for this position because they share "humanlike rituals of greeting and subservience" that have earned them a reputation as man's best friend (p. 126). On the surface, pigs are improbable candidates for friendship with humans, given their long history as a domesticated food source. Today, however, as the massive scale of pork production around the world steadily hastens a global loss of biodiversity and threatens public health, ethical reassessment of our human relationships to pigs has become an urgent matter. In imagining pigs as friends instead of food, coming-of-age novels function beyond mere entertainment, as moral instruction that advances a biocentric ethic by challenging the human-centered morality of pig domestication and pork consumption.

My own geographical and cultural perspective comes from the U.S. heartland, specifically my home state of Iowa, where I came of age on a farm in a vast agricultural expanse punctuated by once-thriving small towns. From the 1950s through the 1970s, when I was growing up, pigs were

2 Other examples of immersive biology education for children include Joseph Cornell's Sharing Nature Foundation, presented in Cornell's many books, including Sharing Nature with Children (1979) and Sharing Nature with Children II (1989), and Gary Paul Nabhan and Stephen Trimble's The Geography of Childhood: Why Children Need Wild Places (1994). 
part of the landscape. We kept ours in a lot, a pasture, a barn, and a hog house to the east and south of our own house. Today, although the number of pigs alive in Iowa has topped 23.7 million, and Iowa is by far the lead contributor to the new record, 73.5 million pigs living in the U.S. at any given moment (Associated Press 2018), you can drive across the state on country roads and never see a pig. Nearly all of Iowa's pigs are confined in concentrated animal feeding operations (CAFOs), and the process of breeding, feeding, and slaughtering pigs and packing and shipping pork is one of the few mainstays of our state's economy. Iowa has an especially large and concentrated pig population, but comparable conditions prevail in many spots across the globe. China tops the list of countries by national herd size, followed by the European Union, the United States, Brazil, and Russia (Global Mega Producer). The living conditions of the vast majority of domesticated pigs around the world are remarkably similar, as industrialization has imposed on pig farming the standardizing imperatives of mass production. Despite the geographical and cultural limitations of my own personal and academic standpoint, then, the problems that concern me in this article are global. In my very precise selection of narrative types to study, I necessarily overlook differences in human valuations of pigs across cultures, and changes in these valuations over time. For Jewish and Muslim cultures, for instance, pigs have never occupied the category of food animals, being classified instead as unclean beings that are both inedible and unfit for human companionship. In these cultures, pigs have been categorized as something akin to vermin. This despised status resonates with pigs' position in the Western culture that has produced the novels analyzed here. As nouns in the English language, "pig" and "hog" (along with "swine") are derogatory terms that describe people as greedy, fat, slovenly, and brutish, while as verbs they denote selfish, sloppy, and excessive consumption. These extremely negative associations coupled with the fast-growing, global spread of industrial hog farming conditions that keep pigs out of sight and out of mind spotlight the radical transformation of pig-people relationships advanced by the farmed animal sanctuary movement in the US and elsewhere and by the US coming-of-age narratives of relationship examined in this article. Mizelle's (2011) Pig gives a more comprehensive account of humanity's often conflicted relationships with pigs across cultures and over time. Prized for their meat and hides, favored for their ease of upkeep, despised for their ugly appearance and destructive habits, and sometimes cherished for their intelligence and personable dispositions, pigs resist easy or universal classification by humans. For this reason, they present a significant challenge to the necessary task of realigning human relationships with the rest of nature in the present age of environmental crisis.

\section{Coming of Age as a Relational Process}

A Bildungsroman tells of moral development through life experiences that transport a character from childhood to maturity. In many coming-of-age stories, these transformative learning experiences are relationships that a central character must choose to continue or terminate. Tragic romances like the tale of young King Arthur, for example, present growing up as a process of severing ties, resulting in the loneliness of lost relationships. A picaresque, like Tom Jones (1749), presents the path to adulthood as a story about making and breaking relationships with ill-chosen (but fun) companions. Romantic comedy likewise depicts coming-of-age as a process of learning to distinguish right from wrong relationships on a path to perfect partnership. Across all these genres, the coming-of-age story assumes an overarching narrative form that the moral philosopher Margaret Urban Walker (2007) refers to as a "narrative of relationship"-a biography of them or an autobiography of us. Walker maintains that narratives of relationship are one of the fundamental building blocks of moral understanding. Examining self-development in social relationships with others, she explains, illuminates "the acquired content and developed expectations" of relational identity and "the type of trust" in which relationships are rooted. Thus, probing the essential links between self and other, narratives of relationship prompt storytellers and listeners alike to ponder a relationship's "possibilities for ... continuation," (p. 117) including, of course, its possibilities for discontinuation. 
Many relational coming-of-age narratives spotlight young protagonists' fraught relationships with authority figures, who range from older siblings and parents to teachers, clerics, and representatives of the law. Others examine the peer relationships that mediate a young person's moral development, as in John Knowles' A Separate Peace (1959), a young-adult friendship story of betrayal and regret. A special subset of the coming-of-age friendship story features young people in relationships with non-human animals.

Interspecies relationship stories are common in children's literature, which freely fashions human friendship with a wide variety of species, including toy animals, as in A.A. Milne's Winnie the Pooh or Margaret Williams' The Velveteen Rabbit (1922). By contrast, stories for young-adult readers tend to tighten the range of nonhuman friends to popular companion animals, the foremost being dogs and horses. Notable examples are Enid Bagnold's National Velvet (1935), John Steinbeck's The Red Pony (1937), Eric Knight's Lassie Come Home (1940), Mary O'Hara's My Friend Flicka (1941), Fred Gibson's Old Yeller (1957), and William Armstrong's Sounder (1969). Some exceptions to this rule extend the bond of interspecies friendship to non-domesticated species; Marjorie Rawlings' The Yearling (1938), for instance, tells of a boy's friendship with a deer, and Sterling North's Rascal (1963) is about a boy and a raccoon. A different type of exception, and the focus of my study, features friendships between young people and livestock animals, and in particular, pigs.

A species commonly derided for gluttony and filth, pigs are surprisingly popular friends in stories for children and maintain a vigorous presence in young adult stories as well. White's Charlotte's Web (White 1952) exemplifies the distinctive feature of children's stories of this type: The pigs miraculously escape a tragic ending as edible livestock. One of the central characters, a pig named Wilbur, first appears as the infant ward of an 8-year-old human rescuer, Fern. As the plot unfolds, Wilbur's fate migrates from dependence on Fern to friendship with Charlotte the spider, who engineers the miracle of Wilbur's permanent escape from the livestock category. Wilbur's story further illustrates a popular feature of friendship stories about pigs, their beginning in a pink-and-white infancy that calls to mind Caucasian human babies. This is the impression Wilbur, in Charlotte's Web, initially makes on Fern when she opens the box and sees him for the first time: "There inside, looking up at her, was the newborn pig. It was a white one. The morning sun shone through its ears, turning them pink" (p. 4). From this moment, Fern adopts Wilbur as her baby and mothers him until he is too big to live in the family's house or yard, at which point she sells him (as a commodity) to her neighboring uncle.

Porcine biographies such as Sy Montgomery's The Good, Good Pig (Montgomery 2016), Jenkins' and Walter's Esther the Wonder Pig (Jenkins and Walter 2016) and Matt Whyman's The Unexpected Genius of Pigs (Whyman 2018) demonstrate that in real life, pigs' social intelligence and trainability can lead to their prolonged friendship stories with humans, and these traits no doubt further contribute to pigs' popularity in fiction. With a flexible repertoire of social behaviors broadly overlapping those of established companion animals such as dogs, pigs can in fact actively solicit and engage human attention and build interspecies companionship. Pigs' reputation for intelligence and affability, coupled with their despised status among domesticated animals, further explains their popularity in coming-of-age stories, as their position surely resonates with the miseries of adolescent alienation.

In real life, pigs stand out among livestock animals as creatures domesticated exclusively for slaughter. Sheep, goats, and llamas provide wool; sheep, goats, cows, and camels provide dairy; fowl produce eggs and down; horses, oxen, camels, and llamas are workers, but pigs are simply pork and leather. Most stories of relationships between people and pigs, therefore, unfold as tragedies of sacrifice and betrayal, a storyline that tests an interspecies morality framing domestication as "animal consent." 3 Budiansky (1992), an early proponent of this perspective, defines human-livestock animal relationships as the outcome of an ancient "covenant of the wild," by which, he explains, livestock species long ago made an "evolutionary choice" to affiliate with humans. According to Budiansky,

3 For a discussion of "the myth of animal consent," see Foer (2009), pp. 99-101. 
accepting the biological trade-off between the captivity and slaughter of individuals on the one hand, and the long-term survival and proliferation of the species on the other, livestock animals have in effect agreed to co-author the tragedy of their friendship story with humans. Honoring our side of this bargain, Budiansky argues, means accepting a relational morality such as Walker proposes-one grounded in a trust that one another's expectations will contribute to the terms of a relational identity. In Budiansky's words, "just as sheep may 'expect' to be killed ... , they also impose moral demands on us because they ... 'expect' to be better off than in the wild" (p. 167).

In the case of pigs and people, an ethics of animal consent requires that people consider the expectations of pigs in their domesticated captivity, the very subject examined in a recent spate of coming-of-age novels about friendships between young adults and pigs. All published in 2017, Jodi Kendall's The Unlikely Story of a Pig in the City, Paul Griffin's Saving Marty, and Corabel Shofner's Almost Paradise invite young adult readers to imagine individual pigs' expectations of their captive relationships with humans. The coming-of-age storyline shared by all three novels features a young person faced with decisions about how to continue or terminate a friendship with a pig. All three prompt imaginative speculation: What if pig slaughter were not an inevitability? What alternatives to tragedy might describe pigs' and people's relationship narratives? In response to these questions, all three stories reclassify pigs from food to companion animals, proposing a categorical shift that challenges the ethical norm of porcine consent to captivity and slaughter. ${ }^{4}$

Individual humans shifting individual animals from their "natural" destiny as human food to a radically different destiny as human companions neither stops nor perceptibly slows the growth of industrial pig farming and its massive environmental impact on the biosphere. But marketing data reveal that stories about pigs do affect the food choices of young consumers. Consumption of pork at fast food restaurants fell temporarily but significantly in the wake of movie releases of Charlotte's Web and Babe (O'Connor 1995; Nobis 2009), for instance. Therefore, I surmise that the stories about pigs that I study here may also somehow matter as a cultural force that nurtures an expression of biophilia, an attitude of caring about non-human beings in a new, more expansive way. Imagining pigs not as commodities but as participants in the pages and chapters of human biography, I contend, is a psychological exercise that cultivates biophilic ethics.

\section{Coming to Terms with Slaughter}

Pig-centered friendship stories for very young children generally avoid mentioning the terms of pigs' real-world domestication, while stories for older children tend to acknowledge the sad destiny of pigs, but only until fantasy intervenes to alter this fate and produce a happy ending. For young adults, however, the traditional pig-human friendship narrative equates adulthood with accepting the inevitability of pig slaughter. The Born-again Carnivore, a guide for small-scale farmers committed to humane meat production, endorses this tragic version of moral maturity when it warns against befriending pigs or regarding them as anything but food. "It's best not to give the animals names other than Freezer or Pork Chop," authors Sue Mellis and Barbara Davidson advise (Mellis and Davidson 1990, pp. 33-34). In the classic U.S. pig-human tragedy for young adults, Peck's (1972) A Day No Pigs Would Die, an autobiographical narrator fails to heed such advice but eventually crosses into adulthood when, for the sake of his family, he helps his father, a butcher, slaughter his beloved pig, Pinky.

The 2017 novels replace this tragic plotline with a story of lasting trust, if not continued association, between pigs and their young human friends. Collectively, they work to enlarge and diversify an anthropocentric worldview in which pig slaughter is unquestionably warranted by human carnism. By drawing attention to domesticated pigs' expectations of their human keepers, the stories assert an interspecies ethical perspective at a moment when the multi-billion-dollar pork-production industry is

4 On categorization of nonhuman animals, see Herzog's (2010) Some We Love, Some We Hate, and Some We Eat and Joy's (2010) Why We Love Dogs, Eat Pigs and Wear Cows. 
intent on controlling the narrative of pig-people relationships with what it calls "the pork story" or "the industry story." ${ }^{5}$ In this story, pigs' welfare expectations are explicitly defined as the living conditions that enable their swift and uncomplicated progress from infancy to death. Pork producers uphold the human side of the domestication covenant with pigs by providing these conditions, measuring their success against standards that quantifying pig-life as litter size, survival rate, time-to-market weight gain, and feed-to-meat ratios. In the industry's pork story, good care for pigs translates into human profit, while poor care leads to human loss. As a 2017 article in the U.S. labor and trade publication, National Hog Farmer asserts,

$[\mathrm{P}]$ ig farming is all about selling pork. It is not about selling individual animals but raising delicious pork for the global table, and that all starts with the sow. The production and efficiency of the sow is quintessential to the success of the swine business. She has one job-to deliver the best pigs that perform well.

In response to animal welfare advocates' claims that pigs confined in CAFOs are worse off than they would be in the wild, the industry defends its production practices as "science-based" and justifiable by economic logic. As the Iowa Pork Producers Association declares on its website, modern production methods are "good for consumers, good for pigs," and "just good business."6

To support this anthropocentric interpretation of the covenant, pork industry marketing professionals use narrative strategically, often encouraging and coaching farmers on how to spread "the real story" of pigs and the people who know them best. ${ }^{7}$ In the U.S., Pork Checkoff, a National Pork Producers Council product-promotion fund, advises farmers to use blogs, social media sites, and other outlets to broadcast "real pig-farming stories" premised on the human appetite for pork and depicting farmers as first responders to human need. Pork producers learn from marketing experts to promote and capitalize on food trends like "bacon-mania" in the U.S. and Canada and the entry of pork belly, lard, and chicharron into haute cuisine restaurants around the world. In the U.S. and perhaps elsewhere, the industry is particularly intent on spreading this message to an impressionable young-adult audience whose dietary choices may still be in flux. In a column advising hog farmers to think of their business as "feeding the masses," industry spokesman Kevin Schulz pondered the optimal age for planting the pork story in the minds of potential customers: "Some say junior high is when children are making their own decisions about what they are going to eat ... Still others say college students are a prime target due to all sorts of dietary messages being thrown their way" ("Feeding the Masses").

Emphasizing economic and dietary considerations in its pitch to young adults, the pork story circumvents questions about the relational expectations of livestock that are central to animal consent ethics. One way the industry dismisses concerns about pigs' expectations is by characterizing animal welfare advocates as outsiders who do not know "the real story" of pork production. It performs this move as the conditions of present-day pig farming actively discourage public attention to pigs' expectations by keeping pigs contained in CAFO buildings and slaughter houses to which public entry is prohibited by biosecurity regulations and "ag gag" laws that define efforts to expose the conditions

5 A good example of this discourse can be found in the National Pork Board's (2014) 2015-2020 Strategic Plan: People, Pigs and Planet (2014). www.pork.org. The plan outlines an approach to the task of "telling the pork industry's story" and characterizes pork production as the activity of an industry that "has the best interests of consumers and pigs at heart."

6 An example of how the pork industry calculates pig welfare is the research report by Cyril Roy, et al., "Determining Optimum Stocking Density in Nursing Pigs" in National Hog Farmer, 22 January 2018. The report acknowledges that "optimal space allowance increases productivity by maximizing feed intake and average daily gains of animals. However, optimum economic performance is influenced by high growth rates as well as by increasing the number of pigs per pen and overall barn throughput."

7 See, for example, Kevin Schulz, "Food for Thought: Telling Pork's Story" National Hog Farmer, 24 October 2017; Hora, Greg, "Sharing Our Responsible Pork Production Story on the 2018 Heartland Tour," Pork Checkoff Blog https://www.pork.org/blog/ shaing-responsible-pork-production-story-2018-heartland-tour/; Cheryl Day, "What is Your Excuse for not Telling Your Real Pig Farming Story?" National Hog Farmer, 17 October 2017 
of pigs' living and dying as a form of domestic terrorism. Only occasionally do natural disasters such as tornados and floods abruptly reveal the conditions of pigs' present-day domestication to the general public and suggest the magnitude of this industrial enterprise by calling attention to pigs whose lives were contained within the pork production system. The recent young-adult pig-human friendship stories resist this erasure of pigs' expectations by substituting a narrative, relational morality in place of the contractual framework of pigs' domestication. These interspecies Bildungsromane thus open onto the larger questions Wilson has posed about the relational terms of humans' connection with and disconnection from other forms of life on planet Earth.

\section{Fantasy Friendship Stories about Pigs for Children}

"The Three Little Pigs" typifies pig stories for young children in overlooking any and all questions about the pigs' fate as domesticated animals. No version of the tale that I can recall speculates on how the pigs might taste, because a wild predator-the big, bad wolf-obscures any threat to the pigs from human predation. In fact, the pigs in the story stand in for humans as sapiens, thinkers whose superior wit enables them to dispatch the wolf. The especially clever and generous third little pig in particular turns the balance of predator and prey against the wolf, engineering a story ending in which the wolf tumbles through the chimney and into a cauldron to be cooked, presumably so the little pigs can eat him.

In the early 20th century, a popular pig character who remained similarly free from concerns about human dietary choices was Freddy from Brooks' Freddy the Pig (Brooks 1927-1958) series of 26 adventure novels and a book of poetry (Hochschild 1994). Unlike the three little pigs, Freddy does interact with humans, but his relationships with them rarely exceed acquaintanceship. Most people in Freddy's adventure stories are mildly comic characters on the outer orbit of his friendship circle. Often, they earn laughs by expressing vague surprise but no disbelief at discovering that a pig can talk and perform other "human" activities. As a character, Freddy is something of a clown; lazy and comfort-loving, he is a supremely affable companion to the other barnyard animals, who are his closest friends. But like the pigs who outsmart the wolf, Freddy distinguishes himself with a shrewd intellect that enables him to plan, orchestrate, and successfully carry out his schemes, even when they transport him and his barnyard companions into human venues such as airplanes and detective agencies. Unlike George Orwell's Animal Farm (1945), which presents a dark picture of porcine intelligence, children's stories generally represent pigs as good-natured tricksters who use their minds to maximize their own pleasure and comfort without depriving or threatening others.

A 21st-century children's book series about a pig, Mercy Watson (DiCamillo 2005-2009), plants the pig character, Mercy, in the center of a human family. Her human "parents," Mr. and Mrs. Watson, dote on her and refer to her as "the porcine wonder." Like a human child she eats at their table, rides in their car, and even sleeps in their bed, and like Freddy, she is pleasure-seeking and comfort-loving; the prime motivation in her life is her insatiable taste for buttered toast. Mercy resembles Freddy in pursuing adventures and accomplishing heroic feats—-though often her achievements are inadvertent and performed in a comically bumbling fashion. While her human parents infantilize Mercy as a darling or a pet, other human characters recognize her as friendship material. The Watsons' neighbors, two elderly sisters named Eugenia and Baby Lincoln, are human onlookers who often get involved in Mercy's exploits. Eugenia, the rigid and overbearing elder sister, disapproves of pigs in general and Mercy in particular, but Baby secretly holds that "Mercy is good company" (Mercy Watson to the Rescue, p. 27), as she often finds herself unexpectedly accompanying Mercy on adventures that Eugenia would never permit. Firmly established as a pseudo-human companion and family member, Mercy is insulated from the individual sacrifices required of pigs by the domestication covenant.

The pig novels of the popular 20th-century British children's writer, Dick King-Smith, target slightly older readers than Mercy Watson's. The stories resemble Charlotte's Web and Freddy the Pig in their farmyard settings and domesticated animal communities, where pigs' social ties to fellow nonhuman animals, initially at least, take priority over their relationships with humans. King-Smith's 
stories further resemble Charlotte's Web in raising the specter of livestock slaughter but dispelling it through fantasy. In Wilbur's case, Charlotte the spider miraculously intervenes in Wilbur's fate, persuading the humans who control his destiny that Wilbur has been divinely chosen for public adoration instead of consumption. Through Charlotte's machinations, Wilbur shifts his relational position with humans from livestock animal to permanent pensioner or pet in the Zuckerman's barnyard. In King-Smith's novels, by contrast, pigs are the engineers of their own categorical migration from livestock to companion animals.

The best-known of King-Smith's stories, Babe, the Gallant Pig (King-Smith 1983) became a popular film for children in 1995. Babe's story begins when Farmer Hoggett wins him as a tiny piglet in a contest at the fair. When Hoggett brings Babe home to the barn, the sheep dog, Fly, explains to her puppies that "the boss" will eventually eat the pig. This prompts a canine family discussion that reduces the differences between livestock and companion animals to distinctions between "stupid" and "clever" animals. When one of Fly's puppies asks anxiously if the boss will eat them when they grow up, his mother reassures her children, "People only eat stupid animals. Like sheep and cows and ducks and chickens. They don't eat clever ones like dogs" (p. 17). Babe, like other pig protagonists in King-Smith's novels, proves that pigs are at least as clever as dogs, implying that their intelligence entitles pigs to companion-animal rights and privileges. Babe successfully manages this shift in status by learning sheepherding skills from his foster mother Fly and from the sheep themselves. By the end of the novel, Babe is ultra-domesticated; the sheep trust him because he has polite manners, and Farmer Hoggett has "complete confidence" in his skills as a sheep-pig (p. 113).

Babe's public triumph at the sheepherding contest, like Wilbur's rescue by Charlotte, is a "miracle" (p. 113) to the human crowds who witness it, but to Farmer Hoggett, Babe's performance merely reaffirms the terms of companionable trust between human and nonhuman work partners. In the closing scene, Hoggett bends to scratch Babe between his ears, at which point "he uttered those words that every handler always says to his working companion when the job is finally done. Perhaps no one else heard the words, but if they did, there was no doubting the truth of them. 'That'll do,' said Farmer Hoggett to his sheep-pig. 'That'll do'" (pp. 117-18).

In Pigs Might Fly (King-Smith 1980), published three years before Babe, King-Smith tells the story of Daggie Dogfoot, a plucky runt of the litter who manages, through his own wiles and pig-headed determination, to permanently escape classification as livestock. His story, like Babe's, unfolds in a barnyard setting; Daggie's mother and her friends refer to the farmer as "Pigman," while the ducks all know him as "Duckman," each species believing that the farmer exists solely to tend to the needs of their own kind. The sows do not question the culling of runts, referring obscurely to those unfortunate offspring as "taken away." Their understanding of weaning is similarly vague and complacent, as they talk of their piglets' ritual "crossing the yard." After this termination of their maternal relationship with their piglets, the sows look forward to relaxing in the special meadow they call "Resthaven" where they can recover from the rigors of motherhood before their next breeding session with the boar, who is known in the barnyard as the Squire.

Initially "taken away" but miraculously escaping and returning to his mother, Daggie gains a reputation among the farm workers as an escape artist who is not worth the trouble to catch and kill. Small and deformed, he stays with his mother in Resthaven, where he makes friends with ducks who teach him how to swim. Because his deformed feet make him a powerful swimmer, Daggie is eventually able to save Pigman from being washed away in a flash flood. Through this heroic deed, Daggie, like Wilbur and Babe, miraculously escapes the inevitable fate of livestock animals. After rescuing Pigman and summoning help, Daggie, who has been swept downstream, rides back to the farm suspended on a rope from a helicopter, affirming the title's incredible assertion that "pigs might fly" as well as swim. When Daggie returns to the farm, Pigman is reduced to tears of gratitude, and the final scene shows Daggie swimming happily in the pond at Resthaven while crows look down in admiration, acknowledging Daggie's successful transcendence of categorical limits through "the miraculous skills of the amazing swimming pig" (p. 158). 
King-Smith's third pig novel, Ace: The Very Important Pig (King-Smith 1990), introduces Ace as a food animal. Farmer Tubbs, when he first encounters Ace, contemplates the newborn piglet's destiny as meat for humans: "you will never be full grown ... I shall sell you and your brothers and sisters when you'm eight weeks old, and a few months after that, you'll all be pork" (p. 6). Shortly thereafter, however, Farmer Tubbs begins to realize that Ace understands the speech of humans, and he will eventually discover that Ace also understands and converses with all the other animals on the farm. At first, Farmer Tubbs cannot decide if he is going crazy or witnessing a miracle, but eventually, like Hoggett, he grows confident that Ace understands every word he says, and he begins to accord Ace the privileges of a companion animal. Gradually, Ace wins the trust of Farmer Tubbs' cat and dog, and through these friendships with favored companion animals he gains access to the house, where the three animals like to gather on the sofa in the afternoon to watch their favorite television shows. Like the humans in Freddy the Pig, Farmer Tubbs is surprised but credulous when he discovers that Ace has learned how to read the tv programming guide and can operate the television set. Tubbs begins to invite Ace to accompany him on trips to town and even to drink with him in the local tavern.

By the end of the novel, Ace's companion-animal performance has earned him regional and then national fame; he accompanies Farmer Tubbs to London for a televised appearance that increases his fame and draws prospective buyers to offer Tubbs large sums of money for his amazing pig. By this time, however, Ace's position as a companion animal is firmly fixed, and the farmer claims Ace as a friend instead of a commodity. In the closing scene Tubbs muses to himself, "What good would any amount of money be to you if you had to part with him? Why you wouldn't have no one to watch West Country Farming with. You wouldn't have no one to keep you company in the old pickup. You wouldn't have no one to enjoy a drink with at the Bull" (pp. 133-34). Over the course of the novel, Ace successfully engineers a permanent relational shift from food to friend, even coming to assume the exclusive status of "best friend" to his human companion.

A final example of human-pig relationship stories for preadolescents is Briggs-Martin's The Water Gift and the Pig of the Pig (Briggs-Martin 2003), narrated by Isabel, the granddaughter of a retired sea captain who keeps as a companion the last pig of the last litter of the pig who once sailed with him around Cape Horn. Isabel describes the pig as doglike in her intelligence, and on that basis she, like Farmer Tubbs, accords the pig exclusive best-friend status: "She is smart enough to count to five. She follows me like a dog and sits in the front of the boat when Grandfather and I go fishing for haddock. I would say the Pig of the Pig is my best friend. We have a secret handshake" (np). But eventually the Pig of the Pig's position as friend and companion is threatened when she disappears and an evil neighbor, Ben Stinchfield, goes looking for her. "I knew Ben Stinchfield was thinking of bacon and ham, pork chops and pigskin gloves" (np), Isabel worries, knowing that outside her family circle, the Pig of the Pig defaults to livestock status. Determined to save her friend from this fate, the narrator rouses her grandfather to action and learns from him the mysterious "water gift" of dousing (finding underground water) with a forked stick. After the stick in Isabel's hand points to where the Pig of the Pig has fallen into a hole, Isabel and the pig reunite with their secret handshake and dance together, the pig happily restored to the category of friend.

\section{Coming of Age as a Carnivore}

The Water Gift and the Pig of the Pig anticipates coming-of-age stories about human-pig relationships in casting Isabel as a moral agent whose decisions and actions determine, at least in part, whether and how the human-pig relationship will continue or end. Like Isabel's story in which the Pig of the Pig is nothing but pork to Ben Stinchfield, coming-of-age versions of the pig-human friendship story explicitly acknowledge the relational limits imposed by pigs' livestock classification, but they no longer invoke fantasy to make this troubling reality miraculously disappear. As a result, the human protagonists in these stories must confront the moral problem of determining whether and how to continue or conclude the relational story that joins their lives with the lives of pigs. This problem 
wrenches them from an anthropocentric view of the world by forcing them to consider the demands of other denizens of the more-than-human world.

In Peck's A Day No Pigs Would Die (Peck 1972), the narrator named Robert Peck ends his friendship with his pig Pinky by conceding her default status as livestock and performing his part in her slaughter. For Robert, the grim reality of adulthood is that he has to kill the thing he loves. His despair as he assists in Pinky's slaughter is the tragic culmination of his coming-of-age experience; he gains adulthood when he accepts that his friendship with Pinky is bound to an inexorable fate. Initially, Robert describes the friendship as one of mutual fondness and delight in one another's company:

I'd had her just ten weeks and already she was about my size. I lay on my back on the grass so she could come up to me and I could see her face. It always looked to me like she was smiling. In fact I know she was. Lots of things smile, like a flower to the sun. And one thing sure, I knew that just like I could smile to see Pinky, she sure could smile to see me (p. 51).

For a while, Robert believes he will be able to continue his relationship with Pinky long into the future, as he intends to make her a breeder sow, producing pork rather than becoming pork herself. But when Pinky proves barren, this hope evaporates, and the relationship story proceeds inevitably to Pinky's slaughter and Robert's complicity in the deed. When Pinky first appears to Robert on her final day, she, like the Pig of the Pig, is doglike in her expression of affection, prompting Robert to comment, "People say pigs don't feel. And that they don't wag their tails. All I know is that Pinky sure knew who I was and her tail did too" (p. 136). Robert vainly seeks to rewrite the tragic ending of his relationship story with Pinky, silently and apologetically addressing his desperate hopes to her as he hugs her neck and breathes in the smell of her body: " . . try and understand. If there was any other way. If only Papa had got a deer this fall. Or if I was old enough to earn money. If only ... " (p. 136). But despite his reluctance, Robert complies when his father tells him, "It's time" (p. 136).

After holding the stunned Pinky down in the snow so his father can slit her throat, Robert watches Pinky bleed to death at his feet, then helps his father hook her jaws and haul her to a cauldron of boiling water. Robert's father makes it clear that accepting Pinky's true identity as pork is the definitive sign of Robert's manhood. Robert describes how, after scraping Pinky's hide and beginning to carve her into meat, his father paused to acknowledge his coming of age:

At last he stopped, pushing me away from the pork and turning me around so as my back was to it. He stood close by, facing me, and his whole body was wet with work. I couldn't help it. I started thinking about Pinky. My sweet big clean white Pinky who followed me all over. She was the only thing I ever really owned. The only thing I could point to and say ... mine. But now there was no Pinky. Just a sopping wet lake of red slush. So I cried.

"Oh, Papa. My heart's broke."

"So is mine," said Papa. "But I'm thankful you're a man."

I just broke down, and Papa let me cry it all out. I just sobbed and sobbed with my head up toward the sky and my eyes closed, hoping God would hear it.

"That's what being a man is all about, boy. It's just doing what's got to be done."

(pp. 138-39)

A Day No Pigs Would Die has been widely censored in the U.S. as unsuitable for young adult readers. Most charges that put it on several American Library Association's (American Library Association 1990-1999) most-banned-book lists in the 1980s and 1990s target the novel's raw depiction of farm life, often citing Robert's intervention in the problematic birthing of a calf, a staged fight to the death between a dog and a weasel, and a brutal and unsuccessful mating episode that leaves Pinky bruised and bleeding. Objections that the breeding scene between Pinky and Samson the boar connotes the human crime of rape were especially troubling to parents and educators, as some of the book's detractors feared the description of pig breeding was so explicit that young female readers, encouraged 
to consider Pinky's feelings and empathize with her experience, might internalize and someday re-experience the scene as a traumatizing flashback. Critics did not particularly object, however, to the underlying ethics of pig slaughter that traumatize the narrator when he has to kill his friend. Pinky's slaughter, the novel suggests, is consistent with an ethical acceptance of humanity's place in a naturally occurring food chain of predator and prey. Reminders of this chain occur throughout the novel, when Robert hears a rabbit's death cry in the talons of a hawk, for instance, and when he shoots and dresses a squirrel for his family to eat. Robert's full and final acceptance of the covenant that legitimizes human carnivory is his ticket to adult status in his family and community.

\section{Friends Don't Eat Friends}

In his 2007 study of human relationships with nonhuman animals, Brutal: Manhood and the Exploitation of Animals, Brian Luke has argued that a coming-of-age course of action such as Robert's is born of a concept of masculinity distorted by sexism. Certainly, the ethical framework of the domestication covenant upholds a similarly masculinized ethic of exploitation, valorizing the expectations of humans by presuming non-human "consent" as a justification for violence and self-gratification. Indeed, it has long been noted that the scientific perspective participates in this distorted worldview, positioning Nature as a feminized "other" to be conquered and forced to reveal her secrets. This masculinized anthropocentric worldview trivializes and dismisses the affective and aesthetic ways of knowing nonhuman nature that Wilson seeks to restore with a biophilic conservation ethic. As numerous feminist critiques of science since the 1970s and 1980s have argued, the interests and methodologies of science often replicate the patriarchal value of male dominance by policing the boundaries between "science" and "not science," and by validating masculine epistemic norms of distance, objectivity, abstraction, and rationality, while excluding feminized ways of knowing such as intuition and emotionality (Arditte 1980). When it comes to animals, the assumption of human domination of nature justifies an instrumentalist approach that converts laboratory animals to pieces of scientific apparatus and enforces objective distance between scientist and subject (Bowling and Brian 1985; Fee 1982; Fausto-Sterling 1981; Leiss [1972] 1994).

The 2017 updates on the coming-of-age narratives about young people's friendship with pigs reject the logic of domination and dismantle the ethical framework of animal consent and human necessity that undergirds the plot of A Day No Pigs Would Die. All three novels resemble Charlotte's $W e b$ in featuring pigs who are rescued in their infancy from a pre-ordained, domesticated fate, and like Wilbur and Pinkie, the pigs in these novels bear a likeness to human babies; when Josie first lays eyes on Hamlet in The Unlikely Story of a Pig in the City, she describes the piglet as "all pink and squirmy and perfect" (Kendall 2017, p. 1). But while Fern Arable is an eight-year-old child when she stays her father's ax-wielding hand to rescue Wilbur, the protagonists in Almost Paradise, Saving Marty, and The Unlikely Story of a Pig in the City are troubled teenagers who must eventually assume the weight of responsibility for the lives of fast-growing hogs. In the process, all of them come to depend on their pigs for moral and emotional support, and in the context of this friendship they learn to consider their pigs' moral and emotional expectations. Fourteen-year-old Lorenzo in Saving Marty reflects that learning to respond to his pig Marty's expectations endows his life with purpose. Naming his pig after his absent father, a decorated soldier whose suicide Lorenzo learns about and comes to accept as he is caring for his pig, Lorenzo enters into a relationship that focuses his attention beyond himself and his human family and friends. His relational identity makes his growing-up experience a process of coming to recognize himself not just as a responsible member of the human family but as a participant in a much vaster kinship network with other forms of life. When the pig, Marty, seemingly empathizing with Lorenzo's teen-aged confusion and sadness, rests his head on Lorenzo's shoulder, Lorenzo has trouble distinguishing himself from his friendship with Marty, and wonders, "if I could still be me without him there every day" (Griffin 2017, p. 162). He credits this relationship with creating "a new me, the one Marty made me into" and explains that he "needed" to learn how protecting and caring for another could nurture the self (p. 162). 
Josie, of The Unlikely Story of a Pig in the City, (Shofner 2017) feels lost in her large and financially insecure family, and she fears her recent growth spurt will exclude her from gymnastics, the single arena where she feels she can make her mark. As Hamlet, the baby pig rescued by her older brother, grows toward full-sized adulthood and the family's economic problems worsen, Josie comes to realize that the city is no home for a pig, however much comfort and emotional support she may provide. Assisted by her closest friends, Josie accepts the responsibility of finding a "forever home" for Hamlet, in the process developing self-confidence and learning to appreciate her family and neighbors. Thanks to Josie and her friends, Hamlet, like Marty, is successfully rehomed in a safe and welcoming place. While Marty moves to a farm sanctuary, Hamlet makes her new home on a small hobby farm, and both pigs' relocations are close enough to their former homes that their friendships with their people can continue through frequent visits.

Like Lorenzo, Ruby Clyde in Almost Paradise is fatherless, and her irresponsible mother requires more care from Ruby Clyde than she can provide in return. When the story begins, Ruby Clyde and her mother are traveling in a camper, pursuing a get-rich scheme of her mother's unscrupulous and controlling boyfriend, known to Ruby Clyde as "the Catfish." After the three travelers steal Bunny, a young pig in a trained-animal circus in Hot Springs, Arkansas, the Catfish fumbles an armed robbery attempt. When he and Ruby Clyde's mother are arrested and taken into custody, Ruby Clyde and Bunny escape the police by hiding in the bushes. Like Marty and Hamlet, Bunny begins to accompany his human companion on walks, sleeps and snuggles with her in bed, and becomes a critical emotional support system in her troubled life. As she works through her complicated family problems, Ruby Clyde takes responsibility for finding Bunny a safe, comfortable, and permanent home with the kindly owner of the truck stop the Catfish once attempted to rob. Unlike Lorenzo and Josie, Ruby Clyde does not anticipate a continuing relationship with her pig at the end of the novel, but she feels secure in knowing she has satisfied his expectations by providing a safe and happy home where he can live out his natural life. She reports of their relational story's ending, "And that is how I left my pig. Under the big eye that had seen that whole part of my life, one that I would shortly leave behind. Bunny. Living at the Red Eye Truck Stop, where he would spend the rest of his days lolling in the mud by Frank's door and winking at cowboys who stopped for gas or food. No Cadillac, no bacon. Life had worked out for Circus God's pig" (p. 267).

The transformation of tragedy to happily-ever-after endings occurs in all of these novels when the young protagonists deliberately resist the overarching pork narrative of their time. In all three novels, the pigs' young caregivers are, like Isabel in The Water Gift and the Pig of the Pig, acutely aware that the rest of the world regards their friends as food. In Saving Marty, Lorenzo's mother defers to the pork story when she first sees her son cradling the baby pig and asks, "You know that's livestock, right?" (p. 23). Later, when she sees the relationship developing further between Lorenzo and Marty, she implicitly invokes this story again as a reminder of real-world conditions: "A pig for a friend?" (p. 53). At the story's outset, Lorenzo too accepts the pork story as the inevitable overarching narrative of his relationship with Marty. From the beginning of this relationship, he anticipates its sad ending: "Already I knew how bad it would hurt, the day he'd take that last walk up the ramp into Mom's truck for the auction" (pp. 16-17). Ruby Clyde in Almost Paradise similarly ponders a dismal future for Bunny and identifies with his hopeless story. With her father dead and her mother in jail, she sees herself, like Bunny, as a "stray" and muses, "If they put stray girls in the state orphanage, what did they do to stray pigs? Bacon, that's what" (p. 77). Josie, in The Unlikely Story of a Pig in the City, immediately sees a need to protect Hamlet from her own family's appetite. Surveying her parents and siblings at the breakfast table amid the smell of bacon the morning Hamlet arrives, Josie thinks, "If it were up to them, Hamlet would be ham - and that was her destiny if I didn't stand up for her" (p. 13). Lorenzo has similar worries about Marty's fate when the pig goes missing and is captured by a neighbor who, like Ben Stinchfield, regards pigs only as human food: “'He was roadside, no tags,' Mr. Taylor said. 'Finder's keepers. I'll send you some steaks'” (Griffin 2017, p. 93). 
The young humans in these stories all attain adulthood by preserving mutual trust in their friendships with pigs. Within these friendships, the pigs are active agents too, not just offering companionship, entertainment, and emotional support, but taking active steps to sustain and deepen the trust, thereby placing relational demands on their young human friends. Of the three pigs, Marty plays the most active role in building a friendship with his human; near the end of the novel, he saves Lorenzo from an attacking dog (Saving Marty, p. 179). The other pig characters contribute to their relationships more subtly. At a low point in Josie's life, for example, Hamlet expresses empathy and follows through with action: "Hamlet climbed out of the basket and snuggled up next to me like she knew I needed a friend right now" (Unlikely Story, p. 184). Ruby Clyde takes similar pleasure and comfort in Bunny's responsiveness to her feelings, and early on, when she and Bunny are hiding from the police, she suspects the pig has dragged her into the bushes with his makeshift leash to protect her from capture by the police.

The human-pig friendships in these novels thus prompt the human friends to ponder what it means for the pigs to be "better off" in the care of humans. Josie, deciphering Hamlet's wordless expectation of greater freedom than a city apartment can afford, decides that her responsibility is not, as she initially believed, to figure out how to keep Hamlet with her, but to find Hamlet a better place to live. Ruby Clyde, in transferring Bunny's care to a friend, similarly makes a moral decision on the grounds that "I had to do what was best for my pig" (Almost Paradise, p. 268). Lorenzo, although he knows that "wanting to spend time with him ... would stay strong in me for as long as he lived" (Saving Marty, p. 163), arranges for Marty to live apart from him, though close enough to continue the friendship.

Considering how their pig friends can be better off in human custody than on their own prompts the young protagonists in these stories to change their behavior along with their thinking. All of them credit their pigs with modeling a good-natured optimism that they begin to incorporate into their own human worldviews. Beyond this, friendship with a pig also leads both Ruby Clyde and Josie to question the morality of meat-eating in ways that had not occurred to them before. Early in her relationship with Bunny, for instance, a very hungry Ruby Clyde impulsively orders "Pancakes please, with bacon" and is immediately assailed by conscience: "I thought of Bunny and I got a stabbing pain. "Wait! No bacon" (Almost Paradise, p. 88). For Josie, in The Unlikely Story of a Pig in the City, friendship with a pig coincides with an experiment with vegetarianism.

The pig-people friendships in these novels, moreover, all involve an intimate physicality, as Robert's delight in Pinky's smell, her gaze, her smile, and her wagging tail in A Day No Pigs Would Die echoes through these more recent stories of pig-human friendship. When Ruby Clyde bids her final farewell to Bunny, for example, she seals the moment with an intimate embrace in which their interspecies identities seem to merge: "I kneeled down beside him and wrapped both arms around his neck. Our hearts beat together for a few brief moments, then I let go and stood up" (Almost Paradise, p. 266). Lorenzo, too, takes pleasure in the physicality of his friendship with Marty, and reflects on this as a transcendent experience: "I'd miss scratching the fur on the side of his neck, his chest. I'd feel his heart in my fingertips, in my arms, rising into my spirit" (Saving Marty, p. 163). This type of physical intimacy, common in stories of human relationships with dogs, is rare beyond the infant stage in real-world relational narratives of pigs and people today. Outside of fiction, the overwhelming majority of these relationships unfold in conditions of CAFOs where the pig-to-human ratio may average approximately 3000:1 (Genoways 2014, p. 196).

Like Pinky and the Pig of the Pig, the pigs in these young-adult novels inhabit fictional worlds where a categorical shift from food to friend is justified by pigs' intellectual and behavioral resemblance to dogs. Marty and Hamlet both play with tennis balls and learn to sit, fetch, roll over, play dead, and perform other tricks commonly associated with dogs. Like Babe, Marty even breaks the companion-species barrier by excelling in a competition intended for dogs-in this case, a dog race rather than a herding contest. In all three novels, the pigs sleep in the beds of their human companions and accompany them on outdoor rambles. Bunny, for instance, crosses into canine territory by keeping 
close to Ruby Clyde's heels and "trotting like a dog" (Almost Paradise, p. 123), an identity shift that other characters acknowledge by feeding Bunny peanut butter dog treats. Endowing pigs with qualities associated with dogs, the quintessential companion animal in most Western cultures, the novels naturalize the interpersonal friendships between young people and pigs, thereby facilitating pigs' escape from abstractions like "livestock" or "meat", to which Carol Adams (1998) attributes the moral erasure of food animals.

\section{Pig Stories, Pork Stories, and the Narrative Universe of the Anthropocene}

Publication of the novels in 2017 coincided with rising public doubts about the environmental sustainability of the CAFO model that steadily expands the environmental footprint of pig farming in the U.S. and elsewhere. That same year, Robert Gloss reported in If Pigs Could Talk (Gloss 2017) that a total of 115.4 million hogs were being slaughtered annually in the U.S., while the National Hog Farmer, a U.S. publication, reported that "all the major pork-producing countries want to grow their market footprint" (GlobalMegaProducer 2017). Simultaneously, scientists were attributing the unprecedented size of the hypoxic "dead zone" in the Gulf of Mexico to agricultural run-off from Midwestern U.S. states where hog-farming is most intensive (e.g., Eller 2018); public health groups were circulating concerns about hog CAFOs as potential breeding grounds for rapid swine flu virus evolution and transmission (e.g., Lantro et al. 2016); and citizens in leading pork-production states, North Carolina and Iowa, were bringing suits against large-scale pork producers for compromised air quality and declining property values near the facilities (e.g., Blythe 2018; Cooke 2018). In this discursive environment, young-adult friendship stories about pigs foreground a relational interspecies morality that challenges prevailing terms of our human covenant with the ultimate food animal: The domesticated pig.

As moral tales, these stories of interspecies friendship encourage readers to question certain human privileges in the domestication deal we have struck with pigs. When humans regard captive pigs through the relational lens of friendship, an entirely different set of expectations appear much more reasonable than when pigs are instrumentally defined as industrial farm products. Indeed, the interspecies relationships of the young-adult characters reveal to them the welfare expectations of pigs that Temple Grandin's research on environmental enrichment began to uncover in the mid 1980s, including demands for social bonds, intellectual stimulation, and the expression of innate behaviors such as rooting and nesting (e.g., Grandin 1988, 1989).

While animal welfare science exposes unmet expectations of pigs in CAFO settings and recommends ways to mitigate the suffering of pigs in these conditions, the 2017 novels mention factory farming only obliquely if at all. If the fictional pigs face an imminent threat of slaughter, it is individualized or only vaguely conceived. Marty, when captured by ne'er-do-well neighbors who intend to kill and butcher him on the spot, has the closest brush with the meat market, but his story never mentions the industrial-sized norms of pig slaughter today, nor does it probe the living conditions of pigs in the industrial pork-production system. Josie, in The Unlikely Story of a Pig in the City, suspects that a man responding to her classified ad about a home for Hamlet is somehow connected to pork production, but she quickly blocks this development in Hamlet's biography by rejecting the man's offer.

Rather than mirroring the reality of today's pork industry, these novels, in selecting pigs as a particular embodiment of interspecies friend for readers to imagine, emphasize particular friendship virtues for emulation. The young humans who befriend pigs in these stories must rapidly adjust their own expectations of the friendship to accommodate the ever-increasing welfare demands of the pigs. They are all at some point in their stories nonplussed by their cute little pigs' rapidly growing size and appetite; they all struggle to meet their pigs' good-natured insistence on ever more food, space, and freedom; and they all choose to preserve the interspecies trust at the heart of the relationship on terms largely set by the pigs. 
By rejecting the option to terminate the relationship as it gets harder to maintain, the young protagonists disrupt anthropocentric norms and incline to a biocentric worldview anchored in relational understandings of the other-than-human world. In honoring improbable interspecies friendships despite social and economic pressures to abandon them, they come of age by refusing to regard a non-human life as disposable. Choosing to continue the interspecies plural narration of "my pig and I" or "we," the characters affirm the affective and aesthetic interspecies ties of biophilia and carry them forward to adult understanding.

Persistence in interspecies friendships with beings that typically inspire revulsion and contempt is a different kind of virtue than persistence in friendships with conventional companion animals. It calls for a shifting of categories and a rearrangement of values, and it represents a step toward a deep-caring biophilic conservation ethic of the sort E.O. Wilson and others prescribe for this moment on the planet. These novels do not simply invite young readers to imagine an unlikely friendship story, they also invite them to imagine a world in which young people like themselves can choose to continue these friendship stories in defiance of their "inevitable" endings. In this, they anticipate the moral questions humanity must ponder in the time of the sixth great extinction on Earth-questions of whether and how we will continue in the company of other Earthlings.

I have argued that the books in this study contribute to a moral education project that current conditions demand. Massive losses of biodiversity across the Earth herald the dawning of the Age of Loneliness and illuminate the need for an ethical orientation that values interspecies relationships and prompts human action to preserve them. In befriending food animals and rejecting the inevitability of their slaughter and consumption, the young human protagonists demonstrate what one of my reviewers described as "a willingness to fall back into a natural order," an acceptance of humanity as a part of, rather than apart from, the rest of nature. To be sure, the books fail to address the enormous scope and reach of the CAFO system in which millions of characters like Marty, Hamlet, and Bunny complete their brief and "unnatural" lives. To introduce the real-world conditions of factory farming would dampen the happy ending of any of these stories by conjuring a backdrop of massive tragedy. Clearly, much work remains in the task of reintegrating humanity with the rest of nature throughout the world, but I contend that novels such as these are laying the groundwork for the work remaining. Moral philosophers Gruen and Chris (1997) assert that "exploring the positive political implications of our intimate relationships with companion animals" is an important extension of the feminist credo, "the personal is political." They argue that logics of detachment and domination (12) that govern human relationships with nature "obscure "a great deal of knowledge concerning our continuity with nature" (12). Contending, like Wilson, that environmentalism must transcend these rationales and engage other ways of knowing, they express concern that environmentalists in particular have inadequately credited the power of interspecies intimacy as a source of moral knowledge. They propose that interspecies friendships constitute an "ethical starting point" for bridging the moral distance that prevents us from caring what happens to other species. Interspecies friendships, they submit, enable "radical transformations of our orientations toward nature" (20) by providing access to biocentric moral reasoning that anthropocentrism so deftly excludes from the human worldview.

One way the pork industry maintains control of the pig-human narrative of relationship is by keeping pigs away from the human worldview. When humans are denied entry to slaughterhouses and CAFOs for whatever reasons-biosecurity, food safety, product quality control, or concerns about property damage and economic loss_-pigs become what moral philosophers know as "distant others" for whom it is difficult to care. Imagining a real, live pig as a companion is as close as many young readers and video viewers today will ever get to interacting with life in its porcine form, but books like the 2017 coming-of-age novels help them make this approach. Imagining pigs as friends instead of food or vermin is an exercise that can have long-term effects if it finds reinforcement in the surrounding narrative environment. The industrial pork story is a powerful force in this environment, but its narrative monopoly is challenged by the texts I have presented and a host of others, including pig stories coming from a proliferation of farmed-animal sanctuaries, from the social media presence of 
"celebrity pigs" like Esther the Wonder Pig and Priscilla, and from tourists in the Bahamas who tell stories about swimming with the "Pigs of Paradise." When, at last, it becomes clear that we cannot continue to live on this Earth while maintaining our present relationship with pigs, such alternative narratives of people and pigs together may persuade us that although we no longer eat them, pigs are companions we do not want to lose as we advance into the Age of Loneliness.

Author Contributions: Mary Trachsel was solely responsible for all research and writing.

Funding: This research received no external funding.

Conflicts of Interest: None.

\section{References}

Adams, Carol. 1998. The Sexual Politics of Meat. New York: Continuum.

American Library Association. 1990-1999. 100 Most Frequently Challenged Books: 1990-1999. Available online: ala.org/advocacy/bbooks/100-most-frequently-challenged-books-1990-1999 (accessed on 30 March 2019).

Arditte, Rita. 1980. Feminism and Science. In Science and Liberation. Edited by Rita Arditte, Pat Brennan and Steve Cravak. Boston: South End Press.

Associated Press. 2018. Led by Iowa, US Sets Pig Record with 73.5 Million Animals. In Des Moines Register. New York: Associated Press.

Blythe, Ann. 2018. Jury Awards More than $\$ 25$ Million to Duplin County Couple in Hog-Farm Case. The News \& Observer, June 29.

Bowling, Jill, and Martin Brian. 1985. Science: A Masculine Disorder? Science and Public Policy 12: 308-16.

Briggs-Martin, Jacqueline. 2003. The Water Gift and the Pig of the Pig. New York: Houghton-Mifflin.

Brooks, Walter. 1927-1958. Freddy the Pig Series. New York: Alfred A. Knopf.

Budiansky, Stephen. 1992. The Covenant of the Wild. New York: William Morrow.

Cooke, Christina. 2018. Iowa Residents to Sue the State Over Air Emissions from Industrial Hogfarms. CivilEats, May 16.

DiCamillo, Kate. 2005-2009. Mercy Watson Series. Somerville: Candlewick.

Eller, Donnelle. 2018. Iowa Nitrogen Pollution in the Water is Getting Worse, Despite Hundreds of Millions of Dollars in Spending, Study Shows. Des Moines Register, June 22.

Fausto-Sterling, Anne. 1981. Women and Science. Women's Studies International Quarterly 4: 41-58. [CrossRef]

Fee, Elizabeth. 1982. A Feminist Critique of Scientific Objectivity. Science for People 14: 5-8.

Foer, Jonathan Safran. 2009. Eating Animals. New York: Little Brown.

Genoways, Ted. 2014. The Chain. New York: Harper.

GlobalMegaProducer. 2017. Competition to Supply World with Pork is Heating Up. National Hog Farmer, June 7.

Gloss, Robert. 2017. If Pigs Could Talk. Lexington: Robert Gloss.

Grandin, Temple. 1988. Environmental Enrichment for Confinement Pigs. Hinsdale: Livestock Conservation Institute.

Grandin, Temple. 1989. Effect of Rearing Environment and Environmental Enrichment on the Behavior and Neural Development of Young Pigs. Doctoral dissertation, University of Illinois, Champaign, IL, USA.

Griffin, Paul. 2017. Saving Marty. New York: Dial.

Gruen, Lori, and Cuomo Chris. 1997. Animals, Intimacy \& Moral Distance. In Daring to be Good. Edited by Bar-On, Bat Ami and Ann Ferguson. New York: Routledge, pp. 129-42.

Herzog, Hal. 2010. Some We Love, Some We Hate, and Some We Eat. New York: Harper Collins.

Hochschild, Adam. 1994. That Paradigm of Porkers: Remembering Freddy the Pig. New York Times, May 22.

Jenkins, Steve, and Derek Walter. 2016. Esther the Wonder Pig. New York: Grand Central.

Joy, Melanie. 2010. Why We Love Dogs, Eat Pigs and Wear Cows. San Francisco: Conari.

Kendall, Jodi. 2017. The Unlikely Story of a Pig in the City. New York: Harper.

King-Smith, Dick. 1980. Pigs Might Fly. New York: Yearling.

King-Smith, Dick. 1983. Babe the Gallant Pig. New York: Penguin.

King-Smith, Dick. 1990. Ace: The Very Important Pig. New York: Yearling.

Kolbert, Elizabeth. 2014. The Sixth Extinction: An Unnatural History. New York: Henry Holt. 
Lantro, Paul, Kate Hoffman, Michael Höhle, Benjamin Anderson, and Gregory C. Gray. 2016. Are People Living Near Modern Swine Production Facilities at Increased Risk of Influenza Virus Infection? Clinical Infectious Diseases 63: 1558-63.

Leakey, Richard, and Roger Lewin. 1995. The Sixth Extinction: Patterns of Life and the Future of Mankind. New York: Anchor.

Leiss, William. 1994. The Domination of Nature. Montreal: McGill-Queens University Press. First published 1972.

Louv, Richard. 2005. Last Child in the Woods. Chapel Hill: Algonquin.

Louv, Richard. 2011. The Nature Principle. Chapel Hill: Algonquin.

Mellis, Sue, and Barbara Davidson. 1990. The Born-Again Carnivore. London: Optima.

Mizelle, Brett. 2011. Pig. London: Reaktion Books.

Montgomery, Sy. 2016. The Good, Good Pig. New York: Random House.

National Pork Board. 2014. 2015-2020 Strategic Plan: Pigs, People, Planet. Available online: porkcdn.s3. amazonaws.com/sites/all/files/documents/nationalporkboardstragegicplan.pdf (accessed on 30 March 2019).

Nobis, Nathan. 2009. The 'Babe Vegetarians': Bioethics, Animal Minds \& Moral Methodology. In Bioethics at the Movies. Baltimore: Johns Hopkins UP, pp. 56-73.

O'Connor, Amy. 1995. When Pigs Fly. Vegetarian Times 220: 16.

Peck, Robert. 1972. A Day No Pigs Would Die. New York: Random House.

Shofner, Corabel. 2017. Almost Paradise. New York: Farrar, Straus, Giroux.

Walker, Margaret Urban. 2007. Moral Understandings. Oxford: Oxford University Press.

White, Elwyn Brooks. 1952. Charlotte's Web. New York: Harper.

Whyman, Matt. 2018. The Unexpected Genius of Pigs. New York: Harper Collins.

Wilson, Edward O. 1984. Biophilia. Cambridge: Harvard UP.

Wilson, Edward O. 2002. The Future of Life. New York: Random House.

Wilson, Edward O. 2016. Half-Earth. New York: Norton.

(C) 2019 by the author. Licensee MDPI, Basel, Switzerland. This article is an open access article distributed under the terms and conditions of the Creative Commons Attribution (CC BY) license (http://creativecommons.org/licenses/by/4.0/). 


\title{
Article \\ Chattel or Child: The Liminal Status of Companion Animals in Society and Law
}

\author{
Nicole R. Pallotta \\ Animal Legal Defense Fund, Portland, OR 97214, USA; npallotta@aldf.org \\ Received: 28 March 2019; Accepted: 16 May 2019; Published: 23 May 2019
}

\begin{abstract}
Companion animals in the U.S. are increasingly regarded as members of the family with whom one may share a strong emotional bond. However, despite an evolving social construction that has elevated their status in the dominant culture, companion animals lack meaningful legal rights, and "family member" is a provisional status that can be dissolved at will based on the discretion of the sole rights-holder in the relationship: the human owner. Because they are still defined within the U.S. legal system as property, it is a common lament within the animal protection movement that the law has not kept pace with the emergent cultural perception of companion animals as family or best friends who may occupy a significant place in one's constellation of interpersonal relationships. But how divergent are the laws that govern our treatment of companion animals from prevailing social norms? This article examines current trends in animal law and society to shed light on this question. I find that while a new family member cultural status is emerging for companion animals in the U.S., their legal status as property is a countervailing force, enabling contradictory practices and beliefs that construct animals as expendable. The fact that their cultural status is in flux in turn reinforces their status under the law. I conclude with proposed policy reforms that will facilitate the integration of companion animals into society as true rather than rhetorical family members.
\end{abstract}

Keywords: animal law; human-animal bond; legal status of companion animals; animal protection

\section{Introduction}

The existing legal framework as it applies to companion animals is situated within the larger context of two evolving social trends: (1) the development of the field of animal law in the U.S. and (2) the emergent (in some cultural milieus, dominant) cultural perception of pets as surrogate family members. While animal law is a relatively new field (Tischler 2012), ethical concern for nonhuman animals ${ }^{1}$ has a long history, the tenor of which has changed over time depending upon several factors, including prevailing social norms, changing economic conditions, scientific advances regarding the cognitive and emotional capacities of animals, and the emergence of the animal protection movement. That concern is amplified and perhaps at its most contradictory when it comes to those animals who are culturally defined as "pets" (and more recently, "companions"), and hence are afforded greater legal protections than other biologically similar, but differentially socially constructed, categories of animals (e.g., farmed animals, who are often excluded from the protection of cruelty laws).

Americans increasingly report a strong emotional bond with their companion animals and regard them as family members. According to a 2015 Harris Poll, more than three in five Americans (62 percent) have at least one pet, with the highest percentage being among the two youngest generations tested, Millennials and Gen Xers. ${ }^{2}$ Ninety-five percent of these respondents considered

I will mostly refer to nonhuman animals as "animals" in the following discussion.

2 As of 2018, Millennials comprise the largest segment of companion animal owners at 72-73 percent (TD Ameritrade 2018, American Pet Products Association 2017-2018). 
their animal to be a member of the family-a number that has increased each year the question was asked (Shannon-Missal 2015). A 2018 Harris Poll revealed a majority of Americans with pets (69 percent) see them as "family members," and one in five (23 percent) see their pets as children. Compared to other generations, millennials view their pets as "starter children" as they delay having kids of their own (Lane 2018).

This shifting cultural norm is reflected in current trends in animal law. For example, in recent years, there has been an increase in custody battles over beloved companion animals, which can become as bitter and emotionally fraught as those involving human children (American Academy of Matrimonial Lawyers 2014). Additionally, more people are making provisions for their companion animals in their wills, and there are now "pet trust" laws on the books in all 50 states. Victims of domestic violence often delay leaving an abusive partner out of fear the abuser will harm or kill a cherished animal companion as a means of control and retaliation. Unfortunately, this fear is often justified (Ascione et al. 2007; Hardesty et al. 2013). Compounding this difficulty is the fact that most domestic violence shelters have "no-pets" policies. As their role in the family continues to become more significant, animals are increasingly entangled in the web of domestic violence and abuse, and several states now have laws allowing domestic violence protective orders to include pets. ${ }^{3}$ For better or worse, companion animals occupy surrogate positions in the family.

This is a provisional status, however-a fact that is brought into stark relief when we consider the staggering number of pets put to death every year in animal shelter facilities because they are no longer anyone's family member, or perhaps never were. "Family member" is a conditional position that confers life or death on individual animals, and this status can be dissolved at any time based entirely on the discretion of the sole rights-holder in the relationship: the human owner. ${ }^{4}$

A common lament in the animal protection movement is that the law has not kept pace with changing societal norms regarding animals. ${ }^{5}$ Proponents of this view cite the fact that despite the shifting social understanding of companion animals as family members, they are still defined as property under the law. As noted in a Harvard Magazine article on the evolution of animal law:

As the role of animals in society and the economy has evolved, and more recently, as scientific research has revealed more about animals' cognitive abilities and social development, public sensibility has changed dramatically, often leaving outmoded law behind. As a result, lawyers worldwide have begun searching for innovative ways to make animals more visible to the law: strengthening and enacting new anti-cruelty statutes, improving basic protections, and, in some more radical cases, challenging animals' property status itself in an effort to grant them fundamental rights. (Feinberg 2016)

In the case of companion animals, the outmoded aspect of law most frequently cited is that their legal status as property is inconsistent with their current cultural status as quasi-family members. This is a compelling assertion that jibes with the intuitive sense and quotidian experience of animal advocates, who are more likely to associate with likeminded others whose companion animals are true family members and best friends. Further lending credence to this claim, the law is an inherently conservative social institution that tends to follow rather than lead social change. ${ }^{6}$ But how divergent are the laws that govern our treatment of companion animals from prevailing social norms?

3 I use the terms "companion animal" and "pet" interchangeably in this article to reflect their common usage in law and culture.

4 Though some argue that animal cruelty laws constitute a weak form of rights (e.g., Sunstein 2003), outside of that narrow context and within the domain of the family, the human owner is the only party with appreciable rights, holding virtually absolute power to control every aspect of the companion animal's life-within the very broad bounds of permissible conduct under cruelty laws.

5 See "Animals' Legal Status" (Animal Legal Defense Fund n.d.a).

6 However, this is not always the case. For example, the Williams Institute found a dramatic drop in anti-gay attitudes in states that legalized marriage equality. Following changes in these laws, " $47 \%$ of residents who initially were opposed changed their minds" (Flores and Barclay 2015). Other studies have found that smoking bans changed behavior and social norms (Satterlund et al. 2012; Orbell et al. 2009). 
In examining in this question, I will first give a brief overview of the current status of animals in the U.S legal system. I will then highlight areas in society and law in which the status of animals as family members is gaining increasing recognition. Next, I will consider the contradictory social construction of companion animals as expendable, which challenges the common belief that their status as family members is ascendant and even normative. I will then revisit the legal status of animals and how it enables practices and beliefs that construct companion animals as disposable commodities in contrast to family members. In conclusion, I will propose policy reforms that will facilitate the integration of companion animals into society as true rather than rhetorical family members. ${ }^{7}$

\section{The Legal Status of Companion Animals}

If the law is a reflection of norms and values in society ${ }^{8}$ (Hessler 2010), what does the body of laws that pertains to companion animals tell us about our relationship with them? While the dominant cultural narrative regarding pets has transformed over the last century from a utilitarian view to one in which they are primarily defined as surrogate family members, this colloquial designation has little bearing within the legal system. ${ }^{9}$ Companion animals are still defined as property under the law.

In a discussion of the legal status of companion animals in Australia, White articulates the uneasy relationship between the conceptualization of animals as both property and family member:

On the one hand, opinion surveys and an emerging body of sociological literature suggest that our relationship with companion animals is vested with such meaning and significance that they have come to be regarded by many as 'members of the family'. Consistent with this significance, animal welfare law is more stringent in protecting the interests of companion animals than it is for any other category of animal. On the other hand, significant numbers of companion animals are relinquished to animal shelters every year, where the fate of many, especially kittens and cats, is death. Although animal welfare law criminalises the abandonment of companion animals, it provides no sanction for the relinquishment of companion animals to animal shelters. (White 2009, p. 2)

This dual status places companion animals in a liminal space in society, elevated above both mere chattel and other animals who are not defined as companions, ${ }^{10}$ yet uniquely vulnerable due to both their legal classification as property and inconsistencies in the cultural narrative that defines them as family.

\subsection{Animals as Property}

Their legal status as property means that courts have been reluctant to recognize that animals have meaningful legal rights, including standing, or the ability to bring a lawsuit to court (Cassuto et al. 2006; Magnotti 2006). Standing is an obstacle for animal advocates as well, who in civil cases typically

7 Animals have intrinsic worth and deserve basic legal protections regardless of their cultural status or value to humans. However, the focus of this article is on culture and the law, specifically: (1) the current gap between the legal and cultural perception of companion animals, (2) the fact that the cultural perception itself is not uniform but in a state of flux, and (3) the law's role in enabling one or the other competing status to prevail. Since the relationship between social norms and the law is multi-directional, the cultural status that becomes ascendant will in turn affect companion animals' treatment within the legal system.

8 And, in cases where there is ambiguity or room for interpretation, judges tend to make decisions based on dominant social norms and values (Liebman 2011).

9 Likewise, although some jurisdictions have passed legislation changing the status of pet owners to "guardians," these resolutions are symbolic and have no legal bearing. For this reason, I also use the term "owner," which is the way this relationship is characterized under the law.

10 Despite their legal status as property and the shortcomings of animal cruelty laws, companion animals are easily the most protected class of animals in society. Farmed animals are among the least. The majority of modern state animal cruelty laws expressly exempt either farmed animals or standard agricultural practices. These include "accepted," "common," "customary," or "normal" farming practices, which are defined by the industry itself (Wolfson and Sullivan 2004). In addition to the limitations in current law, prosecutions for the abuse of farmed animals are vanishingly rare. 
have to show that they themselves have suffered an injury as a result of an animal being abused (Morrish 2014; Sunstein 2000). Direct harm to the animal is rarely enough to bring a lawsuit and criminal animal cruelty laws, with some exceptions, can only be enforced by prosecutors, not private citizens (Reppy 2005). ${ }^{11}$

Because it has been a persistent barrier to protecting them from exploitation and other harmful conduct, many legal experts believe that animals must be removed from the category of property in order to be granted fundamental legal rights (Francione 2004; Wise 2010). ${ }^{12}$ Because, in some important ways, the U.S. legal system contains a fundamental distinction between "things" and "persons" (Wise 2000), one way to change the status of animals as property is for them to be redefined as legal persons-which do not have to be human beings. In the U.S., both corporations and ships are defined as persons for limited legal purposes. Outside the U.S., an Argentinian court in 2016 declared a chimpanzee named Cecilia to be a "non-human legal person" in its decision that she should be released from a zoo and sent to a sanctuary. ${ }^{13}$ And in 2018, a high court in India granted animals the status of "legal entity/legal person." ${ }^{14}$ In recent years, rivers in New Zealand and India have also been granted personhood. ${ }^{15}$

Although animals are defined as property in the legal system, there are ways the law treats them distinctly from other, inanimate property. Chief among these are animal cruelty laws. You will not be punished for kicking your coffee table or trashing your bicycle. However, if you abuse your dog or cat, you may be in violation of the law and could be prosecuted for animal cruelty. The existence of animal cruelty laws indicates companion animals are fundamentally different from other types of property, and such laws may be construed as conferring limited rights; however, they do not nullify animals' designation as property. ${ }^{16}$

\subsection{Animal Cruelty Laws}

Despite their legal status as property, the history of animal law in the U.S. as it pertains to companion animals has reflected an increasing concern with their welfare. The first anti-cruelty laws were passed in New York and Massachusetts in the 1820s and 1830s, but no enforcement agencies existed until the founding of the American Society for the Prevention of Cruelty to Animals (ASPCA) in 1866 by Henry Bergh, who recognized that passing legislation was not enough to help animals—dedicated

11 In addition to criminal laws to protect animals from cruelty, North Carolina (Chapter 19A) and Oregon (ORS 105.597) provide civil remedies that allow private citizens to sue to stop animal cruelty in limited instances.

12 Other legal scholars, while noting shortcomings in the law, believe animals receive sufficient benefits from human ownership that the property category should be retained, though it could be revised in a way to provide better legal protections for animals (Cupp 2016; Sunstein 2003; Favre 2000, 2010; Epstein 2002).

13 For more on this decision, including a link to the translated ruling in English, see the Nonhuman Rights Project's media release, "The NhRP Praises Argentine Court's Recognition of Captive Chimpanzee's Legal Personhood and Rights:" https://www.nonhumanrights.org/media-center/12-5-16-media-release-nhrp-praises-argentine-court-on-legalpersonhood-for-chimpanzee/.

14 Press Trust of India, "Animals are 'legal persons', all citizens their parents, orders Uttarakhand HC," India Today 4 July 2018. https:/www.indiatoday.in/india/story/animals-are-legal-persons-all-citizens-their-parents-orders-uttarakhand-hc1277559-2018-07-04.

15 For an overview of decisions regarding river personhood and the legal rights of nature, see "Creating legal rights for rivers: lessons from Australia, New Zealand, and India" (O'Donnell and Talbot-Jones 2018. Ecology and Society 23(1):7)) and "Rights of Nature: Rivers That Can Stand in Court" (Cano Pecharroman 2018. Resources. 7(13)). In the U.S., on 26 February 2019, voters in Toledo, Ohio, approved a ballot measure to give legal rights to Lake Eerie, which would theoretically give the lake standing so that people could sue polluters on its behalf. The following day, a farmer filed a federal lawsuit challenging its constitutionality (Williams 2019). The new legislation, dubbed the Lake Eerie Bill of Rights, would establish "irrevocable rights for the Lake Erie Ecosystem to exist, flourish and naturally evolve, a right to a healthy environment for the residents of Toledo, and which elevates the rights of the community and its natural environment over powers claimed by certain corporations."

16 While animal cruelty laws differentiate animals from inanimate property in the legal system, it is interesting to note that property protection was one of the purposes of early versions of many animal cruelty statues, "which only criminalized conduct if it was directed at animals owned by others-it was not illegal to commit the same acts upon one's own animals or wild animals." Animal cruelty laws also have historically served as a type of "moral legislation," enforcing a code of behavior that says certain behaviors are immoral or socially unacceptable (Waisman et al. 2014, p. 71), rather than being motivated by concern for the animal him or herself. 
enforcement was also needed. ${ }^{17}$ Bergh's advocacy and high profile campaigns against animal cruelty were a catalyst, but the rapid creation of state and local humane agencies modeled on the ASPCA and enactment of animal protection legislation around the country signaled a societal shift in attitudes about animal welfare that was already underway (Finsen and Finsen 1994; Waisman et al. 2014, pp. 70-71).

As of 2014, all 50 states have a felony animal cruelty provision. However, under-enforcement is a persistent problem, due to issues such as limited prosecutorial resources and funding, the perception that animal abuse is not a serious crime, and lack of expertise in animal cruelty cases, which have unique challenges. Among these are forensic and evidentiary issues (the animal is both victim and evidence in cruelty cases), vagueness in the way many animal cruelty statutes are written, confusion over which agency or agencies are responsible for enforcement, lack of training of law enforcement officers on cruelty laws and animal care issues, potential costs of animal care and logistical complications involved with seizing multiple animals, and the fact that the animal victim cannot speak on their own behalf (Smith-Blackmore 2018; Ramsey 2014; Merck 2012; New Hampshire Governor's Commission on the Humane Treatment of Animals 2009; Animal Legal Defense Fund n.d.b). Even when animal cruelty laws are enforced, it is a common lament that those convicted of serious crimes against animals receive light sentences. ${ }^{18}$

This is changing, however. With increasing evidence and awareness of the connection between cruelty to animals and violence against humans (Nelson 2011; Linzey 2009; Arkow and Ascione 1998; Ascione and Lockwood 1997), there has been a cultural shift toward taking crimes against animals more seriously -if not for the animal's sake, then out of concern that animal abuse is a "gateway" crime that will lead to violence against humans in the future (National Sheriffs' Association 2018). ${ }^{19}$ However, beyond the concern that animal cruelty may be linked to other criminal or anti-social behavior, courts are increasingly recognizing animals themselves as crime victims (Animal Legal Defense Fund n.d.c; Cima 2014). ${ }^{20}$

\section{Societal and Legal Trends: Companion Animals as Family}

Despite the general trajectory of improvement in animal cruelty laws over the last 150 years, and a lively academic debate around the question of animal personhood, there have been few significant challenges mounted against the property status of an animal through U.S. courts until relatively recently. ${ }^{21}$ The shift in the dominant social construction of companion animals as family members with little to no corresponding erosion of their property status has led to mounting cultural tension

17 Organized efforts to protect children gained momentum during this time as well. Bergh also founded the first organization dedicated to child welfare, the New York Society for the Prevention of Cruelty to Children, eight years after he founded the ASPCA.

18 Not all animal advocates believe that enhanced criminal penalties and increased enforcement are positive trends. In Beyond Cages: Animal Law and Criminal Punishment (2019), law professor Justin Marceau argues that the animal protection movement's focus on "carceral animal law" has placed it at odds with other social justice movements, and that this focus may be detrimental to both humans and animals.

19 Though this narrative has had an impact on policy, and there is a correlation between animal abuse and other violent crimes, the available data does not support a predictive causal relationship (Marceau 2019).

20 For a discussion of the inherent speciesism of the discipline of victimology and suggestions for ways its theory and practice could be extended to include nonhuman suffering, see Flynn and Hall (2017). In two recent cases, State v. Nix and State v. Fessenden, the Oregon Supreme Court found that animals can be victims of a crime (Animal Legal Defense Fund 2014). In the former, the court rejected the defense's argument that property, which animals are under Oregon law, cannot be seen as crime victims (instead, the public or the owner would be the victim).

21 The Nonhuman Rights Project has in recent years mounted unique habeas corpus challenges on behalf of four chimpanzees and three elephants: "The world's first habeas corpus hearing on behalf of an elephant and the second habeas corpus hearing on behalf of a nonhuman animal in the US ... argued that Happy [an elephant], as an autonomous being, is a legal person with the fundamental right to bodily liberty protected by a common law writ of habeas corpus" (Choplin 2018). In 2018, the Animal Legal Defense Fund filed a unique lawsuit in Oregon on behalf of a severely neglected horse named Justice: "What makes this lawsuit unusual is that Justice [a horse] is named as the plaintiff ... If successful, this would be the first case to establish that animals have a right to sue their abusers" (Pallotta 2018a). And in 2012, People for the Ethical Treatment of Animals filed a lawsuit (ultimately unsuccessful) on behalf of five orcas against Seaworld for enslaving the orcas in violation of the Thirteenth Amendment of the U.S. Constitution, arguing the amendment's protections can extend to nonhuman animals (Kerr et al. 2013). 
and ambivalence about their place in society, which in turn has created confusion and inconsistency in law and policy issues affecting both companion animals and their human guardians, which I will discuss further below.

The following sections examine key areas of society and law that highlight the cultural status of companion animals as family members, followed by a discussion of countertrends that reinforce the notion that they are expendable. Contrasting these contradictory cultural currents raises questions about whether the popular perception of companion animals as valued family members in society is more myth than reality. I will then return to the legal status of animals to examine its relationship to these dual social constructions.

\subsection{Financial Expenditures on Companion Animals}

Looking at societal trends, the amount of money Americans spend on companion animals has steadily increased over time. ${ }^{22}$ According to the American Pet Products Association (APPA), an industry trade group that tracks consumer spending in this area, Americans spent about 70 billion on companion animals in 2017, which was a 32 percent increase from 2012's total of 53 billion. When the APPA first began tracking spending on pets in 1994, total spending was 28 billion (adjusted for inflation). ${ }^{23}$

Despite attention-grabbing media stories about outrageously "pampered pets," 24 which suggest lavish lifestyles are the new normal for dogs and cats ${ }^{25}$ in U.S. households, most of the money spent on companion animals covers basics such as food, medicine, and veterinary care. Following food, the largest overall expense is veterinary care. Although "luxuries" do not represent the bulk of spending on companion animals, spending has also increased in categories such as daycare, toys, and treats. ${ }^{26}$

The strongest growth sectors of consumer spending on companion animals include services such as grooming and dog and cat sitting (APPA 2018). The pet health insurance industry is also rapidly growing, as both the cost of veterinary care and insurance options have increased, ${ }^{27}$ expanding from one provider in 1997 to 12 companies in North America today. In the span of one year, from 2016 to 2017, the total number of companion animals insured in the U.S. and Canada increased 17 percent (North American Pet Health Insurance Association 2018).

Though the media displays a fondness for stories about affluent individuals who spend large sums of money on luxuries for their companion animals, ${ }^{28}$ with the implication this behavior is depraved and wasteful, individuals experiencing poverty or homelessness often put their companion animals'

22 While spending may also have increased over time for inanimate objects such as houses and cars, and their associated maintenance, expenditures on companion animals tend to go toward enhancing their well-being rather than their utility (since the vast majority of companion animals are not working animals).

23 Included in this figure are live purchases of pets themselves, so the data does not indicate expenditures exclusively for an animals' well-being. The categories used by the APPA include (listed from highest to lowest expenditures for dogs) in 2017: Food; Supplies/OTC Medicine; Vet Care; Live Animal Purchases; and Other Pet Services, which include grooming and boarding (https://www.americanpetproducts.org/press_industrytrends.asp).

24 See "How the Rich Pamper Their Pets" (Mann 2008): http://www.forbes.com/2008/01/14/pets-pampering-celebs-oped-cx pma_0115pets.html; "For Owners, It's More Than Puppy Love" (Warren 2010): https://www.chicagotribune.com/lifestyles/ctxpm-2010-04-29-sc-fash-0429-ellen-pet-shopping-column-story.html; "Pet 'Parents' Pamper to the Extreme" (Benbow 2013): https://www.usatoday.com/story/news/nation/2013/07/21/pet-parents-pamper-to-the-extreme/2572021/.

25 While they are the most common companion animals, dogs and cats also are typically included in the legal definition of "pet" or "companion animal," whereas other species included in that category vary by state and locality (as does which animals are included in the legal definition of "animal" itself). However, many other species are kept as companion animals. For a discussion of inherent challenges to the well-being of specific species kept as pets, see Run, Spot, Run: The Ethics of Keeping Pets (Pierce 2016.)

26 "These 4 Charts Explain Exactly How Americans Spend \$52 Billion on Our Pets in a Year" (Thompson 2013): http://www.theatlantic.com/business/archive/2013/02/these-4-charts-explain-exactly-how-americans-spend-52-billionon-our-pets-in-a-year/273446/.

27 "The Dog Maxed Out My Credit Card" (Bounds 2011), available online: http://www.wsj.com/articles/ SB10001424052970204394804577011824160591082; “Who Suffers Most from the Rising Cost of Veterinary Care?” (Dale 2013): http://veterinarybusiness.dvm360.com/who-suffers-most-rising-cost-veterinary-care.

28 "The Problem of Pampered Pets" (Berger 2012): http://www.seattlemag.com/article/problem-pampered-pets; “When Nothing is Too Fancy for Fido" (Griggs 2013): http://www.cnn.com/2013/04/15/living/pampered-pets/. 
needs ahead of their own (Irvine 2013). Exaggerated media stories about spoiled pets frame the overall increase in societal spending on companion animals as a problem, indicative of anthropomorphism run amok. But stories of those in difficult circumstances who nevertheless find a way to provide for their companion animals - even if it means going hungry themselves ${ }^{29}$-receive less attention. It is relatively easy for the media to make fun of affluent people spending their discretionary income on something "frivolous." It is more difficult to ridicule an elderly person living on a fixed income or someone who is homeless and struggling to feed his or her animal, not out of a misguided allocation of financial resources, but out of genuine love and concern for their well-being. In recognition that some clients were feeding their meals to their companion animals, Meals on Wheels in recent years has launched efforts to assist local chapters in establishing programs to also donate food and services to help seniors care for their companion animals (Meals on Wheels 2016).

In the category of municipal spending, there has also been a significant increase on dog parks, which began to appear in the 1980s in response to the widespread adoption of leash laws and have proliferated in recent years (Krohe 2005). The fastest growing urban parks are off-leash dog parks, which have grown by 89 percent since 2007 (The Trust for Public Land 2016). This increasing demand reflects demographic shifts, as households with dogs now outnumber those with children. According to Peter Harnik of The Trust for Public Land, which compiles annual data on the nation's largest urban parks, "there was a playground movement 100 years ago. In the last 15 to 20 years, it's these off-leash dog areas. There's a tremendous upsurge in demand and love for them" (El Nasser 2011).

\subsection{Companion Animal Loss and Grief}

In perhaps the most profound example of the significance of companion animals as family members and best friends, it is now well-documented that losing a cherished animal companion can be as devastating as losing an important human relationship. People can experience intense grief over the death of a beloved animal (Toray 2004; Carmack 2003; Cowels 1985; Adrian et al. 2009).

Although the death of a companion animal can still result in experiences of "disenfranchised grief," in which the emotions associated with a loss are not recognized by society as legitimate (Doka 1989), ${ }^{30}$ the societal acceptance of companion animals as legitimate objects of grief has become more widespread alongside greater recognition of the strong bond that can be forged with an animal, and the proportionate impact that can result from loss. ${ }^{31}$

Companion animals who are treated as family members become woven into the fabric of daily life. In addition to the primary loss of the relationship, those who lose an animal companion may also lose a reliable source of social support, stability, and the daily routine involved in caring for the animal. In addition to a constant presence and source of routine and stability, dogs and cats provide dependable companionship, the perception of unconditional love, and consistent emotional support to their human caregivers-all of which can complicate the grieving process (Pallotta 2016).

In recent decades, mounting research about the human-animal bond has raised awareness within the mental health field about the potential impact of companion animal loss, and both self-help books

29 "After Meals on Wheels volunteers noticed a growing number of clients giving their food away to their furry friends, they started working with shelters and other pet groups to add free pet food to their meal deliveries." (Associated Press 2013, "Meals on Wheels helps feed pets of seniors, disabled." CBS News, 25 December 2013.)

30 This is communicated through dismissive phrases like "it's only an animal."

31 While this has been the general trend, there are still areas in which the loss of a companion animal may be socially unrecognized. For example, workplace bereavement policies that include companion animals are uncommon, and support or acknowledgement from friends and family may be lacking. Public rituals such as funerals are also less normative, though some do hold ceremonies celebrating the life of a companion animal and mourning their death. For a general discussion of this subject, see Mourning Animals: Rituals and Practices Surrounding Animal Deaths (DeMello 2016). A cultural deficit with regard to mourning and death in the U.S. is not limited to companion animals, though it is starker here. Some have noted that upon the death of a close human family member, Americans are often allowed to take only a week or two off work (or in some cases, just a few days), with the fact that the person is still grieving often left unacknowledged by others outside a very short period of expected mourning (Noel and Blair 2000). 
and support groups addressing this issue have proliferated (Pash 2015; Clements et al. 2003). This growing recognition has informed policy debates about the legal issues mentioned in later sections, such as damages available upon wrongful death of companion animals. Of course, support groups and grief counseling are not necessary for other forms of property.

\subsection{Domestic Violence and Animal Abuse}

Despite their legal status as property, the important place of companion animals in the family-for better or worse-is highlighted when they, along with other vulnerable members of the family, become targets of domestic violence. Although domestic violence is a social problem and not a positive trend, the fact that companion animals are frequently targets of abuse clearly demonstrates their place in the family: companion animals are part of the abuser's web of dominance and control. Companion animals occupy the bottom rung of the power hierarchy within the family, having less autonomy even than children (and indeed are sometimes abused by children). Additionally, threatening to harm a partner's cherished animal companion is a common tactic of control and manipulation used by abusers to terrorize and coerce the victimized partner to stay. If she leaves, the abuser may harm or kill her animal as a means of retaliation. Therefore, many victims of domestic violence delay leaving an abusive relationship because they have no safe place for their animals (Ascione et al. 1997). A 2017 study showed that 56 percent of women in domestic violence shelters had delayed their escape out of fear for their animals and a desire to protect them (Barrett et al. 2017).

Victims of domestic violence often find themselves in this difficult position because most domestic violence shelters have "no-pets" policies. Such policies are one of the many indicators of the context-dependence and inherent instability of the family member role. The social construction of this relationship_-so real in the context of the micro-world shared by the animal and his or her family (which may comprise just one person) —encounters obdurate limits in the wider society, in the form of exclusionary law and policy that defines animals differently. "No-pets" policies in shelters, rental housing, and other lodging significantly reduce options for a victim who wants to flee an abuser but not leave her animal in harm's way.

"No-pets" policies also disproportionately affect poor and working-class women who lack resources to pay higher prices for pet-friendly apartments or lodging, and thus find themselves with far fewer options for safe spaces-unless they leave behind their animal, who may not only be in grave danger if their human companion leaves, but who also may be a primary source of comfort, support, and emotional stability for the victim.

This is one of the many areas where a companion animal may be considered a family member in one context but not another. The risk of being entangled in the web of domestic violence also demonstrates that being part of the family does not mean that an animal will be treated well. Here, the tension between property and family member is also evident:

Complicating the issue is the fact that animals are considered property in all 50 states. If an abuser refuses to relinquish a pet and the pet is not listed on a temporary restraining order (TRO), police and even courts are often reluctant to get involved in what is usually considered a marital property dispute. As a result, abusers have been known to threaten to harm or kill a pet if a victim does not return to the home, or dismiss criminal charges or restraining orders against an abuser. In one such case, a woman suddenly left a domestic violence shelter after she received pictures of her husband cutting her dog's ears off with garden shears. Another woman was forced to watch as her husband shot and killed her dog in front of her young son. (Ramsey et al. 2010, p. 17)

However, in light of mounting research that shows a connection between animal abuse and violence against humans (Nelson 2011), there have been positive legal and policy developments in this area. To address the problem that most domestic violence shelters do not allow animals, "safe havens for pets" programs have been created to provide emergency care for companion animals while their 
guardians stay at a domestic violence shelter or other temporary housing situation that does not allow pets (Nelson 2011; Ramsey et al. 2010).

A positive trend in the legal system reflecting awareness of the link between family violence and animal abuse - and the recognition that animals are more than mere property - is the increase in legislation allowing courts to include animals in domestic violence protective orders. In 2006, Maine enacted the first statute that specifically allowed judges to include companion animals in protection orders issued against domestic abusers (Ramsey et al. 2010), and other states have followed suit. As of 2018, 32 states had such laws on the books.

In 2018, further progress was made with the passage of the bipartisan Pet and Women Safety (PAWS) Act, which expands existing federal domestic violence protections (which aid in the enforcement of state-issued protection orders) to include companion animals. Among other provisions, the PAWS Act broadens the definition of stalking under the criminal code "to include conduct that causes a person to experience a reasonable fear of death or serious bodily injury to his or her pet." 32 The new law also urges states that have not already done so to adopt legislation allowing courts to include animals in domestic violence protective orders. In recognition of the problem posed by "no-pets" policies in domestic violence shelters, the PAWS Act also establishes a grant program to assist programs that address the shelter and housing needs of domestic violence victims with companion animals.

Due to a growing awareness of the co-occurrence of child abuse and animal cruelty (Nelson 2011), there has also been an increase in laws mandating or permitting cross-reporting. ${ }^{33}$ The fact that animal abuse has also been found in many homes under investigation for child abuse further demonstrates companion animals' vulnerable place in the family.

Increased societal awareness of the connection between animal cruelty and violence against humans has led to the former being taken more seriously by law enforcement. In a relatively new development, programs dedicated to investigating and prosecuting animal cruelty and neglect are rapidly appearing in district attorneys' offices and police departments across the country.

The first unit of this kind, the Los Angeles County Animal Cruelty Prosecution Program, was created in 2007 and became a model for others around the country. It followed the formation two years earlier of the Los Angeles Police Department (LAPD) Animal Cruelty Task Force. In supporting the measure to create the task force, LAPD officials "cited studies finding that animal abusers were often involved in other crimes such as drug trafficking, child abuse and domestic violence" (Leonard 2009).

In the decade since, similar units have been established in other jurisdictions. In 2016, the state attorney for Orange and Osceola Counties in central Florida created a dedicated animal cruelty unit, consisting of attorneys who volunteered to take additional casework and develop expertise in the applicable laws and special challenges involved in prosecuting animal cruelty cases. In 2016, the Queens County district attorney created an Animal Cruelty Investigations Unit, which was the first of its kind in New York City. The previous year, the district attorney for Fresno County, California, established an Animal Cruelty Unit dedicated to addressing animal abuse cases, in part to break the connection between animal abuse and human violence (County of Fresno 2015). Also, in 2015, Virginia's attorney general created the nation's first statewide Animal Law Unit. Most recently, in 2018, the San Diego County District Attorney's Office launched an Animal Prosecution Unit to provide investigative support and dedicated expertise in animal cruelty cases-fittingly, it is housed within the DA's Family Protection Division (County of San Diego, Office of the District Attorney 2018).

While concern that abusing animals will lead to other crimes has helped bring awareness to the problem of animal cruelty, it is also being taken more seriously as a crime in itself-not because

32 H.R.909 - Pet and Women Safety Act of 2017-115th Congress (2017-2018).

33 See "Table of Veterinary Reporting Requirement and Immunity Laws" (Wisch 2017): https://www.animallaw.info/topic/ table-veterinary-reporting-requirement-and-immunity-laws). 
animal abuse portends other criminal behavior but because it is wrong to abuse an animal, full stop. ${ }^{34}$ This is evident in the abovementioned trend to recognize animals as crime victims. In addition, in 2016, the FBI added "animal cruelty" as a distinct category to the agency's Uniform Crime Report, a nationwide crime-reporting system, which enabled crimes against animals to be tracked for the first time. Prior to this, animal cruelty offenses were lumped into a miscellaneous "all other offenses" category (Federal Bureau of Investigation 2016).

\subsection{Companion Animal Custody}

Custody battles over companion animals have been on the rise in recent years and represent another arena in which the legal landscape has been shifting toward increased recognition that animals are more than property. A 2014 survey found that more than 25 percent of matrimonial lawyers had seen an increase in pet custody cases during the previous five years, and 22 percent noted that courts are more frequently allowing these cases (American Academy of Matrimonial Lawyers 2014).

Although custody disputes of this nature reflect the important role of animals in people's lives and families, courts typically resolve these disputes based on one criterion: the property status of the animal, or who the more rightful owner is. This is determined by who purchased the animal or paid her adoption fee, typically without regard to quality of life factors such as who is the more involved caregiver, has a closer bond with the animal, takes the animal to the vet, spends more time with the animal, or does most of the purchasing of food, treats, and toys. In short, courts generally are not required to consider an animal's well-being or treat her differently from other marital property that must be fairly divided in a divorce.

Because the legal dispensation of companion animals in divorce has historically been decided no differently than the division of other jointly owned material assets (such as furniture, vehicles, and other inanimate objects), the word "custody" is a misnomer in these cases. In legal terms, they are about property distribution. For those who share their lives with animals, the prospect of a judge treating a cherished animal in the same manner as a car or toaster often seems odd, even for attorneys:

The very first question posed to me as a new member of the bar some twenty-six years ago was, "When a couple divorce, who gets custody of the dog?" Bewildered, I sought the advice of a more experienced attorney. She supposed that custody of the dog would be awarded to the individual who fed it, walked it, groomed it, took it to the veterinarian, and got up at 6:30 A.M. to let it out. In short, she described a primary caregiver test that, although not much articulated then, has come to be a force majeure in child custody cases. Her answer, though logical, was almost certainly incorrect. A deep divide separates the attitude of most families, who view pets as family members, from the law, which regards pets as chattels, not different in kind from household property such as a sofa or coffee cup. For years courts have successfully straddled this divide; however, the influx of pet ownership has shifted the issue of pet custody to the forefront. (Britton 2006, pp. 1-2)

In addition to receiving heightened media attention in recent years, ${ }^{35}$ the issue of companion animal custody has been evolving in the legal system. A growing number of courts have acknowledged that people have a special relationship with their companion animals that is different from their relationship with other types of inanimate property.

However, while judges have the discretion to consider a companion animal's interests in divorce proceedings-and some have done so-the legal norm is still to adhere to a strict property analysis.

34 It is again worth noting, the vast majority of these cruelty laws apply only to animals defined as companions. The same acts that would be considered torture, abuse, or neglect in the case of a companion animal would usually not be prosecuted-or in most cases even deemed illegal-if done to a farmed animal.

35 Glamour Magazine recently ran a series about millennial divorce, which included the article, "Your Marriage Is Over-Who Gets Custody of the Pets?" (Wranke 2018). 
Some have speculated that reticence to employ a "best interests" standard, which is the norm in child custody cases, in cases involving companion animals is due to judges' reluctance to appear as activists (Mele 2017). Also, in cases where courts have strayed from a strict property analysis-for example, in awarding joint custody or visitation for an animal-appellate courts have sometimes overturned the decision, on the grounds that the lower court lacked authority because animals are property. The court's reasoning in Bennett v. Bennett (1995) is typical:

While a dog may be considered by many to be a member of the family, under Florida law, animals are considered to be personal property. There is no authority which provides for a trial court to grant custody or visitation pertaining to personal property. While several states have given family pets special status within dissolution proceedings, we think such a course is unwise. Determinations as to custody and visitation lead to continuing enforcement and supervision problems (as evidenced by the proceedings in the instant case). Our courts are overwhelmed with the supervision of custody, visitation, and support matters related to the protection of our children. We cannot undertake the same responsibility as to animals. While the trial judge was endeavoring to reach a fair solution under difficult circumstances, we must reverse the order relating to the custody of "Roddy," and remand for the trial court to award the animal pursuant to the dictates of the equitable distribution statute. (quoted in Waisman et al. 2014, p. 552)

Although in the U.S. the most common approach to determining custody of companion animals has been a strict property analysis, a number of courts have deviated from that standard in favor of a "best interests of the animal" test (Rook 2014). However, this remains a murky legal area. Recently, though, a new legislative trend empowering courts to take the well-being of animals into account in divorce proceedings has emerged. These new laws are accelerating the shift already underway that is challenging the strict property paradigm as applied to animals in custody cases.

In 2016, with a groundbreaking amendment to its divorce law, Alaska became the first state to require judges to take into account the "well-being of the animal" in custody disputes. This law was the first of its kind in the U.S. to expressly require courts to address the interests of companion animals when deciding how to assign ownership in divorce and dissolution proceedings. It was also the first to explicitly allow joint ownership of a companion animal. In 2017, Illinois enacted a similar law (Pallotta 2017b, 2018b). California followed suit in 2018 with a weaker version that authorizes, rather than requires, courts to take into account the care of companion animals. Despite it being permissive rather than mandatory, California's custody law still provides important guidance to courts in distinguishing companion animals from other forms of property, where before there was none.

\subsection{Tort Law and Valuation of Companion Animals in Wrongful Death}

As financial spending on companion animals' well-being has increased, a related question arises: what is their value in civil lawsuits if wrongfully injured or killed? Because animals are legally defined as personal property, the worth of a companion animal is generally restricted to his or her market value (typically the animals' purchase price or adoption fee). This is a limiting factor when we consider whether the legal status of companion animals has kept pace with their increasing importance in society.

Although in tort cases involving humans, such as medical malpractice, the court may consider an individual's pain and suffering, when an animal is wrongfully injured or killed-for example, in cases of veterinary malpractice-there is no legal mechanism to redress their pain and suffering because they are generally not considered "persons" under the law. Therefore, tort lawsuits involving companion animals typically must show the owner has been harmed and address the loss suffered by the human.

Three common types of tort cases include personal injury, injury to property, and injury to others with whom the law recognizes a close relationship. While the wrongful death of a companion animal does not constitute a personal injury (except in rare cases involving service animals, whom courts have 
conceptualized as being extensions of the human ${ }^{36}$ ), both of the latter two may be used to describe the wrongful death of a companion animal. Generally, non-economic damages are not recoverable for injury to property but can be recoverable for injury to another party with whom the law recognizes a close relationship.

Some have argued that, despite their classification as property, it is more sensible to treat cases where a companion animal is wrongfully killed as "wrongful death" rather than "destruction of property" cases (Martin 2011, p. 939). This legal theory also better reflects the relationship many people have with their companion animal, as "people do not plan memorial services, or invest in serious medical treatment for their books or lawnmowers" (Hessler 2007).

Most people who consider their animal to be part of the family would balk at the idea of placing a dollar value on their life, as they would with a human being. But this is the legal remedy available in such cases, and it can be a confusing area of law when it comes to companion animals. It is beyond the scope of this paper to attempt a succinct overview of this "muddled, but evolving, area of the law" (Frasch et al. 2011, p. 142), but for purposes of this discussion, although there have been some exceptions, companion animals' designation as personal property has meant non-economic damages, such as for loss of companionship or emotional distress, are generally not available in cases of wrongful injury or death of an animal. Additionally, compensatory damages to cover economic losses such as veterinary bills are typically limited to the animal's "fair market value."

Market value is calculated using economic factors such as purchase price, special training, pedigree, and age of the animal. If an animal is negligently injured or killed, using the fair market value standard, an owner would be eligible to recover the amount for which the animal could have been sold on the open market. So, if your animal is a purebred for whom you paid thousands of dollars, you could potentially recover that purchase cost. However, if you adopted your mixed breed dog from a shelter, his or her economic worth would be minimal, especially if the animal were older. The market value standard only allows recovery for the cost to "replace" that animal (as with other types of property) and does not take into account the value of the special relationship that may exist with that unique animal. Most courts have been unwilling to see beyond the traditional notion of "market value" for the loss of a pet, despite their evolving social status (Favre 2003).

Many companion animals have little monetary worth using a strict economic analysis, and replacing him or her with another animal of the same age and physical characteristics would strike most animal guardians as absurd as the suggestion that a child could be replaced by having another. Yet requests to add "sentimental value" or "loss of companionship" to the calculation of actual value of an animal companion to the owner have typically been denied by the courts. Although in a narrow set of circumstances, some courts and legislatures have allowed non-economic damages in lawsuits involving harm to companion animals, the general rule is that companion animal owners are not allowed to recover for mental or emotional distress due to their animal's injury, because these damages are not allowed in claims for damage to property (Seps 2010, p. 1345).

Although courts sometimes express remorse and empathy for animals and their owners, they routinely declare that their hands are tied by common law. In Rabideau v. City of Racine, the court said "we are uncomfortable with the law's cold characterization of a dog as mere 'property," yet proceeded to use this characterization in its ruling, claiming it must apply the "established legal doctrine" (Seps 2010, p. 1347). In this 2001 case, where an owner sued for negligent infliction of emotional distress after a police officer shot her dog, the court further elaborated:

36 For example, in the case In the Matter of Lillian Kline, no. A-1788-95T5 (N.J. Super. Ct. App. Div. 12 July 1996), a service dog's owner was permitted recovery under New Jersey's crime victim compensation law although it was her service dog and not herself who was attacked by teenagers throwing stones; Ms. Kline was not injured and in fact witnessed the attack from inside her home. In allowing recovery, the court concluded "in view of the function of the dog as a veritable extension of the appellant's own body, an injury to the dog is tantamount to an injury to the appellant's person." The court went on to analogize a trained service dog to an artificial limb (Waisman et al. 2014, pp. 525-26). 
Labeling a dog "property" fails to describe the value human beings place upon the companionship that they enjoy with the dog. A companion dog is not a fungible item, equivalent to other items of personal property. A companion dog is not a living room sofa or dining room furniture. This term inadequately and inaccurately describes the relationship between a human and a dog ... Nevertheless, the law characterizes the dog as personal property ... to the extent this opinion uses the term "property" in describing how humans value the dogs they live with, it is done only as means of applying established legal doctrine to the facts of this case. (quoted in Waisman et al. 2014, pp. 171-72)

From a policy perspective, some have argued that adding broad emotion-based damages for companion animals would increase the cost of veterinary care and other companion animal services due to increased liability (Goldberg 2013). In addition to the purported limits of established legal doctrine, courts (including the above) have also employed slippery slope concerns about "opening the floodgates of litigation" to justify decisions to not include animals in the sphere of close family relationships eligible for recovery of noneconomic damages. Thus, although the court in Rabideau v. City of Racine sympathized with the notion that animals are more than mere property, it nevertheless determined that "since emotional distress cases are limited to a closed set of close family members, pets cannot fit into that category" and held that "allowing emotional distress claims by a pet's human companion enter[s] a field that has no sensible or just stopping point"” (Schwartz and Laird 2006, p. 255).

This highlights an interesting question in considering the place of companion animals in tort law. How do we conceptualize the human-companion animal relationship: are they best friends or family members? This makes a difference in cases of injury or death of humans, and the categories are not interchangeable.

Recovery of damages in cases of wrongful death or injury to a human tends to be restricted to spouses, parents, and children (and sometimes minor siblings). Many other close relationships are excluded. For example, damages are not typically available for the death of a best friend. Therefore, some legal experts note that expanding this area of tort law to include companion animals would "elevate" relationships with animals above other close human relationships that are not currently eligible to receive recovery for non-economic damages:

Another unintended consequence of expanding non-economic damages is the fact that human-animal relationships would be elevated above many human-human relationships, a truly bizarre result. Recovery for negligent infliction of emotional distress is generally limited to very close relationships, such as spouses, children, or parents ... Grandparents, aunts, fiancés, and friends generally cannot recover emotional distress damages, regardless of how close these individuals were with the deceased. Expanding non-economic damages to the human-animal relationship would deem it to be more important than those human-human relationships. (Cook and Hochstadt 2009, p. 35)

Other critics of expanding damages for the loss of an animal companion cite public policy considerations regarding potentially increased caseloads on already burdened courts. The "floodgates of litigation" concern is frequently raised in objection to efforts to expand legal protections for animals, or their status under the law. Although it is an oft-cited argument, whether expanding these remedies would in fact lead to excessive litigation is the subject of debate. Some experts argue that predictions of excessive recoveries, fraudulent claims, or a flood of litigation are a red herring — "theoretically unsound and empirically disproven" (Martin 2011, p. 256). Others point to Hawaii as a counterexample:

The "floodgates of litigation" concern would seem to be addressed by past history in Hawaii, a jurisdiction unique in the fact that for approximately 16 years recovery of emotional distress damages for harm to property was permitted. ... Throughout the entire 16 year period during which individuals could seek emotional distress damages for negligent harm to their companion animals ... [there was one] single published case on the issue and 
there is no commentary in the literature regarding an onslaught of animal injury cases.

(Frasch et al. 2011, p. 111)

It is worth noting that the Hawaii statute (which has since been abolished-though not as a result of litigation over companion animals ${ }^{37}$ ) addressed damage to property, yet still allowed recovery for mental distress. This highlights the viability of disparate approaches in this area. While a "wrongful death" claim may more accurately reflect the relationship between a caregiver and his dog, abolishing the property status of companion animals or redefining them as "family members" in the common law or legislature is not necessary to allow for recovery of damages beyond fair market value in tort law. This informs the wider debate over whether the abolition of animals' property status is the best (or only) path forward to securing greater protections and recognition of their interests under the law.

Beyond unwillingness to elevate the status of animals in the legal system, it is also important to note that courts have shown a general reluctance to award damages for mental pain and suffering-not just in cases involving animals. And as noted above, the category of humans who can recover damages for emotional distress or loss of companionship is usually quite circumscribed and limited to close family relationships. Best friends, roommates, unmarried partners, and many others are typically excluded from making these claims, regardless of how close or family-like their relationship is.

Yet, some courts have begun to stray from the traditional treatment of animals as property in these cases and consider them more as "family-like persons" (Seps 2010). Although damages that have been awarded for non-economic harm such as emotional distress and loss of companionship have often been minimal, some animal law experts predict "as the human/companion animal bond is increasingly being recognized in society and in the courts, awards in the future [will] more accurately reflect this evolution" (Frasch et al. 2011, p. 104).

\subsection{Wills and Trusts for Companion Animals}

Interest among guardians in providing for their companion animals in the event of the guardian's death or incapacitation is not a new phenomenon. The legal recognition of such arrangements, however, is a more recent development. In the past, owners frequently encountered legal obstacles when attempting to provide for the care of their animals through a will or trust, but recent changes in the law authorizing what are commonly called "pet trusts" represent a significant shift in this area (Aflatooni 2011; Hirschfeld 2007).

Pet trusts are distinct from bequeathing an animal to another person as property in a will. Trusts provide a sum of money to a designated caregiver and can include specific instructions pertaining to exercise, recreation, veterinary visits, diet, and other aspects of care for a companion animal. Until recently, most states did not formally allow trusts for animals-which means that although a person could create one, they were unenforceable if challenged:

Under traditional trusts and estate law, a pet owner could do little to ensure that their animal would be provided for properly after the owner's death. Those who did attempt to create some sort of "trust," ran into legal problems because animals are considered a type of property and the pet could not legally be a beneficiary to a trust. (American Veterinary Medical Association 2018)

37 "Years later, as part of sweeping tort reform prompted by the numerous property damage claims after a hurricane, the state legislature statutorily abolished emotional distress claims arising solely from damage to property" (Frasch et al. 2011, p. 111). 
However, this area of law has evolved relatively quickly in response to changing social norms. ${ }^{38}$ With the addition of Minnesota in 2016, all 50 states and the District of Columbia now have pet trust laws on their books, enabling owners to create legally sanctioned and enforceable arrangements for the care and maintenance of their animal companion.

Pet trust statutes, like animal cruelty statutes, are among the few areas of law that vividly distinguish companion animals from ordinary property. Some have argued it therefore follows that the wrongful "destruction" of companion animals (as in tort cases discussed above) should be compensated differently than the destruction of other property (Martin 2011, p. 951). However, as discussed in the preceding section, this is not typically the case. Whether that is primarily due to courts' inflexible view of animals as property or reflects an unwillingness to expand tort law generally (or both) is subject to debate.

It should be noted that, despite general shifts in societal norms regarding animals, efforts to elevate their status in the legal system is not universally perceived as a positive turn. For some, it is a cause for alarm. Obvious dissenters include industries that profit from animal exploitation, but even constituencies that serve animals have competing interests that provoke disagreement about trends in animal law. For example, the American Veterinary Medical Association (AVMA) has opposed legislation that it perceives could be harmful to the veterinary profession and to the professional and financial interests of its members (for example, recovery of non-economic damages in veterinary malpractice cases). Industry front groups that feign interest in defending animals' interests (e.g., the National Animal Interest Alliance ${ }^{39}$ ) also actively lobby against even modest animal protection reforms and oppose any efforts to elevate the legal status of animals in defense of owners' absolute right over their "property."

\section{Countertrends: Companion Animals as Expendable}

The previous sections underscored areas of society and law where the emerging status of companion animals as family members is beginning to be recognized. Although there has been some improvement in the legal system, with courts and legislatures recognizing that companion animals are distinct from other types of property, animals are in many ways still treated as property under the law. Therefore, the argument that the legal system has not kept pace with changing social norms or advances in cognitive ethology has merit. But how disparate are the dual frameworks of animals as family and animals as property? And can they comfortably and coherently coexist?

Although companion animals receive the most legal protections of all animals in the U.S., significant limitations exist even within this relatively privileged class when it comes to treatment under the law. Similarly, when we take a closer look at the cultural construction of companion animals as family members, contradictions emerge, revealing a status in flux.

\subsection{Family According to Whom?}

A number of opinion polls have demonstrated the importance of companion animals in people's lives. For example, the Harris Poll cited above found that 95 percent of pet owners considered their animal to be a family member in 2015, up from 88 percent in 2007. The American Pet Products Association (APPA) annual survey, which reports similar findings, is also cited frequently in media reports about the special status of pets (APPA 2018).

38 In addition, despite the unique and nontraditional characteristics of pet trusts, they have earned widespread acceptance and been adopted relatively quickly compared to other novel types of trusts (Vokolek 2008).

39 The National Animal Interest Alliance is an industry-funded lobbying organization for animal commerce and agribusiness based in Portland, Oregon. Board members "representing breeding, agribusiness, hunting, horse racing, rodeos, circuses and vivisection industries appear to be so concerned about 'animal rights extremism' that virtually any attempt at humane advocacy falls neatly into this category" (The Center for Media \& Democracy 2011, https://www.sourcewatch.org/index.php/ National_Animal_Interest_Alliance). 
Those are just the metaphorical tip of the iceberg with regard to polls indicating that people's relationship with their animal companions more closely approximates that of a close friend or family member than property. Here, I will include just a small sample. The Pew Research Center found that 85 percent of dog owners and 78 percent of cat owners consider their pet to be a member of the family (Pew Research Center 2006). In a 2018 survey commissioned by Mercure, a dog-friendly chain of hotels, 53 percent of the 2000 people polled said they preferred spending time with their pet than with a human companion (Bailey 2018). An online survey of 1166 American dog owners conducted by dog food manufacturer Beneful found that "nearly all American dog owners surveyed consider their beloved pups a part of their family (97 percent) and one of their best friends (93 percent)" (Purina 2016). In an online survey of dog owners conducted by Kelton Global, 83 percent consider their dog to be their best friend (Kelton Global 2017). An earlier study found that 99 percent of pet owners consider their pets family members (Voith 1985). Surveys of pet owner attitudes conducted by the American Animal Hospital Association (AAHA) found that 83 percent refer to themselves as their animal's mom or dad (AAHA 2001) and half would prefer their dog (40 percent) or cat (10 percent) as their only companion if stranded on a desert island (AAHA 2004). Finally, genogram drawings in which they are asked to sketch their important family members have revealed that young children consider their companion animals to be part of the family (Walsh 2009).

The Kelton poll mentioned above also found that adult Americans perceive a change in the status and treatment of companion animals since they were children:

It appears that in the minds of the Americans who responded to the survey, dogs are becoming more important as family members, particularly as children. Most recognize that this represents a change in attitude since nearly $60 \%$ believe that their dogs are currently more important in their lives than were the dogs that they had during their childhood days. Two out of three also feel that they are more caring and treat their pet dogs better than did their mother and father. (Coren 2011)

Despite the general finding that people who own companion animals say they are family members, opinion polls are limited in what they can tell us, simply because what people say in polls (or in casual conversations) and what they do in real life are not always the same. Additionally, not all polls are conducted in a scientific manner. Though there may be a cultural truth underlying such surveys, the statistics they yield can be suspect.

It is something you say. Everybody says it. "Pets are part of the family!" is a mantra of the media, the pet industry, and even the academic veterinary literature ... So, I dug in a little and tried to track down where the " $90 \%$ of pets are family" data came from. This sound bite-and that's really all it is_-comes from an online survey of 1200 pet owners, conducted by the American Pet Products Association-so, basically a marketing survey done on people who purchase pet products. This does not count as "data." (Pierce 2015)

In addition, many dogs are kept as guard, breeding, or yard dogs, rather than companions. These owners might not be reached by—or may choose not to respond to-marketing or other online surveys asking about the family status of animals. Further, people who own companion animals but do not treat them like family are likely underrepresented in convenience samples drawn from companion animal-centric settings such as vet hospitals or dog parks.

Though reliable quantitative data may be limited, qualitative studies incorporating ethnography, participant observation, and interviews have repeatedly demonstrated the importance of companion animals in people's lives (Brooks et al. 2018; Reisbig et al. 2017; Charles 2016; Brooks et al. 2016, 2018; Irvine 2013; Maharaj and Haney 2014; Cavanaugh et al. 2008). However, broad conclusions are typically limited when looking at qualitative studies, which tend to use smaller sample sizes, case studies, or a particular social setting to focus on describing and understanding specific experiences and social phenomena, rather than counting and measuring large-scale numerical data. 
In addition, sites where participants are recruited for qualitative studies can introduce a self-selection bias. For example, a study that recruited participants from among clients at a large urban veterinary hospital found that 85 percent considered their animals to be family members (Cohen 2002). However, their presence at the vet hospital already marks these respondents as potentially more responsible animal caregivers than the general population of those who own pets.

Due to the limitations inherent in both qualitative and quantitative research, and because the underlying questions driving each tend to be different, a combination of both methodologies yields the richest insights about social phenomena like the meaning of companion animals in people's lives. Qualitative studies can provide deep insights about meaning attribution and interpretation that cannot be captured through quantitative methods, which, when conducted properly, can provide a "big picture" snapshot of larger populations and broad trends through statistics that are generalizable.

However, the lack of reliable data about companion animals as family members-and deeper questions, such as what that term means to those who agree with such a statement-highlights a central question: how widespread is the family member conceptualization, really? And, a more troubling question: What proportion of those who claim their animals are family members actually treat them as such, with the care and respect befitting such a status? ${ }^{40}$

\subsection{Provisional Status as Family}

All social science research has limitations because social phenomena are messy. People notoriously hold and employ contradictory beliefs, attitudes, and actions simultaneously. Even the most scientifically solid surveys cannot accurately predict human behavior, for the simple fact that reported attitudes and actual behavior often diverge. People who call their dog or cat a family member now may still get rid of them in the future. I wrote the following on my personal blog in 2009, around the time I began seriously thinking about this issue, particularly in the context of the cultural trope of "unconditional love" as attributed to companion animals:

What got me started thinking about this most recently was an ad I saw on the Portland Craigslist. I never go on the "pets" section of CL, but I was looking for something specific and while there I was surprised and depressed to see all the "free to good home" ads (surprised because for some reason I thought CL disallowed this type of listing, but apparently they only prohibit sales of animals). Out of curiosity, I clicked on a listing that advertised a free pair of Weimaraners. The ad showed a picture of two dogs, a mother and son, and contained a story about how the owner had fallen on rough times during the recent "economic storm" and could no longer keep these cherished family members. After a few paragraphs detailing the charms of the breed and of these two dogs in particular, the person giving her dogs away had the gall to list as a requirement that the new owner love them "unconditionally." Holy shit-are you kidding me? (Pallotta 2009)

Pierce articulates a similar sentiment via a notable encounter she relayed in Psychology Today:

The other day, I was with my two dogs, Maya and Bella, at one my local parks. I was throwing the ball for Bella and letting Maya nibble on grass. Maya started barking at a woman walking past. I apologized for Maya's rude behavior-she doesn't always follow the conventions of human etiquette - and the woman was very nice and said "Don't worry about it. I'm a dog person." She went on to tell me about a Manchester Terrier she had had and how much she had adored the dog. She said that watching Bella chase reminded her of him; and she

40 An obvious parallel with humans in the family comes to mind. It is certainly not the case that all human family members are treated well, so bestowing care and respect is not a necessary prerequisite for a sincere attribution of family status. Vulnerable members of the family such as children are particularly susceptible to maltreatment. But whether society recognizes certain behaviors as abuse when it comes to animals-e.g., less obvious forms of neglect and lack of consideration for animals' needs versus overt acts of cruelty-is another question. 
pressed her hands over her heart, in an "I love you" sign. And she told me and how her little terrier was obsessed with balls. He would stand at the top of the stairs and drop the ball and watch it bounce all the way down; then retrieve the ball and do it again. Then she said, "I got rid of him when I moved." On the outside, I kept a poker face and said something trite like "That's too bad." And inside, I'm thinking to myself, WTF? This dog is part of your family and when you move you just get rid of him? Now, I know this sounds just as judgmental as hell, but seriously: what does "pets are family" really mean? (Pierce 2015)

While the status of animals as family members has gained cultural legitimacy, do the majority of Americans accept and live by this definition in their daily lives? Or do animal advocates see what they want to see, and what is reflected in our homes? A casual glance at popular media may suggest that pet pampering and anthropomorphism have run amok and that we have entered a new era in which companion animals are treated as well as children. And the fact is, some people do both cherish and respect their animal companions and try to give them the best possible life within the confines of an anthropocentric society.

Yet, the fact remains that "pet as family" is a vulnerable status that can be removed at will. Obviously, no other family member relationship can be so easily dissolved. Even divorce (which involves a voluntary relationship) is a legal process involving the state, and parents are typically not allowed to drop their children off at a shelter facility. And in cases of estranged siblings or parents, where a choice is made to sever the relationship socially, these relationships are still recognized by law (although the specific legal definitions of these kinship relationships vary by state).

While the everyday understanding of animals as kin is not a new phenomenon (Charles 2014), it is a more recent development that people have begun to openly include their pets as part of the family (Irvine and Cilia 2017). However, the fact remains that multi-species kinship and a post-human family model have yet to be recognized by the law.

The provisional cultural status of family intersects with the legal status of animals. The fact that animals, as property, lack fundamental legal rights reinforces the precarious and often ephemeral nature of their position in the family, which can be eliminated by the more powerful members at any time. The termination of pseudo-family privileges can have dire, at times fatal, consequences for companion animals who find themselves without a home. ${ }^{41}$

The term "flexible personhood" captures the limits, inconsistencies, and potentially fleeting nature of animals' place in the human family:

Pets are treated as loving and loved members of the family, very similar to small children. At the same time, long-term ethnographic research reveals that many loving relationships with animals do not endure: when life changes and unexpected situations pose obstacles to the human-animal love, the people involved may redefine or terminate it. Pets are treated as "flexible persons" or "emotional commodities"; they are loved and incorporated into human lives but can at any moment be demoted and moved outside of the home and the family. (Shir-Vertesh 2012, p. 420)

\subsection{Culture Shift or Cultural Myth? Animal Neglect and Commodification}

As we have seen, family member status for dogs and cats is not backed by the force of law. However, neither is this status supported by social consensus. Although the social construction of animals as family has undoubtedly gained traction in recent years, it is not the only framework through which to view the position of companion animals in society. Pierce (2016) argues the cultural narrative of "pets as family" is just that-a narrative, used to support the multibillion dollar-per-year pet industry, built on a fragile foundation of inflated statistics derived from leading questions, with little underlying substance.

41 Approximately 1.5 million (or 23 percent) of the 6.5 million dogs and cat who enter shelters in the U.S. are killed (ASPCA n.d.). 
Sure, some pets truly are woven into the lives of families, but Pierce is saying that when we hear the pets-as-family line over and over, we should recognize it for what it is: a hard corporate sell. As she puts it: "A gossamer pets-are-family thread has been woven over the ugliness." What ugliness? According to Pierce: At least 30 percent of "family" dogs and cats never once visit a veterinarian; lonely animals are confined to tanks, cages or backyards; high rates of animal cancer occur owing to the poor quality of pet food; people have sex with animals, including at animal brothels, at shocking rates; the "euthanasia" deaths carried out at animal shelters often aren't good deaths at all. (quoted in King 2016)

Returning to the crux of the matter, "companion animal as family member" is an elective and in many cases temporary status which is bestowed at the will and whim of a benevolent powerholder upon a vulnerable animal who lacks practical autonomy ${ }^{42}$ and cannot define (or leave) the situation. This provisional status can be taken away just as easily as it was given. For the small subset of animal guardians who not only consider their animals to be family but also care for them responsibly by addressing their species-specific needs, the inclusion of an animal into the family is meaningful and significant. Still others proclaim their animal is family while letting them languish in neglectful circumstances, which may be intentional or the result of careless ignorance on the part of the caregiver. Either way, the outcome is the same for the animal trapped in a home where their basic physical and psychological needs are ignored.

A parallel could be drawn to human children, who also have minimal autonomy and agency in the family and are susceptible to neglect and mistreatment. Not all families are functional and not all parents, whether "pet parents" or parents of human children, are responsible and good. Yet, a fundamental difference is that the human child's agency will build over time as they grow up; one day they can leave the situation. An animal never will, unless she runs away ${ }^{43}$-which is obviously a perilous proposition for an animal in human society. She could be hit by a car, put to death in a shelter facility, picked up by someone who will abuse or harm her, die of starvation, and the list goes on. A companion animal without an owner is extremely vulnerable-though depending on the owner, the animal may be in just as much danger under their "protection," which is precisely the double-edged sword of property status.

Countless dogs - fundamentally social creatures who crave companionship — are forced to live in isolation and/or at the end of a chain, rope, or other containment device. Although some jurisdictions have enacted laws against tethering, they are under-enforced. Or an owner may unchain their dog to comply with a tether law, only to leave them isolated in a small pen instead, which does not address the animal welfare issue (Logan 2013). Animal neglect is usually a misdemeanor that can be difficult to charge because animal neglect laws mandate only minimal standards of care-typically just requiring an animal has water, food, and some form of shelter from the elements. ${ }^{44}$ These laws do not address important social, physical, and psychological needs such as companionship, exercise, and mental stimulation. ${ }^{45}$ Further, while overt abuse is more evident, there is not a social consensus on what

42 I use "practical autonomy" to distinguish between the capacity for autonomy (which companion animals possess) and the ability to exercise it in a meaningful way (which they are generally denied).

43 This is not to suggest that animals cannot have agency. My point is that they lack practical autonomy, which is to say the barriers in human society to companion and captive animals exercising their agency to any significant degree are so many and so total as to render the concept essentially meaningless. However, although their efforts are almost always thwarted by those in power (i.e., any human in the situation), animals do resist. For more on this issue, see Fear of the Animal Planet: The Hidden History of Animal Resistance (Hribal 2010) and "Animals Without Borders: Farmed Animal Resistance in New York" (Colling 2014).

44 See "Animal Neglect Facts: State and Local Law" (Animal Legal Defense Fund n.d.d).

45 While the discussion here has been mostly limited to dogs and cats, other species of animals are bought and sold as pets, and they most likely suffer even more. According to Pierce: "When kept alone in a small cage, birds, small mammals like hamsters and gerbils, and even fish lack adequate physical, mental, and social stimulation. Solitary confinement of human prisoners is considered a violation of basic human rights, yet this is essentially what we do to some of our pet animals" (quoted in King 2016). 
constitutes neglect. However, the more we learn about the mental and emotional capacities of animals and their ability to suffer psychologically, the clearer it becomes that many are enduring lives of quiet neglect.

Beyond the neglectful treatment of animals trapped in homes (or confined in yards) with people who ignore them or fail to attend to their needs, it is commonplace for healthy dogs and cats to be killed each day in shelter facilities due to lack of space and available homes. On the other hand, "no-kill" shelters are criticized for warehousing animals who do not have a realistic chance of being adopted and end up sentenced to life in substandard kennel conditions for years on end, which may prolong their suffering while they wait for a "forever home" that never comes. And owners still relinquish their companion animals for reasons that would seem nonsensical if applied to someone who was a true family member, such as moving, new family member (e.g., a baby), or correctable behavior issues. Doubtless some of these issues are exacerbated by social policy-for example, the difficulty and expense of finding rental housing that does not prohibit companion animals (notably, this practice is illegal in some jurisdictions outside the U.S.). However, the fact remains that in this sense, the treatment of dogs and cats in society is, unfortunately, exactly in sync with their property designation.

Also worth noting is that the overall increase in financial expenditures on companion animals discussed above does not tell the whole story. While many individuals who are not well-off make financial sacrifices to care for their companion animals, others abandon them in tough times. In 2014, USA Today reported an increase in owners choosing "economic euthanasia" for their animals as vet costs have risen:

At the Thomas Beath Veterinary Clinic in Fredericksburg, Va., two-thirds of the pets put to sleep every week are euthanized for economic reasons, clinic owners say. "I've never seen as many people lining up to turn over pets," says Kumpf, former executive director of the National Animal Control Association. "It's heart-wrenching to see so many people come through the door." (McGinnis and McElhaney 2014)

Further detracting from the pets as family narrative, despite the fact that many dogs and cats who enter shelter facilities are put to death, it is still legal to breed and sell them. ${ }^{46}$ That it is both legal and socially acceptable for animals to be bought and sold sharply highlights their property status and reinforces the attitude that they are disposable commodities. ${ }^{47}$

\section{4. "No-Pets" Policies}

As seen to tragic effect in disasters like Hurricane Katrina, ${ }^{48}$ guardians of companion animals are also prohibited from boarding public transit with their animals in the U.S. ${ }^{49}$ This is not the case globally.

46 Precise data is difficult to obtain, but some sources say approximately 670,000 dogs and 860,000 cats are put to death in shelters annually (ASPCA n.d.). Other estimates place that number higher, and calculate that 2.7 million of the 7.6 million animals who enter shelters annually in the U.S. are killed (Fox 2014).

47 A growing number of jurisdictions, including two states as of 2019 (Maryland and California), have enacted laws banning the retail sale of dogs and cats, which mandate that any animals sold in pet stores come from rescue agencies. The impetus for these laws is to combat puppy and kitten mills, and they still allow people to purchase animals from individual breeders. Even without retail sales bans, cities like Portland, San Francisco, New York City, and many others have made tremendous strides in reducing the killing of healthy, adoptable animals in shelter facilities. See https: //www.sfspca.org/who-we-are/successes (San Francisco-93\% live release rate); http://www.oregonhumane.org/resourcespublications/end-petlessness-more/ (Portland-98\% adoption rate; one of the best in the nation); http://www.nytimes.com/ 2016/01/21/nyregion/animal-adoptions-rise-amid-reforms-at-new-yorks-shelters.html (New York City-euthanasia rate is not as low as the former two cities but has drastically improved).

48 Hurricane Katrina, which devastated the Gulf Coast and especially the city of New Orleans in 2005, was a tragic background against which the tension between animals as family and animals as property was highlighted. During the storm, companion animals were not allowed on most rescue vehicles or in shelters. When ordered to leave their companion animals behind, many residents refused to evacuate. One survey found that 44 percent of the storm's human victims who chose not to evacuate did so because they were unwilling to abandon their animals (Fritz Institute 2006). Other residents were forcibly separated from their companion animals_some at gunpoint-by emergency responders.

49 This does not apply to designated service animals, who are allowed broad access to public spaces and other accommodations under the federal Americans with Disabilities Act, and are defined differently under the law than family pets. 
For example, throughout Europe, dogs and cats are allowed on many trains and buses. In addition to public transportation, the list of spaces in society from which companion animals are legally barred includes much rental housing, most commercial establishments, and trails in all national parks and some state parks (for example, all state parks in California prohibit pets).

"No-pets" restrictions in rental housing and public transportation, in particular, disproportionately affect poor and working-class individuals. It is not only more difficult to find animal-friendly rental housing, but also often more expensive. In addition to simply having far fewer choices, some landlords charge extra "pet rent" or nonrefundable deposits. A study examining the reasons people relinquish their companion animals found that "for respondents who rented, housing reasons were the number one reason for re-homing, and for respondents of lower income, they were significantly more likely to re-home due to cost and housing issues as opposed to pet-related issues" (Weiss et al. 2015). ${ }^{50}$

In addition, the inability to take your companion animal on the bus might not be important to a person who owns a car, but for people whose mobility depends on public transportation, it is a hardship, as well as a barrier to responsible guardianship. ${ }^{51}$ How do you transport your animal to a vet, out for a hike, or to a friend's house or park that is not within easy walking distance (or accessible via wheelchair or other assistive device for those with disabilities)?

These policies not only contribute to the loneliness and isolation of companion animals ${ }^{52}$ but are also likely to discourage responsible people from adopting an animal. So it is with "no-pets" clauses in rental leases: those predisposed to be the best guardians will take into account the fact that they may at some point have trouble finding housing that permits companion animals and-not wanting to be forced to give up their animal in that situation-choose to defer adoption to the day when they own their own house. Having a companion animal is a privilege, not a right, but prohibitive companion animal policies should be reformed if as a society we do not want to restrict animal adoption and responsible guardianship to only the most affluent socioeconomic classes. ${ }^{53}$

\section{The Legal Status of Companion Animals Enables their Treatment as Expendable}

While in many cases the law has lagged behind emerging social norms and current scientific understanding regarding companion animals, the preceding section has revealed a secondary area of dissonance: their cultural status. While companion animals are increasingly referred to as family members in common parlance, the practices and beliefs underlying this sentiment are in flux. And not everyone shares this sentiment. While a subset of those who share their lives with companion animals treat them with respect, care, and dignity, others invoke the label "family member" as more of a rhetorical than substantive statement, and still others would not consider an animal they own to be part of the family at all. Thus, the cultural status of companion animals is unstable.

One function of the law is to "take a side" when social norms are in conflict-crowding out some and reinforcing others (Carbonara 2017). The legal status of companion animals as property dampens rather than accelerates the transition currently underway toward greater awareness of, and respect, for their subjectivity as individual beings rather than replaceable objects. The increasing prevalence of the family member label is a symbol of this shifting awareness, though the transition is not complete. Many people still treat their companion animals as expendable. This group-unless they run afoul

50 Not all of these animals received new homes. The study's authors defined "re-home" broadly and included relinquishment to shelters.

51 This applies mostly to medium- and large-sized dogs, since small dogs and cats are permitted if they are in a carrier that fits on the caregiver's lap.

52 This applies specifically to dogs, since most cats have neither the need nor desire to accompany their caregivers around town. However, cats have separate and significant welfare issues associated with whether they are kept as "outdoor" or "indoor" cats.

53 This is by no means to suggest that affluent individuals take better care of their companion animals, but merely to acknowledge that socioeconomic barriers to responsible animal guardianship exist. Housing and transportation are two basic human necessities, and having to rely on public transit or rent a home with nonhuman family members significantly restricts available options due to existing social policies. 
of the minimal protections offered by animal cruelty and neglect statutes-are typically acting in accordance with the law.

Property status enables and reinforces social practices that devalue animals, but law does not dictate culture. Only when social norms change sufficiently-that is, when more people begin to treat their animals like true family members, with all of the care and attention that entails-is it likely we will see significant change in the legal system.

However, because the relationship between law and social norms is multidirectional, changing the legal status of animals-e.g., redefining them as other-than-property-may be equally important. This is in part due to the law's expressive function, which can shape group values and norms (Nadler 2017). If the simple act of criminalizing conduct can sometimes reduce its prevalence, even in the absence of enforcement (Rachlinski 2000, p. 1544), would reclassifying animals as something other than property inspire better treatment and greater respect for their interests?

\subsection{Beyond Property}

The title of this article, chattel or child, refers to the dual and at times contradictory social construction of companion animals in the private versus public spheres. Tension exists between the ascendant private understanding of animals as family and their classification as property in the public realm of law and policy. Yet, as we have seen, even within the private sphere of the home duality exists, with some treating their animal companions as family and others treating them more like the objects they for the most part are in the U.S. legal system.

Focusing on the child or chattel distinction, animals are not unique in being placed in this position. Human children were themselves defined as chattel for much of history, as were other categories of people. Although opinions abound about the relationship between property status and animal protection, the question remains: can a family member also be property? Reflecting on the case of married women, who at one time had a "legal nonexistence" similar to chattel, and children, who historically were considered the property of their parents, the answer seems to be yes (Waisman et al. 2014, pp. 42, 45). In the current case of companion animals, they are in a position of subjugation similar to that of children and women in the classic patriarchal household before their legal rights were expanded. Yet, children and women were eventually given greater legal rights and redefined as non-property. Will we one day view the classification of sentient nonhuman animals as "legal things" as unenlightened, similar to the way we now view this characterization of human beings?

While the debate over the legal status of animals has often been framed in dualistic terms-property or personhood-some argue that an entity can be both; being property does not mean you cannot also be a person under the law (M. Liebman, personal conversation, 28 January 2019). The fact that corporations and ships can be both property and persons highlights that these categories are not mutually exclusive. In rejecting this binary, Fernandez (2019) argues for a quasi-property/quasi-personhood approach that reformulates the status of nonhuman animals in terms of both property and personhood. Others eschew the property/person categorization altogether in favor of an approach that focuses on animals' capabilities (Nussbaum 2018a; Satz 2009), their status as vulnerable subjects (Deckha 2015), or a different concept for legal subjectivity such as "selfhood" (Donaldson and Kymlicka 2011) or "beingnness" (Deckha 2017).

Whether defined as property or legal persons, animals could have the right to participate in legal proceedings through a guardian, surrogate, or other representative. ${ }^{54}$ Courts adjudicate issues concerning young children and adults with severe cognitive disabilities ${ }^{55}$ on a regular basis using this

54 Animal protection laws could also be "amended to grant a private cause of action against those who violate them, so as to allow private claimants, either human beings or animals, to supplement currently weak agency enforcement efforts" (Sunstein 2000, p. 1336)

55 This is not to suggest that animals are cognitively impaired, but they obviously do not understand human social institutions like the legal system, and cannot speak in the language of the court. Therefore, surrogacy is required. 
mechanism. ${ }^{56}$ Despite this method being well-established, courts have thus far rarely allowed its use on behalf of animals. Therefore, although legal standing for animals theoretically does not have to be an obstacle, in reality it has been. As discussed above, some cracks have begun to appear in the judicial foundation, but the longstanding status of animals as property has thus far proven to be a significant barrier to their interests being represented in court. ${ }^{57}$

Although skeptics commonly invoke images of fearsome slippery slopes when the issue of animal personhood is raised, it is also worth recalling that "person" is a legal fiction not currently reserved for human beings. ${ }^{58}$ As mentioned above, ships and corporations (and recently, entities of nature such as rivers) have been defined as persons under the law for limited purposes. Given that ships and corporations are not sentient, it seems especially archaic that animals are still defined as property rather than persons. Yet, to the extent that we as a species slaughter billions of animals per year, and wish to continue to do so, the specter of a slippery slope may have less to do with the line separating humans from all other animals, and more to do with the bright line we are invested in keeping firm between companion animals and farmed animals.

In thinking about the best path forward, it is also important to consider whether property status is, in fact, more protective than oppressive for companion animals. In critiquing the concept of "owner," 59 Pierce ponders her dog:

At the same time, the fact that Maya is my property isn't all bad. In practical terms, it is a good thing. It means no one can take her from me. As long as animals are considered property, they will not gain legal protection as "persons," but their status as property offers a tiny thread of protection. (Pierce 2016, p. 215) ${ }^{60}$

Undoubtedly, this is true. For companion animals fortunate enough to have responsible and attentive guardians, property status can be protective. And some of the reforms discussed in the next section could be construed as extending owner rights, not animal rights (e.g., access to rental housing and public transit). But for companion animals with neglectful and careless guardians, this status is detrimental. Beyond concerns for the well-being of individual animals, defining animals as property contributes to a cultural narrative that legitimizes and reinforces their negligent treatment. While the average person may not be aware of the precise legal status of animals, this status frames our social relations with animals and defines what is acceptable within a cultural context that, like the proverbial water in which fishes swim, we do not need to be consciously aware of to be profoundly affected by.

Whether property status is abolished, a hybrid personhood/property model is adopted, or a third status altogether comes to ascendancy, we must move beyond property when considering companion animals' place in the legal system.

56 Connecticut's so-called Desmond's Law comes close, but allows court-appointed advocates to represent the interests of "justice" in animal cruelty cases, not the animals themselves (Pallotta 2017a).

57 Property status, rather than being construed as the underlying problem, can also be considered a symptom of the fact that most people and institutions are unwilling or unready to commit to taking the claims of animals seriously. This lack of readiness is manifest in the still-viable social construction of animals as expendable. While property status arose from dominant beliefs and practices, once it was codified into law, this understanding of animals became reified. The symptom and the problem are now essentially the same; property classification in the law has a circular ossifying effect on the culture, mutually reinforcing this understanding and making it harder to change.

58 In confronting the slippery slope, sentience, or the ability to feel or perceive, seems like a rational and reasonably low bar. For animals about whom we are not sure, we can give the benefit of the doubt in our daily interactions, but the law can use current scientific knowledge as its basis, with updates via legislation and the common law as needed-as happens in the case of new scientific findings about humans. For example, in 2005 the U.S. Supreme Court ruled that the death penalty for juveniles is unconstitutional in light of recent research on brain development. For a summary of this research, see the amicus brief submitted in this case by the American Psychological Association: https://www.apa.org/about/offices/ogc/amicus/roper.pdf.

59 The concept of owner is "technically accurate, but many find it morally offensive and believe that taking ownership over another living being is an act of violence" (Pierce 2016, p. 214).

60 As noted above, some animal law experts would disagree that because her dog is property, she cannot also be a person. 


\subsection{Animals Deserve a Status That Reflects the Types of Beings They Are}

Barring the creation of a comprehensive new status for animals, at the very least their classification as property should be modified to acknowledge their sentience, and that their interests deserve recognition and respect based on this fact. ${ }^{61}$ Whatever the ideal legal status for animals, they are not objects or things, and the law should be clear on this fact. This trend is already underway, especially in countries outside the U.S.

For example, the European Union recognized animals as "sentient beings" in 2007 with an amendment to the Lisbon Treaty. In 2015, France, New Zealand, and the Canadian province of Quebec amended their laws to recognize animals as sentient beings. In 2018, Slovakia updated the definition of "animals" in its civil code to reflect that they are living beings rather than things. Several countries have also included provisions relating to animal sentience, dignity, or protection in their constitutions. ${ }^{62}$ Some U.S. state legislatures have also addressed animal sentience. For example, Oregon law recognizes that "animals are sentient beings capable of experiencing pain, stress and fear." 63

While such laws signal a growing awareness that the conception of animals in the legal system is generally antiquated, whether they are mainly symbolic or will have a widespread positive effect on everyday practices or enforcement remains to be seen. ${ }^{64}$ But because of the expressive function of the law- "making statements" as opposed to directly controlling behavior-even legislation that is primarily symbolic in nature can help shape the culture and change social norms (Sunstein 1996). Therefore, even though acknowledging animal sentience or dignity may not go far enough, it is a step in the right direction.

Beyond sentience, or the ability to feel, there is a plethora of scientific evidence demonstrating the capacities and capabilities of animals across a wide array of species. Currently, the law lags behind our knowledge about animals, which has steadily mounted since the cognitive ethology revolution

61 Sentience has been defined as the capacity of animals to experience pleasurable states such as joy and aversive states such as pain and fear (Broom 2007). For an overview of research regarding animal sentience and its importance to animal welfare science and the animal protection movement, see "Searching for Animal Sentience: A Systematic Review of the Scientific Literature" (Proctor et al. 2013) and "Animal Sentience: Where are We and Where are We Heading?" (Proctor 2012), both published in the journal Animals. As pointed out in these articles, knowledge of vertebrate sentience is much more developed than invertebrates. However, while limited, research on invertebrate sentience is increasing.

62 For an overview of constitutional animal protection provisions, see Jessica Eisen and Kristen Stilt's entry, "Protection and Status of Animals," in the Max Planck Encyclopedia of Comparative Constitutional Law (Eisen and Stilt 2016). Eisen (2017) cautions against overstating the extent to which the emergence of such provisions represents a sea change in constitutional priorities because human interests remain significant, if not dominant (p. 918). However, she views them as a positive step, noting that "despite the persistence of human-centric concerns in constitutional animal protection jurisprudence, the lived experiences of animals themselves are now recognized as constitutionally significant in a number of diverse jurisdictions" (p. 922).

63 Courts in a recent trio of important Oregon cases also relied on sentience to focus on the distinction between animals and all other kinds of legally defined property, "revealing a jurisprudence that approaches the legal status of animals critically, rejecting absolutist constructs that insist animals must either be situated analogous to any other property or analogous to humans" (Dunn and Rosengard 2017, p. 451).

64 Bolliger (2015) notes that, in the case of Switzerland, which added protection of animal dignity to its constitution in 1992 and enshrined this principle in its federal Animal Welfare Act in 2008, this constitutional provision is unique in the world and a milestone for animal welfare. However, "despite the far-reaching conceptual reorganization of Swiss animal law, no essential change in the human-animal relationship has been observed in practice. To the contrary, in many cases animals still are exploited in ways that are hardly consistent with respect for their dignity" (p. 314). France's 2015 law, which updated its civil code to align with its penal and rural codes (which already recognized animals as sentient beings), shifted animals from "moveable property" to "beings gifted with sentience," but did not specify additional legal protections, raising doubts about its practical impact (Garric 2014). However, DiConcetto (2016) writes, "the amendment to the Civil Code is more than just a symbolic victory: it is in fact an important step that opens the door to more change in the way animals are and will be approached under French law ... It is now up to the courts to give a meaningful interpretation of section 515-14 of the Civil Code, and to confirm that animals are non-property. Under French law, which has only two categories [persons and things], the autonomous category of animals as non-things might be the corner stone of an animal personhood yet to be built through case law." Likewise, Neumann (2015) notes, "the change is not a revolution for sure, but the change may allow further developments in the law and, therefore, can be considered as paving the way for an evolution of the status of animals in French law in the next coming decades. As such, it can be considered as a highly 'symbolic move' which should be warmly welcomed" (p. 13). 
spearheaded by Donald Griffin in the late 1970s (Allen and Bekoff 2007). ${ }^{65}$ As contemporary ethologist Marc Bekoff writes:

A strong and rapidly growing database on animal sentience supports the acceptance of the fact that other animals are sentient beings. We know that individuals of a wide variety of species experience emotions ranging from joy and happiness to deep sadness, grief, and PTSD, along with empathy, jealousy and resentment. (Bekoff 2013)

While we already know enough about animals to see that the law does not treat them justly, to the extent that such research continues, studies should be designed to be as naturalistic and unobtrusive as possible, not only for ethical reasons but also to obtain the most accurate data about animal experiences. Field research can present ethical problems, but it is far preferable to laboratory research, except in rare cases where the animals do not live in the lab and are given a choice to participate. An example of this type of research is neuroscientist Gregory Berns' studies of dogs' brains using an MRI machine. The dogs in the study, who lived in homes and were brought to the lab for the day, were trained to lie in the machine, but not forced. Berns told the New York Times:

After perfecting a training system, we sent out a call to local dog owners for volunteers for the study. Since 2012, we've trained and scanned a total of about 90 dogs. As a matter of principle, we never restrained or drugged any. If a dog wants to get up from the M.R.I. and leave, they can. There's no compulsion. (quoted in Dreifus 2017)

This type of research should also emphasize the point of view of the animal. ${ }^{66}$ The results of Berns' MRI studies are recounted in his 2017 book What it's Like to Be a Dog: And Other Adventures in Animal Neuroscience, which encourages readers to take the perspective of animals of several species based on their subjective experience of the world. According to the book jacket, the scientific breakthroughs discussed prove "definitively that animals have feelings very much like we do-a revelation which forces us to reconsider what animal rights ought to be" (Berns 2017).

The last sentence is important. The body of research pertaining to animals' capabilities and ways of perceiving the world should have a practical impact on law, policy, and social norms regarding their treatment. The "animal capital" we gain from studies like this should be used both to help animals on a grand scale and improve our relations with those with whom we share our lives and homes:

Animal capital has nothing to do with knowing about animals to exploit them; it has to do with knowing about them to minimize their exploitation. It has to do with recognizing the intrinsic value of animals' lives. It makes a qualitatively different relationship with animals possible .... (Irvine 2004, pp. 66-67)

Within the animal protection movement, there has been much emphasis on animals' ability to suffer and feel pain-with good reason, given the persistent denial of their sentience and the historical weaponization of anthropomorphism in the scientific community. However, we should be mindful to also give attention to the full spectrum of animals' experiences and the richness of their lives, which include positive emotions and capacities, such as for play, friendship, happiness, and love (Corman 2017; Liebman 2018). We should also consider other emotions that thus far have received less attention-e.g., boredom in animals, which is ripe for further investigation (Burn 2017)—but have profound implications for understanding and improving the lives of animals, if only we will

65 Interestingly, Donald Griffin's influential The Question of Animal Awareness (1976) was published one year after Peter Singer's Animal Liberation (1975), which is frequently credited for igniting the modern animal rights movement.

66 An excellent example of this style of research is Alexandra Horowitz's 2009 bestseller Inside of a Dog: What Dogs, See Smell, and Know. And Marc Bekoff and Jessica Pierce's 2019 book Unleashing Your Dog: A Field Guide to Giving Your Canine Companion the Best Life Possible synthesizes the available research about dogs into an advocacy guide to encourage guardians to better understand and enhance their dogs' experiences in a human-centered world. 
assimilate and act on this information. ${ }^{67}$ Deep knowledge of animals is key; coupled with respect for their intrinsic value, it would be transformative.

Those who refer to animals as "voiceless" typically do not mean this literally, but rather are referring to the fact that animals are denied a voice in our political institutions. That said, animals do have voices - they are just too often ignored. As law professor Martha Nussbaum said in a recent keynote address and essay, "Why Freedom of Speech is an Important Right and Why Animals Should Have It:"

Animals provide information about their welfare in many ways. Some really do have some form of quasi-linguistic communication. For instance, whales have song and elephants have patterns of trumpeting. But that isn't really the whole issue because in many ways-through their behavior and evidence of their delight, fear, and pain-animals are giving us information all the time even without anything like speech if we would stop, look, and interact with them. (Nussbaum 2018b, p. 849)

In considering a co-citizenship model for animals, Nussbaum agrees with Donaldson and Kymlicka (2011) that "the many ways in which domesticated animals give evidence of their preferences, satisfactions, dissatisfactions, fears, and longings should be taken into account through an established system of surrogacy when making law and policy" (Nussbaum 2018b, p. 849).

What is certain from the perspective of anyone with an interest in animal protection and justice is that there is plenty of need for reform. And this article has only examined companion animals. What happens when we widen our lens out to take in all the other animals living in the world, both free and kept in captivity? ${ }^{68}$ What should their ideal status be from a philosophical, legal, and advocacy standpoint? American Naturalist Henry Beston famously referred to nonhuman animals as "other nations:"

For the animal shall not be measured by man. In a world older and more complete than ours they move finished and complete, gifted with extension of the senses we have lost or never attained, living by voices we shall never hear. They are not brethren, they are not underlings; they are other nations, caught with ourselves in the net of life and time, fellow prisoners of the splendor and travail of the earth. (Beston 1928, p. 25)

This metaphor has limits, especially as humans continue to relentlessly encroach on other animals' lives and habitats. But it is a helpful frame to think about how we might respect other animals who live among us - to adopt an attitude of diplomacy and cooperation rather than colonialism and subjugation. Though the animal nations have no emissaries who can speak to us in a language we understand, we could appoint a human ambassador to speak on their behalf. Not just anyone, but someone with the appropriate animal capital (Irvine 2004) - a duck expert to speak on behalf of ducks and a bear behaviorist to represent the ursine community, for example. The model of diplomacy and respect could be restricted to relations between human society and communities of nonhuman animals. We would not need to intervene in interactions between nonhuman animals, who have their own ways of existing together. ${ }^{69}$

67 In addition to the emphasis on animals' negative experiences such as pain and suffering, some have noted that animal rights theory has focused narrowly on the negative rights of animals (e.g., "the right not to be owned, killed, confined, tortured, or separated from one's family") but says little about the positive obligations we may owe them (Donaldson and Kymlicka 2011, pp. 5-6).

68 Additionally, while slippery slope arguments tend to be facile, the question regarding sentience as a baseline for enhanced legal protections is an interesting one when it comes to animals other than mammals, birds, and fishes and other aquatic animals, such as cephalopods, whom science has shown to be sentient. While research in this area continues apace, there is much that is still unknown about certain types of invertebrates, the broad category that includes insects (which comprise a significant percentage of known animal species worldwide).

69 Or would we? Some argue that human intervention to alleviate wild animal suffering is an ethical obligation, in contrast to the idealized view that anything associated with the "natural world" is inherently good (sometimes called the nature fallacy) and must therefore be left alone (Effective Altruism Foundation 2017; Tomasik 2009). 
Returning to companion animals specifically, a legal status that more closely reflects the growing perception of them as family members would help to extinguish the counter-construction of them as disposable commodities by delegitimizing practices that enable their treatment as expendable.

\subsection{Animals as Legal Dependents}

While dogs, cats, and other companion animals are different from both chattel and children, there are elements of each in both the reality of our current relationships with them and likely whatever ideal future we envision. Our relationships with companion animals are also distinct from our relationships with human friends, given our incontrovertible position of power over them. I do not think of my relationship with my dog Teagan as one of power, but of course it inherently is. She is utterly dependent on me for all of her needs. While I choose to take this responsibility seriously, this does not diminish the power dynamic that cannot help but exist between me and any domesticated animal in human society. Therefore, a social and legal status that embodies elements of her being "mine" (in the sense a human child would be mine, meaning no one could take her from me) while also recognizing both her "animalhood" (as a dog) and her individuality (as Teagan) would be ideal.

A status like "legal animal dependent" could capture this and would constitute a form of personhood. This status is similar to equitable self-ownership for animals (Favre 2000) and quasi-property/ personhood (Fernandez 2019) but would not necessarily rely on the property paradigm. It would capture that, like a child, Teagan is dependent on me (and that therefore, as her caregiver, I have obligations) but that unlike a human child, she is of another species. The status of legal animal dependent would recognize that Teagan has needs and interests stemming from her identity as both (1) a dog (she needs exercise, companionship, and nutritious food) and (2) an individual (she is introverted, likes soft beds, and is afraid of cats). This status would be recognized under the law, clearing up confusion and alleviating tension created by labeling sentient animals—who, despite the provisional nature of this role, are in many cases treated as family members and friends-as property.

This term is already used in the legal system to refer to humans (e.g., children) who are dependent on another human that is obligated by law to support them. Adding "animal" would allow for duties to be assigned in relation to the role of guardian, but not the same obligations that are owed to human dependents, due to obvious qualitative distinctions in the nature and needs of members of different species. The panoply of duties and rights attached to the role of legal animal guardian, and attendant rights of the legal animal dependent (which should take into account the animal's intrinsic value, not just their value to a human owner or guardian) are matters for future policymakers. But we can pursue this ideal now in our everyday interactions with companion animals, in hopes of shifting the culture.

While the word "dependent" may have uncomfortable connotations for some, it has a legal meaning currently only reserved for children and other humans. It would therefore elevate animals' status significantly beyond what it currently is. Also, while words like autonomy and agency have a more respectful ring, companion animals are dependent on us. As much as a status like "autonomous animal" may be preferable philosophically, this is neither politically feasible nor logistically possible at this time. For wild animals, perhaps ${ }^{70}$ — but how would legal autonomy work at the present time for domesticated animals?

It is not helpful to deny that domesticated animals are currently reliant on humans and occupy an inherently vulnerable position in a society that is - at least for now-thoroughly anthropocentric. A future in which animals become integrated into society on more equal footing could see an embrace of an "animal citizenship" rather than-or in conjunction with—a legal dependent model,

70 Though even in the case of wild animals, this idea is utopian on practical terms and not remotely on the political horizon for myriad reasons that are beyond the scope of this paper to discuss. 
in which domesticated animals would play an active role in shaping their communities, not just their private families.

In their 2011 book, Zoopolis, a Political Theory of Animal Rights, Donaldson and Kymlicka articulate a theory of domesticated animal citizenship:

Drawing on recent work in disability theory, we show that there are many ways for individuals with varying levels of cognitive ability to be treated as citizens and to exercise their citizenship, and that there is no reason why domesticated animals cannot be included within these more expansive ideas of citizenship. (p. 103)

They also argue against a "wardship" model (presumably similar to the legal dependent model discussed here) because it ignores domesticated animals' capacities for "agency, cooperation, and participation in mixed human-animal settings" and treats them:

As wholly passive and dependent on humans ... located on the (literal and figural) margins of human society, having no claims regarding how the broader community governs itself and its public spaces. It treats domesticated animals as something like protected aliens or guests, who don't really belong here, but whom we have a duty to treat humanely. (pp. 102-3)

I disagree with this critique of wardship and believe it has positive potential for the same reasons the American Veterinary Association (AVMA) has issued a position statement against it. The AVMA objects to wardship for companion animals precisely because it would bestow significant legal rights that they do not currently have, including the fundamental legal right of standing (which is essential to personhood):

Use of guardian gives rise to its counterpart "ward." The ward is defined as the person for whose benefit the guardianship has been established. Wards have legal rights. Applying human guardianship law to animals would mean that animals have legal rights that can be recognized in court (i.e., animals would have legal standing). (American Veterinary Medical Association 2005)

While an animal citizenship model is ideal, the incremental advance of viewing animals as wards or legal dependents could be an intermediate — and still groundbreaking — step preceding the revolutionary leap to full citizenship for animals. This status would give them access to the legal system that they do no currently have, and place their lives and interests more on par with children than chattel. While animals are not children, expansion of a category currently reserved for them (and other humans) to include animals is a better fit than classifying living beings as mere property, and would be a significant advance in recognizing the legitimacy of multi-species families.

These conceptions-legal dependent and co-citizens-are not incompatible. Human children are both. Starting with legal dependent status for some domesticated animals, e.g., dogs and cats, can spur society further along the path toward a more enlightened co-citizenship model. As Kymlicka (2017) writes:

Legal reforms to date have largely focused on acknowledging animals' membership within private families, but ... justice requires that [domestic animals] be recognized as members of the broader society and polity as well. To be fully recognized as a member of society would not just involve being treated as a member within private familial settings, but also being treated as a member of the public, with rights to public goods, public services and public spaces. (p. 145)

Given the current position of companion animals in society, a legal dependent or ward model that codifies their role in the family beyond rhetoric would itself be revolutionary. Since companion animals are not yet universally perceived as family members, this, or a similar step, is likely a prerequisite to them being recognized as active and participatory members of the broader polity. It is hard to imagine how a dog who is (legally) confined and isolated by her owner-deprived of companionship, physical 
and mental stimulation, the ability to express natural behaviors, and any semblance of agency-could participate as a co-citizen in the wider community. Therefore, while family status for companion animals is still fragile, the first step is to secure their membership in private families. Reframing their status as legal dependents (or another status beyond property) would accomplish this while also giving them legal personhood via the expanded legal obligations placed on guardians ${ }^{71}$ and its similarity to children's status as legal dependents. ${ }^{72}$

\section{Policy Recommendations}

Social policies can help facilitate and strengthen the human-animal bond and provide support for the continued integration of companion animals into society, while taking into account the interests and welfare of all species (including humans). Or they can do the opposite. Along with augmenting the legal status of animals, social reforms would strengthen their cultural status as family:

There are two ways to increase the rate of a desirable social behavior: either augment the social forces that increase its prevalence or dampen those social forces that reduce its prevalence. In other words, sometimes the question is not what encourages people to do something, but rather what discourages them from doing it. Often, social reforms emphasize the former issue to the neglect of the latter. (Rachlinski 2000, p. 1567)

Many social policies discourage responsible companion animal guardianship, which tips the scales away from the understanding that companion animals are family, and toward the competing social construction that they are expendable property. People may want to provide a loving home to an animal, but lack knowledge and resources. For example, research has shown people who are in the process of relinquishing their animal to a shelter facility would be open to keeping that animal if help or resources were offered (Weiss et al. 2014). ${ }^{73}$

\subsection{Access}

Of primary importance is access to rental housing. "No-pets" restrictions are a significant obstacle to obtaining affordable housing and a main reason that companion animals are relinquished to shelters (Weiss et al. 2014; Shore et al. 2003; Patronek et al. 1996). One study found:

The majority had given up their pets solely because they were moving. Most had relatively low income, were moving for employment reasons, and were renting their homes. Landlord restrictions were an important factor in relinquishment. High scores on the bonding scale and spontaneous expressions of discomfort and sorrow suggest that external pressures overrode attachment to the animal and the pain of relinquishment. (Shore et al. 2003, p. 39)

For this reason, blanket "no-pets" restrictions should be banned, especially those based on size, breed, or other arbitrary criteria. In their place, non-discriminatory policies should be mandated, which could require references and deposits to cover potential damages or other liability but would ultimately base the decision to rent on information about the individual caregiver and her particular animal(s).

Evictions would be allowed in cases of nuisance or noise disturbance, property damage, or if the animal proves dangerous, but not for the mere fact of owning a companion animal. There is precedent for such legislation, though not yet in the U.S. The Canadian province of Ontario currently bans "no-pets"

71 Redefining animals as "legal dependents" would also include redefining their owners as "legal guardians." As mentioned above, there are some jurisdictions that have passed ordinances proclaiming support for the word "guardian" over "owner," but these laws have thus far been merely symbolic.

72 Legal duties could include providing opportunities for physical exercise and social interaction/companionship, for example.

73 This study found that "many people wanted to keep their dogs and had clear ideas of what could have helped. Many ideas provided by the respondents, such as temporary pet-friendly housing or boarding, or financial help for dog costs, such as veterinary care or training, could be addressed with targeted programs or services" (Weiss et al. 2014, p. 424). 
clauses in rental agreements and lobbying efforts are underway to institute similar legislation in the British Columbia cities of Vancouver and Victoria (Britten 2017; Larsen 2016).

Caregivers of well-behaved companion animals should also be granted limited access to public transit by allowing leashed and under-control animals on buses and trains when space allows. Dogs and cats are permitted to ride on many trains and buses throughout Europe, and are more likely to be allowed inside stores, restaurants, and cafes (though laws vary by city and country). Clear codes of conduct could be posted and enforced, just like for human riders, and certain cars or buses could be designated animal-free zones to accommodate those with allergies.

As discussed above, "no-pets" restrictions in rental housing, public transportation, and other public and private spaces disproportionately affect poor and working-class individuals and act as barriers to companion animals being integrated into the family. ${ }^{74}$

\subsection{Education}

There is also a need for widespread public education campaigns about animal behavior to raise awareness about species-specific physical, social, and psychological needs. Education is critically important to increase animal well-being and prevent neglect, as well as to reduce human-animal conflicts such as dog bites and violence against animals. Systematic and consistent humane education programs to teach children about the responsibility and long-term commitment involved in companion animal guardianship, as well as respect and appropriate behavior in the company of animals, are crucial. Humane education programs targeted to young people are important because their attitudes and values are still forming; it can be more difficult to change the behavior of adults who have been socialized to think of animals in instrumental or objective ways. But new programs can address the issue of humane education for adults.

Beyond teaching people to treat animals with kindness and compassion, such programs would instill cross-species understanding and respect for the nature, needs, and individuality of nonhuman animals-for example, how the world is perceived through the eyes (or more accurately, the nose) of a $\mathrm{dog}$, and how their ontological experience of being-in-the-world differs from ours. Besides encouraging animal guardians to take the perspective of the animal for greater understanding, these programs could impart additional "animal capital," or resources that enable caregivers to develop meaningful, nonexploitive companionship with animals, including:

Knowledge about behavior, nutrition, health, history, training, and the variety of things that can enrich animals' lives. I also include a rapport with animals based on an active interest on their emotions, communication, and cognition. In addition, animal capital means knowing how to find things out. This implies seeking out resources such as veterinarians, trainers, or behaviorists in case of behavioral or health problems. (Irvine 2004, p. 66)

Outside of school programs for youth, humane education for adults could be implemented in a number of ways. Free community classes could be offered, funded through donations to human societies or other nonprofit organizations, or revenue from the sale of specialty license plates could fund government programs on humane education for adults. Nonprofits or government agencies could offer free webinars or short films by animal behaviorists and ethicists that would impart messages, such as those presented in the book Unleashing Your Dog: A Field Guide to Giving Your Canine Companion the Best Life Possible (Bekoff and Pierce 2019), about taking the perspective of your companion animal and learning about their species-specific needs. Since motivation may be an issue, participants could be paid a nominal fee to attend classes or watch webinars. Organizations producing these webinars or videos could also offer giveaways or other incentives to view them, and provide before and after surveys

74 For a discussion of access and other policy issues that specifically affect companion animals with disabilities and their caregivers, see "Reframing Companion Animal Disability Using the Social Model: Removing Barriers and Facilitating Care" (Pallotta 2019) 
to track effectiveness. In addition, advertisements and public service announcements (PSAs) could spread positive messages about animals and their needs as part of a community education campaign. ${ }^{75}$

The Oregon Humane Society's (OHS) "End Petlessness" campaign is an example of a successful program of this nature. This colorful visual campaign was intended to encourage animal adoption through a series of engaging and whimsical advertisements (created for free by a local ad agency) that appeared in print media and on billboards and buses throughout Portland.

They've been a huge hit, says Terra Spencer, a manager at Portland firm Leopold Ketel and Partners, which created the ads pro bono. "People have already written in-they want to know where they can buy posters, they want to know what we're doing with the outdoor posters when we're done." Spencer says. "They want to hang them in their house" ... The murals are intensely cute and devastatingly effective. Oregon's animal adoptions are up 21.2 percent in the five years since the campaign began, which the Humane Society credits to the ads. Likewise, volunteerism at the OHS is up, says spokeswoman Barbara Baugnon, which she attributes to "the good will the campaign had generated." (Cizmar 2017)

\subsection{Emotional Support Animals}

Laws and policies regarding emotional support animals (ESAs) are currently in the media spotlight as an area in need of reform and clarification. Indeed, this is a trend well underway, with a number of jurisdictions considering or having enacted new legislation addressing the issue of "fake service animals" (Hernandez-Silk 2018; Siler 2018; Edelman 2018; Ollove 2017). The law in this area is poorly understood, which has caused mounting tension and confusion over what exactly the ESA designation means. ${ }^{76}$ In recent years, there has been a proliferation of ESAs (some real, some fraudulent) in public spaces and other settings where animals generally are not allowed, leading to a backlash against individuals with service animals defined under the Americans with Disabilities Act (ADA), as well as widespread misconceptions about the difference between ESAs and service animals and the rules and rights associated with each (Schoenfeld-Tacher et al. 2017). ${ }^{77}$

In practice, this has meant special privileges for some, as the current lack of clarity around laws and regulations means that what rules do exist are easily circumvented by people working the system. ${ }^{78}$ But should they have to work the system? A growing body of research shows companion animals provide numerous psychological and emotional benefits to their human caregivers, regardless of whether that person has a diagnosed mental disability. Therefore, many companion animals could be correctly considered emotional support animals, without a doctor's note or having to prove the existence of a mental disorder (Pallotta 2016).

75 For example, the website of veterinarian Sophia Yin has a host of educational resources, such as this poster that explains through colorful illustrations the right and wrong ways to approach a dog: https://drsophiayin.com/app//uploads/2017/08/ How-to-Greet-a-Dog-Poster.pdf. Posters are also available on how children should and should not interact with dogs, the body language of feline anxiety, and the body language of fear in dogs. Information like this could be presented via radio or television PSAs, or through print advertisements or posters prominently displayed in key community locations.

76 Currently, a letter from a medical professional stating an animal is an ESA for a verifiable disability allows the owner to claim a "reasonable accommodation" under the Fair Housing Amendments Act (to obtain access to rental housing) and the Air Carrier Access Act (to be able to fly with their animal in an airplane cabin), but does not allow the broad access to public spaces afforded to designated service animals under the ADA. Unlike ESAs, where the mere presence of the animal is considered therapeutic and no special training is necessary, ADA service animals are required to have special training to perform a specific task.

77 Though this study also found that, “despite the media's focus on abuses and false representation of these dogs, most participants reported feeling the majority of people are not taking advantage of the system" (p. 642).

78 ESAs are currently only covered under the federal Fair Housing Act and Air Carrier Access Act, meaning those who have a doctor's note stating their companion animal's presence provides a therapeutic benefit for an emotional disability are allowed to have them in rental housing that otherwise prohibits pets and to have their animal in the cabin on flights that otherwise prohibit animals over a certain size. Although ESAs are not granted the broad access to public accommodations that ADA service animals are, this is not well-known. Furthermore, websites selling doctor's notes and fake service/support animal vests have proliferated, with the public and business owners often not knowing the difference. 
Although mental disorders such as anxiety and depression are common in the U.S. ${ }^{79}$ some scholars have noted that the meteoric rise in mental illness is due to a relatively recent shift in the medicalization of what used to be considered normal thoughts, feelings, and behaviors (Stolzer 2016). Critiques of how mental illness is defined and treated underscore a related fundamental question: what does—and what should-"emotional support animal" mean? Should ESAs be covered under the ADA as some have argued (Hernandez-Silk 2018), or should companion animals be recognized as legitimate social support, similar to human family, and hence not need a special label or medical designation to accompany their caregivers in public?

If fewer societal spaces were off-limits to animals, this question would become moot, as "no-pets" policies have undoubtedly contributed to the current situation. Indeed, the Department of Justice (DOJ) expressly and intentionally excludes ESAs from the definition of service animals out of concern that "'some individuals with impairments who would not be covered as individuals with disabilities [would claim] that their animals are legitimate service animals, whether fraudulently or sincerely (albeit mistakenly), to gain access' to public accommodations" (quoted in Hernandez-Silk 2018, p. 316). Given the fact that companion animals are not allowed in airplane cabins (unless they are small enough to fit under the seat in a carrier) and instead must fly in the cargo hold as checked baggage, where they risk injury and death, ${ }^{80}$ and much rental housing prohibits animals, it is predictable that people would be motivated to obtain this designation for their animals in order to gain access to these accommodations.

An examination of the (rapidly evolving) patchwork of laws regulating emotional support animals versus ADA-defined service animals is beyond the scope of this article, but it highlights an area in which animals' dual private and public status is a cause of tension, in part due to the restrictive policies mentioned above. ${ }^{81}$

\subsection{Workplace Policies}

Company policies that permit employees to bring companion animals to work also reinforce responsible animal guardianship and the notion that they are family who should not be left home alone all day. Though analogies to children are sometimes useful, here it is important to emphasize that animals occupy a special category of family, which should recognize their animalhood and that they are not, in fact, human children - who are not typically allowed to accompany parents to work. However, companion animals need less supervision than children, so it is possible to work in their proximity without disruption (provided the animal is well-socialized and suitable to the work environment). Allowing flex-time or remote work options (for either those with animals or those with allergies) would

79 The National Institute of Mental Health estimates that one in five adults live with mental illness. (https://www.nimh.nih. gov/health/statistics/mental-illness.shtml).

80 "Records show that across all airlines from 2015 through 2017, there were 151 animal-related incidents-85 deaths, 62 injuries, and four lost animals" (Rocheleau 2018). Even when animals arrive relatively unscathed, being transported as luggage in the cargo hold of an airplane is, as one can imagine, stressful: "Conditions in the cargo hold of commercial jets are not always friendly; temperatures can fluctuate wildly, noise can be tremendous and air pressure can drop significantly, and pets that are checked into this dark space beneath the passenger cabin sometimes die. In 2011, thirty-five pets died while (or shortly before or after) traveling on commercial flights with U.S. airline companies. Nine animals were injured and two lost entirely. And in 2012, 29 pets died, 26 were injured and one was lost" (Bland 2013). In 2015, in response to a rulemaking petition by the Animal Legal Defense Fund, the Department of Transportation expanded its reporting requirements for airlines regarding the loss, injury, or death of companion animals. See "U.S. Department of Transportation Expands Air Carrier Reporting Requirements for Incidents Involving Animals During Air Transport," https://www.transportation.gov/ briefing-room/us-department-transportation-expands-air-carrier-reporting-requirements-incidents; see the Animal Legal Defense Fund's petition here: https://www.regulations.gov/document?D=DOT-OST-2010-0211-0001). For an overview of reasons why animals die in transport, see also "Dying in the Cargo Hold: Is There an Acceptable Level of Loss in Animal Air Transport?" http://doglawreporter.blogspot.com/2012/12/dying-in-cargo-hold-is-there-acceptable.html.

81 There are also ethical issues pertaining to service animals in general-in contrast to emotional support animals, who are in essence the same as family pets since they are not trained to perform specific tasks and thus are theoretically allowed greater agency - but that discussion is also beyond the scope of this article. 
accomplish the same goals of supporting the human-animal bond and mitigating companion animal neglect and loneliness.

Many people who would like to adopt an animal—and who would be responsible and loving caregivers - are understandably reluctant to welcome an animal into their life because they work full-time and would either have to leave the animal alone all day or pay for a dog-walking service or "doggie daycare," a circumstance which again makes responsible animal adoption less accessible to those who are not financially well-off. If a workplace wishes to accommodate companion animals, research shows this can be done in a way that takes everyone's interests into account, including those with allergies. Examples of large companies with policies permitting their employees to bring their dogs to work include Google, Amazon, and Etsy (Foreman et al. 2017). Employers can take specific measures to assess and address the needs and desires of employees and the physical constraints of the available workspace to determine the feasibility of allowing a dog-friendly office. As an added bonus, studies have shown that companion animals in the workplace can have a positive effect on employee happiness and productivity (Barker et al. 2012; Wells and Perrine 2001).

Public policy presents challenges when it comes to balancing competing interests, and the arena of companion animals and their guardians is no different. But these challenges must be addressed. Integrating companion animals into human society in such a way that their needs are considered, respected, and accommodated is an ethical imperative.

As we consider formulating social policies for a future that is friendly to both animals and people, we must also ask fundamental questions like: do animals belong in public spaces? Is it possible to balance competing interests (e.g., those of people with allergies or who do not like animals) in creating social spaces that are more inclusive of companion animals? We manage it with other groups. For example, not everyone enjoys being around children, but they are permitted almost everywhere, with notable exceptions such as bars and other "adults only" establishments. Likewise, some spaces would be off-limits to animals. Tolerance and compromise will always be an issue in a pluralistic society, so the existence of competing interests should not shut down the conversation. Rather, it presents an opportunity to craft rational policy solutions.

\subsection{Choice and Consent}

While recognizing this would fundamentally transform human-animal relations if universally applied, when considering social policy reform, greater attention should be given to issues of consent and choice. A good place to start is with the companion animals who share our homes. These concepts could also be relayed and reinforced through cultural messaging and humane education for adults.

A few years ago, I happened across a short YouTube video called "Does your dog REALLY want to be petted?" that articulated this concept. ${ }^{82}$ The video discusses how to read a dog's body language to discern whether they actually enjoy being petted or merely tolerate it. Since I first came across that video, there has been a notable proliferation of dog training articles and blogs discussing this issue, which is a welcome turn and promising trend. These concepts go beyond advocating positive training methods (over those grounded in punishment, domination, and fear) to a deeper consideration of a dog's desires. This approach implicitly recognizes an animal's individuality and respects her agency. The concepts of consent and choice have the potential to radically transform our relationships with companion animals and improve their lives, and have been missing from the general discourse for too long.

I have pondered this issue with my dog Teagan. During our walks together, it is common for people (often children) to approach and ask, "Can I pet your dog?" which has caused me to think about ways I can introduce consent into the conversation. This can be challenging during fleeting

82 https://www.youtube.com/watch?v=-cGDYI-s-cQ 
encounters, especially with young children. ${ }^{83}$ I usually say something like, "If she wants to be," in a friendly manner, which can earn me puzzled looks. The thing is, it depends-on the day, the context, the stranger, Teagan's mood. While Teagan tolerates being touched by strangers, and sometimes actively seeks it out depending on the situation, she is not a dog who is always enthusiastic about greeting strangers. And this should be respected. She is not there for other people's pleasure.

I think, for the most part, the frequency with which people expect that they should be allowed to pet unknown dogs in public stems from a genuine lack of knowledge and the misguided belief that dogs universally enjoy being touched by strangers. I have observed an increase over the years in the number of people who ask (and teach their children to ask) whether they may pet a strange dog before approaching, which is progress. However, the question is typically framed as an inquiry into whether the dog is "friendly" (meaning non-aggressive) even though this is not synonymous with enjoying being touched. So, the next step is to bring an understanding of consent into the conversation. ${ }^{84}$

Likewise, preference should be noticed, and choices respected, when possible. Once you learn even a small amount about dog behavior, a trip to an off-leash area or just a walk down the street can become a frustrating experience, as so many dogs clearly are in uncomfortable situations to which their guardians are oblivious. It is sadly commonplace to observe dogs being roughly yanked along on a walk (often by a "choke chain" tightened around their neck), forcibly dragged away from some enticing smell by the human on the other end of the leash-with no regard for the fact that this walk is likely the most exciting part of a day spent mostly indoors, and that a dog's sense of smell, and the role of odor in their world, is profoundly important. ${ }^{85}$

Choice is also important in thinking about ways to increase animal agency in the confines of life in a human world. There are limits to this concept of course, mostly related to safety. Teagan might prefer to chase that squirrel into the street, or eat that disgusting thing she found on the sidewalk, or not have blood drawn during a veterinary exam, but this is not in her best interests. So, there are hard rules, as with any parental or guardian relationship. But within the universe of harmless activities, I have become mindful to give her choices whenever possible. ${ }^{86}$

This is fun because it strengthens our bond and communication as well. It has made me more attuned to Teagan, and she to me. As she has realized I "listen" when she expresses choices, ${ }^{87}$ she has become more likely to communicate them to me. I try to make all walks "smell walks" (where she can sniff as long as she wants) and we do "choice walks" as well. One day, Teagan started doing a new thing where she would slow her pace (or sometimes stop completely) while looking up at me. Then, once she caught my eye, she would pointedly turned her gaze (willing mine to follow) in the direction

83 However, a parallel movement has emerged in recent years to teach children about consent and bodily autonomy (no more forced hugs!), so cultural awareness around this issue will likely only increase. See Theriault, Anne. "It's never too early to teach children about consent and boundaries." Washington Post. February 13, 2015. Accessed on 9 March 2019. https://www.washingtonpost.com/news/parenting/wp/2015/02/13/its-never-too-early-to-teach-children-aboutconsent-and-boundaries/?utm_term=.599ab9d92c32.

84 The Microsanctuary Resource Center articulates animal subjectivity and choice as one of its core principles: "A resident should never be presented as an object for human touching, and any resident who is shy or does not want to be touched/held/hugged/etc. should be treated appropriately" (https:/microsanctuary.org/2018/08/20/core-principles/).

85 As Horowitz (2009) writes:

Dog-walks are often not done with the dog's sake in mind, but strangely playing out a very human definition of a walk. We want to make good time; to keep a brisk pace; to get to the post office and back. People yank their dogs along, tugging at leashes to noses out of smells, pulling past tempting dogs, to get on with the walk. The dog doesn't care about making good time. Instead, consider the walk your dog wants. (pp. 284-85)

86 It is helpful to think of training in this context-i.e., as a practical necessity in a human-centric world rather than as a means of domination and control, akin to teaching children manners and social norms to ease their experience of being in society. Clarifying expectations and boundaries aids in safety and social adjustment, for both children and companion animals. In this sense, the training of companion animals can be conceptualized more as socialization and should focus on imparting behaviors they need to flourish in society.

87 Even when I cannot honor it, I stop and acknowledge her desire to go down that street, or to that place, but say "sorry, we can't go there right now" and gently coax her (never yank!) along the alternate route. 
she wanted to go. ${ }^{88}$ These are lovely moments of communication between us, and they have gotten stronger and more frequent.

Teagan will now sometimes hesitate at an intersection without obviously indicating through eye contact which direction she wants to go. I learned that if I initiate a step in one direction she will merely stand and stare at me, while if I turn to make a move in the other direction (apparently the preferable route), she will eagerly match my step. So, this is another way I can discern her preferences through careful observation. Though how carefully I must observe has diminished; as Teagan has grown more confident that the choices she expresses during walks will be respected, she has become more obvious in communicating them. (As is probably apparent, Teagan is relatively relaxed on walks. Of course, careful observation to discern preferences would not be needed with a dog of a different temperament, such as one who pulls on leash!).

Finding opportunities to recognize and incorporate choice and consent into our companion animals' lives would greatly improve their well-being. Regardless of their legal status, we can forge relationships with the animals in our care based on mutual cooperation and trust, rather than domination and casual indifference. These relationships can serve as a model for the wider society and, once they become more widespread, will have an impact on legal norms as well.

\section{Conclusions}

The status of companion animals is constructed on both an individual and societal level, originating in the home and reflected and codified in law and public policy. Sometimes these levels are in harmony and sometimes they are discordant. The private and public spheres, while distinct, are also intimately intertwined, however, as aggregate micro-level actions comprise the macro social institutions that govern our lives.

To the extent that the law is out of sync with our private understanding of companion animals, this is in part due to dissonance in that private understanding itself. The cultural perception of companion animals as family is not uniformly accepted, and practices and beliefs that treat them as expendable are still prevalent. While a family member understanding is ascending, social forces, including the law, are in conflict, with some bolstering an emergent respect for animals as individuals with inherent value, and others reinforcing an antiquated notion that they are disposable commodities with minimal intrinsic worth. Which social construction will become dominant, and which will be relegated to the historical dustbin? As I have argued, the law plays a key role here.

Yet, the relationship between the law and social norms is multidirectional, with each influencing the other in ways that defy easy measurement. As individuals, we can improve our knowledge of animals generally, and of the animals for whom we are responsible specifically, and use this knowledge to treat them with greater respect and autonomy — both as a means to improve their well-being and, more widely, influence normative behavior regarding animals through social modeling (Bandura 1986). Because individual actions create the culture and social structure in which our relationships with animals are embedded, sustained improvements in the everyday treatment of companion animals can lead to new normative expectations that will also elevate their status in the legal system. Granting companion animals a legal status beyond property can, in turn, shape group values and norms due to the law's expressive function (Nadler 2017).

Because the law expresses social values, it can tip a system of social norms into a new equilibrium (Cooter 1998). Therefore, challenging the property status of animals in the legal system may be as important as changing attitudes and behaviors, even if this functions, at least at first, on a mostly symbolic level.

88 I realize anyone who lives with a more headstrong dog (as I have in the past) will find this description of subtle cues laughable-but Teagan is a well-mannered and relatively reserved dog, and her communication style is generally low-key. 
Many debates over the appropriate content of law are really debates over the statement that law makes, independent of its (direct) consequences ... The expressive function of law has a great deal to do with the effects of law on prevailing social norms. Often law's "statement" is designed to move norms in fresh directions. (Sunstein 1996, p. 721)

Where discrepancy exists among competing social norms, the expressive function of law can reinforce some narratives and crowd out others (Carbonara 2017). In the situation of companion animals, where dual definitions of family and property are competing for cultural ascendancy, changing the law could tip the scales and lead to social change.

Funding: This research received no external funding.

Acknowledgments: I would like to thank Leslie Irvine and the anonymous reviewers for their helpful feedback in shaping this article.

Conflicts of Interest: The author declares no conflict of interest. The views expressed in this paper are my own and do not represent the Animal Legal Defense Fund as an organization.

\section{References}

American Animal Hospital Association (AAHA). 2001. 2001 AAHA Pet Owners Survey. Lakewood: American Animal Hospital Association.

American Animal Hospital Association (AAHA). 2004. 2004 AAHA Pet Owners Survey. Lakewood: American Animal Hospital Association.

Adrian, Julie A. Luiz, Aimee N. Deliramich, and B. Christopher Frueh. 2009. Complicated Grief and Posttraumatic Stress Disorder in Humans Response to the Death of Pets/animals. Bulletin of the Menninger Clinic 73: 176-87. [CrossRef] [PubMed]

Aflatooni, Shidon. 2011. The Statutory Pet Trust: Recommendations for a New Uniform Law Based on the Past Twenty-One Years. Animal Law 18: 1.

Allen, Colin, and Marc Bekoff. 2007. Animal Minds, Cognitive Ethology, and Ethics. The Journal of Ethics 11: 299-317. [CrossRef]

American Academy of Matrimonial Lawyers. 2014. Pet Custody Disputed on the Rise Find Nation's Top Matrimonial Lawyers—Survey Reveals More Couples Clawing Through Divorce. News Release. February 12. Available online: http://aaml.org/about-the-academy/press/press-releases/pets/pet-custody-disputed-risefind-nations-top-matrimonial-1 (accessed on 21 February 2019).

American Veterinary Medical Association. 2005. State Advocacy Issue: Ownership versus Guardianship. Available online: https://www.avma.org/Advocacy/StateAndLocal/Pages/ownership-vs-guardianship.aspx (accessed on 24 April 2019).

American Veterinary Medical Association. 2018. Pet Trusts: Caring for a Pet That Outlives Its Owner. Available online: https://www.avma.org/Advocacy/StateAndLocal/Pages/sr-pet-trusts.aspx (accessed on 17 March 2019).

Animal Legal Defense Fund. 2014. Two Great Legal Victories for Animals in Oregon. Available online: https://aldf.org/article/two-great-legal-victories-for-animals-in-oregon/ (accessed on 19 May 2019).

Animal Legal Defense Fund. n.d.a. Animals' Legal Status. Available online: https:/aldf.org/issue/animals-legalstatus/ (accessed on 9 March 2019).

Animal Legal Defense Fund. n.d.b. Charging Considerations in Criminal Animal Abuse Cases. Available online: https://aldf.org/article/charging-considerations-in-criminal-animal-abuse-cases/ (accessed on 17 March 2019).

Animal Legal Defense Fund. n.d.c. Animals as Crime Victims: Development of a New Legal Status. Available online: https://aldf.org/article/animals-as-crime-victims-development-of-a-new-legal-status/ (accessed on 22 May 2019).

Animal Legal Defense Fund. n.d.d. Animal Neglect Facts: State and Local Law. Available online: https: //aldf.org/article/animal-neglect-facts/animal-neglect-facts-state-law/ (accessed on 18 May 2019).

American Pet Product Association (APPA). 2018. The 2017-2018 APPA National Pet Owners Survey Debut. Available online: https://americanpetproducts.org/Uploads/MemServices/GPE2017_NPOS_Seminar.pdf (accessed on 25 March 2019). 
Arkow, Phil, and Frank R. Ascione. 1998. Child Abuse, Domestic Violence, and Animal Abuse: Linking the Circles of Compassion for Prevention and Intervention. West Lafayette: Purdue University Press.

Ascione, Frank R., and Randall Lockwood, eds. 1997. Cruelty to Animals and Interpersonal Violence: Readings in Research and Application. West Lafayette: Purdue University Press.

Ascione, Frank R., Claudia V. Weber, and David S. Wood. 1997. The Abuse of Animals and Domestic Violence: A National Survey of Shelters for Women Who Are Battered. Society and Animals 5: 205-18. [CrossRef]

Ascione, Frank R., Claudia V. Weber, T. M. Thompson, J. Heath, M. Maruyama, and K. Hayashi. 2007. Battered pets and domestic violence: Animal abuse reported by women experiencing intimate violence and by non-abused women. Violence Against Women 13: 354-73. [CrossRef] [PubMed]

American Society for the Prevention of Cruelty to Animals (ASPCA). n.d. Shelter Intake and Surrender: Pet Statistics. Available online: http://www.aspca.org/animal-homelessness/shelter-intake-and-surrender/pet-statistics (accessed on 20 March 2019).

Associated Press. 2013. Meals on Wheels Helps Feed Pets of Seniors, Disabled. CBS News. Available online: https://www.cbsnews.com/news/meals-on-wheels-helps-feed-pets-of-seniors-disabled/ (accessed on 7 March 2019).

Bailey, Grant. 2018. Pet Owners Prefer Company of Animals Over their Human Best Friends, Poll Claims. The Independent. Available online: https://www.independent.co.uk/life-style/pet-owners-prefer-animalshumans-best-friends-study-dog-cat-survey-a8644451.html (accessed on 24 March 2019).

Bandura, Albert. 1986. Social Foundations of Thought and Action: A Social Cognitive Theory. Upper Saddle River: Prentice Hall.

Barker, R. T., J. S. Knisely, S. B. Barker, R. K. Cobb, and C. M. Schubert. 2012. Preliminary investigation of employee's dog presence on stress and organizational perceptions. International Journal of Workplace Health Management 5: 15-30. [CrossRef]

Barrett, Betty Jo, Amy Fitzgerald, Rochelle Stevenson, and Chi Ho Cheung. 2017. Animal Maltreatment as a Risk Marker of More Frequent and Severe Forms of Intimate Partner Violence. Journal of Interpersonal Violence 26: 0886260517719542. [CrossRef]

Bekoff, Marc. 2013. A Universal Declaration on Animal Sentience: No Pretending. Psychology Today. Available online: https://www.psychologytoday.com/us/blog/animal-emotions/201306/universal-declaration-animalsentience-no-pretending (accessed on 29 April 2019).

Bekoff, Marc, and Jessica Pierce. 2019. Unleashing Your Dog: A Field Guide to Giving Your Canine Companion the Best Life Possible. Novato: New World Library.

Benbow, Dana Hunsinger. 2013. Pet 'Parents' Pamper to the Extreme. USA Today. Available online: https: //www.usatoday.com/story/news/nation/2013/07/21/pet-parents-pamper-to-the-extreme/2572021/ (accessed on 24 March 2019).

Berger, Knute. 2012. The Problem of Pampered Pets. Seattle Magazine. Available online: https://www.seattlemag. com/article/problem-pampered-pets (accessed on 13 May 2019).

Berns, Gregory. 2017. What It's Like to Be a Dog. New York: Basic Books.

Beston, Henry. 1928. The Outermost House. New York City: Henry Holt and Company.

Bland, Alastair. 2013. Is Taking Your Pet on an Airplane Worth the Risk? Smithsonian.com. Available online: https: //www.smithsonianmag.com/travel/is-taking-your-pet-on-an-airplane-worth-the-risk-6241533/ (accessed on 30 April 2019).

Bolliger, Gieri. 2015. Legal Protection of Animal Dignity in Switzerland: Status Quo and Future Perspectives. Animal Law 22: 311.

Bounds, Gwendolyn. 2011. The Dog Maxed Out My Credit Card. The Wall Street Journal. Available online: https://www.wsj.com/articles/SB10001424052970204394804577011824160591082 (accessed on 13 May 2018).

Britten, Liam. 2017. Petition calls for end to 'no pets' policies in rental housing. CBC News. Available online: https:/www.cbc.ca/news/canada/british-columbia/no-pets-rental-1.3985220 (accessed on 18 March 2019).

Britton, Ann Hartwell. 2006. Bones of Contention: Custody of Family Pets. Journal of the American Academy of Matrimonial Lawyers 20: 1.

Brooks, Helen, Kelly Rushton, Sandra Walker, Karina Lovell, and Anne Rogers. 2016. Ontological security and connectivity provided by pets: A study in the self-management of the everyday lives of people diagnosed with a long-term mental health condition. BMC Psychiatry 16: 409. [CrossRef] 
Brooks, H. L., K. Rushton, K. Lovell, P. Bee, L. Walker, L. Grant, and A. Rogers. 2018. The power of support from companion animals for people living with mental health problems: A systematic review and narrative synthesis of the evidence. BMC Psychiatry 18: 31. [CrossRef] [PubMed]

Broom, D. M. 2007. Cognitive ability and sentience: Which aquatic animals should be protected? Diseases of Aquatic Organisims 75: 99-108. [CrossRef]

Burn, Charlotte C. 2017. Bestial boredom: A biological perspective on animal boredom and suggestions for its scientific investigation. Animal Behaviour 130: 141-51. [CrossRef]

Cano Pecharroman, Lidia. 2018. Rights of Nature: Rivers That Can Stand in Court. Resources 7: 13. [CrossRef]

Carbonara, Emanuela. 2017. Law and Social Norms. In The Oxford Handbook of Law and Economics: Volume 1: Methodology and Concepts. Edited by Francesco Parisi. Oxford: Oxford University Press.

Carmack, Betty J. 2003. Grieving the Death of a Pet. Minneapolis: Augsburg Press.

Cassuto, David, Jonathan Lovvorn, Katherine Meyer, and Joyce Tischler. 2006. Legal Standing for Animals and Advocates. Animal Law 13: 61-86.

Cavanaugh, Lisa A., Hillary A. Leonard, and Debra L. Scammon. 2008. A Tail of Two Personalities: How Canine Companions Shape Relationships and Well-being. Journal of Business Research 61: 469-79. [CrossRef]

Charles, Nickie. 2014. 'Animals Just Love You as You Are': Experiencing Kinship across the Species Barrier. Sociology 48: 715-30. [CrossRef]

Charles, Nickie. 2016. Post-Human Families? Dog-Human Relations in the Domestic Sphere. Sociological Research Online 21: 1-12. [CrossRef]

Choplin, Lauren. 2018. Nonhuman Rights Project Argues for Elephant Personhood, Rights in New York Supreme Court. Available online: https://www.nonhumanrights.org/blog/happy-habeas-hearing-albion/ (accessed on 18 March 2019).

Cima, Greg. 2014. Animals Can Be Considered Crime Victims in Oregon. Journal of the American Veterinary Medical Association. Available online: https://www.avma.org/News/JAVMANews/Pages/141015i.aspx (accessed on 18 March 2019).

Cizmar, Martin. 2017. Cute Counts: Meet Kevin Reynolds, the Guy Who Drew Those Adorable 'End Petlessness' Billboards. Willamette Week. Available online: https://www.wweek.com/portland/article-18206-cute-counts. html (accessed on 18 March 2019).

Clements, Paul T., Kathleen M. Benasutti, and Andy Carmone. 2003. Support for Bereaved Owners of Pets. Perspectives in Psychiatric Care 39: 49-54. [CrossRef] [PubMed]

Cohen, S. P. 2002. Can pets function as family members? Western Journal of Nursing Research 24: 621-38. [CrossRef] [PubMed]

Colling, Sarat. 2014. Animals without Borders: Farmed Animal Resistance in New York. Master's thesis, Brock University, Catharines, ON, Canada. Available online: https://dr.library.brocku.ca/handle/10464/5229 (accessed on 23 March 2019).

Cook, James O., and Adrian Hochstadt. 2009. Non-Economic Damages in Pet Lawsuits. GPSolo Magazine 26: 33.

Cooter, Robert. 1998. Expressive Law and Economics. The Journal of Legal Studies 27: 585. [CrossRef]

Coren, Stanley. 2011. Do We Treat Dogs the Same Way as Children in Our Families? Psychology Today. Available online: https://www.psychologytoday.com/us/blog/canine-corner/201105/do-we-treat-dogs-the-same-waychildren-in-our-families (accessed on 17 March 2019).

Corman, L. 2017. Ideological Monkey Wrenching: Nonhuman Animal Politics beyond Suffering. In Animal Oppression and Capitalism - Volume 2: The Oppressive and Destructive Role of Capitalism. Edited by D. Nibert. Santa Barbara and Denver: Praeger Press, pp. 252-69.

County of Fresno, Office of the District Attorney. 2015. District Attorney Forms 'Animal Cruelty' Unit for Fresno County. News Release. Available online: https://www.co.fresno.ca.us/Home/ShowDocument?id=10372 (accessed on 21 February 2019).

County of San Diego, Office of the District Attorney. 2018. District Attorney Summer Stephan Establishes New Animal Cruelty Prosecution Unit. News Release. Available online: https://www.sdcda.org/files/Animal\% 20Cruelty\%20Unit\%205-30-18.pdf (accessed on 21 February 2019).

Cowels, Kathleen V. 1985. The Death of a Pet: Human Responses to the Breaking of the Bond. Marriage and Family Review 8: 135-48. [CrossRef]

Cupp, Richard L., Jr. 2016. Animals as More Than 'Mere Things,' But Still Property: A Call for Continuing Evolution of the Animal Welfare Paradigm. University of Cincinnati Law Review 84: 1023. 
Dale, Steve. 2013. Who Suffers Most from the Rising Cost of Veterinary Care? Veterinary Economics, dvm360. Available online: http://veterinarybusiness.dvm360.com/who-suffers-most-rising-cost-veterinary-care (accessed on 13 May 2019).

Deckha, Maneesha. 2015. Vulnerability, Equality, and Animals. Canadian Journal of Women and the Law 1: 47-70. [CrossRef]

Deckha, Maneesha. 2017. Humanizing the Nonhuman: A Legitimate Way for Animals to Escape Juridical Property Status? In Critical Animal Studies: Towards Trans-Species Social Justice. Edited by Atsuko Karin Matsuoka and John Sorenson. London: Rowan and Littlefield International.

DeMello, Margo, ed. 2016. Mourning Animals: Rituals and Practices Surrounding Animal Death. East Lansing: Michigan State University Press.

DiConcetto, Alice. 2016. The 2015 Amendment to the Code Civil in France: Animals as Sentient Beings, and as Non-Property. Animales y Derecho. Available online: https://www.danla-derechoanimal.com/singlepost/2016/05/28/The-2015-Amendment-to-the-Code-Civil-in-France-Animals-as-sentient-beings-and-asnonproperty-1 (accessed on 12 May 2019).

Doka, Kenneth J., ed. 1989. Disenfranchised Grief: Recognizing Hidden Sorrow. Lanham: Lexington Books.

Donaldson, Sue, and Will Kymlicka. 2011. Zoopolis: A Political Theory of Animal Rights. Oxford: Oxford University Press.

Dreifus, Claudia. 2017. Gregory Berns Knows What Your Dog Is Thinking (It's Sweet). New York Times. Available online: https://www.nytimes.com/2017/09/08/science/gregory-berns-dogs-brains.html (accessed on 18 March 2019).

Dunn, Lora, and David B. Rosengard. 2017. A Dog is Not a Stereo: The Role of Animal Sentience in Determining the Scope of Owner Privacy Interests Under Oregon Law. Animal Law 23: 451.

Edelman, Adam. 2018. Collared: New laws crack down on fake service dogs. NBC News. Available online: https://www.nbcnews.com/politics/politics-news/collared-new-laws-crack-down-fake-service-dogsn871541 (accessed on 7 March 2019).

Effective Altruism Foundation. 2017. The Relevance of Wild Animal Suffering. Effective Altruism Foundation. Available online: https://ea-foundation.org/blog/the-relevance-of-wild-animal-suffering/ (accessed on 7 March 2019).

Eisen, Jessica. 2017. Animals in the constitutional state. International Journal of Constitutional Law 15: 909-54. [CrossRef]

Eisen, Jessica, and Kristen Stilt. 2016. Protection and Status of Animals. In Max Planck Encyclopedia of Comparative Constitutional Law. Edited by Rainer Grote, Frauke Lachenmann and Rüdiger Wolfrum. New York: Oxford University Press.

El Nasser, Haya. 2011. Fastest-Growing Urban Parks Are for the Dogs. USA Today. Available online: http: //usatoday30.usatoday.com/news/nation/story/2011-12-07/dog-parks/51715340/1 (accessed on 17 March 2019).

Epstein, Richard A. 2002. Animals as Objects, or Subjects, of Rights. In Animal Rights: Current Debates and New Directions. Edited by Martha Nussbaum and Cass R. Sunstein. Oxford: Oxford University Press.

Favre, David. 2000. Equitable Self-Ownership for Animals. Duke Law Journal 50: 473-502. [CrossRef]

Favre, David. 2003. Overview of Damages for Injury to Animals-Pet losses. Animal Legal E Historical Center; Michigan State University College of Law. Available online: https://www.animallaw.info/article/overviewdamages-injury-animals-pet-losses (accessed on 23 March 2009).

Favre, David. 2010. Living Property: A New Status for Animals Within the Legal System. Marquette Law Review 93: 1021.

Federal Bureau of Investigation. 2016. Tracking Animal Cruelty: FBI Collecting Data on Crimes Against Animals. News Release. Available online: https://www.fbi.gov/news/stories/-tracking-animal-cruelty (accessed on 21 February 2019).

Feinberg, Cara. 2016. Are Animals 'Things'? Harvard Magazine. Available online: https://harvardmagazine.com/ 2016/03/are-animals-things (accessed on 18 March 2019).

Fernandez, Angela. 2019. Not Quite Property, Not Quite Persons: A 'Quasi’ Approach for Nonhuman Animals. Canadian Journal of Comparative and Contemporary Law. Forthcoming.

Finsen, Lawrence, and Susan Finsen. 1994. From Compassion to Respect: The Animal Rights Movement in America. New York: Twayne Publishers. 
Flores, Andrew R., and Scott Barclay. 2015. Backlash, Consensus, Legitimacy, or Polarization: The Effect of Same-Sex Marriage Policy on Mass Attitudes. Political Research Quarterly 69: 43-56. [CrossRef]

Flynn, Melanie, and Matthew Hall. 2017. The case for a victimology of nonhuman animal harms. Contemporary Justice Review: Issues in Criminal, Social, and Restorative Justice 20: 3. [CrossRef]

Foreman, Anne M., Margaret K. Glenn, B. Jean Meade, and Oliver Wirth. 2017. Dogs in the Workplace: A Review of the Benefits and Potential Challenges. International Journal of Environmental Research and Public Health 14: 498. [CrossRef] [PubMed]

Fox, Michael. 2014. Shelters destroy millions of animals each year. The Washington Post. Available online: https://www.washingtonpost.com/local/shelters-destroy-millions-of-animals-each-year/2014/11/28/ 1759aef4-702c-11e4-ad12-3734c461eab6_story.html?utm_term=.6da647e2359c (accessed on 23 March 2019).

Francione, Gary. 2004. Animals, Property, and the Law. Philadelphia: Temple University Press.

Frasch, Pamela D., Katherine M. Hessler, Sarah M. Kutil, and Sonia S. Waisman. 2011. Animal Law in a Nutshell. St. Paul: Thompson Reuters.

Fritz Institute. 2006. Hurricane Katrina: Perceptions of the Affected. Available online: http://www.fritzinstitute. org/PDFs/findings/Hurricanekatrina_Perceptions.pdf (accessed on 24 March 2019).

Garric, Audrey. 2014. Why Animals Are Still Considered Property. Le Monde. Available online: https://www.lemonde.fr/planete/article/2014/04/17/pourquoi-les-animaux-sont-toujours-considerescomme-des-biens_4402810_3244.html (accessed on 12 May 2019).

Goldberg, Phil. 2013. Courts and Legislatures Have Kept the Proper Leash on Pet Injury Lawsuits Why Rejecting Emotion-Based Damages Promotes the Rule of Law, Modern Values, and Animal Welfare. Stanford Journal of Animal Law \& Policy 6: 30.

Griggs, Kristy. 2013. When Nothing Is Too Fancy for Fido. CNN. Available online: https://www.cnn.com/2013/04/ 15/living/pampered-pets/ (accessed on 13 May 2019).

Hardesty, J. L., L. Khaw, M. D. Ridgway, C. Weber, and T. Miles. 2013. Coercive control and abused women's decisions about their pets when seeking shelter. Journal of Interpersonal Violence 28: 2617-39. [CrossRef] [PubMed]

Hernandez-Silk, Chelsea. 2018. They Say Emotional Support Dog, We Say Service Dog: Why the Americans with Disabilities Act Should Recognize Emotional Support Dogs as Service Animals. Richmond Public Interest Law Review 21: 313.

Hessler, Kathy. 2007. Mediating Animal Law Matters. Journal of Animal Law \& Ethics 2: 21.

Hessler, Kathy. 2010. The Role of the Animal Law Clinic. Journal of Legal Education 60: 263-80. [CrossRef]

Hirschfeld, Rachel. 2007. Ensure Your Pet's Future: Estate Planning for Owners and Their Animal Companions. Marquette Elder's Advisor 9: 155.

Horowitz, Alexandra. 2009. Inside of a Dog: What Dogs, See Smell, and Know. New York: Scribner.

Hribal, Jason. 2010. Fear of the Animal Planet: The Hidden History of Animal Resistance. Petrolia: CounterPunch; Oakland: AK Press.

Irvine, Leslie. 2004. If You Tame Me: Understanding Our Connection with Animals. Philadelphia: Temple University Press.

Irvine, Leslie. 2013. My Dog Always Eats First: Homeless People and Their Animals. Boulder: Lynne Rienner Publishers, Inc.

Irvine, Leslie, and Laurent Cilia. 2017. More-than-human families: Pets, people, and practices in multispecies households. Sociology Compass 11: e12455. [CrossRef]

Kelton Global. 2017. New Study Finds Dogs Make People Better, Happier and Healthier Humans. Blog Post. Available online: https://www.keltonglobal.com/recognition/new-study-finds-dogs-make-people-betterhappier-healthier-humans/ (accessed on 20 February 2019).

Kerr, Jeffrey S., Martina Bernstein, Amanda Schwoerke, Matthew D. Strugar, and Jared S. Goodman. 2013. A Slave by any Other Name is Still a Slave: The Tilikum Case and Application of the Third Amendment to Nonhuman Animals. Animal Law 19: 221.

King, Barbara J. 2016. Should We Really Be Keeping Cats and Dogs-And Geckos-As Pets? National Public Radio. Available online: http://www.npr.org/sections/13.7/2016/05/05/476853317/should-we-really-be-keeping-catsand-dogs-and-geckos-as-pets (accessed on 17 March 2019).

Krohe, James, Jr. 2005. Who Let the Dogs Out? Planning 71: 24.

Kymlicka, Will. 2017. Social Membership: Animal Law Beyond the Property/Personhood Impasse. Dalhousie Law Journal 40: 123-55. 
Lane, Lea. 2018. Just Out: New Report on American Attitudes about Pets \& Their Safety in Cars. Forbes. Available online: https:/www.forbes.com/sites/lealane/2018/03/23/surprising-new-report-on-americanattitudes-about-pets-and-their-safety-in-cars/\#786e75b7054d (accessed on 8 March 2019).

Larsen, Karin. 2016. Should Pet Bans Be Banned? Renters and Landlords Square Off. CBS News. Available online: http://www.cbc.ca/news/canada/british-columbia/pet-bans-rental-tenancy-laws-1.3487719 (accessed on 17 March 2019).

Leonard, Jack. 2009. Animal cruelty crackdown in Los Angeles has results. Los Angeles Times. Available online: http://www.latimes.com/local/la-me-cruelty8-2009feb08-story.html (accessed on 12 February 2019).

Liebman, Matthew. 2011. Who the Judge Ate for Breakfast: On the Limits of Creativity in Animal Law and the Redeeming Power of Powerlessness. Animal Law 18: 133.

Liebman, Matthew. 2018. Right Now It's Like This. Paper presented at the 26th Animal Law Conference, Chicago, IL, USA, October 12-14.

Linzey, Andrew, ed. 2009. The Link between Animal Abuse and Human Violence. East Sussex: Sussex Academic Press. Logan, Jacqueline M. 2013. Detailed Discussion of Emerging Issues in Municipal Ordinances. Animal Legal E Historical Center; Michigan State University College of Law. Available online: https:/www.animallaw.info/ article/detailed-discussion-emerging-issues-municipal-ordinances (accessed on 23 March 2019).

Magnotti, Lauren. 2006. Pawing Open the Courthouse Door: Why Animals' Interests Should Matter. Saint John's Law Review 80: 455.

Maharaj, Nandini, and Colleen J. Haney. 2014. A Qualitative Investigation of the Significance of Companion Dogs. Western Journal of Nursing Research 37: 1175-93. [CrossRef]

Mann, Paul. 2008. How the Rich Pamper Their Pets. Forbes. Available online: https://www.forbes.com/2008/01/14/ pets-pampering-celebs-oped-cx_pma_0115pets.html\#195456e640ba (accessed on 24 March 2019).

Marceau, Justin. 2019. Beyond Cages: Animal Law and Criminal Punishment. Paper presented at the Lewis \& Clark Law School's 8th Annual Animal Law Review Symposium, Portland, OR, USA, March 15.

Martin, Logan. 2011. Dog Damages: The Case for Expanding Available Remedies for the Owners of Wrongfully Killed Pets in Colorado. University of Colorado Law Review 82: 921.

McGinnis, Annika, and Alicia McElhaney. 2014. Euthanizing Pets Increasing as Vet Costs Rise. USA Today. Available online: https:/www.usatoday.com/story/news/nation/2014/06/07/economic-euthanasia-petsincreases/7790733/ (accessed on 7 March 2019).

Meals on Wheels. 2016. Meals on Wheels America Awards \$300,000 to Local Meals on wheels Programs Working to Keep Seniors and their Pets Together. News Release. Available online: https: //www.mealsonwheelsamerica.org/learn-more/national/press-room/2016/06/03/meals-on-wheels-americaawards-\$300-000-to-local-meals-on-wheels-programs-working-to-keep-seniors-and-their-pets-together (accessed on 7 March 2019).

Mele, Christopher. 2017. When Couples Divorce, Who Gets to Keep the Dog? (Or Cat.). New York Times. Available online: https://www.nytimes.com/2017/03/23/us/divorce-pet-custody-dog-cat.html (accessed on 23 March 2019).

Merck, Melinda. 2012. Veterinary Forensics: Animal Cruelty Investigations. Hoboken: Wiley-Blackwell.

Morrish, Lisa Marie. 2014. The Elephant in the Room: Detrimental Effects of Animals' Property Status on Standing in Animal Protection Cases. Santa Clara Law Review 53: 1127.

Nadler, Janice. 2017. Expressive Law, Social Norms, and Social Groups. Law \& Social Inquiry 42: 60-75.

National Sheriffs' Association. 2018. Animal Cruelty as a Gateway Crime. Washington: Office of Community Oriented Policing Services. Available online: https://www.sheriffs.org/animalcrueltygateway (accessed on 17 March 2019).

Nelson, Sharon L. 2011. The Connection between Animal Abuse and Family Violence: A Selected Annotated Bibliography. Animal Law 17: 369.

Neumann, Jean-Marc. 2015. The Legal Status of Animals in the French Civil Code. Global Journal of Animal Law 1: 1-13.

New Hampshire Governor's Commission on the Humane Treatment of Animals. 2009. Analysis of Three Animal Cruelty Cases: 2009 Annual Report. Available online: https:/www.nh.gov/humane/documents/2009-abusereport.pdf (accessed on 17 March 2019).

Noel, Brook, and Pamela D. Blair. 2000. I Wasn't Ready to Say Goodbye. Naperville: Sourcebooks Press. 
North American Pet Health Insurance Association. 2018. State of the Industry Report 2018. Available online: https://naphia.org/industry/research-and-reports/ (accessed on 23 March 2019).

Nussbaum, Martha. 2018a. Working with and for Animals: Getting the Theoretical Framework Right. Journal of Human Development and Capabilities 19: 2-18. [CrossRef]

Nussbaum, Martha. 2018b. Why Freedom of Speech Is an Important Right and Why Animals Should Have It. Denver Law Review 95: 843.

O'Donnell, Erin L., and Julia Talbot-Jones. 2018. Creating legal rights for rivers: Lessons from Australia, New Zealand, and India. Ecology and Society 23: 7. [CrossRef]

Ollove, Michael. 2017. Several States Crack Down 'Fake' Service Animals. USA Today. Available online: https:/www.usatoday.com/story/news/2017/10/29/several-states-crack-down-fake-service-animals/ 807676001/ (accessed on 7 March 2019).

Orbell, Sheina, Patrick Lidierth, Caroline J. Henderson, Nicolas Geeraert, Claudia Uller, Ayse K. Uskul, and Maria Kyriakaki. 2009. Social-cognitive beliefs, alcohol, and tobacco use: A prospective community study of change following a ban on smoking in public places. Health Psychology 28: 753-61. [CrossRef] [PubMed]

Pallotta, Nicole R. 2009. Conditional. Alec's Story. Available online: https://alec-story.com/2009/07/04/conditional/ (accessed on 17 March 2019).

Pallotta, Nicole R. 2016. You're My Sanctuary: Grief, Vulnerability, and Unexpected Secondary Losses for Animal Advocates Mourning a Companion Animal. In Mourning Animals: Rituals and Practices Surrounding Animal Death. Edited by Margo DeMello. East Lansing: Michigan State University Press.

Pallotta, Nicole. 2017a. Unique Connecticut Law Allows Court-Appointed Advocates to Represent Animals. Animal Legal Defense Fund. Available online: https://aldf.org/article/unique-connecticut-law-allows-courtappointed-advocates-to-represent-animals/ (accessed on 20 March 2019).

Pallotta, Nicole. 2017b. Alaska Legislature Becomes First to Require Consideration of Animals' Interests in Custody Cases. Animal Legal Defense Fund. Available online: https:/aldf.org/article/alaska-legislature-becomes-firstto-require-consideration-of-animals-interests-in-custody-cases/ (accessed on 20 March 2019).

Pallotta, Nicole. 2018a. Advocating for Justice in Oregon: Neglected Horse Sues Former Owner. Animal Legal Defense Fund. Available online: https://aldf.org/article/advocating-for-justice-in-oregon-neglected-horsesues-former-owner/ (accessed on 27 February 2019).

Pallotta, Nicole. 2018b. Illinois Becomes Second State to Require Courts to Consider Well-being of Companion Animals in Custody Disputes. Animal Legal Defense Fund. Available online: https://aldf.org/article/illinoisbecomes-second-state-require-courts-consider-wellbeing-companion-animals-custody-disputes/ (accessed on 20 March 2019).

Pallotta, Nicole R. 2019. Reframing Companion Animal Disability Using the Social Model: Removing Barriers and Facilitating Care. In Animals, Disability, and the End of Capitalism: Voices from the Eco-ability Movement. Edited by Anthony J. Nocella II, Amber E. George and John Lupinacci. New York: Peter Lang Publishing.

Pash, Barbara. 2015. More Support Groups Helping with Loss of Pet. The Baltimore Sun. Available online: http://www.freep.com/story/life/2015/01/27/pet-loss-support-groups/22428305/ (accessed on 17 March 2019).

Patronek, G. J., L. T. Glickman, A. M. Beck, G. P. McCabe, and C. Ecker. 1996. Risk factors for relinquishment of dogs to an animal shelter. Journal of the American Veterinary Medical Association 209: 572-81. [PubMed]

Pew Research Center. 2006. Gauging Family Intimacy: Dogs Edge Cats (Dads Trail Both). Available online: https://www.pewsocialtrends.org/2006/03/07/gauging-family-intimacy/ (accessed on 25 March 2019).

Pierce, Jessica. 2015. Are Pets Really Family? Psychology Today. Available online: https://www.psychologytoday. com/us/blog/all-dogs-go-heaven/201510/are-pets-really-family (accessed on 17 March 2019).

Pierce, Jessica. 2016. Run, Spot, Run: The Ethics of Keeping Pets. Chicago: University of Chicago Press.

Proctor, Helen. S. 2012. Animal Sentience: Where are We and Where are We Heading? Animals 2: 628-39. [CrossRef]

Proctor, Helen S., Gemma Carder, and Amelia R. Cornish. 2013. Searching for Animal Sentience: A Systematic Review of the Scientific Literature. Animals 3: 882-906. [CrossRef]

Purina. 2016. Not Just A Saying: New Survey Confirms Dogs Really Are Man's Best Friend. News Release. Available online: http://newscenter.purina.com/2016-09-19-Not-Just-A-Saying-New-Survey-Confirms-DogsReally-Are-Mans-Best-Friend (accessed on 20 February 2019).

Rachlinski, Jeffrey J. 2000. The Limits of Social Norms. Chicago-Kent Law Review 74: 1537. 
Ramsey, Sherry. 2014. Enforcing Your State Animal Cruelty Laws. In Deputy and Court Officer. Alexandria: National Sheriffs' Association, Available online: https://www.sheriffs.org/publications/Animal-Cruelty-Issue.pdf (accessed on 23 March 2019).

Ramsey, Sherry, Mary Lou Randour, Nancy Blaney, and Maya Gupta. 2010. Protecting Domestic Violence Victims by Protecting Their Pets. Juvenile \& Family Justice Today. Available online: https://awionline.org/sites/default/files/ uploads/legacy-uploads/documents/DV-NCJFCJArticleSpring2010-040611-1302122112-document-38932.pdf (accessed on 23 March 2019).

Reisbig, Allison M. J., McArthur Hafen Jr., Adryanna A. Siqueira Drake, Destiny Girard, and Zachary B. Breunig. 2017. Companion Animal Death: A Qualitative Analysis of Relationship Quality, Loss, and Coping. OMEGA-Journal of Death and Dying 75: 124-50. [CrossRef]

Reppy, William A., Jr. 2005. Citizen Standing to Enforce Anti-Cruelty Laws by Obtaining Injunctions: The North Carolina Experience. Animal Law 11: 39-68.

Rocheleau, Matt. 2018. There Were 85 Pet Deaths on Flights in 3 Years. United Had 41 of Them. Boston Globe. Available online: https://www2.bostonglobe.com/metro/2018/03/15/united-animal-safety-record-drawsscrutiny-after-puppy-dies-overhead-bin/LIds3HhU29nWJiNlKDl7DO/story.html (accessed on 30 April 2019).

Rook, Deborah. 2014. Who Gets Charlie? The Emergence of Pet Custody Disputes in Family Law: Adapting Theoretical Tools from Child Law. International Journal of Law, Policy and the Family 28: 177-93. [CrossRef]

Satterlund, Travis D., Juliet P. Lee, and Roland S. Moore. 2012. Changes in smoking-related norms in bars resulting from California's Smoke-Free Workplace Act. Journal of Drug Education 42: 315-26. [CrossRef]

Satz, Ani. 2009. Animals as Vulnerable subjects: Beyond Interest-Convergence Hierarchy, and Property. Animal Law 16: 65-122.

Schoenfeld-Tacher, Regina, Peter Hellyer, Louana Cheung, and Lori Kogan. 2017. Public Perceptions of Service Dogs, Emotional Support Dogs, and Therapy Dogs. International Journal of Environmental Research and Public Health 14: 642. [CrossRef]

Schwartz, Victor E., and Emily J. Laird. 2006. Non-Economic Damages in Pet Litigation: The Serious Need to Preserve a Rational Rule. Pepperdine Law Review 33: 227-74.

Seps, Christopher D. 2010. Animal Law Evolution: Treating Pets as Persons in Tort and Custody Disputes. University of Illinois Law Review 4: 1334-74.

Shannon-Missal, Larry. 2015. More Than Ever, Pets Are Members of the Family. Available online: http: //www.theharrispoll.com/health-and-life/Pets-are-Members-of-the-Family.html (accessed on 23 March 2019).

Shir-Vertesh, Dafna. 2012. 'Flexible Personhood:' Loving Animals as Family Members in Israel. American Anthropologist 114: 420-32. [CrossRef]

Shore, E. R., C. L. Petersen, and D. K. Douglas. 2003. Moving as a reason for pet relinquishment: A closer look. Journal of Applied Animal Welfare Science 6: 39-52. [CrossRef]

Siler, Wes. 2018. You May Never Fly with Your Fake Service Dog Again. Outside. Available online: https: //www.outsideonline.com/2313991/flying-your-fake-service-dog-may-be-over (accessed on 7 March 2019).

Smith-Blackmore, Martha. 2018. The role of Veterinary Forensics in Animal Cruelty investigations. The Police Chief. Available online: http://nationallinkcoalition.org/wp-content/uploads/2018/02/Smith-Blackmore-VetForensics-IACP-2018.pdf (accessed on 17 March 2019).

Stolzer, Jeanne M. 2016. The Meteoric Rise of Mental Illness in America and Implications for Other Countries. The European Journal of Counselling Psychology 4: 228-46. [CrossRef]

Sunstein, Cass R. 1996. On the Expressive Function of Law. East European Constitutional Review 5: 66. [CrossRef] Sunstein, Cass R. 2000. Standing for Animals (with Notes on Animal Rights) A Tribute to Kenneth L. Karst. University of California at Los Angeles Law Review 47: 1333.

Sunstein, Cass R. 2003. The Rights of Animals. University of Chicago Law Review 70: 25. [CrossRef]

TD Ameritrade. 2018. Millennials and Their Fur Babies. Available online: https://s2.q4cdn.com/437609071/files/ doc_news/research/2018/Millennials-and-Their-Fur-Babies.pdf (accessed on 26 February 2018).

The Trust for Public Land. 2016. Dog Parks Lead Growth in Urban Parks. News Release. Available online: https://www.tpl.org/media-room/dog-parks-lead-growth-urban-parks (accessed on 7 March 2019).

Thompson, Derek. 2013. These 4 Charts Explain Exactly How Americans Spend \$52 Billion on Our Pets in a Year. The Atlantic. Available online: https://www.theatlantic.com/business/archive/2013/02/these-4-charts-explainexactly-how-americans-spend-52-billion-on-our-pets-in-a-year/273446/ (accessed on 13 May 2019). 
Tischler, Joyce. 2012. A Brief History of Animal Law, Part II (1985-2011). Stanford Journal of Animal Law and Policy 5: 27-77.

Tomasik, Brian. 2009. The Importance of Wild-Animal Suffering. Foundational Research Institute. Available online: https://foundational-research.org/the-importance-of-wild-animal-suffering/ (accessed on 7 March 2019).

Toray, Tamina. 2004. The Human-animal Bond and Loss: Providing Support for Grieving Clients. Journal of Mental Health Counseling 26: 244-59. [CrossRef]

Voith, V. L. 1985. Attachment of people to companion animals. Veterinary Clinics of North America: Small Animal Practice 15: 289-95. [CrossRef]

Vokolek, Breahn. 2008. America Gets What it Wants: Pet Trusts and a Future for its Companion Animals. UMKC Law Review 76: 1109.

Waisman, Sonia A., Pamela D. Frasch, and Bruce A. Wagman. 2014. Animal Law: Cases and Materials, 5th ed. Durham: Carolina Academic Press.

Walsh, Froma. 2009. Human-Animal Bonds II: The Role of Pets in Family. Family Process 48: 481-99. [CrossRef]

Wranke, Melissa Batchelor. 2018. Your Marriage Is Over-Who Gets Custody of the Pets? Glamour. Available online: https://www.glamour.com/story/who-gets-pet-custody-divorce (accessed on 8 March 2019).

Warren, Ellen. 2010. For Owners, It's More than Puppy Love. Chicago Tribune. Available online: https://www. chicagotribune.com/living/ct-xpm-2010-04-29-sc-fash-0429-ellen-pet-shopping-column-story.html (accessed on 24 March 2019).

Weiss, Emily, Margaret Slater, L. Garrison, N. Drain, E. D. Dolan, J. M. Scarlett, and S. Zawistowski. 2014. Large dog relinquishment to two municipal facilities in New York City and Washington, D.C.: Identifying targets for intervention. Animals 4: 409-33. [CrossRef]

Weiss, Emily, Shannon Gramann, C. Victor Spain, and Margaret Slater. 2015. Goodbye to a Good Friend: An Exploration of the Re-Homing of Cats and Dogs in the U.S. Open Journal of Animal Sciences 5: 435-56. [CrossRef]

Wells, M., and R. Perrine. 2001. Critters in the cube farm: Perceived psychological and organizational effects of pets in the workplace. Journal of Occupational Health Psychology 6: 81-87. [CrossRef] [PubMed]

White, Steve. 2009. Companion Animals: Members of the Family or Legally Discarded Objects? University of New South Wales Law Journal 42: 852.

Williams, Timothy. 2019. Legal Rights for Lake Erie? Voters in Ohio City Will Decide. New York Times. Available online: https://www.nytimes.com/2019/02/17/us/lake-erie-legal-rights.html (accessed on 27 February 2019).

Wisch, Rebecca F. 2017. Table of Veterinary Reporting Requirement and Immunity Laws. Animal Legal \& Historical Center. Available online: https://www.animallaw.info/topic/table-veterinary-reporting-requirement-andimmunity-laws (accessed on 18 May 2019).

Wise, Steven. 2000. Rattling the Cage: Toward Legal Rights for Animals. New York: Perseus Publishing.

Wise, Steven M. 2010. Legal Personhood and the Nonhuman rights Project. Animal Law 17: 1.

Wolfson, David J., and Mariann Sullivan. 2004. Foxes in the hen house. In Animal Rights: Current Debates and New Directions. Edited by Cass R. Sunstein and Martha Craven Nussbaum. Oxford: Oxford University Press, pp. 205-28.

(C) 2019 by the author. Licensee MDPI, Basel, Switzerland. This article is an open access article distributed under the terms and conditions of the Creative Commons Attribution (CC BY) license (http://creativecommons.org/licenses/by/4.0/). 
Article

\title{
Framing 'Friend': Media Framing of 'Man's Best Friend' and the Pattern of Police Shootings of Dogs
}

\author{
Devon Thacker Thomas ${ }^{1, *}$ and Jenny R. Vermilya ${ }^{2}$ \\ 1 Department of Sociology, California State University, Fullerton, CA 92831, USA \\ 2 Department of Sociology \& Human Services, University of North Georgia, Dahlonega, GA 30597, USA; \\ Jenny.Vermilya@ung.edu \\ * Correspondence: dethomas@fullerton.edu
}

Received: 16 February 2019; Accepted: 26 March 2019; Published: 2 April 2019

\begin{abstract}
The representation and framing of events by news sources plays a critical role in the way society comes to understand a given phenomenon. For example, the use of force by police officers against civilians is covered regularly by news media outlets. Far less widely examined, however, is the excessive use of force against companion animals or pets. Thus, to understand the ways in which police use of force against animals is framed in the media, we conducted qualitative content analyses of 189 print news articles published in diverse regions of the U.S. over the course of a six-year period (2011-2016). Drawing on symbolic interactionism, analysis reveals that the media's representation of incidents of police shootings of dogs speaks not only to the social value dogs have in society, but also to the acceptability of friendships between humans and dogs. Specifically, we argue that some dog-human relationships are more socially acceptable than others and, therefore, shootings against some dogs are perceived as less acceptable than others. Ultimately, we find that news media representation and the ways in which incidents are framed reify existent social hierarchies. This research contributes to growing bodies of literature on police violence, the shift in perspectives on animals in society, and the power of the media to affect public perception of incidents.
\end{abstract}

Keywords: dog-human friendship; companion animals; interspecies hierarchy; media and crime

\section{Introduction}

The social definition of a dog as a companion who lives in one's home or as a member of the family is relatively new. After World War II, as economic prosperity, and therefore disposable income, grew within the U.S., pet-keeping increased in popularity (Swabe 1999; Jones 2003). Dogs historically, and still today, held various social statuses. They have been working animals on farms or ranches, in the entertainment industry as racing or show dogs, and in human families as companions (Sanders 1999; Irvine 2004). Though the move to companion is more recent, the idea of the dog as 'man's best friend' is deeply embedded in American society today. The evolution of social definitions of species, such as dogs, illustrates the changing relationships humans have with other species. In this article, we use this shift in the societal definition of the dog to highlight the contemporary allowance of a new type of friendship: the dog-human friendship. This relationship represents a transition in the social value and societal understanding of species, dog and human alike.

The role and social value of dogs within families is shaped and challenged by social institutions. In particular, as society experiences increased incidents in which police shoot family dogs (Olsen 2016; Gaffney 2018), law enforcement plays an increasingly important role in the public's perception of dogs. Accordingly, the use of force by law enforcement is a source of interest and concern among the civilian public. With this in mind, news media, another influential social institution, continues to follow and report situations in which police use what is deemed as excessive use of force against human civilians (Sacco 1995; Lersch and Mieczkowski 2005; Harris 2009; Klahm and Tillyer 2010). 
However, the use of force by police extends past humans, though, and also includes nonhuman animals. Recent media publications, citing the Department of Justice, estimate that law enforcement kills approximately 25 dogs every day in the United States within a single year (see Scott 2016; Chappell 2018). Accordingly, we examine how journalists, and thereby media, present the narratives involving police use of force against nonhuman animals, specifically, those in which police shoot companion dogs who are family pets.

In reporting on numerous instances of animal cruelty, news media shapes the public's perception of animal-related crimes (Grugan 2019). Simultaneously, law enforcement has experienced an increased rate of visibility, largely due to news media coverage of police shooting incidents and entertainment media focused on crime (Donovan and Klahm 2015). Thus, the police are increasingly noticed for violent interactions occurring in the course of their duties. For example, the social awareness of the police shootings of black and brown individuals is now perceived as more commonplace due to the attention given in the media. Consequently, average citizens are more exposed to the notions that race, social class, and neighborhood community factors-which policing studies have long documented as significant in understanding police use of force-can play a role in incidents of police violence (Garner et al. 2002; Terrill and Reisig 2003). We draw a parallel to this instance of police violence, but examine the phenomenon of the shootings of companion dogs instead of humans and the role media plays in drawing attention to them. Notably, we do not claim a causal relationship between the shootings of mostly young men of color and the shootings of companion dogs; however, paralleling Bierne's (2018) sentiment that nonhuman animals are valued much less highly than humans, we argue that marginalized groups broadly—such as young men of color and nonhuman animals—are devalued when compared against other groups of human lives. As a result, the killings of young men of color and theriocides fail to receive equivalent attention by the public. Given the current social landscape regarding public exposure to acts of police violence, we acknowledge the role the media plays in not only covering such incidents, but also how they frame the incidents.

Drawing on symbolic interactionism, we conducted a qualitative content analysis of print news articles covering cases of police shootings of dogs within the United States. Findings demonstrate that the media's portrayal of incidents of police shootings of dogs sheds great light not only on the social value of dogs in society, but also on the acceptability of friendships between humans and dogs. Specifically, we argue that the media's representation of incidents in which police shoot dogs suggests that certain dog-human relationships are more socially acceptable than others based on the placement of the dog and the human within their own species hierarchy as constructed by U.S. society.

In this article, we explore the history of dogs and humans, noting that while the dog-human relationship has a well-documented past, the recognition of dog-human friendships is lacking. We begin with a review of the literature on social changes that were necessary to foster an emerging narrative that nonhuman and human animals could be friends. Next, we explain the stratification of a species hierarchy that places certain nonhuman animals, along with certain humans, as more or less 'friend-worthy'. We use the theoretical lenses of media framing and symbolic interactionism to examine the significance of symbolic frames in shaping these friend designations. We then explain the methodological approach employed in the present study before presenting the findings. Data cover a variety of themes found in print media articles that influence how readers of these news publications assess not only the dog-human relationship, but also the outcome of the violent police interaction as well. In this way, we contend that print news media commands very real power to shape how humans decide which dog-human friendships are more or less socially acceptable and, as a result, how the public evaluates incidents, such as police shootings of dogs, which involve these friendships. 


\section{Literature Review}

\subsection{The Historical Relationship of Dogs and Humans}

Much of the literature on early dog-human relationships focuses on a symbiotic relationship of survival. Evidence of dogs and humans as hunting partners or as reciprocal protectors substantiates this focus (DeMello 2012). However, the interesting relationship in the present study extends beyond simple survival. We focus on friendships-the actual relationship between the dog-human dyad-and the 'friend-worthy' characteristics held by a given dog or human within a dyad based on the perceived social hierarchies of each species. 'Friend-worthy' characteristics include access to individuality, empathy, and justice. In other words, when we grant dogs and/or humans the symbolic label of 'friend', we frame their stories in ways that personalize them as sentient beings undeserving of suffering violence.

It is difficult to determine when exactly dogs and humans first became friends, companions, or family members, especially considering how social context matters. In many current social environments, dogs are defined as working animals and are not seen as being equal friends with humans; in other situations, dogs can be defined as food (Singer 1975; Arluke and Sanders 1996; Sanders 1999; Swabe 1999; Jones 2003; Irvine 2004; Herzog 2010; Hamilton and Taylor 2013). Regardless, an undeniable shift in the social definition of dogs within U.S. society has clearly occurred.

\subsection{Dog-Human Friendships}

The notion that dogs and humans can experience meaningful relationships is relatively commonplace in contemporary U.S. society. Cultural mantras such as 'man's best friend' permeate the American social landscape (Sanders 1999; Irvine 2004). Film depictions that range from humorous (e.g., Beethoven) to distressing (e.g., Marley $\mathcal{E} M e$ ) showcase the wide range of emotional connections humans can share with dogs. Similarly, literature contains many examples of this friendship (e.g., Where the Red Fern Grows and Merle's Door). The capitalistic economy even has a market for dog caretakers to engage in consumerism on behalf of their pets, with birthday or holiday gift-giving now a norm within this relationship. Healthcare and veterinary services also enjoy a growing marketplace niche as canines have evolved into a species that receives significant attention and care from practitioners (Swabe 1999; Jones 2003). Numerous institutions and areas of social life presently have the dog-human friendship embedded within them. Yet, the idea that dogs, or any animal for that matter, could be friends, is fairly recent. The following demonstrates how animals, specifically dogs, came to be embraced as friends, while also addressing how not all animals are deemed as 'friend-worthy'. Notably, we also include a discussion of human animals as friends to dogs, as well, because humans are also on a species hierarchy and their label of 'friend' likewise influences our assessment of the dog-human interaction. Finally, we argue that even certain breeds within socially approved species are deemed unworthy of friendship relative to all humans, resulting in an intra-species hierarchy.

\subsubsection{Can Animals be Friends?}

Historically, similar justifications for why animals were abused and exploited were also used to deny human-animal friendships. Scholars such as Mead (1934) proposed that humans and nonhuman animals were inherently different; that nonhuman animals lacked language and other skills that humans possessed. This distinction, according to Mead, placed animals on a different, inferior, cognitive level than humans. If animals lacked language, then they lacked the ability to communicate with us in similar ways. This reasoning has been used to claim that humans corner the market on language and, consequently, on relationships that rely on shared communication methods.

However, contemporary scholars demonstrated that nonhuman animals, including dogs, possess mindedness and thereby can engage in intersubjective interactions with humans. Sanders (1999), in his ethnographic monograph Understanding Dogs: Living and Working with Canine Companions, determined that dogs not only help humans create and maintain a social self for themselves, but dogs also possess 
a sense of personhood of their own. Sanders (1999) found that those who lived and worked with dogs fully acknowledged that their dog had a personality, goals, preferences, and emotional intelligence that allowed them to be in meaningful relationships with them. Similarly, Irvine (2004), in her book If You Tame Me: Understanding our Connection with Animals, challenged the historical notion that humans and nonhuman animals, specifically dogs and cats, cannot relate intersubjectively because animals lack a sense of self. Her study of shelter animals provides compelling support debunking the claim that to suggest nonhuman animals possess a sense of self is simple anthropomorphism.

Bierne (2018) applies these more current conceptualizations of self and personhood in animals to the phenomena of human killing of nonhuman animals (in varied forms and contexts), which he identifies as theriocide. In his work, Murdering Animals, he examines the rights of animals and questions humans as "the only beings worthy of entitlement to rights" (Bierne 2018, p. 3). He contends that the presence of speciesism leads humans to categorize nonhuman animals as subordinate and, as a result, human-induced deaths of domesticated and wild animals are neither seen as wrong nor illegal and, ultimately, remain invisible. Bierne (2018) argues for advancement in the recognition of animals to not only have the right to life, but to their own lives, and not the lives humans think a given nonhuman animal should live. Additionally, founded in his claims of self and personhood, Bierne (2018) claims animals have the right to be treated with respect and not as property. Assertions such as these challenge the omnipresent species hierarchy and more easily allow for the possibility of development and recognition of friendship between animal and human.

\subsubsection{Species Hierarchy}

While much social redefinition has allowed animals, specifically dogs, to be seen as friends, it is crucial to note that not all animals are given this title; not even all dogs are afforded it. Nonhuman animal species have long been placed into hierarchical statuses. Whether humans consume the animal or not has been used as a justification for the animal's social value or lack thereof (Singer 1975; Herzog 2010). The animal's social role as a companion (e.g., dogs), working tool (e.g., cattle), object of disgust (e.g., rats), or threatening fear tactic in cultural imaginings (e.g., pit bull terriers) also has been used to determine an animal's place in a hierarchy (Arluke and Sanders 1996).

Whereas the above criteria draw on animal purpose and social role in determining its place within a hierarchy, Brickel (1985) proposes a view of the animal hierarchy based in social learning. He contends that humans do not have an innate understanding of certain species or breeds as socially valued while others are not. Rather, humans learn, in a systematic way within Western culture, "that certain classes of animals (e.g., dogs and cats) exist primarily to be loved [and] other animals (e.g., snakes) are to be feared or avoided" (pp. 33-34). Not only does the media emphasize these disparate messages, but, likewise, Brickel contends that families support the construction of the animal hierarchy, and even a hierarchy of breeds within a given species, through selection, monitoring, and omission of certain animals and breeds during the formative years in children's lives. While the institutions of media and family offer a context of learning within childhood, especially, Brickel (1985) suggests that "it is up to the animals themselves to encourage bond maintenance" (p. 40) through exemplifying qualities that are socially valued. The demonstration, or lack thereof, of these characteristics (e.g., warm, soft, playful, fun, or otherwise affectionate) and the ability for humans to bond, or not, with the animals as a result, offers a mechanism through which adult humans continue to accept different species, and even breeds within a given species such as dogs, as 'friend-worthy' or not.

Like Brickel (1985) who identifies traits required by animals to be categorized as 'friend-worthy', Bierne (2018) offers a list of characteristics that deny animals the 'friend-worthy' designation and, instead, present them as problematic and disposable to humans. Interestingly, this list is embedded in a discussion of state theriocide, which Bierne explains takes place when either the state or its appointees, including law enforcement, private shelters, military, and state departments, kill animals. In offering an example, Bierne (2018, p. 28) discusses state theriocide occurring indirectly when private shelters "euthanize animals who are homeless, elderly, unwell, unwanted or deemed dangerous to 
humans". This list of traits, taken together with the list suggested by Brickel (1985), bolster the claim of a species hierarchy.

Though centered in different explanations for the existence of an animal hierarchy, the explanations above share the notion that only some species are granted the title of friend and, furthermore, within a species, only some types of the species (e.g., breeds) are granted the title. So, while dogs have reached a high status level compared to other animals, many dogs are still seen as unbefitting as friends for humans. Notably, the work of Payne et al. (2015) is of particular interest to the current study considering its goal of explaining why some dog-human dyads are successful in terms of mutual benefit to both human and dog while others are not. Payne et al.'s review of recent research includes the finding that the physical traits of a dog, such as ear shape and coat color, affect human ratings of dog behavior and personality as well as work supporting the notion that human factors generally have more influence on the dog-human bond than canine factors. The implications of these findings are significant as they suggest that physical features of dogs, unrelated to the dog's actual personality or behavior, can lead to human discrimination against certain dogs and/or breeds. This reifies the presence of a human socially-constructed hierarchy of dogs. Also, this work offers criteria upon which humans, as dog caretakers and trainers, can be hierarchically understood as a species within the dog-human dyad.

Like the work of Payne et al. (2015) and others, Blouin (2013) examines the dog-human dyad. Blouin (2013) offers a typology of three cultural types or orientations of dog owners (i.e., dominionistic, humanistic, and protectionistic), which can, along with the work of Payne et al. (2015) described above, serve as a foundation upon which a creation of a hierarchy of dog caretakers can be understood. Blouin's orientations consider how humans relate to their dogs, care for their dogs, and what views the human has of animals generally. Humans within the dominionistic orientation view dogs as lesser than humans in value and status, are most likely to have less attachment within a dog-human relationship, and ultimately, often view dogs as 'objects' rather than as 'subjects'. In comparison, both the humanistic and protectionistic orientations place great social and emotional value on dogs. A critical distinguishing aspect of these orientations is that humanistic caretakers often view themselves as 'parents' of their dogs. As a result, they may spoil their dogs based on what the human perceives as needed and/or beneficial to the dog. However, in this way, the human often prioritizes their own interests over the dogs and, at times, this may lead to anthropomorphizing the dog (e.g., with costumes, toys, fancy collars). Ultimately, while the actions of a humanistic dog owner are unlikely to be deemed as harmful to the dog by society, the placement of oneself in the role of parent allows the human to hold a socially valued role that has been modeled within family and social settings from childhood (Brickel 1985). In comparison, protectionistic caretakers view dogs, and all animals, as having personhood and, as a result, engage in direct care and broader social activism with the intent of benefitting the animals. This orientation views humans and animals as equal and, as a result, works to highlight and elevate the status of animals without requiring "surrogate personhood" as does the humanistic orientation (Blouin 2013, p. 287). In this way, Blouin (2013) contends that the protectionist orientation exhibits biocentric attitudes, respectful of all nature, in comparison to the anthropocentric views of the humanistic orientation.

Aside from the dog-human dyad specifically, humans can be placed into social hierarchies based on many characteristics. Often, their perceived social value is key in determining their placement on such a hierarchy. As with certain breeds of dogs, marginalized humans are also not always seen as 'friend-worthy'. In the same way nonhuman animals were historically, and often are presently, not granted full personhood, human social groups such as the disabled, the homeless, the elderly, and children are also not granted such status. Additionally, felons and others charged with criminal behavior are often stigmatized, stripped of full personhood, and denied complete participation in society (Goffman 1963). This latter group is of particular interest to the present study as a central focus of our work is on the institution of law enforcement. Law enforcement already has a historical relationship with social groups that fall low on the social hierarchy scale of value. Here, though, 
our interest is on nonhuman animals, specifically dogs, who are either granted or denied higher social status through the label of 'friend'. While the actions and attitudes of law enforcement and the criminal justice system communicate a social hierarchy of humans, we argue this same institution applies a similar hierarchy formula to dogs. Likewise, other social institutions, such as media, further shape these social hierarchies. Indeed, just as the media has helped to illuminate the incidence of police shootings of a marginalized social group —individuals of color — so too has the media aided in generating exposure, albeit differentially framed as acceptable or unacceptable and reflective of the interspecies hierarchy, of the incidence of police shootings of companion dogs.

\subsection{Media Framing}

The media is an increasingly influential institution. Its power to frame stories is the central focus of much scholarship. As Sacco states, "because they are able to legitimate some views and to marginalize others, the news media are an important part of this framing process" (Sacco 1995, p. 149). Communication scholars have documented numerous examples of framing, along with their consequences for social discourse (see, for examples, De Vreese et al. 2001; Dimitrova et al. 2005; Olausson 2009). Within the discipline of sociology, symbolic interactionists have analyzed the importance of language and dramaturgical elements to social scenes that are characterized by other concepts such as scripting, which notes that social interactions have their own guidelines for actors, settings, and narrative (e.g., Goffman 1959; Berger and Luckmann 1967; Gagnon and Simon 1973). Because the present study analyzes news media, not the original words of either police or dog caretakers, media framing and symbolic interactionism serve as strong analytic lenses. While some articles directly quote dog caretakers and police officers, these stories are still understood through the journalist's perspective. The focus is on this medium as the means by which the public receives information about these cases and, consequently, experiences an emotional reaction shaped by it. Since the authors examine the reporting of police shootings of dogs and the social designations of acceptable dog-human friendships, this also means that the media is powerful in shaping social discourse around human-animal friendships in general.

In recent decades, scholars have more frequently used framing as a conceptual tool. Carragee and Roefs (2004) note that the definition of frames can vary among such scholars. They emphasize that framing needs to be linked to political and social power. Thus, framing is not simply a media effect, but a part of larger ideological processes. This critique employs early symbolic interactionist notions of social construction and meaning making as part of structural forces (see Goffman 1974). The working definition of frames applied in the present study attempts to reflect this critique as the authors also agree, "Although specific characterizations of frames differ, meaningful definitions emphasize the ways in which frames organize news stories and other discourses by their patterns of selection, emphasis, interpretation, and exclusion" (Carragee and Roefs 2004, pp. 215-216). Following the call of Entman (1993) in his seminal article Framing: Toward Clarification of a Fractured Paradigm, scholars employing framing can use this concept to examine the power of a communicating text, one that chooses certain aspects of a perceived reality to make them more prominent. Therefore, in deconstructing media frames around the police shootings of dogs, the authors deeply engage in the deconstruction of power structures within policing, the hierarchical social definitions of nonhuman animals, and the influence of the media as a social institution.

\section{Methods}

Using inductive qualitative content analysis, the authors examine how news sources represent various aspects of events involving police shootings of domesticated dogs. Qualitative content analysis goes beyond examining frequencies of words, phrases, and imagery, and instead allows researchers to condense raw data into categories and themes based on interpretation (Erlingsson and Brysiewicz 2017). This process, by its nature, involves inductive reasoning whereby themes and categories emerge from the data based on the researcher's careful examination and sustained comparison. 


\subsection{Data Collection and Sampling}

For this study, original data consisted of editorials, news articles, and commentary from print newspapers published in English between 2011-2016 across the United States. The authors used the search interface ProQuest Newsstand (now Newsstream) to input the search terms "police AND (dogs or pets) AND shoot". Filtering for relevance, the authors selected the first 1000 articles as a preliminary selection. From these, 189 distinct publications remained after the authors limited the sample to news articles published in 2011-2016 in the United States, and that involved police shooting activity against non-police dogs.

\subsection{Data Analysis}

Employing the analytic strategy proposed by Matthes and Kohring (2008), we examined each article for several frame elements. These elements, Matthes and Kohring contend, come from the widely accepted definition of frame introduced by Entman (original emphasis): "To frame is to select some aspects of a perceived reality and make them more salient in a communicating context, in such a way as to promote a particular problem definition, causal interpretation, moral evaluation, and/or treatment recommendation for the item described" (Entman 1993, p. 2). Within this definition, Matthes and Kohring identify the following elements comprising a given frame: (1) a problem definition which "can consist of an issue and relevant actors that discuss the problem"; (2) a causal interpretation which "is an attribution of failure or success regarding a specific outcome"; (3) a moral evaluation which "can be positive, negative, or neutral and can refer to different objects"; and (4) a treatment recommendation which "can include a call for or against a certain action" (Matthes and Kohring 2008, p. 264). Ultimately, after examination for the above elements, we engaged in hierarchical cluster analysis wherein there were "high differences between the clusters and low differences within a cluster" (Matthes and Kohring 2008, p. 264). Each cluster represented a media frame.

Applying the above method, the authors treated each news article as a singular unit of analysis. The first author began by performing initial coding of the first 40 articles. During the initial review, the first author identified the frame elements and also drew on Charmaz's (2014) constant comparative method, noting the police reason for responding to a call, the breed of the dog involved, the reported reason for the shooting of the dog, the dog's outcome from the incident, the officer's outcome from the incident, and the police department's response. This allowed for an additional level of systematic comparison of each unit of data with those already in any given cluster, while also allowing for the integration of additional categories and codes identified through interpretive memos.

Following the initial coding by the first author, the authors engaged in testing the coding scheme and preliminary hierarchical clusters for validity. Both authors agreed on the same set of 20 articles to code independently. The authors then met to discuss and calibrate their analyses. Inter-coder reliability was strong. In cases where one researcher disagreed with the initial coding by the other, both authors performed a second reading, followed by discussion to thereby lead to a final coding and cluster designation.

After completing the calibration, the authors split the full sample of 189 articles equally and coded articles for specific aspects of interest, including frame elements as well as characteristics that personalized animals, characteristics that affected perceptions of human beings, and words and phrases related to the relationship and role animals played within a social context. Both authors engaged in memoing during coding of each article.

\section{Results}

In this paper, we argue that through use of a variety of strategies, print media draws on and reifies existent nonhuman animal and human hierarchies. Specifically, certain social characteristics, practices, and roles are emphasized to effectively position both individual dogs and individual humans as more or less socially valued and, therefore, 'friend-worthy'. Drawing on the work of Brickel (1985); Blouin (2013) and Payne et al. (2015), we use the concept of friendship to describe the relationship 
between the dog-human dyad and, in comparison, employ the concept of 'friend-worthy' or the 'friend-worthiness' of either dog or human, when discussing the ways the dog or human meet or fail to meet, characteristics on the perceived social hierarchies of their species. As a result, when considering a given dog-human relationship within a particular shooting incident, the shooting itself is deemed either more or less justifiable based on the value placed on the individual dog, the individual human, and importantly, the connection and relationship they share. In other words, the news article frames the shooting as either something the readers should care about or not. Below, we identify and discuss the ways print media frame certain friendships between humans and companion dogs as more or less socially acceptable and, therefore, particular shootings of dogs as more or less justifiable or problematic.

\subsection{Incorporating Stereotyped Descriptions}

News media sources included a variety of descriptive characteristics, not including those provided within quoted portions of the articles from dog caretakers ${ }^{1}$ or law enforcement, of both the dogs involved in the shooting incidents as well as of their caretakers when one was identified. As a result, media sources often reify existing hierarchies within each particular species (dog or human) and encouraged reader perceptions of shootings as more or less justifiable based on the social value granted to the parties individually, but, even more poignantly, when taken as a companion animal-caretaker pair. Often these descriptions were specific and most articles included at least one form of description of the dogs involved in any given incident, including the dog's breed, name, age, weight, and, at times, the dog's health condition prior to the incident. The following are examples of succinct descriptive characteristics included in articles:

- “involving a 12-year-old arthritic golden retriever named Boomer" (Nipps 2011)

- “tan pit bull named Debo" (Valentine 2011)

- " "A 15-month old dog named Amore" (DeBolt 2013)

- "The pit bull, a 5-year-old male named Tank" (Graham 2014)

- " "12-year-old male 'pit bull'" (Mester 2014)

- " "staffordshire pit bull terrier named Jackson Smore" (Anderson 2014)

- "6-year-old Basset hound/beagle mix, Willy Pete" (Craig 2014)

- "the 6-year-old pit bull-terrier-boxer mix, named 'Wheezy'" (Day 2015)

- "The dog, a 90-pound German shepherd" (Gerez 2015)

While the above represents the types of descriptions of dogs occurring most often, overwhelmingly, when the breed of the dog was provided it was a pit bull or pit bull mix. Occasionally articles included other "bully" breeds (e.g., rottweilers, German shepherds, bull terrier, or mastiff), but it was more often, breed was noted when the dog shot was a pit bull or, in opposition, if the dog shot was a stereotypically easy-going, non-aggressive breed (e.g., labrador retriever, golden retriever, basset hound, brittany spaniel). Noting the breed in this way, either only in cases involving a stereotypically aggressive breed or harmless breed, emphasizes the ways media draws on pre-existing notions of the breeds to influence readership understanding of the shooting incident. Similarly, when articles included the name of a dog, the age (often either when the dog could be deemed a puppy or a senior), and the (poor) health status of a dog, it personalizes the dog and draws on readership emotion to influence their perspective of the dog as 'friend-worthy' and thereby judge the shooting of the dog as justifiable or not.

1 The authors use the terms "caretaker" and "guardian" in their own analysis of the published materials to acknowledge the personhood animals have. When there is incorporation of the word "owner", it reflects the use by journalists within the articles under analysis. 
In order to examine the consequences of this descriptive writing, take the comparative cases of two differently framed articles such as the one listed above about the 12-year-old arthritic golden retriever named Boomer and the incident concerning the 90-pound German shepherd. In the former article, the journalist and/or news editors begin by framing the shooting as a social violation requiring reform through use of the article's title: Dog's Death Influences Police Policy. This article sets the stage for the readers with its introductory sentences: "Police officers have shot and killed a half-dozen dogs this year in the city. But it was the seventh fatal shooting, involving a 12-year-old arthritic golden retriever named Boomer, that gave St. Petersburg police Chief Chuck Harmon pause" (Nipps 2011). This initial frame introduces the readers to a social problem by providing information about the larger pattern of police shootings of dogs. Then, by noting the consideration of the police chief, the individual in a position of power to implement institutional change, the social problem is justified as a valid issue of concern. The article goes on to describe that "a campaign to demand that police be trained in dealing with animals" was initiated by this dog's caretakers and has since become a "movement [which] includes an online petition at change.org and a dedicated Facebook page with more than 3700 followers" (Nipps 2011). In this article, the dog's caretaker was quoted saying: "'My wife was crying when she heard [of the police department's policy change],' Glass said. 'It's a mixed thing because Boomer had to sacrifice for positive change'"' (Nipps 2011). Here the inclusion of the caretaker's perspective helps to further personalize this dog, who has already been described with a name, age, and medical condition. This article did note that Boomer, albeit a stereotypical friendly breed, "initially seemed 'social,' according to [the officer's] report of the incident" yet "became 'vicious,'" after an officer tried to examine his identification tag (Nipps 2011). The article also relayed that "an internal investigation examining the Oct. 1 incident in which Officer Misty Swanson, 25, shot and killed the dog, police ruled the shooting was justified" (Nipps 2011). Even though the dog's actions could have been framed as justifying the shooting, and although an internal investigation ruled the shooting was indeed justified, the article still frames the story as a social wrong, a part of a larger systemic problem, and needing a social remedy in the form of policy change.

Alternatively, in the latter article focused on the 90-pound German shepherd, the title sets up quite a different frame for readers: Evanston Police Officer Shoots Dog. Article titles, such as this one, read as factual and confer less emotion than articles like the one previously discussed. The dog in this article is identified only by weight and breed in the title and, later in the article, by a young age (i.e., two-year-old). In our analysis of the data set, the choice of which descriptors to use in the articles helped to support the overall frame of the article. Whereas the previous article on Boomer personalized the dog as a stereotypical friendly breed and offered his age and medical condition to emphasize his vulnerability as a shooting victim, the article on the German shepherd does not include the dog's name, and offers descriptors that paint a picture of a large stereotypical aggressive breed. While journalists can use descriptors to relay factual information about a news story, they also can use them to frame the scene and characters within the story. However, descriptors may actually detract from other facts of the story. In this article, the author describes how an officer decided to check the basement of the house under investigation: "The dog, a 90-pound German shepherd, then came running out of the basement door after the officer opened it. The officer attempted to retreat back up the stairs but lost his balance and fell to the floor in a seated position before discharging his weapon several times. The two-year-old dog was taken to an animal hospital but then died, police said" (Gerez 2015). This article lacked information on whether the dog growled, lunged at, or bit the officer, so the actions of the dog may or may not have justified the shooting. Regardless, the reader of this news article is given limited, emotionless information that presents this story in a completely different frame than the story of Boomer, a story filled with emotion, calls for social justice, and reflections of policy changes. Yet, it was Boomer who was described in the police report as "vicious", while this German shepherd, according to the limited information provided in the news article, may have only surprised the officer who stumbled, fell, and undoubtedly was frightened of a dog with those descriptors-a dog without 
personal identity representing a large stereotypically aggressive breed. These two stories help to illustrate the overall patterns we saw regarding the use of dog descriptors in the articles.

Likewise, articles included descriptions of dog caretakers to establish not only the appropriateness of a given companionship, but also then, to suggest whether the shooting of the dog within the companionship was reasonable. Among others, descriptions in these cases included: gender, age, employment status, and disability status. Below are examples of the types of descriptions articles included of dog caretakers.

- "a homeless man named Lech Stankiewicz" (Kemp 2012)

- "its elderly owner" (Quinn and Burness 2014)

- "The dog owner, who has a criminal history that includes assault, protective order violation, assault on a police officer and various weapons offenses" (Mims 2014).

- "The 28-year-old musician, who has been on the road for 12 years, had hopped a freight train from Lafayette, Louisiana, to Sulphur, Louisiana" (Curtis 2014).

As was the case with descriptions of dogs involved in incidents, articles likewise drew on existent social hierarchies within the human species to position the individuals, and therefore the shooting of their $\operatorname{dog}(\mathrm{s})$, as more or less admissible. In many cases, including those above, descriptive characteristics aligned with lower statuses on the social hierarchy, such as in cases of homelessness or criminal records, suggested these individuals were unfit dog caretakers and, therefore, unfit as friends to their dogs. Similarly, when age of animal caretaker was included, it often involved dog-human matching wherein an elderly caretaker had a dog that was inappropriate based on being an aggressive breed, large size, or young age compared to the owner, and therefore-theoretically - the owner would be unable to suitably handle.

In the incident of the homeless caretaker, Lech Stankiewicz, and the incident involving the 83-year-old "elderly owner", the journalists begin the articles by describing the poor health situation of the owners and frame police as intervening as sources of help. In the former, the article opens by stating that, "A NEW VIDEO emerged Thursday that shows police shooting a pit bull in the head in the East Village. The graphic footage, posted to the Gothamist website, shows two uniformed cops approaching the dog's owner Monday as he appeared to be suffering a seizure on E. 14th St. near Second Ave" (Kemp 2012). Similarly, in the case of the elderly owner, the article indicates police approached because of need by the owner: "Police shot and killed a dog Friday morning after the Staffordshire terrier attacked two people-including a police sergeant-who were trying to help its elderly owner who had collapsed in the street" (Quinn and Burness 2014).

Both articles continue to negatively frame the owners through added stigmatized descriptions. In the case of Lech Stankiewicz, the article stated: "Stankiewicz-who sources said was intoxicated-was taken to Bellevue Hospital and treated for minor injuries. He was later cuffed on an arrest warrant for an open-container summons, cops said. His sister said Stankiewicz, who was born in Poland, left the family's Illinois home about a decade ago due to a drug problem" (Kemp 2012). The inclusion of this description minimizes the actual shooting of the dog and, instead, points readers to the status and troubles of the human within the dog-human partnership. This framing suggests the human is not friend-worthy due to his struggles with addiction and the law. While the dog-human friendship relies on responsible caregiving for social approval, addicts and criminals are often socially defined as irresponsible and unable to provide care for themselves, let alone others. Likewise, in the case of the elderly owner, the dog in this incident is contrasted to the owner's weak status (suggested by the mention of both the age and the physical collapse), when the journalist states, "It is not yet known whether the dog had a history of aggression, though Staffordshire terriers are considered similar to pit bulls" (Quinn and Burness 2014). Then the article includes a quote from a neighbor who recalled "the owner often walked his dog in that area, and that the dog typically wore a muzzle. She said the dog was unmuzzled on Friday, however" (Quinn and Burness 2014). The inclusion of the likeness between the dog involved in the incident and that of the breed of pit bulls frames the dog in a stigmatized and stereotyped manner. Additionally, the fact that the owner muzzles the dog when in 
public suggests the need for additional protection from the dog. Thus, the framing of the feeble owner and a strong, potentially unsafe dog do not make for a socially acceptable friendship.

In comparison to the incidents within which descriptors of dog caretakers were involved, many articles omitted descriptors of the owner completely. By omitting this information, writers suggest there is nothing notable or unusual about the human caretaker involved. Or, in some cases, journalists mention identification of an owner, but specifically state that information about the owner has not been released. This removes consideration of the owner, the friend-worthiness of the owner, and possible culpability in the incident from the dog caretaker. Ultimately, then, focus is placed on the dog and/or the shooting incident itself. Examples of such omissions and limited descriptions include:

- "The dog's owner has been identified, but his name was not released" (Staff 2015).

This first example includes no information about the dog caretaker. The following example does provide a name and location of the caretaker, but no other information. Thus, the reader's understanding of this individual as a caretaker is limited, especially compared to the more nuanced stories that include vivid description about the dog caretakers.

- "Buddy's owner, Debra Blackmore of Hesperia, Calif" (Kaufmann 2016).

Specific information about dogs and/or humans involved in incidents was not always available. However, it was not uncommon for articles to still include broad descriptions based on characteristics of size and/or demeanor, which also encouraged particular perspectives from readership. For example, in one brief article describing an officer shooting a dog in the foot after it approached another officer, the article stated: "Police described the animal as a 'large dog,' however the breed was not available" (Day 2014). Likewise, articles noted the reason police originally became involved in situations when not specific to the dog. Often, these cases involved either domestic disturbances between the caretakers of the dog and/or drug usage. For example, in one article describing the shooting of a pit bull, it stated, "to investigate a report of a domestic brawl involving a resident and her ex-boyfriend" (Valentine 2011). Though the articles are not incorporating factual information or characteristics of the dogs specifically, the information provided adds situational context to the incident and portrays parties within the incident, either the dog who was shot or the caretakers of the dog as culpable, and therefore, less friend-worthy. This situates the actual relationship between the dog-human dyad-the friendship-as problematic and, therefore, the police shooting can be understood as more acceptable by the general public.

\section{Scripting for Social Context}

While above we point to the ways demographic and descriptive factors of the dogs and caretakers emphasize their positions within the species hierarchy of which they are part, articles also more directly aligned characteristics with social stereotypes through use of descriptive language and word usage around the events of a given incident. This included use of words such as "muscular" and "strong" when describing an incident involving a pit bull. Or, in some cases, descriptors of the dog's demeanor, pace, or way of interaction aligned with characteristics provided by the journalist. For example, in the below incident, the dog caretaker is noted as breaking a law and the description of his behavior when police arrive (e.g., uncooperative) aligns with this. Similarly, the dog involved is noted as a pit bull and then the language around the dog's behavior (e.g., "aggressively") draws on stereotypes of the breed:

The incident began at about 10:40 p.m. when a woman in the 1900 block of San Francisco Avenue called police to report a man violating a restraining order [ ... ] Officers said the man, identified as Mark Phillips, 37, of Long Beach was uncooperative, and his dog, an unleashed pit bull, was barking and acting aggressively, forcing officers to move away from the front of the home. (Puente 2013)

Likewise, some articles drew on the descriptive characteristics of both the dogs and caretakers involved in an incident to create a comparison in a given incident, which effectively emphasized both 
the culpability of certain dogs and caretakers and the vulnerability of others involved. The following is an example from a case occurring inside a large, chain pet store:

After a 16-year-old girl had entered the store with an approximately 90-pound pit bull on a leash. The pit bull encountered a Maltese, a small breed, on a leash. The two dogs began barking, and the owners pulled them apart, Assistant Chief Steve Deaton said. A short time later, however, the pit bull escaped its owner and ran through the store dragging its leash. It attacked the Maltese, which was still on its leash held by its owner, an elderly woman. The pitbull picked up the smaller dog in its mouth and began to maul it, Deaton said. (Robards-Forbes and Chang 2013)

The above is representative of the ways articles used descriptive characteristics of the parties involved in an incident, both dog and human, to draw on socially recognized stereotypes in order to support police-identified blame (suggested through which dog was shot) within an incident. Specifically, the article draws on age and gender of the owners as well as breed and size of the dogs. The youthful age of the pit bull caretaker, and the associated stereotype of irresponsibility, serves as partial explanation for the inability and/or unwillingness to control the dog. Likewise, the elderly nature of the Maltese caretaker emphasizes increased vulnerability based on social stereotypes of aging populations as unable to respond quickly, feeble, and weak. Similarly, the article draws on opposing stereotypes of the same gender by acknowledging both caretakers as female. The pit bull caretaker is not strong enough to control the dog (but perhaps a boy may have been) and, in opposition, the Maltese caretaker was nurturing when she picked up her companion. Finally, the article includes not only the breeds of the dogs involved, which are both socially stereotyped, but includes the size to further create a comparison. The offending dog is described by weight, reinforcing it as a large, heavy dog, while the victimized dog is described, twice, in terms of its "small" build. Through use of descriptions that hold various stereotypes, both negatively and positively valued, the article supports a particular understanding of the situation. Ultimately, this is that the companionship of the young girl and pit bull is problematic, while that of the elderly woman and the Maltese is favorable. Therefore, the police shooting of this particular dog can be viewed as more socially acceptable.

While it may appear journalists are simply providing the facts of the case, we found that many articles lacked the type of detailed descriptions provided above. The below examples are two articles, nearly in their entirety, demonstrating the lack of descriptive characteristics and word usage provided in other articles.

Example 1:

An Elgin pit bull was shot by police Wednesday after storming fire station 7, according to officials. Police Lt. Dan O'Shea said fire department personnel were outside when a dog ran up from across the street and chased them inside. Another pit bull mix showed up a few minutes later, acting similarly, which prompted firefighters to call the police, O'Shea said. When police arrived shortly after 1 p.m. at the station, 3270 Longcommon Parkway, one of the dogs tried to attack an officer, according to O'Shea. "We truly never want to shoot an animal, much less someone's dog or any kind of pet," O'Shea said. "However, if an officer is going to be bit, he has to take appropriate actions". The dog was wounded by the gunshot and later taken to a South Elgin animal hospital. The dogs' owner lives in the 9 N600 block of Water Road. The owner, whose name was not available Thursday morning, was cited and will have to appear in animal control court in July. Elgin police wrote five citations for each dog because of their behavior and for being at large. (Mathewson 2012)

Example 2:

At 4:55 p.m., two Concord police responded to a complaint related to a homeless camp just off Ponderosa Avenue in Concord. When the officers found the camp, a pitbull terrier 
mix immediately confronted them. Police said the officers ordered the owner to grab the $\mathrm{dog}$, and when the person didn't and the dog charged and tried to attack them, they fired. The dog was hit, Concord police added, before it turned and ran about a mile before officers caught up to it. Animal Control officers picked up the dog, which was taken to be medically evaluated. The dog was still alive, but wounded, when it was transported. The dog's condition is unknown. (Nelson 2013)

Through choosing what and how much information to include, in addition to when and how to include it, journalists ultimately shape not only the reader understanding of the context during which police shoot dogs, but also, as a result, influence the social understanding of both dog-human relationships and police decision-making around shooting dogs.

By introducing humanistic characteristics of dogs into articles, journalists imbued additional social value onto particular dogs, while effectively anonymizing others. When journalists limited the description of the dog to only its breed, or in some cases solely as "the dog", they encourage readers to distance from the dog because those involved cannot be perceived as relatable. Likewise, the use of limited descriptive characteristics offers readers the opportunity to draw on stereotypes they may hold based on what little they do know of the dog, such as when the breed is given. Similarly, through use of descriptive characteristics of dog caretakers, articles draw on the human social hierarchy to position individuals as more or less suited to care for a dog, perhaps even the specific dog they had. Based on the characteristics included, articles frequently incorporated language that matched the social stereotypes associated with either, or both, the dog and dog caretaker. Together, these decisions by the journalists influence readership views of the dog-human relationship as acceptable or not and the shooting incident as justified or not.

\subsection{Applying (In)Humane Rituals toward the Dog}

Articles included human social rituals applied to particular dogs which humanized-and therefore personalized-the dog and also spoke to the caretaker's positioning of the dog as valued or not. This included noting such things as when a dog was buried, received medical treatment following a shooting incident, and when dogs had beds in which to sleep. By including these practices, which are more often applied to humans, dogs could be understood as more valued and, therefore, higher on the species hierarchy. Likewise, we argue that including the presence of these rituals positioned caretakers in certain ways, often mirroring Blouin's (2013) orientations of humanistic or protectionist dog owners. This type of characterization of the caretaker aligns them with Brickel's (1985, pp. 37-38) contention of social learning around positive or good animal caretaking as necessitating "that animals are to be loved and cared for, and that such actions will reward us with the affection of the animal and admiration from others" and also reflect Bierne's (2018) assertion of respect for animals. Therefore, such caretakers are perceived as higher on their species hierarchy. Finally, emphasis of these rituals indicates a well-matched, socially acceptable dog-human friendship and suggests that the shooting of the dog within said friendship is unmerited.

In one article describing the shooting by an Animal Control officer of a 3-year-old pit bull named "Cage" on his owner's front porch, the social ritual of burial was described: "After the dog was shot, Law built a wooden coffin for Cage and buried him Monday night on family property in the county" (Avant 2013). This passage demonstrates not only the humanized practice as applied to Cage, thereby indicating his social value to his caretaker, but also points to his caretaker as having high social value as a dog owner because of the steps he took in caring for his animals in such ways. In this passage, the caretaker not only buried the dog, a human ritual suggesting the dog was worthy and valued enough to be mourned and remembered, but, additionally, the place of burial, "on family property in the country", aligns the dog as a member of the family. Finally, the owner built the coffin in which the dog was buried. This suggests the owner cared for the dog in such a way as to dedicate time, energy, and skill in using his own hands to make the dog's final resting place. This highlights the social value of 
the dog to the owner, which raises the dog on its own species hierarchy, and, simultaneously, positions the owner as deserving of such a dog and in fact, is equally positioned on the human hierarchy.

Another example occurred when a police officer responded to community calls about three pit bulls running loose. Upon investigation, the officer took aim when the dogs charged. Following the incident, the owner sought medical treatment for the dogs: "The owner, Ronnett Chantel Owens, took both dogs to an animal hospital on Bestgate Road where they were treated, police said" (Staff Writer 2011). The receipt of formal medical attention and treatment following an injury is a social ritual that no animal would receive if not for a connection and relationship to a human. Partaking in this ritual includes the transfer of money on the part of the dog caretaker, which further accentuates the social value of the dogs to their caretaker. As with the case of the burial described above, the willingness of the owner to engage her dogs in these human social practices positions her as higher on the human social hierarchy. Notably, an owner's willingness and ability to pay for medical treatment also reflects either the socioeconomic status of the caretaker, as having disposable income, or as being willing to draw on alternative economic resources, such as loans or incurring debt, on behalf of their dog. Regardless, this heightens their 'friend-worthiness'. Taken together then, the social value of both dogs and humans in these situations, again, equate in terms of their dog-human relationship. As a result, the relationships between these particular dogs and humans are established as well-matched and as socially approved friendships. The willingness of the owners to engage in anthropomorphic practices, in the former article, and consideration of what is best for the dog, in the latter incident, suggests the caretakers benefitted from the relationship with their dog and were, therefore, willing to expend resources on the dogs. Simultaneously, the inclusion of these practices in the articles suggests to readers that the dogs benefitted from the humans in the dyad as well-both while alive and, in the former case, after death. Drawing on Payne et al. (2015), the mutual benefit within these dyads positions them as successful and, therefore, as acceptable friendships. Because of this, the shootings of the dogs can be socially understood as less fair, just, and right.

\section{Scripting the Dog-Human Interaction}

The above section explicates the ways journalists included human social rituals applied to dogs in ways that position both the dogs and humans in higher statuses on their species hierarchies. In comparison, however, journalists also employed language and phrasing that facilitated in readership a very different understanding of dog-human relationships. Specifically, while the response to being shot and end-of-life experiences of the dogs described above engage the interaction positively, numerous articles also positioned parties involved in incidents of dog shootings as low on their species hierarchy because of the dehumanizing and inhumane descriptions of events occurring following the police shooting. This framing reflects Bierne's (2018, p. 37) suggestion around speciest language and the contention that "While human 'corpses' garner respect for the dead and are honoured with religious, familial and other ceremonial rights, the overwhelming majority of animal bodies ('carcasses') are disposed of invisibly, silently and without inspection of record". Take, for example, the following two selections, which incorporate the terminology of "destroy[ing]":

- "The dog attempted to attack a Northport city employee and to protect the employee, the dog had to be destroyed," Northport Police Chief Kerry Card said (Avant 2013).

- "But the last thing police officers want to do is use their firearms to destroy a dog," he said (Trice and Gorner 2013).

Similarly, in an article describing an incident in which police had to shoot a pit bull after responding to a human-on-human physical fight resulting in a 23-year-old man running from police and, ultimately, being bitten by said pit bull in the backyard where he sought refuge, the use of the word "collected" dehumanizes the dog following it's death: "A Sonoma County Animal Control officer collected the dog" (Johnson 2013). Just as inanimate objects are destroyed and trash is collected, the dogs in these articles are given less social value. Mead (1934), this language positions nonhuman 
animals and humans as inherently different with nonhuman animals inferior to the human counterpart. Thus, unlike the previous discussion in which dogs are understood as embodying personhood and/or selfhood, the framing here positions the dogs as objects and catalyzes less emotion around the animal's death. As a result, readers can distance more easily from the reality that a human officer killed a dog and, therefore, the death is minimized. In these examples, the dog-human interactions following the shooting demonstrate a weak or missing relationship between dogs and humans, which limits their opportunity for higher placement on their species hierarchy. In the case of the dog being "collected", for instance, there is no mention of an owner interceding or caring for the dog after the shooting, despite inferring the owner was home through mention of the home being accessible (e.g., door unlocked) for a citizen to run away from police through the home and into the backyard where the dog was. Consequently, this aligns the owner as dominionistic according to Blouin's (2013) typology. While this framing is not necessarily accurate, the decision by the journalist to omit discussion of the relationship between the dog-human dyad positions the owner as not invested in the dog. As Blouin (2013, p. 286) posits, "those with dominionistic views often keep their dogs outside. This physical separation provides a symbolic social distance". This suggests the owner views the dog as an object, rather than a subject. Thus, the owner is positioned as lacking friend-worthiness based on failure to meet socially valued standards of 'good' dog owners. Taken together, through incorporating the perspectives of outsiders, such as members of law enforcement, who position, through their word choice, the particular dogs involved as lower on their species hierarchy, and indicate weak friend-worthiness of owners by omitting discussion of care for the animal involved, the friendship is perceived as weak; this gives readers less investment in the shooting of the dog.

Ultimately, the dog-human interactions, or lack thereof, provided within articles had strong impact on the understanding of a police shooting of a given dog as more or less "right". In cases involving strong dog-human relationships wherein dogs held great social value to their caretakers, which resulted in various humanized social rituals, their shootings could be seen as more problematic. Yet, in opposition, when the dog-human interactions described by journalists involved no humanized social rituals, dogs were dehumanized through incorporation of seemingly inhumane language that positioned dogs as undeserving and unworthy of such practices. Ultimately, the inclusion by journalists of whether and how dogs took part in human social rituals indicates the social value of both dog and human, and speaks to the suitability of any given dog-human relationship when present.

\subsection{Inclusion of Social Roles, Status Position, and Performance of Ownership}

When applicable, articles included specific social roles and status positions dogs and/or dog caretakers held within broader society. For example, articles noted when dogs served as therapy dogs to significantly vulnerable human populations (e.g., children, elderly, and individuals in hospice) and those who had passed their Canine Good Citizen certification to become therapy dogs, those registered as companion dogs, and those holding positions as police K9s. While the aforementioned social roles are formally acknowledged through public social structures and organizations, articles also noted informal-yet socially valued—roles dogs held, such as when they served as the protector of their caretakers and families and when their caretakers viewed them as 'family members'. Below are examples of the inclusion of these types of valued social roles:

- " “The dog was my granddaughter's playmate."” (Miller 2011)

- " “The dog was like a son to me and my girls,' she told an officer at the animal hospital." (Valentine 2011)

- "My best friend was shot in the back'." (Moreno 2013)

- "She said Jackson Smore is a registered companion dog to her husband, Rick Rodecap, 56, who is disabled, and that his personal care attendant had let the dog out the back door to relieve itself around 1:30 a.m. Friday." (Anderson 2014)

- "Dutchess, a 2-year-old rescue dog belonging to a family in Florida City, Fla." (Robinson 2015) 
While, articles also included valued social roles of caretakers, such as noting when they were parents, when they owned their home, their occupation, and if they were animal rescuers (their dog was a rescue versus breeder-purchased dog), human social roles were implicated through mention of a dog's social role as well. For example, when a companion animal is required by a human, it indicates the dog caretaker has an unmet need based on mental, emotional, or physical health status. Similarly, in cases when a dog has a Canine Good Citizen certification or is a therapy dog, it indicates that the dog's caretaker is ensuring the dog meets their natural and full potential (pointing to a protectionistic orientation (Blouin 2013)) and, thereby, provides the owner with positive status as a pet guardian. This positively valued form of human caretaking is also seen through the way humans performed the roles associated with their statuses as 'pet owners' and the responses they had following the shooting of their $\operatorname{dog}(\mathrm{s})$. Importantly, the ways dog caretakers were able to perform their social roles related strongly to their economic status positions. Below is a variety of excerpts demonstrating positively valued performances of ownership.

- "Vachon, who lives in one of the apartments, was at work at the time of the shooting but came home afterward. Vachon sat weeping in the back of a sport utility vehicle hours after the shooting as she caressed a yellow sheet that shrouded her dog's lifeless body." (Sullivan 2012)

- "Saathoff said he and his wife have consulted with Springfield attorney Stephen Hedinger about what happened to their pet." (Schenk 2013a)

- "Luu said she was told by a Police Department supervisor that the surgery exceeded the value of the dog, and suggested she just get a new pet. [ . . . ] 'It's not about the money. It's about the love.' Unable to afford the surgery themselves, the family elected to have the dog put down, Luu said. 'It's sad'." (Day 2013)

- "Brown and Hornberger spoke of the incident and are sad about the loss of their female pit bull named Princess and the injuries to the other female dog named Bella. Both were acquired as rescue dogs and were about 2 to 3 years old, spayed and microchipped. [ ... ] Hornberger was visibly upset in describing what happened and shed tears about the loss of Princess and the injuries to Bella." (Usalis 2014)

- "A Facebook group he started called "Justice for Arzy" was quickly accumulating posts of support on Wednesday afternoon. According to Carpenter, protesters also are planning to picket the Sulphur Police Department on Saturday." (Curtis 2014)

All of the above examples demonstrate the ways caretakers of dogs were able to perform in their statuses as 'dog owners' by carrying out various social roles. In some instances, this is demonstrated through exhibiting responsibility, such as having the dog microchipped and spayed, while in other cases, this was shown through the emotional and practical responses following the shooting incidents. While all of the humans described above demonstrate highly and positively valued statuses because they met societal expectations for the roles they fulfilled, these descriptions also, however, reify the positions the caretakers hold within the existent human hierarchy that is largely built around one's economic and social capital. Specifically, the mention of the type of vehicle owned by Vechon, that the Saathoffs could afford to seek counsel from an attorney, and that Brown and Hornberger were able to pay to spay and microchip multiple dogs while the Luu family, for instance, ultimately had to euthanize their dog because they could not afford to pay for the necessary life-saving surgery, affects the performance of ownership and therefore, the understanding readers come to hold about not only the dogs' and dog caretakers' friend-worthiness, but also the suitability of their relationship. The framing of the relationship positions it as meeting or not the standard of mutual benefit (Payne et al. 2015) required for conceptualization as a successful dyad and, therefore, friendship. As a result of the friend-worthiness and/or friendship status within the journalist's framing of an incident, the shooting incident is implicated as more or less acceptable or deserving of public concern.

Contrasting the incorporation of recognized, highly valued social roles and status position recognized as highly socially valued into articles, there were also instances when particular roles and 
statuses pointed more clearly to low social value and status of either the dog or dog caretaker within their given species hierarchy. While this was present in conjunction with descriptions of dogs that largely drew on identifying the type of call to which police were responding (e.g., public nuisance), it was more often the case that articles included low-value dog caretaker social roles and statuses (e.g., felon, suspect, homeless, elderly). In addition, the performance of ownership included within articles also lowered one's placement within the human hierarchy. Below are excerpts demonstrating failures at human performance of animal ownership.

- "the new charges against Zimmerman will include a failure to license the dogs, letting them run unrestrained in public and failing to have them vaccinated against rabies." (Malawsky and Thompson 2011)

- $\quad$ "After Syncere was wounded, Bogansky didn't want to put the dog in her car [because the dog was bleeding]. So police drove the dog to the animal shelter, where it died while police tried to arrange veterinary care." (Jackson 2012)

These two examples position the owners as irresponsible (e.g., not licensing and keeping dogs up-to-date on vaccinations), pretentious (e.g., caring more for an inanimate object, such as ones car, than one's still living, although bleeding, dog) and, ultimately, as uncaring for their animals. In line with Blouin's (2013) dominionistic orientation, the owners fail to meet Brickel's (1985) standard of love and care toward the animal. This results in a weak performance of ownership and suggests that the dog caretakers were undeserving of their dog companions and, therefore, were not friend-worthy themselves. This type of unmatched friendship influences the way readers understand the relationship between the dog and human—suggesting lack of an actual friendship —and may, then, also affect their perspective of the police shooting the dog.

Ultimately, as with the authors' previous discussions, these social roles also worked most effectively when collaboratively positioned to establish whether the partnership between dog and dog caretaker was matched in social value. This was exemplified in a case describing the shooting of a 2-year-old female pit bull named Cindy and the relationship she had to her human caretaker Adam Arroyo: "It was just me and her," Arroyo said of Cindy, a rescue dog he adopted upon his return from combat duty in Iraq. "I would do anything to have her back" (Fairbanks 2015). Taken together, this duo have equal social value as Arroyo increases Cindy's social value given her status in his life and his claim of interdependence with her, as well as his social value through the roles of serving as active duty military and one who cares for rescue dogs. As is seen in the case of Cindy and Arroyo, based on the roles mentioned within articles, dogs and human caretakers are awarded more or less social status, particularly with relationship to the incident involving a police officer shooting a given dog. As a result, this positions the dyad as meeting qualities of friendship.

\section{Scripting the Hierarchy}

While some articles included the social roles, status positions, and descriptions of ways dog caretakers performed their ownership responsibilities, others drew direct comparisons within one or both of the species as a way of further scripting the dog-human hierarchy. In articles that included this type of comparative work, journalists frequently incorporated quotations of parties involved within the incidents, such as the dog caretakers, law enforcement representatives and, at times, government officials. The decision-making power of journalists in determining whose voices are heard and in what ways they represent those voices is especially poignant when examining the construction and reification of hierarchies. Take, for instance, the case of 6-year-old Basset hound/beagle mix, Willy Pete, and his 32-year-old owner, Ginger Sweat, a wife and mother to two toddlers. The article describing the incident states:

She was putting one of the children down for a nap about 1 p.m. when she glanced out the window and saw eight officers in tactical gear coming out of the woods near her home. 
One had a barking police dog on a leash, she said. That piqued the interest of her dog, who had been lying on the porch that afternoon. Her 6-year-old Basset hound/beagle mix, Willy Pete, left the porch and made his way toward the troopers. The dog, she said, suffered from arthritis in his back legs and was not aggressive. Her other dog went into the house. Sweat said she was still inside when she saw the trooper raise a weapon at her dog. 'I ran out my door, jumping up and down screaming don't shoot my dog, he won't bite, just let me get him in the house,' she said. She said the officer fired one shot toward the dog but missed. She said Willy Pete turned tail and was running back toward her. 'He ran towards me with desperation in his eyes,' she said. 'They fired again in my direction. In the direction of my home where my kids were.' She said three more shots were fired, a total of four shots. Willy Pete, she said, was hit three times. The dog went to the back of the mobile home. Sweat said she found the dog near the air conditioning unit. 'I watched my dog struggle and then die,' she said. 'I collapsed in a puddle in the floor, screaming and crying. 'I watched that dog born and I watched him die.' She said the troopers came to her home and one of the officers told her "Ma'am we're dog people, too, but we couldn't let them fight, she recalled him saying. 'He said, I'm sorry. Where's your shovel, I'll bury him.' She said her dog wasn't vicious and that she wouldn't have allowed a vicious dog around her children. (Craig 2014)

There are a number of characteristics included within the coverage of this incident, by both the journalist and the dog caretaker, that affect the social value, hierarchical placement, and, ultimately, friend-worthiness of both the dog and the human within this dyad. First, Sweat is identified as a mother-a socially valued role in society. Not only this, but her concern for the safety of her children positions her as a 'good mother'. Additionally, in her recounting of the incident, she stated that Willy Pete "ran towards me with desperation in his eyes". This suggests that Willy Pete found benefit in his relationship with Sweat through his view of her as a source of protection when he faced danger. Sweat also noted her emotional behavior following the incident and introduced the length of the relationship she had with Willy Pete through mentioning she had witnessed his birth. These characteristics all position Sweat as friend-worthy. In comparison to the clear ways in which the journalist's decision-making and owner's framing positions Sweat, the description of Willy Pete includes differential framing dependent on whose voice is heard. For instance, the journalist includes the dog's name, age, breed (stereotypically known to meet Brickel's (1985) description of animal qualities allowing for dog-human bonding), and health status. Additionally, Sweat identifies Willy Pete as unaggressive, retreating when fearful, and as family-friendly.

In comparison, the journalist presents the juxtaposition of the K9 officer and Willy Pete-pointing to the presence of the intraspecies hierarchy. In Sweat's recounting of the officer explanation for the shooting it is implied that the dogs were fighting and that Willy Pete was perceived to have initiated the fight- thus contrasting Sweat's description of the dog as unaggressive. Through inclusion of the officer's interaction with Sweat, a second dog-human dyad, that of K9 officer and human officer, is introduced. This dyad is socially recognized as a 'partnership', and the officer's choice to shoot Willy Pete, rather than his own dog who was also involved in the fight, points not only to the ways the K9 officer is more highly valued than Willy Pete, but also speaks to the loyalty of the officer to his K9 companion, which positions him as being friend-worthy. The presence of the roles and statuses of both Sweat and Willy Pete, as well as the ownership qualities of Sweat, demonstrate the ways articles effectively represented the friend-worthiness of both dogs and humans within the dog-human dyad. Through comparison to another dog-human dyad, this article speaks to the presence of an interspecies hierarchy built upon both the friend-worthiness of each entity within a dyad, but also the presence of a friendship, too. With much to unpack in this story concerning the dog and human hierarchies and friendships, it is also worth questioning why the type of home (e.g., mobile home) was called to the reader's attention; the relationship between social class and police surveillance, while not the direct focus in the analysis here, nonetheless, is an important and relevant facet. Ultimately, the story of Willy Pete likely leaves the reader feeling upset about the shooting. Due to the rich narrative of the 
social actors involved in the scene, the journalist has helped to paint a picture of an individualized friend-worthy companion dog, cared for by a friend-worthy mother and pet caretaker, and juxtaposed against a working dog and human partner. Albeit perhaps unknowingly, this writer helps to create and maintain multiple species hierarchies.

In another example, the voice of a dog caretaker who initiated a social justice campaign after the shooting of his dog offers a counterargument to framing by law enforcement of the incident. The caretaker contended that law enforcement shot his dog because " [The officer] thought I was just a train-hopping punk, and he could shoot my dog and get away with it,' Carpenter said. 'You messed with the wrong traveler'" (Curtis 2014). Here, the dog caretaker draws on the existing human social hierarchy in their decision-making of shooting his dog. The caretaker rejects his assumed placement on this hierarchy, engaging in tertiary deviance (Kitsuse 1980), and works to establish himself as higher on the human hierarchy by reframing the presumed label (i.e., "train-hopping punk") given by law enforcement to a more socially acceptable label (i.e., traveler). He also engages in a socially valued performance of ownership to the shooting of his dog (i.e., a social justice campaign claiming the dog was unjustly shot).

While the above passage employed the language of the dog caretaker directly, whom often positioned themselves as falling into Blouin's (2013) humanistic or protectionistic orientations, numerous articles involved the perspectives of law enforcement. These articles created a different view of dog caretakers by emphasizing low and heavily stigmatized positions on the human hierarchy. See, for example, the below passages:

- " " "But if you're looking for a felon, you may be kicking the door in and have no time to restrain the dog,' [the police department representative] said. 'Every situation is different'”. (Laker and DeHuff 2015)

- $\quad$ "Pat Camden, a spokesman for the Fraternal Order of Police, said he has no quarrel with officers receiving extra training but believes that dog owners need to do a better job of controlling their pets and making sure they're on a leash." (Trice and Gorner 2013)

In the first of these excerpts, use of the term felon highlights the status of the dog caretaker within the human hierarchy and is used as a justification for not having concern of any dogs who may be in the home. In the second example, the spokesperson for the police attempts to place onus for the shooting of dogs on the dog caretakers, rather than on the police who respond to incidents. The shared perspective within these passages and similar articles to these is their clear indication of the humans holding lower positions on the social hierarchy of humans and as embodying failure in meeting friend-worthy traits. Specifically, law enforcement departments draw on their own socially valued roles and statuses within communities to emphasize the lower placement of other populations (e.g., felons and dog caretakers who are not police officers).

In comparison to the above perspective, some articles incorporated counter claims wherein individuals worked to negotiate or resist the claims by law enforcement about the social status of dog caretakers on the human hierarchy. For example, Colorado congressional representative, David Balmer, himself a dog caretaker said, "'Landscaping companies, delivery companies—they deal with dogs all the time, and they don't shoot dogs'" (Bartels 2013). This quote by Balmer suggests that while law enforcement, which is equipped with weapons, such as guns, cannot seemingly interact with dogs without shooting them; other individuals, often with lesser positioned occupational statuses on the human hierarchy, interact with dogs much more frequently and without the use of any injury or death-inducing weapons. Ultimately, this challenges the assumed placement of police officers, and law enforcement more broadly, as high on the hierarchy.

The above speak to the ways journalists constructed and reinforced the human hierarchy within articles. Below, we point to the ways journalists also elaborated on the dog species hierarchy.

- $\quad$ "Blue pit bulls are generally the same size as standard pit bulls but are considered rare because of their grayish blue coloration. Cage was 85 pounds and slightly taller than the standard pit bull. 
He was considered to have a "purple ribbon" bloodline that can be traced back 14 generations of breeding, Law said". (Avant 2013)

- “On Nov. 17, about 5:30 p.m., a Champaign police officer was called to southwest Champaign where two dogs were fighting. One, a family pet, was on a leash being walked by one of its owners. The other, a stray, was not. [ ... ] [The responding officer's] actions that night resulted in the death of the family pet, a bullet penetrating a nearby apartment, the wounding of the stray, and an offer by the city to pay the family of the dead dog for its loss. [ ... ] [The stray] was euthanized at the county's animal control department about 10 days later because no one claimed it." (Schenk 2013b)

- "Officers shot and killed a pit bull that attacked a police dog and arrested six people, including the pit bull's owner, at a south Livermore apartment complex Tuesday after a shooting into a nearby home, officials said." (Ivie 2013)

Here, the examples work to position the dogs shot by police in high positions on their species hierarchy. In the first passage, Cage, a blue pit bull, is rare and, therefore, special and different from other dogs, especially other pit bulls. This is particularly important given the negative stereotyping the pit bull regularly receives in media and by society more broadly. Likewise, in the second example, a clear comparison is made between the two dogs fighting. One dog was leashed and being walked by its owner, therefore it is cared for and part of a dog-human friendship, while the other dog was identified as a "stray" (i.e., uncoupled from a human) and was unleashed. The use of the dog-human relationship within this excerpt is particularly poignant as a mechanism for reify the dogs' placements on the species hierarchy. Finally, in the last selection, the distinction between a police dog (also referenced in articles as $\mathrm{K} 9$ officer) and a non-police dog (often referenced only by breed, such as in the example) emphasizes the placement of these dogs within their species hierarchy based on social role. Each of these dogs meets one or more of the characteristics outlined by Brickel (1985) as possessing qualities necessary for creation of a dog-human bond and, therefore, catalyzing a possible categorization of friendship.

The ways articles established and built onto existent species hierarchies and coupled dogs and their caretakers, particularly when both held socially valued status positions, works to demonstrate the inter-species hierarchy the authors contend is present in cases of police shooting incidents of domesticated companion dogs. This inter-species hierarchy relies on the strength of the relationship between a given dog-human pairing, which is ascertained based on the individual and collective social roles, status positions, and performance of ownership of the parties involved within the pairing.

\section{Discussion and Conclusions}

Across articles, journalists draw on extant species hierarchies to, ultimately, build an inter-species hierarchy based on dog-human interactions and relationships ranging from non-existent to friends and companions. The framing of either or both of the dog and human within a given dyad identifies the placement on their individual species hierarchy. The individual placements collectively join to establish a position of the dog-human pairing on the inter-species hierarchy. Their location on this new, combined hierarchy impacts a reader's understanding of the level of friendship or companionship between the dog-human pairing. Ultimately, the framing of a relationship_as well as of the individual parties involved within the dyad-affect how a reader perceives a given shooting incident, the culpability a given dog-human pairing have in the incident, and the response of the criminal justice system (during and after the shooting). Indeed, use by journalists of descriptive phrasing and word choice; inclusion of human social rituals applied to dogs; and incorporation of both positively valued and negatively stigmatized social roles, statuses, and pet ownership practices encourage readers to view particular dogs and/or particular owners as more or less deserving of the outcome of the shooting incident. Likewise, journalist decision-making to omit descriptive characteristics of dog or human as well as omission or limiting of situational context influences 
what information a reader is led to perceive as important and, as a result, how a reader understands a particular shooting incident.

Research on the animal-human bond continues to grow and, amongst extant literature, includes a variety of perspectives on the ways humans understand animals, human caretaking responsibilities of animals, and the possibility of friendship between a nonhuman animal and human. As Brickel (1985) posited, social institutions, including that of family and media amongst others, are strong influencers in how children grow to learn about animals and the possible bond with and opposition to particular animals. Dogs, in particular, have long been an accepted animal with whom humans can (and perhaps should) associate. As a result, existing research on the dog-human dyad continues to garner attention. Indeed, our findings both support and build on the theory of social learning around the animal-human bond introduced by Brickel (1985), the dog caretaker typology of Blouin (2013), and the definition of 'bond' as being mutually beneficial suggested by Payne et al. (2015) as we contend that such works create a foundation for assessing and placement of both dogs and caretakers onto an inter-species hierarchy.

Social institutions, such as law enforcement and media, are critical in portraying and enforcing the placement of individuals and collective pairings within given hierarchies. Through responses to and portrayals of incidents involving domesticated dogs in certain ways, the social value of dogs and human caretakers, and their friendships, are socially shaped for society. Drawing on the work of Sacco (1995) who found that most people receive fact-based information about animals and crime from news media sources, the representation of dogs, dog caretakers, and their friendships more broadly, is important to how readers come to view police shootings of dogs as acceptable or not, civilian and police interactions as socially acceptable or not, and whether readers make connections to broader police trends involving excessive use of force. Notably, Bierne (2018) argues that state theriocide, like other forms of theriocide, is rarely experienced as problematic by its human participants and often remains invisible to greater society. In part, this can be explained through the lack of media attention garnered in such cases. Extant literature includes arguments about excessive use of force by police against particular human populations, particularly the racialized use of force by police against black and brown men (Garner et al. 2002; Terrill and Reisig 2003). We build on this by contending that these same responses by police, a state entity, are present in incidents involving dogs, and are particularly prevalent in certain villainized breeds of dogs, such as pit bulls. The demonization of certain nonhuman animals, like pit bulls, is well documented in social hierarchies such as the sociozoologic scale (Arluke and Sanders 1996). We point to the role the media has in representing not only dogs, but also dog caretakers, families, and the dog-human friendships in which they are involved, in certain ways. As a result of the power media holds in shaping social views, the implication is then that, based on representation of both the dog and human, the relationship between them is seen as more or less socially acceptable. Ultimately, if the media frames both parties in a dog-human dyad as 'friend-worthy', and the dog-human partnership as mutually beneficial (Payne et al. 2015) and thereby qualifying as friendship, readers are led to view the shooting of the dog as less justifiable.

The current sociopolitical landscape is significant to our research as it points both to the association of socially devalued humans with nonhuman animals in the form of dehumanizing discourse and practice (see Arluke and Sanders 1996) and also, again, to the issue of friendships. Indeed, devalued companion dogs are often stereotyped and stigmatized as being in relationships with marginalized humans. For example, legal scholars have suggested that breed-specific dog laws that prohibit dogs, such as pit bulls, from communities by claiming public safety might have roots in racial bias because pit bulls have cultural ties to the black and Latino communities (Linder 2018). Linder suggests that, "Breed-specific legislation may be being used as a new form of redlining to keep minorities out of majority-white neighborhoods" (Linder 2018, p. 51). Thus, socially disadvantaged human and nonhuman groups are often grouped together, in the popular social imagination of society members, but also in actual lived experiences; and both experience violent interactions with police. 
Ultimately, this work has implications for policing approaches and practices involving both human and nonhuman animals. While we are not claiming that police violence against marginalized human populations operates in the same way as police violence against nonhuman animals, we would be remiss to not acknowledge the current social landscape. Police have historically been involved in cases of extreme use of force and have been highly criticized for it (Lersch and Mieczkowski 2005; Harris 2009; Klahm and Tillyer 2010). Much of the criticism from the general public is negotiated through the media-the source through which the public learns of these instances of violence (Sacco 1995; Donovan and Klahm 2015). Accordingly, the authors urge that future work to examine the parallel between policing black and brown men and certain breeds of dogs.

In conclusion, we examined the narrative choices of news media journalists to analyze patterns of frames implemented when presenting stories on police shootings of companion dogs. Instead of finding a singular way in which the articles discussed these cases, we found a diverse sample incorporating a variety of strategies that either worked to frame the dog and/or the human caretaker as worthy of being categorized as 'friend', which then linked to public outcry by framing either and/or both of the social actors within a given dyad as 'friend-worthy'. Thus, the contemporary social definitions and hierarchical placement of nonhuman animals and their human connections are reified by the media, along with the assessment of the justifiability of the violent police interaction. For a social institution that already has a spotlight on it for its excessive use of force, the societal understanding of law enforcement, and police shootings in general, is informed with the additional exposure of police-(civilian)dog interactions. The media, an ever-increasingly powerful institution in its own right, helps to maintain symbolic species hierarchies and, in the case of the present work, creates new hierarchies resulting in the continuation of inequality.

Author Contributions: Names are alphabetical to reflect equal contributions. Both authors contributed to all aspects of this work: conceptualization, D.T.T. and J.R.V.; methodology, D.T.T. and J.R.V.; formal analysis, D.T.T. and J.R.V.; writing—original draft preparation, D.T.T. and J.R.V.; writing—review and editing, D.T.T. and J.R.V.

Funding: This research received no external funding.

Conflicts of Interest: The authors declare no conflict of interest.

\section{References}

Anderson, Phil. 2014. Topekan Furious after Police Shoot Dog. Topeka Capital Journal, June 21.

Arluke, Arnold, and Clinton R. Sanders. 1996. Regarding Animals. Philadelphia: Temple University Press.

Avant, Lydia Seabol. 2013. Owners Say Police Shot and Killed Pet Dog. The Tuscaloosa Newws, June 25.

Bartels, Lynn. 2013. Bill Requires Canine Classes for Cops. Denver Post, March 2.

Berger, Peter, and Thomas Luckmann. 1967. The Social Construction of Reality: A Treatise in the Sociology of Knowledge.

New York: Doubleday.

Bierne, Piers. 2018. Murdering Animals. London: Palgrave Macmillan.

Blouin, David D. 2013. Are Dogs Children, Companions, or Just Animals? Understanding Variations in People's Orientations toward Animals. Anthrozoös 26: 279-94. [CrossRef]

Brickel, Clark M. 1985. Initiation and Maintenance of the Human-animal Bond: Familial Roles from a Learning Perspective. In Pets and the Family. New York: Haworth Press, pp. 31-48.

Carragee, Kevin M., and Wim Roefs. 2004. The Neglect of Power in Recent Framing Research. Journal of Communication 54: 214-33. [CrossRef]

Chappell, Dale. 2018. DOJ: Police Shooting Family Dogs has Become 'Epidemic'. Criminal Legal Nerws, July 16.

Charmaz, Kathy. 2014. Constructing Grounded Theory, 2nd ed. London: Sage.

Craig, Ashley B. 2014. Owner of Slain Dog Pushing for Changes. Charleston Daily Mail, June 27.

Curtis, Abigail. 2014. Maine Man Fighting Back after Police Allegedly Shot, Killed His Dog in Louisiana. Bangor Daily News, April 30.

Day, Brian. 2013. Police Shooting of Pet German Shepherd Sparks Outrage by El Monte Family (Video). San Gabriel Valley Tribune, June 21.

Day, Brian. 2014. Officials: Police Officer Shoots Charging Dog in Baldwin Park. San Gabriel Valley Tribune, March 5. 
Day, Brian. 2015. Police Shoot Dog during Search for San Marino Home-Invasion Robber. San Gabriel Valley Tribune, February 19.

De Vreese, Claes H., Jochen Peter, and Holli A. Semetko. 2001. Framing Politics at the Launch of the Euro: A Cross-National Comparative Study of Frames in the News. Political Communication 18: 107-22. [CrossRef]

DeBolt, David. 2013. Albany Police Shoot, Kill Dog at Homeless Encampment. Oakland Tribune, October 29.

DeMello, Margo. 2012. Animals and Society: An Introduction to Human-animal Studies. New York: Columbia University Press.

Dimitrova, Daniela V., Lynda Lee Kaid, Andrew Paul Williams, and Kaye D. Trammell. 2005. War on the Web: The Immediate News Framing of Gulf War II. The Harvard International Journal of Press/Politics 10: $22-44$. [CrossRef]

Donovan, Kathleen M., and Charles F. Klahm IV. 2015. The Role of Entertainment Media in Perceptions of Police Use of Force. Criminal Justice and Behavior 42: 1261-81. [CrossRef]

Entman, Robert. 1993. Framing: Toward Clarification of a Fractured Paradigm. Journal of Communication 43: 51-58. [CrossRef]

Erlingsson, Christen, and Petra Brysiewicz. 2017. A Hands-on Guide to Doing Content Analysis. African Journal of Emergency Medicine 7: 93-9. [CrossRef]

Fairbanks, Phil. 2015. Lawsuit Filed Over Buffalo Police Shooting that Killed Pet Dog. Buffalo News, October 11.

Gaffney, Genette. 2018. 6,083 Dogs Shot and Killed: The Unknown Puppycide Epidemic in America. Animal Law 24: 197-219.

Gagnon, John H., and William Simon. 1973. Sexual Conduct: The Social Sources of Human Sexuality. Piscataway: Transaction Publishers.

Garner, Joel H., Christopher D. Maxwell, and Cedrick G. Heraux. 2002. Characteristics associated with the Prevalence and Severity of Force used by the Police. Justice Quarterly 19: 705-46. [CrossRef]

Gerez, Julian. 2015. Evanston Police Officer Shoots Dog. University Wire, April 30.

Goffman, Erving. 1959. The Presentation of Self in Everyday Life. New York: Doubleday.

Goffman, Erving. 1963. Stigma: Notes on the Management of Spoiled Identity. New York: Touchstone.

Goffman, Erving. 1974. Frame Analysis: An Essay on the Organization of Experience. New York: Harper \& Row.

Graham, Chris. 2014. Ormond Police Shoot Dog after It Attacks Officer. The Daytona Beach News-Journal, April 28.

Grugan, Shannon T. 2019. Capturing Cruelty: A Content Analysis of Companion Animal Cruelty in the News Media. Society \& Animals 27: 92-108. [CrossRef]

Hamilton, Lindsay, and Nik Taylor. 2013. Animals at Work: Identity, Politics and Culture in Work with Animals. Leiden: Brill.

Harris, Christopher J. 2009. Police Use of Improper Force: A Systematic Review of the Evidence. Victims and Offenders 4: 25-41. [CrossRef]

Herzog, Hal. 2010. Some We Love, Some We Hate, Some We Eat: Why It's So Hard to Think Straight about Animals. New York: HarperCollins Publishers.

Irvine, Leslie. 2004. If You Tame Me: Understanding our Connection with Animals. Philadelphia: Temple University Press. Ivie, Erin. 2013. Livermore Officers Shoot and Kill Pit Bull that Attacked Police Dog. Oakland Tribune, May 22. Jackson, Kent. 2012. Hazleton Police Shoot, Kill Pit Bull. Citizens' Voice, July 3.

Johnson, Julie. 2013. Santa Rosa: Police Shoot Pit Bull That Attacked Man. The Press Democrat, May 6.

Jones, Susan D. 2003. Valuing Animals: Veterinarians and Their Patients in Modern America. Baltimore: The Johns Hopkins University Press.

Kaufmann, Gretel. 2016. How Some Police Departments are Trying to Prevent 'Puppycide'. The Christian Science Monitor, June 9.

Kemp, Joe. 2012. LUNGE \& SHOOT Video Shows Protective Pit Bull Sprinting at Police Officer. New York Daily News, August 17.

Kitsuse, John I. 1980. Coming Out All Over: Deviants and the Politics of Social Problems. Social Problem 28: 1-13. [CrossRef]

Klahm, Charles F., IV, and Rob Tillyer. 2010. Understanding Police Use of Force: A Review of the Evidence. Southwest Journal of Criminal Justice 7: 214-39.

Laker, Barbara, and Jenny DeHuff. 2015. Canine Clashes. Philadelphia Daily News, February 26.

Lersch, Kim Michelle, and Tom Mieczkowski. 2005. Violent Police Behavior: Past, Present, and Future Research Directions. Aggression and Violent Behavior 10: 552-68. [CrossRef] 
Linder, Ann. 2018. The Black Man's Dog: The Social Context of Breed Specific Legislation. Animal Law 25: 51-72. Malawsky, Nick, and Charlie Thompson. 2011. Owner of Pit Bulls Faces Charges. The Patriot-News, April 2.

Mathewson, Tara Garcia. 2012. Police Shoot Dog Outside Fire Station. Daily Herald, June 8.

Matthes, Jörg, and Matthias Kohring. 2008. The Content Analysis of Media Frames: Toward Improving Reliability and Validity. Journal of Communication 58: 258-79. [CrossRef]

Mead, George Herbert. 1934. Mind, Self \& Society. Chicago: The University of Chicago Press.

Mester, Alexandra. 2014. Toledo Police Shoot Dog in Yard during Search. The Blade, April 30.

Miller, Michael. 2011. Woodbine Woman Says Troopers Didn't Need to Shoot Dog. Press of Atlantic City, March 11.

Mims, Bob. 2014. Ogden Police Shoot Pit Bull When Welfare Check Goes Wrong. The Salt Lake Tribune, July 23.

Moreno, Ivan. 2013. Colorado Dog Owners: Train Police to Avoid Shootings. The Herald, April 4.

Nelson, Katie. 2013. Concord: Officers Shoot Dog after It Charges. Oakland Tribune, March 22.

Nipps, Emily. 2011. Dog's Death Influences Police Policies. St. Petersburg Times, November 17.

Olausson, Ulrika. 2009. Global Warming-Global Responsibility? Media Frames of Collective Action and Scientific Certainty. Public Understanding of Science 18: 421-36. [CrossRef]

Olsen, Elizabeth. 2016. Paws Up, Don't Shoot: Preventing Officer-Involved Shootings of Companion Canines. Animal Law 23: 65-101.

Payne, Elyssa, Pauleen C. Bennett, and Paul D. McGreevy. 2015. Current Perspectives on Attachment and Bonding in the Dog-Human Dyad. Psychology Research and Behavior Management 8: 71-79. [CrossRef]

Puente, Kelly. 2013. L.B. Police Shoot, Kill Pit Bull. Orange County Register, August 23.

Quinn, Megan, and Alex Burness. 2014. Broomfield Police Shoot, Kill Dog That Attacked 2 People after Its Owner Collapsed. Broomfield Enterprise, June 20.

Robards-Forbes, Esther, and Julie Chang. 2013. Officer Shoots, Kills Pit Bull in Shop. Austin American Statesman, July 5 .

Robinson, Nathan J. 2015. What Happens to Cops When They Shoot Your Dog? Nothing. The Washington Post, November 15.

Sacco, Vincent F. 1995. Media Constructions of Crime. The Annals of the American Academy of Political and Social Science 539: 141-54. [CrossRef]

Sanders, Clinton R. 1999. Understanding Dogs: Living and Working with Canine Companions. Philadelphia: Temple University Press.

Schenk, Mary. 2013a. Officer Who Shot Family's Dog Suspended for Day without Pay. News Gazette, April 4.

Schenk, Mary. 2013b. Champaign Police Will Train to Deal with Dogs. News Gazette, February 3.

Scott, Andrea B. 2016. Police Kill Nearly 25 Dogs Each Day. The Nation, July 5.

Singer, Peter. 1975. Animal Liberation: A New Ethics for Our Treatment of Animals. New York: New York Review.

Staff. 2015. Police Officer Fatally Shoots Loose Dog. The Daily News, October 16.

Staff Writer. 2011. Officer Shoots, Injures Charging Dog. Capital, April 8.

Sullivan, Dan. 2012. Police on Disturbance Call Shoot Dog. Tampa Bay Times, March 2.

Swabe, Joanna. 1999. Animals, Disease, and Human Society: Human-animal Relations and the Rise of Veterinary Medicine. London: Routledge.

Terrill, William, and Michael D. Reisig. 2003. Neighborhood Context and Police Use of Force. Journal of Research in Crime and Delinquency 40: 291-321. [CrossRef]

Trice, Dawn Turner, and Jeremy Gorner. 2013. Bill Aims to Tame Dog-Cop Clashes. Chicago Tribune, August 6.

Usalis, John E. 2014. Police Shoot Pit Bull in West Mahanoy Township. Republican \& Herald, September 17.

Valentine, Danny. 2011. Officer Shoots and Kills Charging Pit Bull. The Ledger, July 26.

(c) 2019 by the authors. Licensee MDPI, Basel, Switzerland. This article is an open access article distributed under the terms and conditions of the Creative Commons Attribution (CC BY) license (http:/ / creativecommons.org/licenses/by/4.0/). 


\title{
"Why Would You Want a Baby When You Could Have a Dog?" Voluntarily Childless Women's "Peternal" Feelings, Longing and Ambivalence
}

\author{
Helen Peterson ${ }^{1, *(\mathbb{D})}$ and Kristina Engwall ${ }^{2}$ \\ 1 Department of Sociology and Work Science, University of Gothenburg, SE-405 30 Gothenburg, Sweden \\ 2 FoU Södertörn, SE-136 44 Handen, Sweden; kristina.engwall@fou-sodertorn.se \\ * Correspondence: helen.peterson@gu.se
}

Received: 16 March 2019; Accepted: 18 April 2019; Published: 20 April 2019

\begin{abstract}
This article explores voluntarily childless women's experiences and understandings of human-animal interactions and their attitudes towards companion animals. It draws on interviews with 15 Swedish women who expressed a lack of "maternal" feelings and therefore had remained voluntarily childless, or childfree (used here as two interchangeable concepts). Instead, the women described how they perceived the attachment bonds to companion animals that they had developed as similar to, or even superior to, the attachments bonds between parents and their children. The article thus introduces the expressions "peternal", and "peternal feelings", to denote these women's attachment bonds to companion animals (primarily cats and dogs). The results, however, also illustrate that few of the women actually took on the role as "pet parent". Although they longed to develop attachment bonds with companion animals, they were conflicted and experienced ambivalence, leading to decisions to develop avoidance strategies, resembling those involved in the childfree decision. Hence, many of them described themselves as both childfree and "petfree".
\end{abstract}

Keywords: voluntary childlessness; women; pets; "peternal"

\section{Introduction}

People's relationships with companion animals have usually been portrayed in a positive light, with research revealing therapeutic, psychological, physiological and psychosocial benefits (Barker et al. 2003; Blouin 2012; Sable 2013; Sussman 1985). Human and non-human bonds have, however, also sometimes been pathologized. Froma Walsh (2009a) explains:

Those whose closest relationships are with animals have often been viewed as strange or deficient, their affections pathologically misplaced. Strong attachments have been assumed to be symptomatic of an inability to forge healthy connection with humans or to handle separation and loss. (Walsh 2009a, p. 467)

One example of pathologizing is the "popular stereotype" (Bartlett 1995, p. 90), which depicts a childless woman's bond with her companion animal as unhealthy compensation for the missing child (Campbell 1999; Blackstone 2014; Morell 1994; Veevers 1980). Voluntary childlessness, especially, has a stigma attached to it and continues to be surrounded by prejudices and stereotypes (cf. e.g., Letherby 2002; Peterson 2010a; Rich et al. 2011). While other stereotypes about voluntarily childless women have been thoroughly researched and disputed, their relationships with animals and pets have not received much attention until recently (Blackstone 2014; Laurent-Simpson 2017; Volsche and Gray 2016). The lack of research means that these myths continue to inform people's affective reactions toward voluntarily childless women. 
The aim of this article is to explore how 15 Swedish voluntarily childless women made sense of their decision to remain voluntarily childless, by drawing specifically on their experiences regarding interspecies relationships. The article adopts a qualitative methodological perspective focusing on understanding human behavior, and on how people interpret and make sense of their life. The broader conceptual framework was inspired by interpretive phenomenological analysis (Smith et al. 1999) and the method for analysis guided by an inductive, hermeneutical approach.

\section{Previous Research}

Previous research has recognized the developmental and health benefits of pets in families (Friedmann and Thomas 1985; Rochberg-Halton 1985). Pets can have a sociability function in families, meaning that they can facilitate human-to-human social interaction, and improve the socialization of children and adolescents (Covert et al. 1985; Davis and Juhasz 1985; Robin and Bensel 1985; Serpell 1999). Studies show that pets can be a source of emotional and social support to their owners, and that a strong sense of community can form through animal companions (Headey 1999; Meehan et al. 2017; Bulsara et al. 2007). Pets can also have a surrogate function in social interaction and serve as substitutes for friends, spouses or children (Veevers 1985). This is especially true for people who are socially isolated and suffer from psychological illness, or who experience a social stigma (Chur-Hansen 2010; Antonacopoulos and Pychyl 2010). The majority of those who bond with companion animals, however, also interact successfully with people and do not develop non-human bonds as substitute for failed interactions with humans (Kurdek 2008).

Companion animals often become part of the construction of "family life" and are sometimes treated as beloved persons, and ascribed agency and autonomy (Blouin 2013). These anthropomorphising processes are manifested in phenomena such as "fur babies", i.e., that pets are pampered, as family members, and "pet parents", reflecting that there is a deep attachment and bond in the interspecies relationship that goes beyond the possessive relationship implied with the word "owner" (Greenebaum 2004; Owens 2015).

People's attitudes towards pets and how and if they bond with companion animals differ greatly, for example due to childhood experiences (Blouin 2012). Studies also show that women generally have more empathetic or positive attitudes toward animals than men, and count pets as family to a higher degree than men (Herzog 2007; Owens and Grauerholz 2018). Research further suggests that women without children in the household are more likely to develop mothering bonds with their pets than women with children (Turner 2001). Childless people or "empty nesters" have even been suggested to use companion animals to compensate for the lack of children in their life (Rockett and Carr 2014). Margolies (1999) offers an explanation to why and how pets can function symbolically as children for the owner:

The primary symbiotic relationship between a mother and a child has many elements in common with that between a person and an animal. Pets are devoted, forgiving, affectionate, un-critical, and available. Their love is given unconditionally. The relationship, like that between a mother and an infant, is essentially non-verbal. Pets offer their owners an opportunity to receive unconditional maternal love again. (Margolies 1999, p. 298)

Although pets are similar to children in this way, animals' needs are simpler than children's, making it easier to be a "pet parent" than a parent (Blouin 2012). There are also species-related differences. While dogs are especially known to display child-like behaviors (Volsche 2018), cats are easier to take care of and cat ownership may therefore be a "response to loneliness" that appeals especially to "isolated individuals" (Beck and Madresh 2008, p. 52).

Previous research has highlighted how childless people's attachment to animals often is interpreted as unhealthy and a replacement for missing children (Campbell 1999; Owens 2015). Veevers (1979) addressed this stereotype in an early study of voluntary childlessness, in which she interviewed 156 voluntarily childless American couples and discovered that only a small minority saw their pets as 
child surrogates. Instead, many of the couples disliked pet ownership, and for some, experiences of pets had reinforced their decision not to have children. Similarly, Morell (1994) discovered that although many of the childless women she interviewed enjoyed companion animals, there were just as many who steered clear of them due to other priorities-mainly their desires to "minimize domestic responsibilities and maximize flexibility" (Morell 1994, p. 94). Bartlett (1995), in her study about childless women, found that companion animals were mentioned only by a small number of interviewees. Many of the voluntarily childless women and men interviewed by Blackstone (2014), however, described having strong emotional bonds with their pets and described them as family members, some even referring to them as their children.

The above-mentioned studies did not focus exclusively on the relationship between companion animals and childless humans, but only touched upon it. Two studies of late, however, concentrated specifically on this topic. Volsche (2018) interviewed 30 voluntarily childless participants residing in the United States, with 28 of the 30 being pet owners. The interviews illustrate the variations in how the childfree constructed their identities in relation to companion animals, with some using the parenting terminology and describing a parent-child relationship, while others carefully avoided any such implications, expressing awareness of the stigma attached to the idea of "fur babies". Andrea Laurent-Simpson (2017) analyzed how 14 childless pet owners constructed a parent identity in relation to their companion animals. She interprets these parent identities as internalized cultural expectations on becoming a parent, and identifies three parental domains that indicated such an internalized parent identity: "caregiving" (physical and emotional care and protection), "parental relationship" (treating and perceiving the pet as a child), and "life modification" (making life decisions regarding e.g., family and work with the animal in mind).

\section{Theoretical Framework}

Research investigating relationships between humans and their companion animals has typically done so from a psychological perspective, mainly drawing on human relationship theories such as attachment theory or social support theory (Kurdek 2008). Attachment theory investigates how infants and children develop attachment bonds with attachment figures such as parents and caregivers, focusing on the internal cognitive processes involved and emphasizing the evolutionary significance of meaningful affectional relationships (Peacock et al. 2012; Sable 2008; Zilcha-Mano et al. 2012). Researchers have extended the application of attachment theory models to also encompass not only adults' varying need for close emotional relationships (Bartholomew and Horowitz 1991), but also interspecies relationships (Beck and Madresh 2008; Sable 2013). This research has demonstrated that people with high levels of attachment to companion animals experience closeness to them similarly to human attachments (Zilcha-Mano et al. 2011). Companion animals can thus serve as attachment figures and humans can form an "enduring close affectional bond that is perceived as providing emotional support and companionship" with their pets (Meehan et al. 2017, p. 277). Researchers have, however, also pointed out that the term "attachment", as defined in traditional attachment theories, may not accurately describe a human-companion animal relationship. Instead, Crawford et al. (2006, p. 100) suggest that although attachment theory is a good starting point to explore human-companion animal relationships, they are more complicated than generally believed, and measuring the degree of attachment does not "adequately depict that relationship".

In order to make it possible to capture more aspects of this complicated relationship, this article adopts a sociological perspective and uses feminist theory as a starting point to investigate the social construction of gender, femininity, motherhood, parenthood and family in society. This allows us to recognize that it is primarily women's attachment to pets that has been pathologized (Margolies 1999). Similar negative cultural views do not exist about men and their interspecies bond, for example with dogs as their trustworthy companions ("man's best friend") (Blazina and Kogan 2016), or about women who are also mothers (Beck and Madresh 2008). Morell (1994) interprets the stereotype about childless women's relationship with companion animals as "a forceful example of how compensatory 
ideology works" (Morell 1994, p. 90). This means that childless women's attachments to companion animals are not taken on their own terms and are not understood as an expression of a genuine bond between humans and non-humans. Instead, these interspecies bonds are interpreted as signifying a substitution for the missing child. The underlying belief is that: "[ . . ] women have a strong desire to nurture and care for living beings", and when this urge or desire cannot be fulfilled by motherhood, women can instead develop: "[ ... ] parent-child relationships with companion animals" (Turner 2001, p. 9). The negative interpretation of the interspecies bond relies on the cultural view that children are the appropriate recipients of women's nurturing behaviors, and that voluntarily childless women do not fulfil their "moral mandate" to have children (Owens 2015). A woman that declares that she has no inclination to become a mother can therefore be viewed as being egoistic, cold, lonely, bitter, emotionally unstable or unable to build close and affectionate bonds with others (Blackstone 2014; Letherby 1994; Rich et al. 2011).

\section{Method}

This article draws on qualitative, in-depth interviews with 15 Swedish women, who defined themselves as voluntarily childless. The interviews were part of a larger data set, constituting a total of 36 interviews (with 30 women and 6 men), collected within the two authors' research studies, which aimed to explore the lived experiences of being voluntarily childless in Sweden.

Already Houseknecht (1987) recognized the problems with recruiting people for studies on voluntary childlessness. One of the challenges has to do with that the topic can be considered as sensitive and stigmatized. For our studies we therefore adopted an open, flexible and inclusive sample method. We came in contact with about half of the women through an online network for voluntarily childless women. The other half were contacted using a combination of sampling methods; some had appeared in media where they shared their experiences of being voluntarily childless, others contacted us themselves after learning of our research through media or online. Finally, a couple of our informants were recruited using snowball techniques (Browne 2005).

Only women who fulfilled the following criteria were interviewed: they had no biological children; they were not expecting any children in the future; it was an intention and/or choice not to have children. We however did not include it as a necessary condition that the women were married at the time of the interview or that their reproductive period was over (cf. Houseknecht 1987). As a result, the women interviewed were between 29 and 61 years old. Eight were single, four cohabiting with a man while two of them lived in long-term relationships with a man without sharing a household with them (so called LAT-relationships, which stands for Living Apart Together). All women presented themselves as heterosexual. They were promised anonymity and pseudonyms are used to refer to them. More detailed information about them will not be revealed here.

Only four of the 15 women talked about that they shared household with companion animals at the time of the interview. Seven more of the women told about having previous experiences of living together with companion animals. In four interviews, the women mentioned companion animals, but it was not disclosed if they had any pets or if they had previously owned pets (see Table 1 below).

The interviews were conducted in an environment preferred by the informant, which meant primarily in the participant's home, but sometimes in coffee shops or interview rooms in public libraries. All interviews were conducted face-to-face. The interviews were semi-structured and based on open questions about their decision not to have children and about living as a voluntarily childless woman in contemporary Swedish society. The interview guide encouraged the women to tell their stories, and reconstruct their experiences about reactions from family and friends on their decision; attitudes in society towards voluntary childlessness; their intimate relationships; their career and working life; what was important in their lives and what they enjoyed and appreciated with living a voluntary childless life. The interviews focused on capturing the women's perspectives in a narrative manner. Narratives are self-defining stories in which the "story teller" make sense of their experiences, their social world, their life and make claims of who they are (Bruner 1991, 2004). There were no explicit 
questions about pets or animals in the interviews. Instead, the analysis of the replies to primarily two questions showed that the women repeatedly referred to companion animals: the questions about why they had chosen to live a voluntary childless life and what they mostly enjoyed with a voluntary childless lifestyle. That many of the answers to these questions contained references to companion animals emerged inductively from the data during the analytical phase of the research.

Table 1. Summary table of the respondents.

\begin{tabular}{ccccc}
\hline Name (Pseudonym) & Age & Partnership Status & Pet Status & Interviewer \\
\hline Alice & 33 & LAT & & Author 1 \\
Beatrice & 44 & Single & (Cat prev.) & Author 1 \\
Caroline & 50 & Single & & Author 1 \\
Doris & 35 & Single & One cat & Author 1 \\
Eva & 29 & Cohabiting & (Cat prev.) & Author 1 \\
Fanny & 40 & Cohabiting & & Author 1 \\
Greta & 43 & Single & Two cats (Dog prev.) & Author 1 \\
Hanna & 43 & LAT & (Dog prev.) & Author 1 \\
Iris & 42 & Single & (Dog prev.) & Author 1 \\
Julia & 33 & Cohabiting & (Cat prev.) & Author 1 \\
Kim & 42 & Single & (Cat prev.) & Author 2 \\
Lena & 40 & Single & One dog & Author 2 \\
Maria & 61 & Married & One cat & Author 2 \\
Nora & 61 & Single & (Cat prev.) & Author 2 \\
Paula & 50 & Cohabiting & & Author 2 \\
\hline
\end{tabular}

The analysis was inspired by a phenomenological and hermeneutical framework (cf. Seidman 1998; Smith et al. 1999) and guided by an interpretivist-theoretical tradition focusing on the notions of self, self-concepts, identities and meaning-making processes (Manning and Kunkel 2014). This is a framework which allows for an emphasis on how the women constructed and negotiated their identities, while taking the cultural, relational, environmental and societal context into account. The analysis thus focused on discerning what the women themselves wanted to tell and what they themselves ascribed value, meaning and importance in their lives (cf. Smith et al. 1999). The analysis also focused on identifying diverse stories and nuances and variations in their self-narratives, i.e., in their stories about self and life (cf. Seidman 1998).

All interviews were recorded and transcribed verbatim. During the analytical phase, the interview transcripts were analyzed in a two-step process with an initial coding where the references to companion animals first emerged as a prominent theme. After the theme had been identified in this initial coding, a more focused and interpretative coding commenced where the interview transcripts were once more thoroughly searched for mentioning of companion animals and these so called "meaning units" (cf. Shaw 2011) were analyzed specifically for this article. Different considerations regarding animals were in this manner discovered in 15 of the interviews. This article is based on an analysis of these 15 interviews. The analysis did not attempt to determine the interviewed women's attachment levels, but instead aimed to explore how they made sense of, and gave meaning to, their own non-human attachments, or lack of such attachments. Both authors engaged in the analysis, using a reflexive and interpretative stance to make sense, in a hermeneutic manner, of the meaning the women ascribed to companion animals. The results presented in this article developed during this reflexive, analytical phase.

The research was conducted in full compliance with ethical codes of conduct for social science research, including informed consent. Ethical research conduct also involves error analysis and not overestimating the significance of the results. The results presented here have been carefully, realistically and critically evaluated regarding reliability, soundness and clarity (cf. Swedish Research Council 2017). 


\section{Results}

The analysis of the interspecies relationships of the Swedish voluntarily childless women resulted in two overarching categories. The first category consisted of the stories told by women who expressed "peternal" feelings, i.e., a strong delight in pets or an intense longing for pets, and had experiences from owning companion animals. The second category comprised the opposite type of stories-told by women who described themselves not only as "childfree", but also as "petfree" and expressed strong feelings about the importance of not being a "pet parent". Each of these two categories, however, included a variety of different approaches and it is important to also emphasize the nuances in how the women made sense of companion animals. The analysis therefore highlights how the women's self-narratives were characterized by ambivalence and reflections regarding responsibilities. Despite "peternal" longings, the responsibilities towards the animals made them refrain from having their own pet. Such a responsibility had too large an impact on their desire for freedom. This also resulted in only one of the voluntarily childless women interviewed discussing her relationship with her companion animals in terms of "parenting".

\section{1. "Peternal" Feelings, Attachments and Longing for a Companion Animal}

When asked about why they had opted out of motherhood, many of the women used childhood narratives to construct a voluntarily childless identity. In several cases, these childhood narratives described relationships with companion animals. Iris recollected about her upbringing: "We had animals in our home. We had a dog when I was born and later on I got a rabbit that I had for a long time. So I've always had animals instead" (Iris). The use of "instead" can be interpreted as reflecting Iris's awareness of expectations on her to develop an attachment orientation towards babies already during her upbringing. Her narrative suggests that the proximity to companion animals in her family could explain why "young Iris" did not develop this attachment orientation towards babies in the same way as other children did (cf. Kurdek 2008; Zilcha-Mano et al. 2011), and why "adult Iris" did not feel a desire to have children.

How an attachment orientation towards babies could/should, manifest itself during childhood emerged in other interviews. When Hanna was asked why she had remained childless she explained: "Babies have never interested me", and she recollected from her early childhood:

I remember in kindergarten, seeing the other girls screaming "oh, a baby!" as soon as they saw a baby carriage, running to almost crawl into it to have a look. It never interested me. [ ... I It could have something to do with that. (Hanna)

Hanna continued to recount, describing her orientation towards animals: "But on the other hand ... I was extremely interested in animals and my greatest wish was to get a dog or a cat so I ran to greet dogs instead" (Hanna). Hanna's "but on the other hand", similarly to Iris's "instead", suggests that her orientation towards pets had replaced the development of an attachment orientation to babies.

Julia, who explained that she had "no interest in children", also ruminated about her upbringing, during which she described interaction with babies as lacking. She used the same expression as Hanna: "on the other hand", when she explained her interest in pets:

Animals on the other hand ... I can think "oh, how cute! That's adorable!" I can't tear my eyes off kitties and puppies. I always make a fuss over them and have to nuzzle them. But not with kids. (Julia)

In contrast to how other people express excitement about babies, most of the women interviewed explained that they had never experienced babies as wonderful and cute. Some of them, however, drew parallels to their own overwhelming feelings towards animals. Beatrice was asked to explain her decision to remain voluntarily childless and she expounded: 
I have never liked children. [-] You are supposed to love children just because they are children. But I can't say that I genuinely like something in a general manner like that. [ . . ] The only thing that I can say, almost say, that about is cats. Just as other people get silly with babies, I get like that with cats. (Beatrice)

Kim also explained how cats, no matter how they looked or behaved, were always cute and compared it to the feelings others expressed about babies: "Yes. I can understand that feeling. The little piffle feeling: 'Oh, how cute!'” (Kim). She could also relate to the feeling of getting totally absorbed by something: "If I'm to be honest... It's clear that you're getting caught up in what's one's interest in the moment. So if I get a cat I will surely only speak cat, cat, cat, cat, cat" (Kim). Iris was less understanding of how parents become totally absorbed by their children. She also rejected the idea that her behavior as a pet parent would simulate that sort of excitement:

Most people seem to go crazy just because they have been able to reproduce. They don't talk about anything else than diapers, vomit and other things that I don't care about. I mean, I had a dog before, but I didn't call my friends to tell them about his poo! (Iris)

Nora reflected, in a similar critical stance, over how she refused to adapt to the social norms and join in on the excitement about babies: "And those of my co-workers who came to work with their babies and everyone said: 'Oh, yes... how sweet!' [But] I just walked away.” (Nora). Not meeting social expectations on a certain behavior usually elicits social disapproval, which the women also were aware of. Julia reflected over her orientation towards companion animals: "It's somehow inhuman in a way, that animals are more important or that I'm a person who prefers animals to humans" (Julia). Turning to self-reflection, Julia continued: "It seems so cold when recounting it" (Julia). Referring to her own behavior as reflecting the character trait "cold" could be interpreted as if Julia had internalized the stereotypes about voluntarily childless women as uncaring, hard-hearted, distant and detached (Blackstone 2014; Letherby 1994; Rich et al. 2011).

The overwhelming delight in babies, as displayed by other girls in the narratives of Hanna and Doris, could be interpreted as an early manifestation of the biological urge to become a mother, commonly believed to be experienced by most adult women and sometimes referred to as "maternal feelings" (cf. Peterson and Engwall 2013). These women thus dissociated themselves from having developed this type of maternal longing for a baby. Two of the women, however, described what could be understood as a "peternal" longing for a companion animal. They discussed their urge for a companion animal as an innate biological urge, similar to how other women described their maternal desire for a baby. Eva reflected on how both the absence of maternal instinct and the strong preference to have a dog, were natural and biological processes:

My boyfriend came up with a theory that I might get the bodily reaction that in other women leads to the feeling "I want children", but in me, these signals are transformed in the brain and what comes out is: "I want a dog!" [laughter] I really want a dog. [-] I have thought about this and maybe I lack some neurological connections. (Eva)

Kim, similarly, emphasized her absent baby fever and instead highlighted her strong longing to have a cat. "I want to... God... mhh mhh [sighing] I want a cat! I have never felt that oh mhh [sighing again] I want a child" (Kim). Kim acknowledged that there was a distinction between the urge for a baby and for a cat, but in order to make the interviewer understand her reasoning she persisted: "that sounds ridiculous [comparing children with cats], but I have to make that parallel" (Kim).

Kim also recounted how she used the analogy between pets and children when she was confronted with the statement "you would be a wonderful mother" (Kim). In order to deal with this implicit suggestion that all women want to become mothers, Kim responded with the counterstatement "you would be a great cat owner" (Kim), aware of that this would also end any discussion about her childfree status. Appraising a childless woman's caring disposition (displayed e.g., towards companion animals) in this manner is a manifestation of so called "pronatalistic pressure" (Peterson 2010b), i.e., the powerful 
normative force coercing women into motherhood, constructing voluntary childlessness as unnatural and as an unconceivable option. Childless women commonly experience manifestations of pronatalistic pressure as more or less explicit attempts to persuade them about the advantages of becoming a mother (Peterson and Engwall 2013). All of the women interviewed had encountered this. Eva reported how she dealt with that:

If someone asks why I don't want children it usually ends with me saying: "As long as I prefer to have a dog to a baby, I shouldn't have children. Period." You can't argue with that. So that's usually the most efficient strategy [to silence them]. (Eva)

Caroline reflected over the power of the pronatalistic pressure as she noted that not all women who become mothers "really crave a baby". Instead, according to Caroline, they get persuaded by society or by a partner, which made her ponder: "Why don't they just get a puppy instead?" (Caroline). Overturning the stereotype about childless women's pets being child substitutes, Caroline thus implied that some children instead are substitutes for pets and that pronatalistic pressure prevents some women from making the most sensible decision, i.e., getting a pet. Eva likewise questioned the choice to have children: "When my friends have told me they're pregnant my first thought has been 'But why would you want a baby when you could have a dog?"' (Eva). Iris, not only implied that children could be substitutes for pets, but explicitly developed her ideas about this:

I don't know if the dog becomes some kind of substitute [for childless people]. I have almost seen having children as a substitute for getting a dog. [laughter] I have heard people being given the advice to have children in order not to have to be alone. Seriously! I've heard it several times! And I feel "but why don't you get a dog? It will be cute and sweet and it won't give you any problems with quarrelling or whining". (Iris)

Only one of the women interviewed expressed what could be interpreted as what in previous research has been defined as a "petparent" identity (Owens 2015; Owens and Grauerholz 2018). Greta expressed that she enjoyed a "special bond" with her two cats and considered them to be the most important in her life. For her, the childfree lifestyle meant that she could protect her two cats from the risks of being subjected to the cruelty of children. Greta explained that she had always, since she was a child, considered children to be "big animal abuser". She continued to account for what that meant for her and her decision to remain childfree: "Right now I have two cats, and I would never dream of exposing them to a life together with children" (Greta). Greta gave an example of her protective attitude:

A colleague of mine asked if she could borrow one of my cats because her daughter wanted a companion animal. "Are you completely crazy?", I replied, and she said: "What do you mean? It's only an animal!" If you have that attitude you shouldn't even have a stick insect as a pet. My God! They are my babies. [-] It would be just as absurd as if I asked to borrow her child to see if I could cope with being a mother. (Greta)

Referring to her cats as her "babies" is a way of drawing on cultural parenting narratives and constructing a childless interspecies family narrative (Owens 2015; Owens and Grauerholz 2018). Comparing her cats to children, and strongly refuting the idea about "only an animal", Greta seemed to oppose the everyday distinction between humans and non-humans in which the parental relationships to animals is minimized and devalued (cf. Owens and Grauerholz 2018). At the same time, she portrayed herself as a more responsible and legitimate parent than her friend. The role as a protector of the companion animal/child is part of the caregiving parental role that Laurent-Simpson (2017) identified in her research on childless/childfree pet owners. Similar to Greta, several of the informants in the study of Laurent-Simpson (2017) were concerned with protecting their companion animal from traumatic memories of teasing and bullying, although no one in her study identified children as the culprits. 


\subsection{Remaining "Childfree" and "Petfree"-Ambivalence and Avoidance Strategies}

Why then, if Eva, Caroline, Kim, Julia and Hanna, had these "peternal" longings, did they not have companion animals? Actually, they, together with Beatrice and Nora, strongly rejected the idea about having pets. As we shall see in this section, references to companion animals were also intertwined in the women's narratives about how children would disrupt their lifestyle. In these narratives the women used similar arguments to explain why they did not have pets that they used to describe the disadvantages of having children.

Just like being a parent, being responsible for pets was perceived, by these women, as restricting the owner's freedom and independence. These women emphasized that they were "childfree" and not "childless", emphasizing "the positive experience of the choice" (cf. e.g., Park 2005, p. 399 for a discussion on the choice of term). Both children and pets would prevent them from feeling "spontaneous" (Beatrice) and made them "feel trapped" (Beatrice). Beatrice: "could imagine that it would be really nice to have a cat" but explained her priorities in life: "It's important for me not to have responsibility for someone else. I don't have any pets either because I don't want to be responsible for it" (Beatrice).

Fanny described how she enjoyed not only the benefits of a "childfree lifestyle", but also a "petfree lifestyle", involving minimal household and caretaking duties. She shared her observation about "mothers who need a pet to take care of and groom" when they become "empty nesters". Contrary to this she explained: "But I feel that those care-taking duties are just a burden to me" (Fanny). Previous research has shown how voluntarily childless women sometimes explain their decision with reference to a lack of a biological urge to have a baby (Peterson and Engwall 2013). Fanny described her decision to forgo motherhood in this manner, as something very "natural" due to absent "maternal instinct". Fanny explained how her childfree decision was linked to her identity and her lifestyle, describing that she had never had: "that motherly, nurturing and caretaking part" (Fanny). She continued to explain what that meant: “I don't have the need to take care of a child or a pet. I don't feel that need very strongly" (Fanny). Instead, her needs gave priority to personal freedom. Nora described a similar experience:

I think children, you know, it had... it had also cropped my freedom. I've had some cats... And I was thinking about getting a cat again, but... if I want to travel or do this and that... who would take care of the cat? (Nora)

As seen above, the women described a need for freedom that not only prevented them from parenting a child but also from parenting a companion animal (cf. Peterson 2015). Similar arguments, regarding these women's need for freedom, were thus used to support their decision not to have children and to support their decision not to have an animal companion. In short, their lifestyle preferences could be summarized in the expression: "I don't even have any pets!" (Beatrice).

Likewise, Julia ruminated over her limited possibilities to care for a companion animal, or a child, due to her lifestyle:

I had a cat a long time ago. Unfortunately, he died. But I love cats. I would really love to have a cat. But with the life I lead right now, travelling a lot, having engagements in the evenings. It would be a miserable life for the cats. When you get home, the poor cat would be starving for affection and attention and then I wouldn't get the space I need. When I tell people that they always support that decision: "That's very sensible of you, don't get a cat". But it's the exact same thing with a child. (Julia)

Julia thus described that it was easier for other people to accept that she, because of life circumstances, opted out of a cat than a child. In contrast to Fanny, Julia and Beatrice expressed feelings of ambivalence regarding pets. Ambivalence, i.e., "mixed feelings", defined as a "mix of positive and negative emotions toward the same relational object" (Lendon et al. 2014, p. 272) is a concept previously often referred to in research on voluntary childlessness (cf. e.g., Letherby 2002; Letherby 
and Williams 1999; Reuter 2018; Veevers 1979). Although Julia longed for a cat, she had decided to give up the idea of having a pet. Her ambivalence and struggle involved taking into account her own need of "space", but she also displayed a high level of empathy with the cat and acknowledged the cat's needs of affection and attention and that she would not be able to fulfil those needs. She compared this line of reasoning, an example of responsible ambivalence, with her decision to forgo children (cf. Reuter 2018).

Three of the women who previously had shared their household with a companion animal described the problems they had experienced. Contrary to what previous research (Owens and Grauerholz 2018; Owens 2015; Walsh 2009b) has shown about pet parenting as a preparation to become a "real" parent, Beatrice, reflected over the experience in the following way:

Having a cat was really a kind of vaccination for me. It made me realize what I already knew. If I can't even take care of two cats without feeling trapped, what would it be like with a child? A cat you can ... If you get upset with your cat you can put it in the bathroom for an hour, of course you wouldn't like to, but still ... (Beatrice)

Even for Eva, who preferred animals to children, a pet could become a burden. She was asked what she enjoyed with her voluntarily childless life and she instantly replied: "To be able to be free" (Eva). She expanded on what this meant by recounting how she and her partner once had a companion animal:

We had a cat once. It was fun and it actually made us feel a little like a family. It was nice and fun. But at the same time... there were some problems with the cat and as you can tell he is no longer with us. It became a burden and it was a little like... it ended up being an encumbrance. (Eva)

Although Eva was deterred by the episode involving the companion animal, it is worth noting the reference to the positive experience of feeling "a little like a family". Two adults living together is not perceived as a family in the social construction of "doing family" (cf. Blackstone 2014; Owens and Grauerholz 2018). A child, or a cat, increases the possibilities of being perceived as a "real" family.

Kim, who expressed how she loved cats, and previously had owned one, came to the decision to not have a cat due to her lifestyle:

I had a cat when I moved home to Sweden. But she died unfortunately and I didn't get a new one.

Because I realized how hard it was ... to be away from home all the time, I traveled a lot with the job

then and worked long days and was gone. And the little kitty ... when I got home she was so happy

to see me after being completely deprived of company, and so rather, I have chosen to opt out a cat.

Because I don't think I have time to take care of it. (Kim)

Kim, similarly to Julia, expressed her ambivalence towards being a cat-owner. While Julia described empathy, as a prerequisite for feeling guilt, Kim was more explicit about wanting to avoid feeling the guilt of leaving the cat alone. Still, such guilt also reflected the concern for the cats (cf. Rotkirch and Janhunen 2009).

The relationship with companion animals was also constituted as problematic by three of the four women who were pet owners. Doris had a cat, and when she was asked to explain why she had chosen to live a life without children she replied: "I would have a hard time coping with having someone that is so dependent on you ... it's quite enough with having a cat [laughter]" (Doris). Doris thus emphasized the distinction between the level of caregiving associated with pets and children. Maria was another cat owner interviewed and she opined that a child would possibly constrain her everyday life even more than her cat already did:

Yes, it is possible. I've always had a cat and ... We get very bound by it. It's coming along everywhere.

It's true that you'll be bound. Maybe not always physically but very bound mentally. (Maria) 
Similarly to Eva, Julia's previous experiences of "pet parenting" only reinforced her choice to remain voluntarily childless. She reflected in a self-aware manner over how she thought she would be able to cope with the motherhood role, and compared it to how she coped with the role as "pet parent":

I'm a very impatient person and with the cat ... when the cat was meowing I felt like hitting it! [laughter] So I can only imagine, what would it be like with a kid? It would be so incredibly much worse! (Julia)

In these cases the women's experiences of pets confirmed their decision to forgo children, whether it was based on refuting what was understood as necessary life modifications or anticipating an unacceptable high level of caregiving. Even Greta, who cared for her two cats to a point where they had become her "fur babies" (cf. Greenebaum 2004), making sure never to let them go outside or be alone at home for too long, described that she had her limits when it came to caring for companion animals. She had previously had a dog and could compare the two different types of companion animals: "I've had a dog also and that was a completely different kind of care-taking and you needed to spend much more time at home with the dog" (Greta). Preferring a cat instead of a dog could be explained with reference to "species-typical differences in social behavior, with cats being more emotionally distant from their owners than dogs" (Zilcha-Mano et al. 2011, p. 348). The cat, with self-reliance and lack of interdependence (Beck and Madresh 2008), was a better fit with Greta's own preferences regarding autonomy.

\section{Discussion}

This study has examined how 15 Swedish voluntarily childless women gave meaning to and constructed their voluntary childless decision by drawing on experiences regarding interspecies relationships. Only four of the 15 women interviewed disclosed that they actually owned pets and only one expressed what could be interpreted as an evident "petparent" identity (cf. Laurent-Simpson 2017; Owens 2015; Owens and Grauerholz 2018). Instead, about a third of the women wanted to be "petfree" for the same reasons as "childfree", and strongly dissociated themselves from the responsibilities associated with pet parenting.

Nevertheless, several of the women without pets were intensely emotionally attached to a particular pet, or particular types of companion animals in a more general sense. Some of them even compared their longing for a pet with other women's maternal longing for a child, and thus expressed "peternal" feelings. Notwithstanding, not even these women, who compared their deep affection for companion animals with the attachment between parents and child, had adopted the full "caregiving" behavior, or attempted extensive "life-modification", with regards to a companion animal (cf. Laurent-Simpson 2017). They rejected the idea about taking on the responsibilities for duties such as feeding, cleaning and providing comfort to children as well as to pets. Previous experiences of companion animals made them refrain from once again sharing their household with a pet as the responsibilities would have too large an impact on their desired lifestyle. Although affections for companion animals were a significant aspect of these Swedish women's voluntary childless identities and sense-making, most of them were not willing to adjust their childfree lifestyle to include a pet. Those who experienced the strongest "peternal" feelings in this study, however, also expressed ambivalence. They struggled to acknowledge that their intense attachment to companion animals was not compatible with their needs for space and freedom. But ultimately, their responsible ambivalence (cf. Reuter 2018) involved both empathy and guilt towards the pet.

Little attention has so far been devoted to understanding voluntary childlessness as a phenomenon contextually dependent on social, cultural, historical, economic and political pre-conditions. We, however, here emphasize the need to interpret these results within the context of the current Swedish society. This is a welfare society characterized by a political commitment to create a 'child-friendly' society where structural measures support the reconciliation of parenthood and professional life. A powerful motivator for women to choose to remain childless has otherwise been professional career 
preferences (Abma and Martinez 2006; Tanturri and Mencarini 2008). This choice-between children or career-is less relevant in the Swedish context. Consequently, this is a societal context in which women's career orientation might not provide a legitimate explanation for the voluntary childless decision. Instead, previous research shows that Swedish women favor references to biological and bodily processes to make sense of their voluntary childless decision. This sense-making strategy is illustrated by expressions such as "silent body", "lack of biological clock", "no urge" (Peterson and Engwall 2013). These expressions mirror societal norms that motherhood should be preceded by a strong and irresistible longing for children.

When Swedish voluntarily childless women describe a lack of maternal feelings in this manner, they make sense of their decision to forgo children in dialogue with the societal discourse about motherhood: just as reproduction is assumed to be biologically programmed, so is voluntary childlessness. References to lack of a maternal instinct are therefore also a way of depicting voluntary childlessness as a "natural" decision in the sense of "not acting against nature".

The results in this article illustrate that similar sense-making occurred with regards to companion animals. Describing strong "peternal" feelings makes sense in a societal context where maternal instincts have been biologized (Peterson and Engwall 2013). To display "peternal" feelings could also be a way of refuting stereotypes about voluntarily childless women being cold and unable to form attachment bonds with others (cf. Blackstone 2014; Letherby 1994; Rich et al. 2011). Expressing such "peternal" longings can therefore also permit voluntarily childless women to embrace their womanhood, regardless of stereotypes about "unwomanly conduct" (cf. Morell 1994; Rich et al. 2011).

Previous research has also highlighted how Swedish voluntarily childless women emphasize their need and desire for "freedom" when they explain and justify their decision to forgo having children (Peterson 2015). The women's justification for living a "childfree" life, and a "petfree" life, even despite having "peternal" longings, seemed to coincide in arguments that these life-decisions were made to prevent disastrous consequences for themselves as well as for the child/pet. The sense-making strategy regarding not having pets thus gave further support and weight to their voluntary childless decision. It is a meaning-making strategy that presented their decisions in a consistent and responsible way, as they avoided being questioned about why they had companion animals but no children. By dissociating themselves from the caring-activities associated both with children and companion animals, their behavior made more sense, to themselves and to the surrounding society. Hence, making sense of a "petfree" lifestyle, in relation to their need of "own space", also supported their childfree decision.

The qualitative, interpretive perspective adopted in the article facilitates a complex and nuanced analysis that highlights voluntarily childless women's meaning-making as a reflexive, complex and continuous process (Manning and Kunkel 2014). The analysis therefore contributes to the growing body of research attempting to understand variations in human-non-human relations (cf. Blouin 2013). However, more research is needed in this area, especially because the voluntary childless population is prognosed to continue to increase. The results highlight the need for more cross-cultural comparisons between different cultural contexts. The article raises questions about whether or not "a desire to nurture" (Laurent-Simpson 2017) or being a "dog mom" (Volsche and Gray 2016) are more accurate arguments, justifications and sense-making strategies in some cultural settings than others, depending on, for example, the strength and influence of traditional gender roles in these cultures. Our research suggests that voluntary childlessness and "petparenting" can have very different meanings in different societal contexts.

Author Contributions: Conceptualization, H.P. and K.E.; methodology, H.P. and K.E.; validation, H.P. and K.E.; formal analysis, H.P. and K.E.; investigation, H.P. and K.E.; resources, H.P. and K.E.; data curation, H.P. and K.E.; writing-original draft preparation, H.P. and K.E.; writing-review and editing, H.P. and K.E.; project administration, H.P. and K.E.; funding acquisition, H.P. and K.E.

Funding: This research was funded by the Swedish Research Council for Health, Working Life and Welfare. 
Conflicts of Interest: The authors declare no conflict of interest. The funders had no role in the design of the study; in the collection, analyses, or interpretation of data; in the writing of the manuscript, or in the decision to publish the results.

\section{References}

Abma, Joyce C., and Gladys M. Martinez. 2006. Childlessness Among Older Women in the United States: Trends and Profiles. Journal of Marriage and Family 68: 1045-56. [CrossRef]

Antonacopoulos, Nikolina M. Duvall, and Timothy A. Pychyl. 2010. An Examination of the Potential Role of Pet Ownership, Human Social Support and Pet Attachment in the Psychological Health of Individuals Living Alone. Anthrozoös 23: 37-54. [CrossRef]

Barker, Sandra B., Christopher S. Rogers, John W. Turner, Ariane S. Karpf, and H. Marie Suthers-McCabe. 2003. Benefits of Interacting with Companion Animals: A Bibliography of Articles Published in Refereed Journals During the Past 5 Years. The American Behavioral Scientist 47: 94-99. [CrossRef]

Bartholomew, Kim, and Leonard M. Horowitz. 1991. Attachment styles among young adults: A test of a four-category model. Journal of Personality and Social Psychology 61: 226-44. [CrossRef] [PubMed]

Bartlett, Jane. 1995. Will You Be Mother? Women Who Choose to Say No. New York: New York University Press.

Beck, Lisa, and Elizabeth A. Madresh. 2008. Romantic partners and four-legged friends: An extension of attachment theory to relationships with pets. Anthrozoös 21: 43-56. [CrossRef]

Blackstone, Amy. 2014. Doing Family without Having Kids. Sociology Compass 8: 52-62. [CrossRef]

Blazina, Christopher, and Lori R. Kogan, eds. 2016. Men and Their Dogs: A New Understanding of Man's Best Friend. Cham: Springer.

Blouin, David D. 2012. Understanding Relations between People and their Pets. Sociology Compass 6: 856-69. [CrossRef]

Blouin, David D. 2013. Are Dogs Children, Companions, or Just Animals? Understanding Variations in People's Orientations toward Animals. Anthrozoös 26: 279-94. [CrossRef]

Browne, Kath. 2005. Snowball sampling: Using social networks to research non-heterosexual women. International Journal of Social Research Methodology 8: 47-60. [CrossRef]

Bruner, Jerome. 1991. The narrative construction of reality. Critical Inquiry 18: 1-21. [CrossRef]

Bruner, Jerome. 2004. Life as narrative. Social Research 5: 691-710.

Bulsara, Max, Lisa Wood, Billie Giles-Corti, and Darcy Bosch. 2007. More Than a Furry Companion: The Ripple Effect of Companion Animals on Neighborhood Interactions and Sense of Community. Society E Animals 15: 43-56.

Campbell, Annily. 1999. Childfree and Sterilized. Women's Decisions and Medical Responses. London and New York: Cassell.

Chur-Hansen, Anna. 2010. Grief and bereavement issues and the loss of a companion animal: People living with a companion animal, owners of livestock, and animal support workers. Clinical Psychologist 14: 14-21. [CrossRef]

Covert, Anita Miller, Alice Phipps Whiren, Joanne Keith, and Christine Nelson. 1985. Pets, Early Adolescents, and Families. Marriage \& Family Review 8: 95-108.

Crawford, Emily K., Nancy L. Worsham, and Elizabeth R. Swinehart. 2006. Benefits Derived from Companion Animals, and the use of the Term "Attachment". Anthrozoös 19: 98-112. [CrossRef]

Davis, Janet Haggerty, and Anne McCreary Juhasz. 1985. The Preadolescent/Pet Bond and Psychosocial Development. Marriage \& Family Review 8: 79-94.

Friedmann, Erika, and Sue Thomas. 1985. Health Benefits of Pets for Families. Marriage \& Family Review 8: 191-203.

Greenebaum, Jessica. 2004. It's a Dog's Life: Elevating Status from Pet to "Fur Baby" at Yappy Hour. Society $\mathcal{E}$ Animals 12: 117-36.

Headey, Bruce. 1999. Health benefits and health cost savings due to pets: Preliminary estimates from an Australian national survey. Social Indicators Research 47: 233-43. [CrossRef]

Herzog, Harold A. 2007. Gender Differences in Human-Animal Interactions. Anthrozoös 20: 7-21. [CrossRef]

Houseknecht, Sharon K. 1987. Voluntary childlessness. In Handbook of Family and Marriage. Edited by Marvin B. Sussman and Suzanne K. Steinmetz. New York: Plenum Press. 
Kurdek, Lawrence A. 2008. Pet dogs as attachment figures. Journal of Social and Personal Relationships 25: 247-66. [CrossRef]

Laurent-Simpson, Andrea. 2017. Considering Alternate Sources of Role Identity: Childless Parents and Their Animal "Kids". Sociological Forum 32: 610-34. [CrossRef]

Lendon, Jessica P., Merril Silverstein, and Roseann Giarrusso. 2014. Ambivalence in Older Parent-Adult Child Relationships: Mixed Feelings, Mixed Measures. Journal of Marriage and Family 76: 272-84. [CrossRef] [PubMed]

Letherby, Gayle. 1994. Mother or not, mother or what? Problems of definition and identity. Women's Studies International Forum 17: 525-32. [CrossRef]

Letherby, Gayle. 2002. Childless and bereft? Stereotypes and realities in relation to 'voluntary' and 'involuntary' childlessness and womanhood. Sociological Inquiry 72: 7-20. [CrossRef]

Letherby, Gayle, and Catherine Williams. 1999. Non-Motherhood: Ambivalent Autobiographies. Feminist Studies 25: 719-28. [CrossRef]

Manning, Jimmie, and Adrianne Kunkel. 2014. Making meaning of meaning-making research: Using qualitative research for studies of social and personal relationships. Journal of Social and Personal Relationships 31: 433-11. [CrossRef]

Margolies, Liz. 1999. The long good-bye: Women, companion animals, and maternal loss. Clinical Social Work Journal 27: 289-304. [CrossRef]

Meehan, Michael, Bronwyn Massavelli, and Nancy Pachana. 2017. Using Attachment Theory and Social Support Theory to Examine and Measure Pets as Sources of Social Support and Attachment Figures. Anthrozoös 30: 273-89. [CrossRef]

Morell, Carolyn Mackelcan. 1994. Unwomanly Conduct. The Challenges of Intentionally Childlessness. New York and London: Routledge.

Owens, Nicole. 2015. The Interspecies Family: Attitudes and Narratives. Ph.D. dissertation, The Department of Sociology, the University of Central Florida, Orlando, FL, USA.

Owens, Nicole, and Liz Grauerholz. 2018. Interspecies Parenting: How Pet Parents Construct Their Roles. Humanity \& Society, 1-24. [CrossRef]

Park, Kristin. 2005. Choosing childlessness: Weber's typology of action and motives of the voluntarily childless. Sociological Inquiry 75: 372-402. [CrossRef]

Peacock, Jasmin, Anna Chur-Hansen, and Helen Winefield. 2012. Mental Health Implications of Human Attachment to Companion Animals. Journal of Clinical Psychology 68: 292-303. [CrossRef] [PubMed]

Peterson, Helen. 2010a. Internationell forskning om frivillig barnlöshet [International research on voluntary childlessness]. In Frivillig Barnlöshet. Barnfrihet $i$ en Nordisk Context [Voluntary Childlessness. Childfreeness in a Nordic Context]. Edited by Engwall Kristina and Peterson Helen. Stockholm: Dialogos, pp. 61-102.

Peterson, Helen. 2010b. Pronatalistisk press eller ökande acceptans [Pronatalistic pressure or increased acceptance]. In Frivillig Barnlöshet. Barnfrihet i en Nordisk Kontext [Voluntary Childlessness. Childfreeness in a Nordic Context]. Edited by Engwall Kristina and Peterson Helen. Stockholm: Dialogos, pp. 257-93.

Peterson, Helen. 2015. Fifty Shades of Freedom. Voluntary Childlessness as Women's Ultimate Liberation. Women's Studies International Forum 53: 182-91. [CrossRef]

Peterson, Helen, and Kristina Engwall. 2013. Silent Bodies: Childfree Women's Gendered and Embodied Experiences. European Journal of Women's Studies 20: 376-89. [CrossRef]

Reuter, Shelley Zipora. 2018. Intersecting ethics of responsibility: Childless academic women and their ambivalence in reproductive decision-making. Women's Studies International Forum 79: 99-108. [CrossRef]

Rich, Stephanie, Ann Taket, Melissa Graham, and Julia Shelley. 2011. 'Unnatural', 'unwomanly', 'uncreditable' and 'undervalued': The significance of being a childless woman in Australian society. Gender Issues 28: 226-47. [CrossRef]

Robin, Michael, and Robert ten Bensel. 1985. Pets and the Socialization of Children. Marriage E Family Review 8: 63-78.

Rochberg-Halton, Eugene. 1985. Life in the Treehouse: Pet Therapy as Family Metaphor and Self-Dialogue. Marriage E Family Review 8: 175-89.

Rockett, Ben, and Sam Carr. 2014. Animals and Attachment Theory. Society \& Animals 22: 415-33.

Rotkirch, Anna, and Kristiina Janhunen. 2009. Maternal Guilt. Evolutionary Psychology 8: 90-106. [CrossRef]

Sable, Pat. 2008. What is Adult Attachment? Clinical Social Work Journal 36: 21-30. [CrossRef] 
Sable, Pat. 2013. The Pet Connection: An Attachment Perspective. Clinical Social Work Journal 41: 93-99. [CrossRef] Seidman, Irving. 1998. Interviewing as Qualitative Research. New York: Teachers College Press.

Serpell, James. 1999. Guest editor's introduction: Animals in children's lives. Society E Animals 7: 87-94.

Shaw, Rachel Louise. 2011. Women's Experiential Journey Toward Voluntary Childlessness: An Interpretative Phenomenological Analysis. Journal of Community \& Applied Social Psychology 21: 151-63.

Smith, Jonathan A., Maria Jarman, and Mike Osborn. 1999. Doing interpretative phenomenological analysis. In Qualitative Health Psychology: Theories and Methods. London: Sage, pp. 218-40.

Sussman, Marvin B. 1985. Pet/Human Bonding: Applications, Conceptual and Research Issues. Marriage \& Family Review 8: 1-5.

Swedish Research Council. 2017. Good Research Practice. Stockholm: Swedish Research Council.

Tanturri, Maria Letizia, and Letizia Mencarini. 2008. Childless or Childfree? Paths to Voluntary Childlessness in Italy. Population and Development Review 34: 51-77. [CrossRef]

Turner, Wendy G. 2001. Our New Children: The Surrogate Role of Companion Animals in Women's Lives. The Qualitative Report 6: 1-10.

Veevers, Jean E. 1979. Voluntary Childlessness: A Review of Issues and Evidence. Marriage and Family Review 2: 1-26. [CrossRef]

Veevers, Jean E. 1980. Childless by Choice. Toronto: Butterworths.

Veevers, Jean E. 1985. The Social Meanings of Pets: Alternative Roles for Companion Animals. Marriage E Family Review 8: 11-30.

Volsche, Shelly. 2018. Negotiated Bonds: The Practice of Childfree Pet Parenting. Anthrozoös 31: 367-77. [CrossRef]

Volsche, Shelly, and Peter Gray. 2016. "Dog Moms" Use Authoritative Parenting Styles. Human-Animal Interaction Bulletin 4: 1-16.

Walsh, Froma. 2009a. Human-Animal Bonds I: The Relational Significance of Companion Animals. Family Process 48: 462-80. [CrossRef] [PubMed]

Walsh, Froma. 2009b. Human-Animal Bonds II: The Role of Pets in Family Systems and Family Therapy. Family Process 48: 481-99. [CrossRef] [PubMed]

Zilcha-Mano, Sigal, Mario Mikulincer, and Phillip R. Shaver. 2011. An attachment perspective on human-pet relationships: Conceptualization and assessment of pet attachment orientations. Journal of Research in Personality 45: 345-57. [CrossRef]

Zilcha-Mano, Sigal, Mario Mikulincer, and Phillip R. Shaver. 2012. Pets as safe havens and secure bases: The moderating role of pet attachment orientations. Journal of Research in Personality 46: 571-80. [CrossRef]

(C) 2019 by the authors. Licensee MDPI, Basel, Switzerland. This article is an open access article distributed under the terms and conditions of the Creative Commons Attribution (CC BY) license (http://creativecommons.org/licenses/by/4.0/). 


\title{
Article \\ Keeping Lily Safe: An Autoethnographic Exploration of Human-Animal Attachment during Adversity
}

\author{
Catherine Lee ${ }^{(1)}$ \\ Faculty of Health, Education, Medicine and Social Care, Anglia Ruskin University, Chelmsford, Essex CM1 1SQ, \\ UK; catherine.lee@anglia.ac.uk
}

Received: 20 May 2019; Accepted: 17 July 2019; Published: 18 July 2019

\begin{abstract}
This article is an autoethnographic examination of my experiences as a pet owner during a particularly challenging time in my life. Beginning with a summary of a critical incident, it shows the way in which fears for the safety of my pet cat, Lily, and my relationship with her impacted my health, wellbeing and identity. Depicting self-knowledge as partial, local and culturally located, I deconstruct the relationship I had with Lily in relation to the particular set of circumstances in which it was situated. I was seen by my doctor and prescribed a course of cognitive behaviour therapy (CBT) during this period, and so, my account draws on my medical records, CBT notes and my CBT thought diary in an attempt to understand how and why my anxiety was manifested in my concern for Lily. The article calls for cognitive behaviour therapists to carefully evaluate external stressors before fears are dismissed irrational and reformulated as alternative thoughts. This article also demonstrates that familiesare diverse, and there are many ways of 'doing family'. For many heterosexual and same-sex couples, pets give stability to a partnership and elevate it to family status, if only within the privacy of the home. Human-animal attachments can be comparable to human-human attachments, and where attachments to pets are as strong as those toward humans, fear of harm can be devastating.
\end{abstract}

Keywords: family; CBT; autoethnography; pets; homophobia; LGBT

\section{Introduction}

This article is an autoethnographic examination of my experiences during a particularly challenging time in my life. Beginning with a summary of a critical incident, my narrative shows the way in which fears for the safety of Lily, my companion animal, and my relationship with her impacted my health, well-being and identity. Grounded in an interpretivist philosophy, my autoethnographic account utilises writing about the self as a method of inquiry. Depicting self-knowledge as partial, local and culturally located, I critically examine the human-animal relationship I had with Lily in relation to the particular set of circumstances in which it was situated. Of primary importance during this period was the imposition of medical definitions of the situation, as I was seen by my doctor and prescribed a course of cognitive behaviour therapy (CBT). Consequently, my autoethnographic account draws on my medical records, CBT notes and my CBT thought diary in an attempt to understand how and why my anxiety was manifested in my concern for Lily. Additionally, since there is a dearth of research on human-animal relationships during adversity, this article answers in part the call of Zilcha-Mano et al. (2012) and others for a scholarly examination of people's relationships with companion animals during 'difficult life situations' (p. 9). My account, similar to the redemption narratives of homeless people elaborated upon in Irvine's (2013) research, shows the ways in which people construct and revise their sense of self by telling stories that describe their relationships with animal companions.

This article begins with a brief description of the critical incident followed by a discussion of the autoethnographic methodology. Then, drawing on pertinent literature, I analyse how my relationship with, and fears for, Lily manifested themselves during this challenging period. 
It is beyond the scope of this paper to share the entire critical incident upon which this article is based. What follows is a synopsis of the salient events. Even though this story is primarily about me, at its core is the behaviour of others, as well as my relationships with them. Tolich (2010) casts the word 'auto' when applied to autoethnography as a "misnomer", describing the self as "porous", inevitably "leaking" onto others, (p. 1608). The others mentioned in the narrative are 'characters', only partially depicted to help tell this story. Pseudonyms (Jo, Mr. Freeman and even Lily) or role titles (e.g., therapist, headteacher) are used throughout to protect the identities of all the others to whom I refer.

During the critical incident, I lived with my civil partner, Jo, and our cat, Lily, in rural southeast England. We had a house surrounded on three sides by fields belonging to the local wildlife trust. In June 2009, the neighbouring farmhouse-the only other property for half a mile-was sold to the Freemans (a pseudonym), a family of seven. They moved in and enrolled three of their children at the school at which I was assistant headteacher. The Freemans had a garden of six acres, but placed a trampoline immediately abutting our property line, no more than 15 feet from our kitchen and living room windows. My partner and I were upset at this intrusion into our privacy and decided to introduce ourselves and welcome the Freemans to the village, hoping in the process for an opportunity to mention the trampoline issue. Mr. Freeman proudly showed us around the grounds of his new property, and Jo sensitively broached the subject of the trampoline, explaining that I was a teacher at the school his children attended and that it was important to me that professional and personal boundaries did not become blurred. Mr. Freeman agreed and happily moved the trampoline. We thanked him for appreciating our position and rounded off the encounter in a cordial and neighbourly manner, leaving with an invitation to their housewarming party. Later that evening, banging on the front door interrupted our conversation. Mr. Freeman was pacing on and off the doorstep shouting that he would not be told what to do by a pair of lesbians and that he was going to make our lives a 'living misery'. He added that he owned a public relationscompany and would expose us online, though for what he did not say. He also told me that he would report me to my headteacher but, again, did not state for what. We stood paralysed as Mr. Freeman spat out more and more frustrated threats.

The following weeks were unhappy and uncomfortable. Though no further words were exchanged with the Freemans, Mr. Freeman pursued and provoked us at every opportunity. He called us 'dykes', and 'lezzers'; he urinated in our garden, appeared at our windows late at night and tried to run us off the narrow country lanes in his enormous black SUV. We became an obsession to him. He could not rest if we were outside, and he shouted or howled and laughed loudly and inexplicably at us. He threw things over the fence to startle us; on one occasion it was a bucket and, on another, the Freeman family bag of clothes pegs.

Because our property and Mr. Freeman's were isolated from the rest of the village, Jo and I were too afraid to contact the police. To do so would provoke Mr. Freeman further, and it was unlikely that the police could protect Jo, Lily or me in such a remote location. Instead, we put our home of 15 years on the market and made plans to relocate to another home well away from Mr. Freeman.

In October 2009, whilst our house was on the market, my headteacher asked to see me in his office. Mr. Freeman had come to the school to tell my headteacher that I was a lesbian and express concern that I was working with children. My headteacher said, "this man has a real problem with you, and I suggest you sell your house as quickly as possible". Although my headteacher stressed that he was not concerned by Mr. Freeman's complaint, he made it clear that it was a personal matter and asked that I keep him out of it, as getting along with parents was key to his role at a middle-class school such as ours.

\section{Autoethnography}

Autoethnography is grounded in a postmodern, interpretivist philosophy and transcends the debate about reflexivity and voice in social research. It emphasises the interpretation of the researcher's behaviours, thoughts and experiences in relation to the culture and relationships in which they are 
situated (Chang 2008). Autoethnography permits access to "covert, elusive, and/or personal experiences like cognitive processes, emotions, motives, concealed actions, omitted actions, and socially restricted activities" (Rodriguez and Ryave 2001, p. 3). The unorthodox position of the autoethnographic researcher makes them well placed to study sensitive topics, giving a voice to those previously silenced or marginalized. Autoethnography has the potential to further academic understanding of the lives of many different people and give legitimacy and a community to those previously isolated and excluded by the dominant discourse of society.

Anderson and Glass-Coffin (2013) suggest that the praxis of autoethnography must remain fluid, and the use of data, documents and artefacts may be deployed in the best interests of supporting the narrative and facilitating visibility of the self. Chang too argues that multiple sources of data provide bases for triangulation that have the potential to help enhance content accuracy and validity of autoethnographic writing. Clandinin and Connelly (2000) also advocate the use of external data sources in autoethnography, stating that they "help fill in the richness, nuance, and complexity of the landscape, returning the reflecting researcher to a richer, more complex, and puzzling landscape than memory alone is likely to construct" (p. 83).

It should be noted that the critical incident occurred seven years before I made the decision to write publicly about it. The starting point for my narrative was to assemble the abundance of external data that had been created between 2009 and 2010, at the time of the critical incident. During this period, I sought medical help from my general practitioner (GP), who referred me to a cognitive behaviour therapist for stress and anxiety. I sought and was granted permission from my GP and CBT therapist to use the notes they made for the purpose of this research, and these documents were sent to me. By utilizing third-party data, I was able to see myself as the GP and the CBT therapist saw me at the time, but equally, I was able to provide a commentary to that evidence, providing footnotes of sorts to the data sources. This data also helps to highlight these professionals' lack of understanding of the way in which I, as a childless lesbian in a same-sex relationship, framed my identity and my notion of family in relation to Lily.

\section{Lily}

Franklin (2015) notes that cats have lived alongside humans for more than 5000 years, aligning their modes of communication and social behaviour with ours. Women are more likely than men to ascribe family membership to a dog or cat, and some report feeling closer to their animals than to other human family members (Charles 2014). Historically, cats became associated with deviant femininity through their association with witches and spinsters (Radulovic 2017). The cat/lesbian connection is a well-documented trope in popular Western culture, representing the rejection of the roles of wife and mother and the queering of the heterosexual, patriarchal family. Radulovic (2017) states that for many lesbians, loving cats is an intrinsic part of queer, lesbian identity. Both lesbians and cats are, according to Radulovic, similar in their rejection of typical modes of social affection. Just as the cat demands attention on her own terms and is considered less people-oriented than the dog, so may lesbians reject traditional female roles. Caring for cats enables lesbians to reclaim elements of caretaking in female identity without being subjected to patriarchal pressures of motherhood Conversely, the same lesbian/cat trope commonly represented as 'the mad cat lady'has a heteronormative and anti-lesbian interpretation in which lesbians who reject parenting are perceived as being odd, deficient or strange in some way (Clarke et al. 2018).

I had 'rescued' Lily as a semi-feral farm kitten in 1997, bringing her home as a surprise present for Jo. I longed to be a parent and especially for Jo and me to be a family. Zilcha-Mano et al. (2012) describe the human-animal relationship as involving mutual interdependence, with companion animals serving as a safe haven and secure base for the people with whom they live. The human-human bond required for psychological and physical health has been expanded to the human-animal bond and can be key in defining one's identity as a nurturing person. 
In 1997, in rural England, same-sex parenthood seemed entirely implausible to Jo and me. Our conservative rural community was not ready for a same-sex couple, let alone a same-sex couple with a child, and our own families acknowledged us only as housemates rather than partners. My role as a teacher also necessitated the careful management of my personal and professional identities. Since 1988, the sanctioning of lesbian and gay families in English schools as 'pretend' had been law. Section 28 of the Local Government Act (1988-2003) prevented "the teaching in any maintained school of the acceptability of homosexuality as a pretended family relationship" (Local Government Act 1988). As a lesbian teacher during that period I, like others, believed that if my sexual identity became common knowledge, I would lose my job. My relationship with Jo was authentic only within the safe haven of our home, and I recognized that parenting would entail us facing the outside world as a couple. At the time, this felt unthinkable, and so, instead, within the safe haven of our home, Lily, for me at least, became the child I perceived society would not let me have.

Lily was twelve years old when the Freemans arrived. A major manifestation of my anxiety during this critical incident surrounded concerns about Lily's safety. As soon as the Freeman family arrived at the farm, I became aware of this emerging anxiety. Even before the critical incident, I felt uneasy about her safety as I observed the family and their animals arrive, unfurl themselves and, with little regard for the boundary separating their garden from ours, begin to explore boisterously their new environment.

Trigg et al. (2016) observe that levels of companion animal and human attachment influence the way in which humans view risk, appraise threat, and respond to environmental hazards. After the initial doorstep threats from Mr. Freeman, my levels of worry for the safety of Lily, Jo and me quickly became unmanageable. I struggled to imagine or articulate the danger that I thought that Jo and I were in, but I could imagine the harm Mr. Freeman might cause Lily. I had a recurring and intrusive thought that if Lily wandered beyond our garden onto the farm, as she had done for her entire twelve years with us, Mr. Freeman might sweep her up by the scruff of her neck, slit her throat with the knife I imagined he carried and toss her back over the fence to land in our garden.

At school, the morning after the doorstep incident, I confided in the school counsellor, telling her all about the events of the previous evening. I described the anxiety I felt, being at school whilst Lily inevitably roamed the fields around Mr. Freeman's farm. The school counsellor booked an appointment at the GP for me. After the consultation, the GP recorded the following observations about me in his notes.

GP Notes 17 July 2009

E: Adjustment Reaction

S: Dispute with new neighbours last night. Feels threatened, fear of harm to her pet cat.

I was embarrassed that my medical records refer to a fear of harm to my 'pet cat'. The statement appears frivolous amongst the courier script pages of serious codes and symbols denoting blood test results and prescription medicine. The discourse with Mr. Freeman was described only as a dispute with a neighbour, but this paid insufficient regard to his aggression and to the fear we felt at the time. When Mr. Freeman swaggered onto our doorstep, his need to hurt us effervesced from him. Lily's innocent and aimless meanderings onto the farm seemed to provide him with the easiest and cruellest of opportunities to achieve his aim. Now, ten years later and able to reflect on the incident from a position of good health, I recognise that my embarrassment is misplaced. Walsh (2009) notes that clinicians seeking to understand family functioning and to identify resources for healing and resilience usually ask about important persons in kin and social networks but rarely consider animal companions. My GP did not consider that as a childless lesbian, my attachment to Lily may have been greater than that of a typical family 'pet'.

Drawing on Mikulincer and Shaver (2007), Trigg et al. (2016) state that human-animal attachments are fundamentally similar to human interpersonal relationships. They assert that for animals to be considered attachment figures, four criteria are required: (1) proximity maintenance-the company 
of the attachment figure is enjoyed and prolonged; (2) safe haven-they are sought out as a source of protection, support and comfort that relieves distress; (3) secure base- - they represent a reliable presence that facilitates and permits risk-taking, tolerance of uncertainty and promotes environmental exploration; and (4) separation distress-a reaction prompted by distancing from or actual loss of the figure (p. 58). Applying the assertions of Trigg et. al. to my own set of circumstances, I feared the loss of Lily at the hands of Mr. Freeman. Lily symbolized for me the home and family, but the security and safe haven of home was compromised each time Lily went outside. Walsh (2009) asserts that families value their animal members most at times of crisis and loss, through disruptive transitions and in weathering prolonged adversity. Lily became the embodiment of my vulnerability as part of a same-sex couple, and as Mr. Freeman's behaviour towards us continued, I needed our family identity more than ever to counter the negativity and threat I faced when I ventured outside of our home.

An additional fear for Lily's safety emerged from a frequently repeated event. Mr. Freeman owned a tom cat and two aggressive dogs. His animals were daily and nightly visitors to our garden and regularly chased Lily back to our house and right up to the cat flap. As Mr. Freeman's cat grew bolder and more successful in his territorial dominance, he often did not curtail his pursuit at the cat flap and continued the chase into the house, up the stairs and into our bedroom. The commotion in the bedroom as Lily tried to fight off Mr. Freeman's cat always woke me with a start, and during the night, this event always seemed especially grave. After one incident, I recorded my concerns in the thought diary I was asked to keep by the CBT therapist:

Thought Diary: Thursday 1:40 a.m.

Lily has nowhere safe left to be. Why is he invading us in our home? Their cat is doing exactly what he [Mr. Freeman] is doing. Please, just leave us in peace and stop making our lives a misery.

Mr. Freeman's tom cat became the representation of Mr. Freeman. Each time the cat entered our house and chased Lily into our bedroom, it was as though Mr. Freeman himself had entered that most intimate and private area of our home. Though I recorded in the thought diary that Lily had nowhere safe left to be, it was perhaps Jo and me to whom I referred. It was impossible to find a single space in which Mr. Freeman was unable to reach us, and he, via his cat, had now penetrated the most intimate place in our home.

Privacy is often closely associated with safety (Elwood 2000). This is because when privacy is successfully achieved, it results in the creation of a place resistant to the influence of others. Comerford et al. (2004) describe the rural home as a site of crucial importance for lesbians and, for some, the only place in the countryside in which the lesbian relationship is acknowledged. Gorman-Murray (2006) similarly suggests that in 'homemaking', lesbian and gay couples seek to create a sanctuary or retreat in which to affirm the identities and relationships that are inhibited in everyday public spaces. It is my contention that for rural lesbian couples seeking to conceal their relationship, the home can feel central to the entire relationship. The home may feel as though it is the only place in which the relationship is real, and consequently, surveillance of the home can feel disproportionately threatening. Equally, when one feels under threat, the home can feel especially important as a site of safety or sanctuary. Mr. Freeman violated our home as a place of safety, but paradoxically, the less safe I felt at home, the more I was compelled to spend time there.

It became very uncomfortable for me to let Lily go outside. However, it was cruel and similarly distressing to keep this farm cat locked inside our cottage all day and all night. Shore et al. (2006), describe how increased attachment to companion animals is associated with greater likelihood of keeping them indoors, as the threatened loss of personally meaningful human-animal attachments can lead to anticipatory distress (Trigg et al. 2016, p. 63).

As my anxiety and fear of Mr. Freeman grew, I kept Lily inside, feeling conflicted as she paced up and down miserably by the door, repeatedly nudging the cat-flap with her head and looking at me to provide a solution. Zilcha-Mano et al. (2012) state that a person's level of anxiety correlates with 
the degree to which he or she worries that an attachment figure will not be available in times of need. This leads to the adoption of "hyperactivating" attachment strategies—energetic, insistent attempts to obtain care and support as a means of regulating distress (p. 1). Not only did I fear that Lily would be harmed by Mr. Freeman, but I also depended on her presence in the home as a source of comfort as I became increasingly distressed.

As Lily had never been kept inside before, she became distressed when I would not let her go outside. I, therefore, let her out, but because I did so in full knowledge that she was in danger, I felt that I had an enhanced sense of responsibility for her fate. According to De Silva and Rachman (2004), people with anxiety have an exaggerated appraisal of risk and an overinflated sense of being personally responsible for avoiding and preventing harm and disaster. Twelve days after my initial referral to the GP, the doctor conducted a review of my progress:

GP Notes 29 July 2009

\section{E: Adjustment Reaction}

S: Anhedonia, obsessive checking, low mood, poor sleep ... self-loathing, poor concentration, anxiety and restlessness ++

The neighbour dispute and fear of harm to my 'pet cat' had made way for anhedonia, obsessive checking and self-loathing. The language presents a deviation from a social model in which I am distressed by aggression from a neighbour and am suffering from an adjustment reaction to an outside stimulus to a medical model in which it is my psychological state, not external circumstances, that is of concern. In simply anticipating through intrusive thoughts that Mr. Freeman might hurt us, it seemed that I had lost the ability to gain enjoyment from anything. Again, the notes taken by the GP imply that my reaction to the homophobic harassment by Mr. Freeman and my concern for Lily's safety was irrational. My symptoms represented my poor health rather than being understood by the GP as proportionate for someone who feels under threat at home and in the workplace and fearful that Lily, a family member, is going to come to physical harm.

Irvine (2013) notes the human perception of the innocence of animals. She states that animals do not judge those on the margins of society and stand as silent witnesses to our behaviour. The name calling caused a dramatic loss of my confidence, and I depended on Lily even more as I perceived her to be the only one not judging me. Putney (2014) suggests that lesbians who have faced societal intolerance often look to companion animals for validation. She states that the relationships between humans and companion animals help nurture an individual's sense of self that may not otherwise be possible. Animals promote self-efficacy and encourage the humans that live with them to accept their strengths and flaws. Companion animals provide a non-judgmental presence that can be internalized in ways that help shape how an individual defines and experiences themselves. The Freeman family had, if only by comparison, exposed us as an odd and anxious lesbian couple, unjustifiably intolerant of the intrusion of the Freeman children and their trampoline into our neat, ordered and peaceful lives. I hated that we were an unorthodox couple, playing at family with only a cat for a child. I consequently began to feel that we belonged on the side-lines and were not entitled to participate fully in real life.

What right did I have to try to control where a proper family might position the children's trampoline?

Roseneil and Budgeon (2004) state that "the idea of 'family' retains an almost unparalleled ability to move people, both emotionally and politically" (p. 135). According to Trussell and Shaw (2009), rurality and family life are synonymous with one another. Rural communities are widely considered to be a more suitable place to raise a family than a town or city. Trussell and Shaw argue that this is because rural communities are often perceived as close-knit, caring and surrounded by the simplicity and peacefulness of the natural environment. However, rural perceptions of the roles of animals differ compared with those of people living in towns and cities (Gorman 2017). A strong tradition of farming means that in rural communities, companion animals are more likely to be conceived of as labour and to live entirely outside the family home. 
The human heterosexual family is privileged and protected in rural communities. Berlant and Warner (1998) argue that heteronormative societal belonging is constructed through the restriction of "a historical relation to futurity" (p. 318) and a discourse that privileges a "generational narrative and reproduction" (Berlant and Warner 1998). It is this focus on reproduction and future generations that gives the heterosexual family its privileged status. Oswald et al. (2005) observe that in heteronormative discourses, only heterosexual families are real. "Pseudo families" (p. 144) are their binary opposite. The privileging of the heterosexual Freeman family reminded me of the inauthentic nature of my partnership with Jo.

My perception of my relationship as 'pretend' was compounded by the lack of appropriate language to describe care-taking relationships beyond the heterosexual family. For example, heterosexual couples are often described as 'trying to start a family', compounding the notion that family can consist only of a heterosexual couple and their biological offspring. Clarke et al. (2018) describe being lesbian and childfree as a "double whammy", identifying that these two "forms of difference" make it 'difficult to connect with (heterosexual) people in mundane situations" (p. 4148).

Whist heterosexual couples could marry, at the time, in England, those in same-sex relationships were instead afforded a civil partnership. Like many same-sex couples, Jo and I entered into a civil partnership. The failure to call the union of a same-sex couple "marriage" in England until 2015, further secured the dominance of heteronormativity by positioning civil partnerships as 'pseudo-marriage'. Kitzinger and Wilkinson (2004) state that "the re-branding of marriage as 'civil partnership' is useful to governments in enabling them to extend rights to, and control over, same-sex relationships, while reserving the privileged status of 'marriage' for heterosexuals only" (p. 127).

That a civil partnership offered (mostly) equal rights and protection is irrelevant. The civil partnership created a binary with marriage, in which the civil partnership was seen as inferior or inauthentic when compared with the real thing. As it applied only to same-sex couples, to declare a civil partnership necessitated outing oneself as lesbian or gay. Hudak and Giammattei (2010) call for a "decentering" (p. 55) of the family. Drawing on Butler's theory of gender performativity, they reject essentialist notions of the family and argue for family as a performative act in which fluid, ambiguous and diverse representations of family can prevail. Perlesz et al. (2006) argue that conceiving of family as a performative act creates possibilities for relating and parenting outside of the bounds of the heterosexual family. According to Hudak and Giammattei (2010), the performative act of family or "doing family" (p. 53) entails "intentionally committing to add elements of responsibility and caretaking to the bonds of love, which usually embody roles traditionally assigned to kinship networks" (p. 52). 'Doing family' transforms it from a static essentialist entity to a verb, encouraging new and diverserepresentations of caretaking and responsibility within loving relationships. When one can 'do family', it becomes possible for kinship- and family-making between humans and animals to exist, recognizing the everyday experiences of those humans who share their domestic space with animals (Blackstone 2014).

The critical incident happened only days before the start of the school summer holidays, and as the long holiday period commenced, I became isolated and disconnected from normal life. As the majority of the adult population, including my partner, continued to work through the summer, I engaged in long solitary days, mostly staying alone at the house to keep an eye on Lily (and Mr. Freeman). I had few internal anchors, and it was very easy to make a new reality. Irvine (2013) explains that animals enrich the debate about isolation and disaffiliation and asserts that pets provide a sense of self-worth at times when resources for establishing personal significance are scarce. Putney (2014) found that in her lesbian participants, caregiving for animals was meaningful as it afforded them the opportunity to attune to something beyond themselves. During those long days inside our home, the only role I performed was of companion to and carer for Lily, and although life felt fairly intolerable, I was driven to get up each day, because I knew that without me, Lily would not be safe. I regularly and obsessively checked Lily's whereabouts. Prior to the school holidays, my concern for what Mr. Freeman might do to Lily caused me to begin locking her inside the house during the day. I came 
home from school at lunchtime to let her out and then would lock her back in the house until I came home in the evening. I continued to lock her inside if I left the house during the holidays, but now, alone all day and with more time to think, I imagined that Mr. Freeman might set fire to the house while I was out. This intrusive thought was soon accompanied by fear of an accidental house fire caused by my negligence. To avert the risk of fire, I began checking that all electrical appliances were unplugged from the wall before I left the house. It took me longer and longer to leave the house, as I walked around, yanking out the plugs to the tumble dryer, the washing machine, the coffeemaker, the kettle and toaster. I also pulled out the plug to the television, the landline phone base unit, the lamps and mobile phone chargers. Although I tried to see and acknowledge that I had removed the plug, I returned to the appliance time and again. I stared at the plug, on the floor or in my hand, trying to capture the image. I told and showed myself over and over again that the plug was well away from its socket until I thought I could retain in my mind a certainty that I had, in fact, removed the plug and not just imagined that I had. The CBT therapist diagnosed me with obsessive compulsive disorder (OCD). She wrote:

\section{CBT Notes 14 September 2009}

Work with OCD model gently encouraging her to challenge idea that it is her actions that are keeping her cat safe. Also to examine rules and assumptions about life and to look at core beliefs with a view to developing flexibility.

When I did manage to leave the house, I imagined the smell of burning, and often, even miles from the cottage, if I could smell a garden bonfire or see smoke in the air, I would immediately curtail my trip and return home to reassure myself that Lily was safe and then begin the compulsive checking process all over again. This process is typical of the cycle of obsession and compulsion described by DeSilva and Rachman:

When an obsessive compulsive patient engages in his compulsion he needs to carry it out precisely as he feels it ought to be done. If the behavior is disrupted then the compulsive ritual is invalidated and needs to be restarted. For long and complicated rituals this can be extremely time-consuming and exhausting (2004:19).

After every trip, I travelled home, becoming ever more anxious as I neared the cottage. On a cloudy or misty day, the natural elements were mistaken for smoke plumes, and this resulted in a frantic dash back to the house. Only when I returned inside could I be absolutely sure that the house was not ablaze. Radomsky et al. (2010) explain that compulsive checking leads to an inflated sense of responsibility for misfortune via a thought-action fusion. Even though I perceived that it was Mr. Freeman who wanted to harm Lily, I soon felt that it would be my carelessness that would cause her death. I saw that the degree of my attentiveness as being directly related to Lily's safety.

As Mr. Freeman's homophobic shouting and trespassing into our garden became more commonplace and extreme, I worried how I was going to manage Lily's safety from my school workplace. However, I did not return to work that September. Before the start of the new term, I was rushed into hospital with abdominal pain. A scan revealed three large ovarian cysts that had lain dormant for some considerable time. Trigg et al. (2016) stresses that an important facet of human psychological reliance on companion animals concerns separation distress. It felt like good timing and good fortune that the subsequent operation resulted in a further eight weeks off work. However, more time to check on Lily and Mr. Freeman also resulted in more time at home alone.

One of the only times each week that I left the house was to attend CBT sessions at the village surgery. In late September, I was allocated a newly qualified female cognitive behaviour therapist. She introduced me in her notes in the following way:

CBT Notes 14 September 2009

Very tearful and anxious. Catherine is in same sex relationship. She is a teacher that hates the job and feels she has sabotaged her career. She has created an environment around herself 
which allows her to be at home as much as possible. This fulfils a need she has to look after their cat. Developed OCD in relation to cat... Wants to be normal and not have unhelpful and frightening thoughts.

I recall stressing my fear of Mr. Freeman to the new therapist, but she does not refer to him at all in her introductory notes. Consequently, my concern for Lily appears devoid of context. Mr. Freeman is conspicuously absent from the list of stressors that have contributed to my problems. He is replaced by references to my same-sex relationship, my relationship with my home and the perception that I hated my teaching job and had 'sabotaged' my career. These aspects were indeed central facets of my distress, but only because Mr. Freeman had, through his homophobic behaviour, exposed and linked them together by way of a threat. Beck and Beck (2011) suggest that the cognitive behavioural therapist should identify the "cognitive, affective, and behavioral mechanisms (adaptive and maladaptive)" (p. 30) developed by the patient to cope with "dysfunctional beliefs" (Beck and Beck 2011, p.30). CBT has a good track record of dealing with obsessive compulsive disorder but is not typically deployed to deal with relationship issues. Perhaps, the CBT therapists honed in on the specifics of my OCD because of the unsuitability of this sort of therapy to address the cause of the OCD-my fear of Mr. Freeman.

The work with the cognitive behavioural therapist focused on challenging my belief that we were unsafe.

The therapist reported how the thought diary led me to recognise the extent to which my fears for Lily were impacting me adversely. he entered the following in her notes:

CBT Notes 25 September 2009

Kept thought diary which caused her to confront full impact of problem which had negative effect on her depression. Thoughts were that it is a scary world out there and it is important to feel safe all the time.

The therapist did not note why I was fearful. Instead, she attributed my fears to a general belief that "it is a scary world out there".

As instructed by the therapist, I wrote in my thought diary as part of an attempt to 'sit' with the uncomfortable feelings until they passed. Salkovskis et al. (2003) identify that compulsive behaviours neutralise intrusive thoughts. However, they also show that anxiety declines to comparable levels without neutralising if the patient can resist the compulsive behaviour. I struggled to sit with the anxiety as instructed and searched for certainty of Lily's safety. My compulsive checking gave me an enhanced sense of responsibility for her fate. It seemed however hard I tried, my mind constantly sought to show me every conceivable danger. Not only did threats emanate from beyond the home, I soon could not be certain of her safety with me, inside our home, either.

Thought Diary Thursday 11:00 p.m.

Lily has come upstairs and is now sleeping in the blanket box I have left open. Instead of being relieved I can see her, I am terrified the lid will fall on her-even though it can't as I've propped it open. Why do I do this? Why do I see danger in absolutely everything?

As I recovered from my operation, I began to worry about leaving Lily and returning to school:

Thought Diary Thursday 11:52 a.m.

Next door's cat has just stuck his head through the cat flap. He saw me and beat a hasty retreat. Is this happening every day? Is it just good luck that I'm here? I can't even feel relaxed that Lily is safe inside, because it's clear she's not even safe when she's indoors. Is it not even safe to go to work now?

This entry in the thought diary suggests something of the anxiety I felt about returning to school. I did not know at the time whether Mr. Freeman had been into school during my period of absence to carry out his threat of reporting me to my headteacher, and whilst I worried about leaving Lily at 
home alone, my question "Is it not even safe to go to work now?" perhaps pertained as much to my own fears about what I might encounter upon my return to school as it did to my fears about being away from Lily and being unable to keep her safe.

Though I returned to work on schedule, my need to neutralize obsessive thoughts by checking on Lily made it very difficult to be away from the house for the duration of the school day. However, Mr. Freeman's homophobic name calling, howling and appearances at our windows made being at home as intolerable as being at school. Paradoxically, I strived all day to be at home, seeking the sanctuary and safe haven our home no longer provided. Of course, this was also in part because being able to monitor the movements of Mr. Freeman was less stressful than being at school and imagining what he might be capable of.

At breaktime, after a particularly difficult weekend with Mr. Freeman, I recorded in my thought diary my fear for Lily's safety, even though she was locked inside the house.

Thought Diary-Monday 11:42 a.m.

I want to go home and check she's OK. I'm convinced he's going to hurt her. What if he hurts her?

Until Mr. Freeman met with my headteacher to express concern about my sexual identity, my problems had been a shameful secret, unravelled once a week in a tiny office set aside for CBT at the GP surgery in the village. There is a man next door who shouts things at us because we are gay. Nobody hears him because we live in the middle of nowhere. I worry that he might hurt us, and I am anxious that somehow something bad will happen to Lily, our cat. Each week, after 50 minutes, I skulked out of the office with my fears temporarily soothed. In order to conquer the Mr. Freeman problem, I just had to change my thinking.

I attended my scheduled appointment with the CBT therapist the day after Mr. Freeman visited the school. In her notes, she wrote:

\section{CBT Notes 2 December 2009}

Catherine came to session in a very distraught state and said neighbour had gone into the school where she works and seen the headmaster apparently making homophobic comments and accusations to him. The head told Catherine that he clearly had a problem with her. Catherine is very frightened and it has raised all the old fears about the cat's safety and her own. She is worried about what this man is capable of doing as he seems to hate her. She feels vindicated that all the thoughts she had about him were actually correct and that she is right to be concerned. Tried to reduce arousal by listening and by reminding her that his behaviour did not undermine the progress she has made with response prevention. Suggested she gets legal advice from Citizens Advice Bureau. Does not want to alert police as she is concerned that this would affect potential sale of house. Feels this development may have an impact on urgency of finding new house.

When the therapist mentioned that I should seek legal advice from the Citizen's Advice Bureau or contact the police, her real-world suggestions startled me, seeming at odds with the dialogue typical of our sessions. Discussions usually stayed within the confines of my irrational 'worry world'. Each week the therapist chipped away at my fears with questions and reasoning, and I, desperate to feel better and be a good patient, did everything I could to accept the conclusions to which I was led. Currently, we were working on the likelihood of Mr. Freeman, 'also a cat owner', hurting Lily if she wandered onto his land. The therapist's repeated and rephrased questions would temporarily wear me down until I was able to concede that it was unlikely that 'a man who had a pet cat would feel able to kill another cat'. This week, however, though I conceded this point, I remained especially sceptical. The therapist's proposal that I seek real-world help suggested to me that she might not be convinced either. A week later, after the next CBT session, the therapist wrote: 


\section{CBT Notes 9 December 2009}

Used session to work on remembering that her learning does not have to be altered by this latest experience. Disentangling thoughts and unreasonable link she has made e.g., although her neighbour is behaving unreasonably to her, this does not mean that he would hurt the cat. Evidence suggests that he is fond of animals and has pets himself.

This entry by the therapist marks the point at which I realized that CBT was not a suitable intervention for my fear of Mr. Freeman. She wrote that my "learning does not have to be altered" by Mr. Freeman's visit to school and that I had made an "unreasonable link" to believe that he was capable of hurting Lily. I desperately wanted the CBT to work and liked the therapist, but I knew that my concern over Mr. Freeman was not completely unreasonable or irrational. The therapist's determination to disregard Mr. Freeman and plough on caused me to lack trust in her. I began to worry that she might not tell me that Lily was in danger even if privately she thought Lily could be. In April 2010, we completed the sale of our home and moved into rented accommodation some fifty miles from Mr. Freeman. The days immediately after the move were amongst the happiest I can recall. Lily survived the long car journey and actually seemed to like her new surroundings. She was inquisitive, brave and playful. Jo and I felt as though we were on holiday. The final entry by the cognitive behaviour therapist, a few weeks after the move, reflected the transformation in my health and well-being.

\section{CBT Notes 6 May 2010}

Catherine was transformed! She was feeling really good and happy, better than she remembered ever feeling. Moving house has been a very positive change for her and she feels that her world has opened up.

Manzo (2005) asserts that home is not one stationary location but the process of travelling itself. She argues that people move on, physically or psychologically, to find places that are more congruent with their sense of self. Separation from previous environments and a movement toward new surroundings mark a new stage in life and new identity constructions. As we began to cover the grubby magnolia walls with fresh paint, I realised that our new house was already more of a family home for Jo, Lily and me than our cottage had been at any time since the arrival of Mr. Freeman.

\section{Conclusions}

In 2009, it was my core belief that Mr. Freeman intended to hurt Lily. Now, some ten years later and in good health, this remains my belief. Kitzinger (1997) argues that cognitive behaviour therapists should carefully evaluate external stressors before fears are dismissed and reformulated through alternative modes of thinking. She warns psychologists that a subjective focus for therapy based entirely on fixing the thinking of the individual potentially diminishes the importance of addressing social inequalities. She states:

If [psychologists'] aim is to decrease 'stress' and to increase the 'ego strength' of the victim, do they risk forgetting that it is the perpetrator, not the victim, who is the real problem? What political choices are they making in focusing on the problems of the oppressed rather than on the problem of the oppressor? (p. 213)

My referral for CBT to fix the problem of Mr. Freeman illustrates the point made by Kitzinger. The subjective approach served to exacerbate my feelings of inadequacy, exclusion and detachment from my surroundings by positing my view of Mr. Freeman's behaviour as irrational. Crucially, the GP and CBT therapist did not understand Lily's role in my life and the bond between us. Implicit in the CBT was a criticism of me being unable to cope with a set of circumstances that I was encouraged to believe were benign. CBT also led me to internalise further negative messages about myself, by making me believe that my judgment and reasoning were flawed. I echo Kitzinger's point in the 
strongest of terms. Those offering subjective interventions in cases of stressful events (such as hate incidents) should look to the external stressors in addition to the resulting manifestations of distress. The patient/client should be supported to get real-world (objective) support, and the credibility of any threat should be thoroughly explored before being dismissed as an irrational fear and reformulated as an alternative thought.

It is also important to recognise that there are many ways of 'doing family' (Hudak and Giammattei 2010). Laurent-Simpson (2017) recommends that professionals recognize modern depictions of families to include human-human companionships of choice and, crucially, multi-species cohabitation. 'Doing family' transforms it from a static essentialist entity to a verb, encouraging new representations of caretaking and responsibility within relationships of choice. For many heterosexual and same-sex couples, companion animals elevate partnerships to family status. According to Charles (2014), we are witnessing the emergence of hybrid families or post-humanist households where humans are de-centred and the species barrier has no meaning. This challenges assumptions that it is only humans who can be construed as kin. Similarly, Laurent-Simpson (2017) states that human-animal relationships may point to a general change in identity meanings and calls for a specialized focus within identity theory on the influence of non-human animals on identity formation (p. 629). In common with Charles and Laurent-Simpson, in this article, I demonstrate that human-animal attachments are comparable with human-human attachments, and where attachments to companion animals are as strong as those toward humans, fear of harm, loss of safe haven and eventually grief over the death of an animal can be devastating and akin to losing a human family member.

A shift in the cultural definition of family is long overdue in the United Kingdom (UK). Same-sex marriage was introduced in 2015, and the notion that family-building is only possible through the birth of biological children to heterosexual couples is becoming outdated as families become more diverse. The human-animal bond can help LGBT adults develop ways of being and seeing themselves that "present a buffer against the chronic strain of living in a heterosexist culture" (Putney 2014, p. 75). Although the body of research into human and companion animal relationships and families has grown since this critical incident took place, medical and psychological services, especially in the UK, must do more to understand and better support families that include companion animals, particularly during periods of adversity.

Funding: This research received no external funding.

Conflicts of Interest: The author declares no conflict of interest.

\section{References}

Anderson, Leon, and Bonnie Glass-Coffin. 2013. I learn by going: Autoethnographic modes of inquiry. In Handbook of Autoethnography. Edited by Stacy Holman Jones, Tony E. Adams and Carolyn Ellis. Walnut Creek: Left Coast Press, pp. 57-83.

Beck, Judith S., and Aaron T. Beck. 2011. Cognitive Behavior Therapy: Basics and Beyond. New York: Guilford Publications.

Berlant, Lauren, and Michael Warner. 1998. Sex in public. Critical Inquiry 24: 547-66. [CrossRef]

Blackstone, Amy. 2014. Doing family without having kids. Sociology Compass 8: 52-62. [CrossRef]

Chang, Heewon. 2008. Autoethnography as Method. Walnut Creek: Left Coast Press.

Charles, Nickie. 2014. Animals just love you as you are': Experiencing kinship across the species barrier. Sociology 48: 715-30. [CrossRef]

Clandinin, D. Jean, and F. Michael Connelly. 2000. Experience and Story in Qualitative Research. San Francisco: Jossey-Bass.

Clarke, Victoria, Nikki Hayfield, Sonja J. Ellis, and Gareth Terry. 2018. Lived Experiences of Childfree Lesbians in the United Kingdom: A Qualitative Exploration. Journal of Family Issues 39: 4133. [CrossRef]

Comerford, Susan A., M. Maxwell Henson-Stroud, Corbett Sionainn, and Elizabeth Wheeler. 2004. Crone songs: Voices of lesbian elders on aging in a rural environment. Affilia 19: 418-36. [CrossRef] 
De Silva, Padmal, and Stanley Rachman. 2004. Obsessive-Compulsive Disorder: The Facts. New York: Oxford University Press.

Elwood, Sarah A. 2000. Lesbian living spaces: Multiple meanings of home. Journal of Lesbian Studies 4: 11-27. [CrossRef]

Franklin, Adrian. 2015. Miffy and me: Developing an auto-ethnographic approach to the study of companion animals and human loneliness. Animal Studies Journal 4: 78-115.

Gorman, Richard. 2017. Therapeutic landscapes and non-human animals: The roles and contested positions of animals within care farming assemblages. Social and Cultural Geography 18: 315-35. [CrossRef]

Gorman-Murray, Andrew. 2006. Gay and lesbian couples at home: Identity work in domestic space. Home Cultures 3: 145-67. [CrossRef]

Hudak, Jacqueline, and Shawn V. Giammattei. 2010. Doing family: Decentering heteronormativity in "marriage" and "family" therapy. In AFTA Monograph Series: Expanding our Social Justice Practices: Advances in Theory and Training. Edited by Jane Ariel, Pilar Hernandez-Wolf and Sarah Stearns. Washington: American Family Therapy Academy, Inc., pp. 49-58.

Irvine, Leslie. 2013. Animals as lifechangers and lifesavers: Pets in the redemption narratives of homeless people. Journal of Contemporary Ethnography 42: 3-30. [CrossRef]

Kitzinger, Celia. 1997. Lesbian and gay psychology: A critical analysis. In Critical Psychology: An Introduction. Edited by Dennis Fox and Isaac Prilleltensk. Thousand Oaks: Sage, pp. 202-16.

Kitzinger, Celia, and Sue Wilkinson. 2004. The re-branding of marriage: Why we got married instead of registering a civil partnership. Feminism and Psychology 14: 127-50. [CrossRef]

Laurent-Simpson, Andrea. 2017. Considering alternate sources of role identity: Childless parents and their animal "kids". Sociological Forum 32: 610-34.

Local Government Act. 1988. Section 28. Available online: http://www.legislation.gov.uk/ukpga/1988/9/contents (accessed on 12 May 2012).

Manzo, Lynne C. 2005. For better or worse: Exploring multiple dimensions of place meaning. Journal of Environmental Psychology 25: 67-86. [CrossRef]

Mikulincer, Mario, and Phillip R. Shaver. 2007. Attachment in Adulthood: Structure, Dynamics, and Change. New York: Guilford Press.

Oswald, Ramona Faith, Libby Balter Blume, and Stephen R. Marks. 2005. Decentering Heteronormativity: A Model for Family Studies. In Sourcebook of Family Theory and Research. Edited by Vern Bengston, Alan C. Acock, Katherine R. Allen, Peggye Dilworth-Anderson and David M. Klein. Thousand Oaks: Sage, pp. 143-65.

Perlesz, Amaryll, Rhonda Brown, Jo Lindsay, Ruth McNair, David De Vaus, and Marian Pitts. 2006. Family in transition: Parents, children and grandparents in lesbian families give meaning to 'doing family'. Journal of Family Therapy 28: 175-99. [CrossRef]

Putney, Jennifer M. 2014. Older lesbian adults' psychological well-being: The significance of pets. Journal of Gay and Lesbian Social Services 26: 1-17. [CrossRef]

Radomsky, Adam S., Roz Shafran, Anna E. Coughtrey, and Stanley Rachman. 2010. Cognitive-behavior therapy for compulsive checking in OCD. Cognitive and Behavioral Practice 17: 119-31. [CrossRef]

Radulovic, Breck. 2017. Cat Call: How Lesbians Queer Society Through Interactions with Cats. Available online: http://midwayreview.uchicago.edu/a/13/1/Radulovic.pdf (accessed on 14 May 2019).

Rodriguez, Noelie Maria, and Alan Lincoln Ryave. 2001. Systematic Self-Observation: A Method for Researching the Hidden and Elusive Features of Everyday Social Life. Thousand Oaks: Sage.

Roseneil, Sasha, and Shelley Budgeon. 2004. Cultures of intimacy and care beyond 'the family': Personal life and social change in the early 21st century. Current Sociology 52: 135-59. [CrossRef]

Salkovskis, Paul M., Susan Thorpe, Karina Wahl, Abigail L. Wroe, and Elizabeth Forrester. 2003. Neutralizing increases discomfort associated with obsessional thoughts: An experimental study with obsessional patients. Journal of Abnormal Psychology 112: 709-15. [CrossRef]

Shore, Elsie R., Michelle L. Riley, and Deanna K. Douglas. 2006. Pet owner behaviors and attachment to yard versus house dogs. Anthrozoös 19: 325-34. [CrossRef]

Tolich, Martin. 2010. A critique of current practice: Ten foundational guidelines for autoethnographers. Qualitative Health Research 20: 1599-610. [CrossRef] 
Trigg, Joshua, Kirrilly Thompson, Bradley Smith, and Pauleen Bennett. 2016. An Animal Just Like Me: The Importance of Preserving the Identities of Companion-Animal Owners in Disaster Contexts. Social and Personality Psychology Compass 10: 26-40. [CrossRef]

Trussell, Dawn E., and Susan M. Shaw. 2009. Changing family life in the rural context: Women's perspectives of family leisure on the farm. Leisure Sciences 31: 434-49. [CrossRef]

Walsh, Froma. 2009. Human-Animal bonds II: The role of pets in family systems and family therapy. Family Process 48: 481-99. [CrossRef] [PubMed]

Zilcha-Mano, Sigal, Mario Mikulincer, and Phillip R. Shaver. 2012. Pets as safe havens and secure bases: The moderating role of pet attachment orientations. Journal of Research in Personality 46: 571-80. [CrossRef]

(C) 2019 by the author. Licensee MDPI, Basel, Switzerland. This article is an open access article distributed under the terms and conditions of the Creative Commons Attribution (CC BY) license (http://creativecommons.org/licenses/by/4.0/). 

MDPI

St. Alban-Anlage 66

4052 Basel

Switzerland

Tel. +41 616837734

Fax +41 613028918

www.mdpi.com

Social Sciences Editorial Office

E-mail: socsci@mdpi.com

www.mdpi.com/journal/socsci

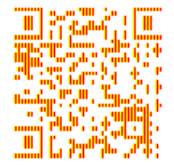



MDPI

St. Alban-Anlage 66

4052 Basel

Switzerland

Tel: +41 616837734

Fax: +41 613028918

www.mdpi.com 